\title{
ipen
}

INSTITUTO DE PESQUISAS ENERGÉTICAS E NUCLEARES

Autarquia Associada à Universidade de São Paulo

\section{Estudo da Hidrogenação para Pulverização de Ligas à base de Terras Raras com Nb para Eletrodos de Hidreto Metálico}

\section{ÉLINER AFFONSO FERREIRA}

Tese apresentada como parte dos requisitos para obtenção do Grau de Doutor em Ciências na Área de Tecnologia Nuclear Materiais

Orientador:

Dr. Rubens Nunes de Faria Jr 


\section{DEDICATÓRIA}

À minha mãe Elisabeth e ao meu pai Vagner pelo amor, carinho, incentivo, formação e principalmente pelo esforço dedicado para que eu não desistisse nos momentos mais complicados dessa árdua caminhada.

Aos meus irmãos Hagner e Haiser, pela ajuda, amizade, alegria e força que nunca deixou e nunca deixará de existir entre nós.

À minha avó Theresinha pela forca e incentivo recebido e acima de tudo pelo carinho e amor sempre.

À minha madrinha Fátima e ao meu padrinho Raul pelo apoio, cainho e alegria.

Às minhas tias Ângela e Rosemeire, ao meu tio Domingos, sem esquecer também do meu primo, Vinícius e da minha prima, Letícia, pelo carinho, amizade e incentivos recebidos.

A todos os colegas dos demais centros do IPEN que direta ou indiretamente ajudaram na realização deste trabalho. 


\section{AGRADECIMENTOS}

Ao Dr. Rubens Nunes de Faria Jr. pela orientação, amizade e compreensão ao longo deste trabalho.

Ao Dr. Hidetoshi Takiishi pela amizade e Co-orientação.

A todos do Laboratório de Materiais Magnéticos pela amizade, companheirismo e incentivo na realização deste trabalho.

Ao Instituto de Pesquisas Energéticas e Nucleares (IPEN/CNEN) pela oportunidade concedida.

A todos de minha família pelo companheirismo.

A todos os colegas dos demais centros do IPEN que direta ou indiretamente ajudaram na realização deste trabalho. 


\title{
ESTUDO DA HIDROGENAÇÃO PARA A PULVERIZAÇÃO DE LIGAS A BASE DE TERRAS RARAS COM Nb PARA ELETRODOS DE HIDRETO METÁLICO
}

\author{
ÉLINER AFFONSO FERREIRA
}

\section{RESUMO}

Neste trabalho foram estudadas as series de ligas $\mathrm{La}_{0,7} \mathrm{Mg}_{0,3} \mathrm{Al}_{0,3} \mathrm{Mn}_{0,4} \mathrm{Co}_{(0,5-}$ ${ }_{x)} \mathrm{Nb}_{x} \mathrm{Ni}_{3,8}$ (x=0 a 0,5) e $\mathrm{La}_{0,7} \mathrm{Mg}_{0,3} \mathrm{Al}_{0,3} \mathrm{Mn}_{0,4} \mathrm{Nb}_{\left(0,5^{-} \times\right)} \mathrm{Ni}_{(3,8-x)}(\mathrm{x}=0,3 ; 0,5$ e 1,3), como eletrodo negativo de baterias de Níquel - Hidreto Metálico. A pulverização das ligas foi realizada com duas pressões de $\mathrm{H}_{2}$ (2 bar e 9 bar). A capacidade de descarga das baterias de níquel hidreto metálico foi analisada pelo equipamento de testes elétricos Arbin BT-4. As ligas, no estado bruto de fusão, foram analisadas por microscopia eletrônica de varredura (MEV), espectroscopia de energia dispersiva (EDS) e difração de raios-X. Com o aumento da concentração de nióbio nas ligas nota-se a diminuição da estabilidade cíclica das baterias e da capacidade máxima de descarga. A capacidade de descarga máxima obtida foi para a liga $\mathrm{La}_{0,7} \mathrm{Mg}_{0,3} \mathrm{Al}_{0,3} \mathrm{Mn}_{0,4} \mathrm{Co}_{0,5} \mathrm{Ni}_{3,8}(45,36 \mathrm{mAh})$ e a bateria que apresentou a melhor performance foi a liga $\mathrm{La}_{0,7} \mathrm{Mg}_{0,3} \mathrm{Al}_{0,3} \mathrm{Mn}_{0,4} \mathrm{Co}_{0,4} \mathrm{Nb}_{0,1} \mathrm{Ni}_{3,8}(44,94 \mathrm{mAh})$. 


\title{
STUDY OF HYDROGENATION FOR PULVERIZATION OF RARE EARTH ALLOYS WITH Nb FOR METAL HYDRIDE ELECTRODES
}

\author{
ÉLINER AFFONSO FERREIRA
}

\begin{abstract}
In this work were studied $\mathrm{La}_{.7} \mathrm{Mg}_{0.3} \mathrm{Al}_{0.3} \mathrm{Mn}_{0,4} \mathrm{Co}_{(0.5-\mathrm{x})} \mathrm{Nb}_{\mathrm{x}} \mathrm{Ni}_{3.8}(\mathrm{x}=0-0.5)$ and $\mathrm{La}_{0,7} \mathrm{Mg}_{0,3} \mathrm{Al}_{0,3} \mathrm{Mn}_{0.4} \mathrm{Nb}_{(05+x)} \mathrm{Co}_{0,5} \mathrm{Ni}_{(3.8-x) .} \quad(\mathrm{x}=0.3 ; 0.5 ; 1.3)$ alloys for negative electrodes of the Nickel-Metal Hydride batteries. The hydrogenation of the alloys was performed varying pressing of $\mathrm{H}_{2}$ (2 and 9 bar). The discharge capacity of the nickel-metal hydride batteries were analyzed in the Arbin BT-4 electrical test equipment. The as-cast alloys were analyzed by scanning electron microscopy (SEM), energy dispersive spectroscopy (EDX) and X-Ray diffraction. The increasing Niobium addition in the alloys decreased cycle life and the maximum discharge capacity of the batteries. The maximum discharge capacity was obtained with the $\mathrm{La}_{.7} \mathrm{Mg}_{0.3} \mathrm{Al}_{0.3} \mathrm{Mn}_{0,4} \mathrm{Co}_{0.5} \mathrm{Ni}_{3.8}$ (45.36 mAh) and the battery which presented the best performance was $\mathrm{La}_{.7} \mathrm{Mg}_{0.3} \mathrm{Al}_{0.3} \mathrm{Mn}_{0.4} \mathrm{Co}_{0.5} \mathrm{Nb}_{0.1} \mathrm{Ni}_{3.8}$ (44.94 $m A h)$.
\end{abstract}


SUMÁRIO

DEDICATÓRIA

AGRADECIMENTOS II

RESUMO III

ABSTRACT IV

1 INTRODUCÃO

1.1 HIDROGÊNIO

1.2 ESTOCAGEM DE HIDROGÊNIO EM METAIS

1.3 BATERIAS DE NÍQUEL HIDRETO METÁLICO (NI-HM) 4

1.4 MOTIVAÇõES PARA A REALIZAÇÃo DESSE TRABALHO 6

2.OBJETIVOS $\quad 7$

3. REVISÃO BIBLIOGRÁFICA

$\begin{array}{lr}3.1 \text { BATERIAS } & 8\end{array}$

3.2 COMPONENTES DAS BATERIAS DE NI-HM 9

3.3 MECANISMOS DE REAÇÕES DAS BATERIAS DE NI-HM 10

3.4 HidRETOS METÁLICOS EM BATERIAS DE Ni-HM 12

3.5 DESEMPENHO DE UMA BATERIA DE NI-HM 14

$\begin{array}{ll}3.6 \text { SUBSTITUIÇÕES NAS LIGAS AB } & 16\end{array}$

3.6.1 SUBSTITUIÇÕES EM A NAS LIGAS AB A $_{5} 16$

3.6.1.1 Efeito do praseodímio e neodímio 16

3.6.1.2 Efeito do cério 19

$\begin{array}{ll}\text { 3.6.1.3 Efeito do titânio e zircônio } & 20\end{array}$

3.6.2 SUBSTITUIÇÕES EM B EM LIGAS AB A $_{5} 21$

3.6.2.1 Efeito do manganês 21

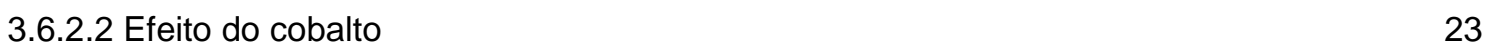

$\begin{array}{ll}\text { 3.6.2.3 Efeito do alumínio } & 26\end{array}$

3.7 EFEITO DO MAGNÉSIO $\quad 29$

3.7.1 TRATAMENTO TÉRMICO EM LIGAS AB ${ }_{5} 33$

3.8 Capacidade de descarga em baterias DE Ni-HM 35

3.9 EFEITOS DA PULVERIZAÇÃO COM HIDROGÊNIO 37

$\begin{array}{llr}3.10 & \text { NIÓBIO } & 39\end{array}$

4. PROCEDIMENTO EXPERIMENTAL $\quad 40$

4.1 CARACTERIZAÇÃo DAS LIGAS METÁLICAS $\quad 41$

4.1.1 MICROSCOPIA ELETRÔNICA DE VARREDURA 41

4.1.2 DIFRAÇÃO DE RAIOS-X 42

4.1.3 DISTRIBUIÇÃO DO TAMANHO DE PARTíCULAS - CILAS 42

4.2 PULVERIZAÇÃo dAS LIGAS METÁLICAS 43

$\begin{array}{ll}\text { 4.3 MONTAGEM DAS BATERIAS DE NI-HM } & 46\end{array}$ 
4.3.1 FABRICAÇÃO DO ELETRODO NEGATIVO

4.3.2 MONTAGEM DA BATERIA DE NI-HM

4.4 TESTES ELÉTRICOS

4.4.1 Voltametria Cíclica e ResistênCIA de PolaRIZAÇÃo 52

4.4.2 POTENCIAL/CORRENTE DE CORROSÃO 53

5 - RESULTADOS E DISCUSSÃO

54

5.1 - CaracterizaÇÃo Microestrutural das Ligas

5.1.1 - COMPOSIÇÃO DAS LIGAS 54

5.1.3 - DIFRAÇÃO de RAIOS - X LA $\mathrm{A}_{0,7} \mathrm{MG}_{0,3} \mathrm{AL}_{0,3} \mathrm{MN}_{0,4} \mathrm{CO}_{(0,5-x)} \mathrm{NB}_{\mathrm{X}} \mathrm{NI}_{3,8}(\mathrm{X}=0$ A 0,5$)$

5.1.4 - Microscopia EletrôNicA de VARReduRA (MEV) $\mathrm{LA}_{0,7} \mathrm{MG}_{0,3} \mathrm{AL}_{0,3} \mathrm{MN}_{0,4} \mathrm{NB}_{(0,5+x)} \mathrm{Ni}_{(3,8--x)}(\mathrm{X}=$

$0,3 ; 0,5 ; 1,3) \quad 68$

5.1.5 - DifraÇÃO de RAIOS - X LA $\mathrm{A}_{0,7} \mathrm{MG}_{0,3} \mathrm{AL}_{0,3} \mathrm{MN}_{0,4} \mathrm{NB}_{(0,5+\times)} \mathrm{NI}_{(3,8-\mathrm{x})}(\mathrm{X}=0,3 ; 0,5 ; 1,3)$

5.2 HIDROGENAÇÃO DAS LIGAS

5.2.1 HIDROGENAÇÃO dA SÉRIE LA $A_{0,7} \mathrm{MG}_{0,3} \mathrm{AL}_{0,3} \mathrm{MN}_{0,4} \mathrm{CO}_{(0,5-x)} \mathrm{NB}_{X} \mathrm{NI}_{3,8}(\mathrm{X}=0 \mathrm{~A} \quad 0,5)$

5.2.2 HIDROGENAÇÃO dA SÉRIE LA ${ }_{0,7} \mathrm{MG}_{0,3} \mathrm{AL}_{0,3} \mathrm{MN}_{0,4} \mathrm{NB}_{(0,5+x)} \mathrm{NI}_{(3,8--x)}(\mathrm{X}=0,3 ; 0,5 ; 1,3)$. 79

5.3 - Caracterização Eletroquímica $\mathbf{8 2}$

5.3.1 CAPACIDADE DE DESCARGA - $\mathrm{LA}_{0,7} \mathrm{MG}_{0,3} \mathrm{AL}_{0,3} \mathrm{MN}_{0,4} \mathrm{CO}_{(0,5-\mathrm{x})} \mathrm{NB}_{\mathrm{X}} \mathrm{NI}_{3,8}(\mathrm{X}=0$ A 0,5) 82

5.3.2 Voltametria CíClicA - $\mathrm{LA}_{0,7} \mathrm{MG}_{0,3} \mathrm{AL}_{0,3} \mathrm{MN}_{0,4} \mathrm{CO}_{(0,5-x)} \mathrm{NB}_{\mathrm{x}} \mathrm{NI}_{3,8}(\mathrm{X}=0$ A 0,5$)$

5.3.3 RESISTÊNCIA de POLARIZAÇÃO - LA $A_{0,7} \mathrm{MG}_{0,3} \mathrm{AL}_{0,3} \mathrm{MN}_{0,4} \mathrm{CO}_{(0,5-x)} \mathrm{NB}_{\mathrm{X}} \mathrm{NI}_{3,8}(\mathrm{X}=0$ A 0,5) 89

5.3.4 CAPACIDADE DE DESCARGA - LA $\mathrm{A}_{0,7} \mathrm{MG}_{0,3} \mathrm{AL}_{0,3} \mathrm{MN}_{0,4} \mathrm{NB}_{(0,5+x)} \mathrm{Nl}_{(3,8-\mathrm{x})}(\mathrm{X}=0,3 ; 0,5 ; 1,3)$

5.3.5 VoltametriA Cí́cLICA - LA $A_{0,7} \mathrm{MG}_{0,3} \mathrm{AL}_{0,3} \mathrm{MN}_{0,4} \mathrm{NB}_{(0,5+x)} \mathrm{NI}_{(3,8-x)}(\mathrm{X}=0,3 ; 0,5 ; 1,3)$

5.3.6 RESISTÊNCIA DE POLARIZAÇÃO - LA $A_{0,7} M_{G_{0,3}} A_{L_{0,3}} M_{N_{0,4}} \mathrm{NB}_{(0,5+x)} \mathrm{Nl}_{(3,8-x)}(X=0,3 ; 0,5 ; 1,3) \quad 98$

5.4 CORROSÃo dAS LIGAS $\quad \mathbf{1 0 0}$

5.4.1 SÉRIE LA $A_{0,7} \mathrm{MG}_{0,3} \mathrm{AL}_{0,3} \mathrm{MN}_{0,4} \mathrm{CO}_{(0,5-x)} \mathrm{NB}_{\mathrm{X}} \mathrm{NI}_{3,8}(\mathrm{X}=0$ A 0,5) 100

5.4.2 SÉRIE LA $A_{0,7} \mathrm{MG}_{0,3} \mathrm{AL}_{0,3} \mathrm{MN}_{0,4} \mathrm{NB}_{(0,5+x)} \mathrm{Nl}_{(3,8-x)}(X=0,3 ; 0,5 ; 1,3) \quad 102$

5.5 - TRATAMENTO TÉrmico $\quad \mathbf{1 0 4}$

5.5.1 MiCROSCOPIA ELETRÔNICA DE VARREDURA (MEV) 104

5.5.2 - DIFRAÇÃO DE RAIOS X 111

5.5.3 CARACTERIZAÇÃo ELÉTRICA 112

5.5.3.1 Capacidade de Descarga 112

5.6 CaracterizaÇÃo da LIGA - LA $0,7 \mathrm{MG}_{0,3} \mathrm{AL}_{0,3} \mathrm{MN}_{0,4} \mathrm{Co}_{0,4} \mathrm{NB}_{0,1} \mathrm{Ni}_{3,8}$

5.6.1 CAPACIDADE DE DESCARGA LA $0,7 \mathrm{MG}_{0,3} \mathrm{AL}_{0,3} \mathrm{MN}_{0,4} \mathrm{CO}_{0,4} \mathrm{NB}_{0,1} \mathrm{Ni}_{3,8}\left(800^{\circ} \mathrm{C}\right)$

5.6.2 CAPACIdAdE DE descARGA LA ${ }_{0,7} \mathrm{MG}_{0,3} \mathrm{AL}_{0,3} \mathrm{MN}_{0,4} \mathrm{Co}_{0,4} \mathrm{NB}_{0,1} \mathrm{Ni}_{3,8}$ (PULVERIZADA) 116

\begin{tabular}{lr} 
6. CONCLUSÕES & 121 \\
\hline
\end{tabular}

7.REFERÊNCIAS BIBLIOGRÁFICAS $\quad 124$

8. TRABALHOS PUBLICADOS 130 


\section{INTRODUÇÃO}

\subsection{Hidrogênio}

O hidrogênio é uma fonte altamente promissora de energia, especialmente quando se leva em conta a diminuição do abastecimento de energia por fontes não renováveis e o aumento da preocupação com o meio ambiente, devido à poluição, é levado em consideração.

Existem recursos para produção de hidrogênio em abundância. A eletrólise da água, por exemplo, é uma tecnologia que existe há mais de um século e apresenta vantagens como a utilização da água como principal insumo e a inexistência de emissões quando a fonte de energia elétrica é a hidroeletricidade ou as fontes renováveis.

Duas excelentes vantagens que tornam mais atraente a energia do hidrogênio são:

1. O hidrogênio possui maior densidade de energia por unidade de peso do que outros elementos químicos.

2. O hidrogênio não polui nossa atmosfera durante a combustão porque seu subproduto é a água.

Além disso, o hidrogênio possui uma vasta variedade de usos práticos, como por exemplo, células a combustível, motores térmicos, etc. No entanto, seu transporte e armazenamento continuam a ser um grande problema para utilização técnicas móveis e estacionárias [2].

Os hidretos metálicos, por exemplo, podem absorver hidrogênio pressurizado e depois liberá-lo em ambiente por aplicação de calor. Alguns destes materiais, como compostos de ferro-titânio ou de lantânio-níquel e ligas à base de magnésio podem guardar mais hidrogênio atômico que o equivalente contentor criogênico do mesmo volume, sem a necessidade de refrigerá-lo $[1,2]$. 
Sendo assim, verifica-se ainda a necessidade de investigações adicionais referente aos hidretos metálicos para explorar o potencial de armazenamento e o seu uso conveniente [2].

\subsection{Estocagem de hidrogênio em metais}

Atualmente existem ligas metálicas que possuem a capacidade de absorver hidrogênio e condições normais de temperatura e pressão, formando os hidretos metálicos [2].

As vantagens do armazenamento utilizando hidretos metálicos estão no fato de que o hidrogênio passa a fazer parte da estrutura do metal e assim não precisa de altíssimas pressões ou estar no estado criogênico para operar.

Há muitos tipos de hidretos metálicos, como por exemplo, as ligas a base de LaNi5. Esta liga foi inicialmente estudada em 1969, nos laboratórios da Philips. Os estudos mostraram as boas propriedades do armazenamento de hidrogênio em ligas do tipo LaNi5, chamando a atenção de muitos cientistas sobre 0 armazenamento de hidrogênio com alta capacidade e boa reversibilidade, à temperatura ambiente [3].

\subsection{Baterias de níquel hidreto metálico (Ni-HM)}

A importância do estudo em combustíveis alternativos é importante devido a alguns fatores, como o aumento do preço e a escassez dos combustíveis fósseis.

Raramente é possível encontrar um produto que possa funcionar idealmente para toda e qualquer aplicação. O mesmo vale para as baterias. Existem diversos tipos de baterias diferentes e cada tipo oferece diferentes características.

As baterias de Ni-HM empregam ligas formadoras de hidreto metálico, como ânodo em um de seus componentes, oferecendo melhorias significativas sobre as baterias recarregáveis convencionais, em termos de desempenho e meio ambiente [4,5]. Além das vantagens ambientais, oferecem mais energia por unidade de volume que as baterias de níquel cádmio (Ni-Cd) [6]. Embora as baterias de íons de lítio (Li-íon) e as baterias de lítio polímero (Li-íon 
polímero) apresentem diversas vantagens, tais como a alta tensão e alta densidade de energia, não podem ser trabalhadas sem um controle eletrônico por razões de segurança. A TAB. 1 compara as características das cinco principais baterias do mercado mundial $[7,8]$.

TABELA 1 - Características das principais baterias do mercado mundial.

\begin{tabular}{ccccc}
\hline & Ni-Cd & Ni-HM & Li-íon & Li-íon Polímero \\
\hline Densidade de energia & $45-80$ & $60-120$ & $110-160$ & $100-130$ \\
$(\mathrm{Wh} / \mathrm{Kg})$ & & & & \\
Duração (ciclos) & $>300$ & $>500$ & $>1000$ & $>1000$ \\
Tempo de carga & $10-14 \mathrm{~h}$ & $2-5 \mathrm{~h}$ & $2-5 \mathrm{~h}$ & $1-2 \mathrm{~h}$ \\
Tensão nominal & $1,25 \mathrm{~V}$ & $1,25 \mathrm{~V}$ & $3,6 \mathrm{~V}$ & $3,6 \mathrm{~V}$ \\
Custo (US\$) & 50 & 60 & 100 & 100 \\
Taxa de descarga/mês & $30 \%$ & $20 \%$ & $20 \%$ & $10 \%$ \\
Modelo cilíndrico & $\mathrm{Sim}$ & $\mathrm{Sim}$ & $\mathrm{Sim}$ & $\mathrm{Não}$ \\
Modelo prismático & $\mathrm{Sim}$ & $\mathrm{Sim}$ & $\mathrm{Sim}$ & $\mathrm{Sim}$ \\
Anos uso comercial & 1950 & 1990 & 1991 & 1999 \\
\hline
\end{tabular}

A TAB. 1 mostra que as baterias de Ni-HM são superiores as baterias de $\mathrm{Ni}-\mathrm{Cd}$ em relação a duração e densidade de energia, mas mostram-se inferiores as baterias de Li-íon e Li-íon polímero.

As vantagens das baterias de $\mathrm{Ni}-\mathrm{HM}$ em relação a sua concorrente Liíon é o custo. Outro fator importante é que sua alta densidade de energia requer alguns cuidados como: evitar curtos-circuitos, sobrecargas, esmagamento, exposição a altas temperaturas ou desmontar. Sua ruptura pode causar a combustão, além de o eletrólito ser altamente inflamável. O circuito de controle das baterias de Li-íon e das baterias de Li-íon polímero torna o custo de fabricação destas baterias elevado [8]. 


\subsection{Motivações para a realização desse trabalho}

As principais motivações para a introdução do Nióbio nas ligas à base La-Ni para eletrodos de baterias $\mathrm{Ni}$-HM podem ser resumidas abaixo:

1) Dentre os mais variados elementos que foram adicionados às ligas de eletrodos negativos para baterias $\mathrm{Ni}-\mathrm{HM}, \mathrm{O}$ nióbio ainda não foi reportado na literatura internacional, deixando aberto um campo de pesquisas inéditas.

2) $O$ nióbio, como elemento refratário, é bem conhecido e empregado como agente refinador de grão em aço inoxidável, fazendo com que $O$ aço produzido com esse metal tenha maior resistência mecânica [9]. A influência do nióbio no refino de grão também é conhecida em ligas magnéticas à base de terras raras e metais de transição. Neste caso o nióbio aumenta a coercividade indutiva desses materiais [10].

3) Com uma massa molar maior que a do níquel e do cobalto, a introdução do nióbio levaria a uma menor capacidade específica teórica das ligas a base de La-Mg-Ni para eletrodos de baterias de Ni-HM. Investigar e avaliar os possíveis benefícios da presença deste metal nas outras propriedades essenciais do eletrodo negativo é de suma importância. A determinação da quantidade máxima tolerável de nióbio nas ligas em relação à capacidade específica é uma investigação imprescindível.

4) O nióbio também foi empregado com sucesso como agente de proteção da corrosão [11]. Neste caso o nióbio foi utilizado em substituição ao níquel. Maior resistência a corrosão e maior eficiência de proteção foram obtidas para os revestimentos de fosfato de zinco em presença de niobatos $(\mathrm{PZn}+\mathrm{Nb})$, quando comparados om a camada tradicional em presença de níquel $(\mathrm{PZn}+\mathrm{Ni})$. Na literatura internacional não foi encontrado nenhum artigo sobre a influência do nióbio na corrosão de eletrodos negativos, deixando um bom potencial para esta aplicação também nas ligas para baterias de Ni-HM. 


\section{OBJETIVOS}

Conforme será apresentado na revisão bibliográfica, o nióbio ainda não foi empregado na literatura como elemento composicional de ligas para 0 eletrodo negativo em baterias de $\mathrm{Ni}-\mathrm{HM}$, sendo sua adição motivo de investigação nesta tese. Assim, o objetivo principal deste trabalho é estudar influência da substituição do cobalto e níquel por nióbio em ligas à base de $\mathrm{La}_{0,7} \mathrm{Mg}_{0,3} \mathrm{Al}_{0,3} \mathrm{Mn}_{0,4} \mathrm{Co}_{(0,5-x)} \mathrm{Nb}_{x} \mathrm{Ni}_{3,8}(\mathrm{x}=0-0,5)$ e $\mathrm{La}_{0,7} \mathrm{Mg}_{0,3} \mathrm{Al}_{0,3} \mathrm{Mn}_{0,4} \mathrm{Co}_{0,5} \mathrm{Nb}_{x} \mathrm{Ni}_{(3,8-}$ x) $(x=0,5 ; 0,8 ; 1,0 ; 1,8)$. Portanto, os objetivos decorrentes disto consistem em:

- Avaliar o efeito do nióbio como elemento refratário e agente refinador de grão na microestrutura das ligas.

- Avaliar a influência do nióbio na pulverização com hidrogênio (em pressões de até $0,9 \mathrm{MPa}$ ) nas ligas para eletrodo negativo.

- Avaliar a influência da presença do nióbio nas características elétricas das ligas. Utilizando as curvas de descarga será determinada a quantidade tolerável de nióbio nas ligas para que não haja comprometimento considerável da característica elétrica essencial, ou seja, a capacidade de descarga especifica do eletrodo negativo. Além disto, o efeito do nióbio será investigado nas outras características elétricas: voltametria cíclica, micropolarização e ciclo de vida útil das baterias.

- $\quad$ Avaliar a influencia do nióbio na resistência a corrosão das ligas à base de terras raras.

- Avaliar o efeito de tratamento térmico de homogeneização em alta temperatura e vácuo nas ligas que apresentarem melhor desempenho. 


\section{REVISÃO BIBLIOGRÁFICA}

\subsection{Baterias}

Uma bateria é um dispositivo que converte energia química, contida em seus materiais ativos, diretamente em energia elétrica por meio de uma reação de oxidação-redução (redox). No caso de um sistema recarregável, a bateria é recarregada pela inversão do processo. Este tipo de reação envolve a transferência de elétrons de um material para outro por meio de um circuito elétrico.

Bateria é um dispositivo que converte energia química em energia elétrica, não sujeita à limitação do ciclo de Carnot ditada pela segunda lei da termodinâmica.

Podemos classificar as pilha, baterias e células eletroquímicas em:

- Primárias (não recarregáveis);

- Secundárias (recarregáveis)

- Células a combustível (alimentação externa).

Os três principais componentes de uma bateria são:

1. Ânodo é o eletrodo negativo das baterias ou eletrodo de redução, ou seja, cede elétrons para um circuito externo e é oxidado durante a reação eletroquímica.

2. Cátodo é eletrodo positivo das baterias ou eletrodo de oxidação,

ou seja, recebe os elétrons de um circuito externo e é reduzido durante a reação eletroquímica.

3. Eletrólito é o condutor iônico, fornece meios de transferência de carga dentro das baterias entre o ânodo e o cátodo [12]. 


\subsection{Componentes das Baterias de Ni-HM}

As baterias de Ni-HM são classificadas como uma bateria secundária. $\mathrm{O}$ ânodo utilizado é a base de uma liga de armazenamento de hidrogênio junto a uma mistura contendo negro de fumo ("Carbon Black") e politetrafluoretileno (PTFE) e o cátodo a base de hidróxido de níquel $\left(\mathrm{NiOH}_{2}\right)$. O eletrólito empregado neste tipo de bateria é o hidróxido de potássio $(\mathrm{KOH})$.

As baterias de Ni-HM são produzidas em três diferentes geometrias: cilíndrica, prismática e botão. A construção em formato cilíndrico é a mais conhecida e utilizada comercialmente. Esta forma é feita por meio de uma embalagem metálica que envolve os eletrodos positivo, negativo e o separador. O eletrólito é injetado no separador.

Na FIG. 1 está apresentada uma imagem do sistema interno de uma bateria de Ni-HM cilíndrica do tipo "AA".

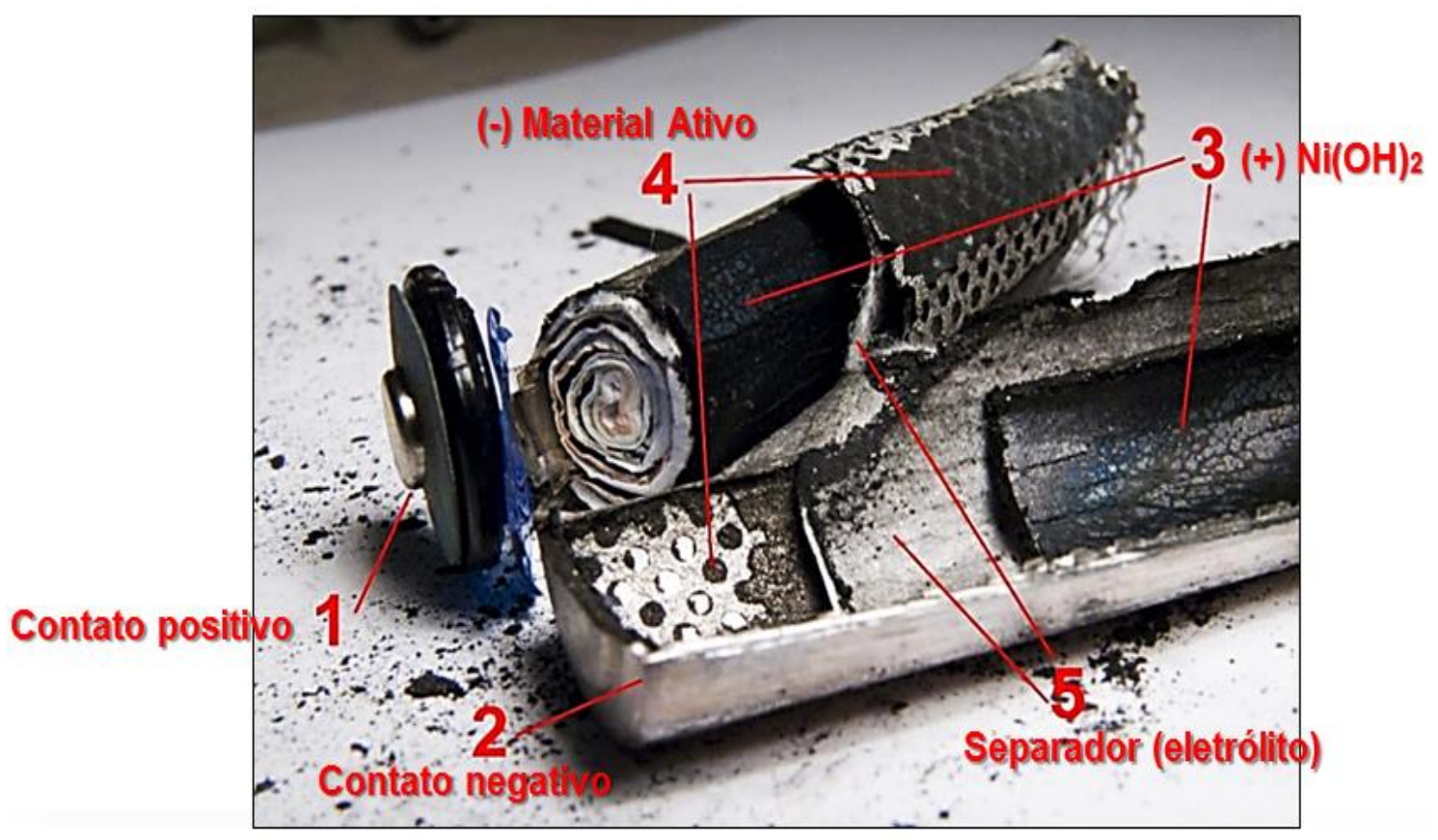

FIGURA 1 - Sistema interno de uma bateria de Ni-HM cilíndrica do tipo "AA", onde: 1 - contato positivo, 2 - carcaça metálica (contato negativo), 3 - eletrodo positivo (hidróxido de níquel), 4 - eletrodo negativo com coletor de corrente (tela de níquel conectada a carcaça) e 5 - separador. 


\subsection{Mecanismos de reações das baterias de Ni-HM}

O eletrodo negativo é composto por ligas metálicas que possuem propriedades de armazenar hidrogênio de forma reversível, absorvendo e dessorvendo íons de hidrogênio quando ocorre o processo de carga/descarga das baterias.

No processo de carga de uma bateria de $\mathrm{Ni}-\mathrm{HM}$, no eletrodo positivo ocorre a combinação do $\mathrm{Ni}(\mathrm{OH})_{2}$ com o hidróxido $(\mathrm{OH}-)$ do eletrólito, gerando o oxihidróxido de níquel $(\mathrm{NiOOH})$, água $\left(\mathrm{H}_{2} \mathrm{O}\right)$ e um elétron (e-). No eletrodo negativo, a liga metálica (M), a água do eletrólito e o elétron interagem para produzir o hidreto metálico $(\mathrm{MH})$.

No processo de descarga da bateria de Ni-HM as reações químicas são inversas das que ocorrem no processo de carga. $O$ hidrogênio armazenado no hidreto metálico é liberado no eletrólito para formar água. A água do eletrólito libera um íon de hidrogênio que é absorvido pelo eletrodo positivo formando $\mathrm{Ni}(\mathrm{OH})_{2}$.

As Eq. 1.1 e 1.2 mostram reações químicas reversíveis que ocorrem na carga e descarga do eletrodo positivo e negativo, respectivamente, e na Eq. 1.3 a reação global da bateria de Ni-HM (e o potencial de cada reação):

$$
\begin{aligned}
& \mathrm{Ni}(\mathrm{OH})_{2}+\mathrm{OH}^{-} \stackrel{\frac{\text { carga }}{\text { descarga }}}{\Longleftrightarrow} \mathrm{NiOOH}+\mathrm{H}_{2} \quad \mathrm{E}_{1}=0,52 \mathrm{~V} \\
& \mathrm{M}+\mathrm{H}_{2} \mathrm{O}+\mathrm{e}^{-} \stackrel{\frac{\text { carga }}{\text { decarga }}}{\Longleftrightarrow} \mathrm{HM}+\mathrm{OH}^{-} \quad \mathrm{E}_{2}=-0,83 \mathrm{~V} \\
& \mathrm{M}+\mathrm{Ni}(\mathrm{OH})_{2} \stackrel{\text { carga }}{\stackrel{\text { descarga }}{\Longleftrightarrow}} \mathrm{HM}+\mathrm{NiOOH} \quad \mathrm{E}_{0}=\mathrm{E}_{1}+\mathrm{E}_{2}=1,35 \mathrm{~V}
\end{aligned}
$$


Na FIG. 2 estão mostradas esquematicamente as reações que ocorrem na carga e descarga de uma bateria de Ni-HM que facilita a compreensão do processo de absorção/dessorção do hidrogênio na liga metálica do eletrodo negativo.

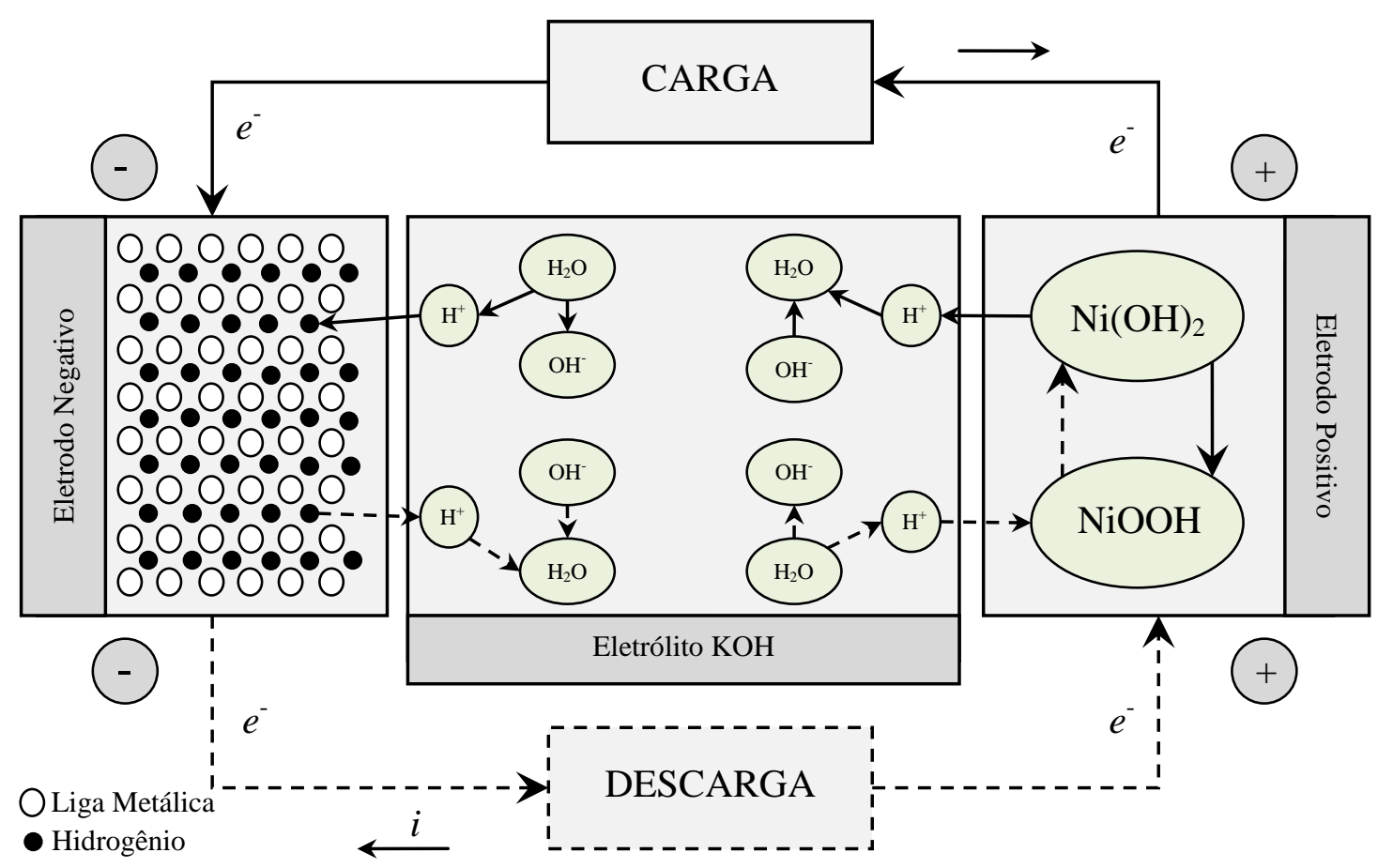

FIGURA 2 - Diagrama do funcionamento de uma bateria de Ni-HM [13].

A FIG. 2 mostra que no processo de carga, o átomo de hidrogênio dissocia do $\mathrm{Ni}(\mathrm{OH})_{2}$ e é absorvido pela liga metálica. No processo de descarga, o átomo de hidrogênio é liberado da liga metálica e reage com $\mathrm{NiOOH}$ para formar $\mathrm{Ni}(\mathrm{OH})_{2}$. 


\subsection{Hidretos metálicos em baterias de Ni-HM}

O componente fundamental das baterias de $\mathrm{Ni}-\mathrm{HM}$ são as ligas de armazenamento de hidrogênio. A composição da liga é formulada para que a bateria possa obter a maior capacidade de descarga e uma alta estabilidade de ciclos de carga - descarga.

Dois tipos de ligas metálicas são geralmente utilizados. A primeira são as compostas de lantânio e níquel (LaNi5) conhecidas como ligas da classe $A B_{5}$. $A$ segunda são do tipo $A B_{2}$, onde tanto a parte $A$ quanto a parte $B$ podem ser um metal de transição, sendo apresentados em geral como $\mathrm{ZrNi2}$.

Em ambos os casos, os metais são substituídos por outros com a finalidade de melhorar as características de desempenho. Estas substituições são os principais métodos de desenvolvimento de novas ligas de armazenamento de hidrogênio.

No caso das ligas tipo $A B 5$, algumas substituições melhoram as baterias na seguinte forma $[14,15]$ :

1. Ce, Nd, Pr, Gd e Y foram utilizados estudados antigamente (1994 1997) substituindo o lantânio puro por outras terras raras, para redução de custos. Atualmente esta redução de custos é feita através da mistura de varias terras raras ("Mischmetal").

2. Al, Ti, Zr, Si e Co são utilizados como substitutos do Ni para diminuir a corrosão resultando em uma maior estabilidade e maior duração.

3. Mg é utilizado para promover aumento na capacidade de descarga das baterias.

No caso de ligas tipos $A B_{2}$ são [16]:

1. V, Ti, Zr são responsáveis pelo melhoramento no armazenamento do hidrogênio.

2. $\mathrm{Ni}$ e $\mathrm{Cr}$ são os principais constituintes que diminuem a corrosão e oferecem um melhor desempenho.

O desempenho das baterias de $\mathrm{Ni}-\mathrm{HM}$ é determinado por alguns parâmetros, como a capacidade de descarga e o numero de ciclos das baterias.

Estes parâmetros dependem da liga $\left(\mathrm{AB}_{5}\right.$ ou $\left.\mathrm{AB}_{2}\right)$ que vai ser utilizado como material ativo do eletrodo negativo das baterias de $\mathrm{Ni}-\mathrm{HM}$. As 
características eletroquímicas podem ser alteradas dependendo do tipo de liga que será utilizado e também das substituições dos elementos para aperfeiçoar seu desempenho.

Ligas do tipo $\mathrm{AB}_{5}$ são significativamente mais comuns, apesar de possuírem menor capacidade de armazenamento de hidrogênio em relação às do tipo $\mathrm{AB}_{2}$ (320 vs $\left.440 \mathrm{mAhg}-1\right)$ [12]. A TAB. 2 mostra as principais características das ligas do tipo $\mathrm{AB}_{2}$ e $\mathrm{AB} 5$.

TABELA 2 - Vantagens e desvantagens do uso de ligas do tipo $A B_{2}$ e $A B_{5}$ em baterias de $\mathrm{Ni}-\mathrm{HM}$.

\begin{tabular}{ccccc}
\hline Ligas & Vantagens & Ref. & Desvantagens & Ref. \\
\hline $\mathbf{A B}_{2}$ & Alta capacidade de & {$[17]$} & Difícil ativação & \\
& $\begin{array}{c}\text { descarga } \\
\text { Cinética rápida }\end{array}$ & {$[17]$} & Baixo ciclo de vida & {$[18]$} \\
\hline \multirow{2}{*}{$\mathbf{A B}_{5}$} & Baixo Custo em relação a & {$[19]$} & Capacidade de descarga abaixo & {$[21]$} \\
& $\mathrm{AB}_{2}$ & & da AB \\
& Fácil ativação & {$[19]$} & Mais suscetíveis à corrosão & \\
& Melhor desempenho & {$[20]$} & & \\
\hline
\end{tabular}




\subsection{Desempenho de uma bateria de Ni-HM}

Os estudos envolvendo a melhoria no desempenho das baterias de $\mathrm{Ni}$ HM visam principalmente adequar as necessidades dos produtos eletrônicos, principalmente aqueles que exigem tensão estável por longos períodos de operação.

A capacidade de uma bateria é a quantidade de energia que a mesma pode oferecer em condições específicas. É representado por ampéres-horas (Ah) ou ampéres-hora/grama (Ah/g). Neste último caso, indica que um grama do material ativo do eletrodo negativo (liga de hidreto metálico) pode fornecer uma quantidade de corrente por um determinado período de tempo. Uma bateria de 50 Ah pode fornecer 50 ampéres por 1 hora ou 5 ampéres por 10 horas, por exemplo.

A FIG. 3 mostra o perfil de descarga de uma típica bateria de Ni-HM [23].

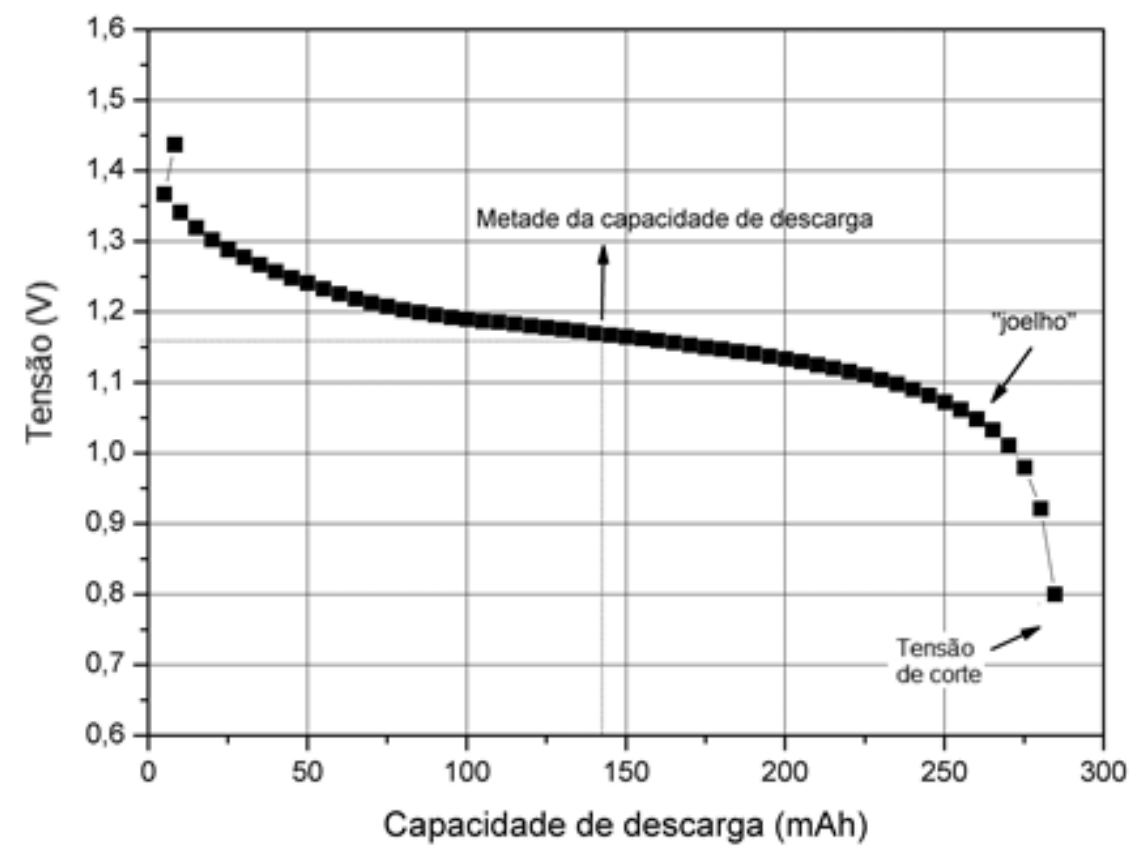

FIGURA 3 - Perfil de descarga de uma bateria de Ni-HM [23].

A queda inicial do potencial de circuito aberto foi de 1,45 volts para 1,35 volts. Ao final do perfil de descarga de uma bateria de $\mathrm{Ni}-\mathrm{HM}$ mostra o chamado joelho ("knee"), onde ocorre a queda acentuada da capacidade de descarga. 
A tensão de corte mostra o final do perfil de descarga, ou seja, é o valor onde cessa o processo de descarga da bateria para evitar danos como a sobredescarga. $O$ valor que geralmente é utilizado depende do experimento que está se realizando, mas para baterias seladas de Ni-HM o valor é de 0,9 volts [12].

O MPV ("mid-point voltage"), mostrado na FIG. 3, é estabelecido quando se tem a metade da capacidade de descarga de uma bateria de $\mathrm{Ni}-\mathrm{HM}$, que é o parâmetro que fornece uma aproximação da tensão da bateria.

As baterias podem sofrer dois efeitos restritivos durante sua operação: a sobrecarga e a sobredescarga. Sobrecarga é o efeito causado quando se mantém uma alta corrente passando por um longo período de tempo pela bateria. Este longo período pode ser contínuo ou com interrupções.

Quando se aumenta a corrente de carga de uma bateria, estamos aumentando a velocidade da reação de carga. Existe um ponto em que a quantidade de energia fornecida à bateria supera a capacidade de ser absorvida pelos materiais ativos e esta energia excedente é transformada em calor. A temperatura elevada leva à deterioração dos elementos das baterias. Os principais efeitos da sobrecarga são: diminuição da quantidade de eletrólito, carcaça da bateria estufada, diminuição na duração da bateria (número de ciclos) e diminuição na capacidade de descarga.

A sobredescarga é o efeito que ocorre quando há a remoção total da carga da bateria. Quando a bateria é danificada permanentemente devido à sobredescarga, hidrogênio em gás se acumula no interior da célula, causando frequentemente liberação do mesmo. Normalmente, há um limite inferior de tensão especificado para descarga que é a tensão de corte.

Existem outros fatores que afetam a vida útil das baterias de Ni-HM. Alguns deles são: temperatura de operação, tipo de material utilizado, correntes de carga e descarga e condições de armazenamento. Alguns destes fatores podem causar geração de gás nas baterias ativando sua válvula de segurança. Em condições ideais as baterias podem durar por muitos ciclos, no entanto, os fatores acima mencionados podem levar a um impacto negativo sobre o número total de ciclos a ser obtido [23]. 


\subsection{Substituições nas ligas $\mathrm{AB}_{5}$}

A liga de armazenamento de hidrogênio é o material ativo do eletrodo negativo das baterias de Ni-HM. Estas ligas desempenham várias funções importantes, como catalisador eletroquímico e um reservatório de hidrogênio no processo de carga/descarga. Contudo, muitas mudanças e substituições de composição são realizadas visando 0 aperfeiçoamento de algumas propriedades desejáveis como aumento da capacidade de descarga, aumento da atividade eletroquímica e aumento da resistência à corrosão.

\subsubsection{Substituições em $A$ nas ligas $A B_{5}$}

\subsubsection{Efeito do praseodímio e neodímio}

Pan et al. [24] investigaram o efeito do praseodímio nas ligas La0,7-xPrx Mg $0,3 \mathrm{Ni}_{2,45} \mathrm{Co0}_{3}, \mathrm{Mnn}_{, 1} \mathrm{Al}_{0,2}(\mathrm{x}=0-0,3)$ após tratamento térmico a 1173 $\mathrm{K}$ por 8 horas. Verificaram que as ligas com diferentes teores de $\mathrm{Pr}$ apresentaram padrão de difração similares e consistiram das fases (La,Mg)Ni3 (estrutura romboédrica tipo- $\mathrm{PuNi}_{3}$ ) e $\mathrm{LaNi}_{5}$ (estrutura hexagonal tipo-CaCu5) mas, com uma diminuição no parâmetro de rede. O resultado da capacidade de descarga das baterias mostrou decréscimo de 366 mAhg-1 $(x=0)$ para 346 $\operatorname{mAhg}_{-1}(x=0,3)[24]$.

Na FIG. 4 (a) estão apresentados as capacidades de descarga em função do número de ciclos dos eletrodos negativos das ligas La0,7-xPrxMgg, ${ }_{3} \mathrm{Ni}_{2,45} \mathrm{Co}_{0,75} \mathrm{Mn}_{0,1} \mathrm{Al}_{0,2}(\mathrm{x}=0$ - 0,3) e na FIG. 4 (b) estão mostradas as capacidades de descarga máxima obtidas em função do teor de praseodímio nas ligas [24]. 


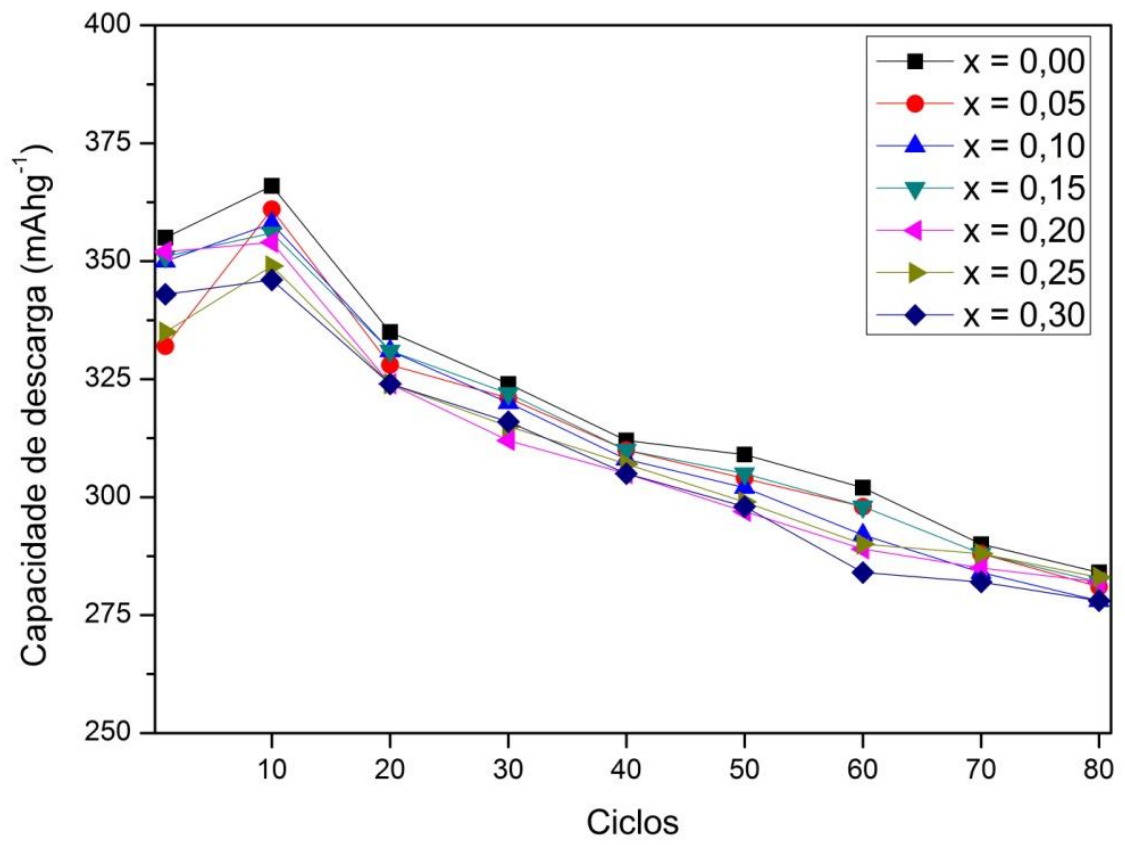

(a)

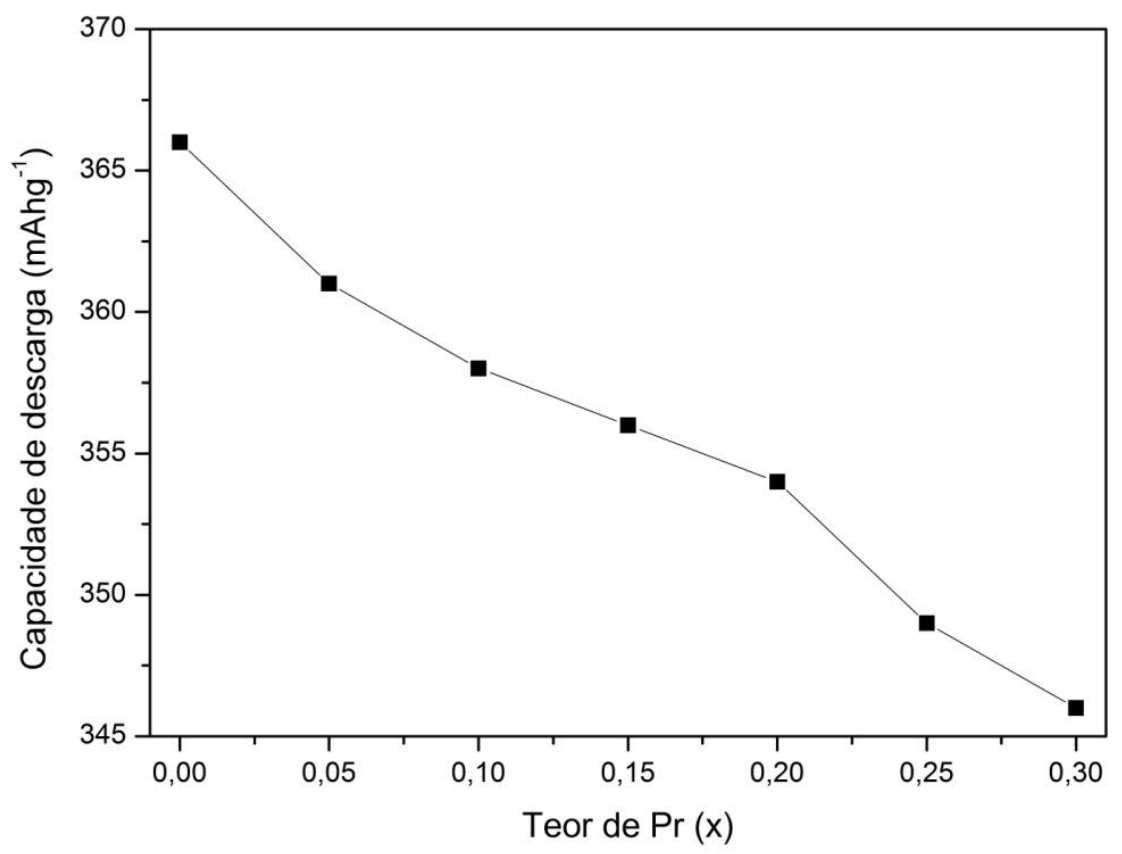

(b)

FIGURA 4 - Capacidades de descarga dos eletrodos negativos das ligas $\mathrm{La}_{0,7-x} \mathrm{Pr}_{x} \mathrm{Mg}_{0,3} \mathrm{Ni}_{2,45} \mathrm{Co}_{0,75} \mathrm{Mn}_{0,1} \mathrm{Al}_{0,2}$ (x= 0 - 0,3); onde: (a) capacidade de descarga em função do número de ciclos e (b) capacidade de descarga máxima em função do teor praseodímio [24]. 
Na TAB. 3 estão apresentadas as capacidades de descarga máxima (Cmáx) e as capacidades de descarga no ciclo $\mathrm{n}^{\circ} 80$ ( $\left.\mathrm{C}_{80}\right)$ obtidas para os eletrodos negativos das ligas $\mathrm{La} a, 7-\times \mathrm{Pr}_{x} \mathrm{Mg}_{0,3} \mathrm{Ni}_{2,45} \mathrm{Co}_{0,75} \mathrm{Mno}_{, 1} \mathrm{Al}_{0,2}(\mathrm{x}=0-0,3)$ [24].

TABELA 3 - Capacidades de descarga obtidas para as ligas

$$
\mathrm{La}_{0,7-\mathrm{x}} \mathrm{Pr}_{\mathrm{x}} \mathrm{Mg}_{0,3} \mathrm{Ni}_{2,45} \mathrm{Co}_{0,75} \mathrm{Mn}_{0,1} \mathrm{Al}_{0,2}(\mathrm{x}=0 \text { - 0,3) [24]. }
$$

\begin{tabular}{cccc}
\hline $\mathrm{x}$ & $\mathrm{C}_{\text {máx }}\left(\mathrm{mAhg}^{-1}\right)$ & $\mathrm{C}_{80}\left(\mathrm{mAhg}^{-1}\right)$ & $\mathrm{C}_{80} / \mathrm{C}_{\text {máx }}(\%)$ \\
\hline 0,00 & 366 & 284 & 77,7 \\
0,05 & 361 & 281 & 77,9 \\
0,10 & 358 & 278 & 77,8 \\
0,15 & 356 & 282 & 79,4 \\
0,20 & 354 & 282 & 79,9 \\
0,25 & 349 & 283 & 81,1 \\
0,30 & 346 & 278 & 80,6 \\
\hline
\end{tabular}

Os resultados de difração de raios- $X$ das ligas Lao,7-xNdxMgo,3Niz,45Co0,75Mno,1Alo,2 ( $x=0,0$ - 3,0) foram similares ao encontrado para o praseodímio, apresentando duas principais fases (La, $\mathrm{Mg}) \mathrm{Ni}_{3}$ e LaNis, com diminuição no parâmetro de rede no aumento do teor de neodímio. A capacidade de descarga das baterias com neodímio diminui de 377 mAhg $-1(x=0)$ para 357 mAhg-1 $(x=0,3)$ [25].

Por outro lado, para ambos os elementos ( $\mathrm{Pr}$ ou $\mathrm{Nd}$ ), houve uma melhora na estabilidade cíclica e na cinética eletroquímica [24,25].

A diminuição da capacidade de descarga foi atribuída à redução da fase (La,Mg)Niz. A mudança na quantidade desta fase provoca uma diminuição do volume da célula unitária levando a melhoria nas propriedades eletroquímicas.

Considerando todos os efeitos envolvidos na substituição parcial do $\mathrm{La}$

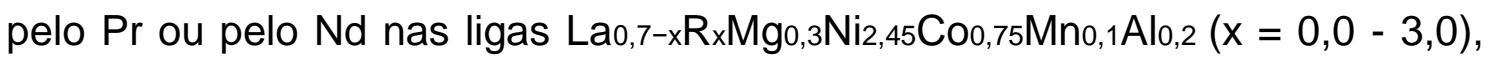
os melhores resultados foram obtidas para $x=0,15$ para praseodímio e $x=0,1$ para neodímio $[24,25]$. 


\subsubsection{Efeito do cério}

Estudos envolvendo a substituição do lantânio por cério tiveram como principal finalidade a redução de custos das ligas de La-Mg-Ni e melhoria na estabilidade cíclica.

Pan et al. [26] estudaram o efeito da substituição do lantânio pelo cério nas ligas La0,7-xCexMgo,3Niz,875Mno, $\mathrm{Co0}_{0,525}(\mathrm{x}=0-0,5)$. Os resultados de difração de raios- $X$ mostraram a presença de duas fases principais: $\mathrm{La}(\mathrm{La}, \mathrm{Mg})_{2} \mathrm{Ni9}$ com estrutura romboédrica tipo-PuNi3 e $\mathrm{LaNi5}$ com estrutura hexagonal tipo-CaCu5. Foi observada a diminuição do parâmetro de rede à medida que aumenta o teor de cério, obtendo como consequência uma menor capacidade de estocagem de hidrogênio. A capacidade de descarga das baterias diminuiu de $382 \mathrm{mAhg}^{-1}(\mathrm{x}=0)$ para $49 \mathrm{mAhg}_{-1}(\mathrm{x}=0,5)$.

Os autores relatam que há dois principais fatores que regulam os efeitos do Ce sobre a estabilidade das baterias. A primeira é que com o aumento no teor de Ce e com a diminuição da célula unitária, há uma redução das partículas durante a carga/descarga. A segunda está na formação de uma película superficial de proteção diminuindo a taxa de corrosão. Os íons de $\mathrm{Ce}_{3+}$ são oxidados passando a $\mathrm{Ce}_{4+}$ em eletrólito alcalino, formando uma película densa de $\mathrm{CeO}_{2}$ na superfície da liga. No entanto, o grande problema encontrado na utilização do Ce como substituto do La é que a capacidade de descarga é drasticamente diminuída de 382 mAhg-1 $(x=0)$ para 48 mAhg-1 $(x=$ 0,5) [26].

Zhang et al. [27] estudaram as ligas La0,7-xCexMgo, $\mathrm{Ni}_{2,8} \mathrm{Co0}_{, 5}(\mathrm{x}=0,1$ $0,5)$ e encontraram resultados semelhantes. Os resultados da quantidade de fases analisada pelo método de Rietveld mostrou que há uma diminuição da fase $\mathrm{La}(\mathrm{La}, \mathrm{Mg})_{2} \mathrm{Niq}$ com o aumento do teor de cério nas ligas. A capacidade de descarga das baterias diminui drasticamente com o aumento do cério, passandode 367 mAhg $-1(x=0)$ para 68 mAhg $_{-1}(x=0,5)$. 


\subsubsection{Efeito do titânio e zircônio}

A adição de zircônio nas ligas La0,7-x $\mathrm{Zr}_{x} \mathrm{Mgg}_{0,3} \mathrm{Ni}_{2,45} \mathrm{Co0}_{, 75} \mathrm{Mnn}_{1,1} \mathrm{Al}_{0,2}$ ( $\mathrm{x}=0$ $0,1)$ mostrou uma diminuição na capacidade de descarga das baterias. As fases determinadas por difração de raios-X foram: (La, Mg)Ni3 e LaNi5. Os resultados eletroquímicos mostraram que a capacidade de descarga diminui de $364 \mathrm{mAhg}_{-1}(\mathrm{x}=0)$ para $306 \mathrm{mAhg}_{-1}(\mathrm{x}=0,1)$. Este fato foi explicado pela diminuição na quantidade da fase ( $\mathrm{La}, \mathrm{Mg}) \mathrm{Ni}$ com aumento do teor de zircônio. No entanto a estabilidade cíclica mostrou-se inalterada ao longo da mudança de composição[28].

Dong et al. [29] estudaram a substituição do lantânio pelo titânio, em

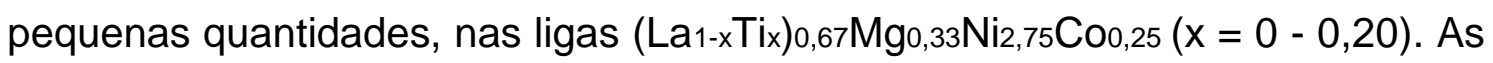
fases encontradas foram as mesmas das obtidas nas ligas de zircônio, com exceção da fase $\mathrm{TiNi}_{3}$, que foi observada em pequenas quantidades a partir da liga com Tio,1. Com o aumento do teor de $\mathrm{Ti}$, os valores de capacidade de descarga máxima diminuem de $384 \mathrm{mAhg}_{-1}(\mathrm{x}=0)$ para $321 \mathrm{mAhg}_{-1}(\mathrm{x}=0,2)$. Os autores verificaram que ativações rápidas foram obtidas para as ligas com titânio, da ordem de três a quatro ciclos. A capacidade de retenção de descarga $\left(\mathrm{C}_{\left.100 / \mathrm{C}_{\text {máx }}\right)}\right.$ aumentou de $51,7 \%(\mathrm{x}=0)$ para $63,0 \%(\mathrm{x}=0,15)$, e depois diminuiu para $56,9 \%$ em $(x=0,20)$ [29]. 


\subsubsection{Substituições em $B$ em ligas $A B_{5}$}

Para as ligas de armazenamento de hidrogênio, a substituição do componente B consiste, em geral, nos metais de transição da tabela periódica.

\subsubsection{Efeito do manganês}

Os trabalhos envolvendo a substituição do níquel por manganês em ligas do tipo La-Mg-Ni-Co apresentaram boas melhorias na ativação das baterias, além de aumentarem a capacidade de descarga das mesmas [30-34].

Em estudos das ligas $\mathrm{La}_{0,7} \mathrm{Mg}_{0,3} \mathrm{Ni}_{2,55-\mathrm{x}} \mathrm{Co}_{0,45} \mathrm{Mn}_{\times}(\mathrm{x}=0-0,5)$ apresentaram somente a presença das fases ( $\mathrm{La}, \mathrm{Mg}) \mathrm{Ni} 3$ e LaNi5,. A capacidade de descarga das baterias aumentou de 342 mAhg- $^{\prime}(x=0)$ para 368 mAhg-1 $^{-1}(x=0,3)$ e decaiu para 333 mAhg-1 $(x=0,5)$ [30].

$\mathrm{Na}$ FIG. 5 (a) estão apresentados as capacidades de descarga em função do número de ciclos para os eletrodos negativos das ligas $\mathrm{La}_{0,7} \mathrm{Mg}_{0,3} \mathrm{Ni}_{2,55-\mathrm{x}} \mathrm{Co}_{0,45} \mathrm{Mn}_{\mathrm{x}}(\mathrm{x}=0-0,5)$ e na FIG. 5 (b) estão mostradas as capacidades de descarga máxima obtidas em função do teor de manganês nas ligas [30]. 


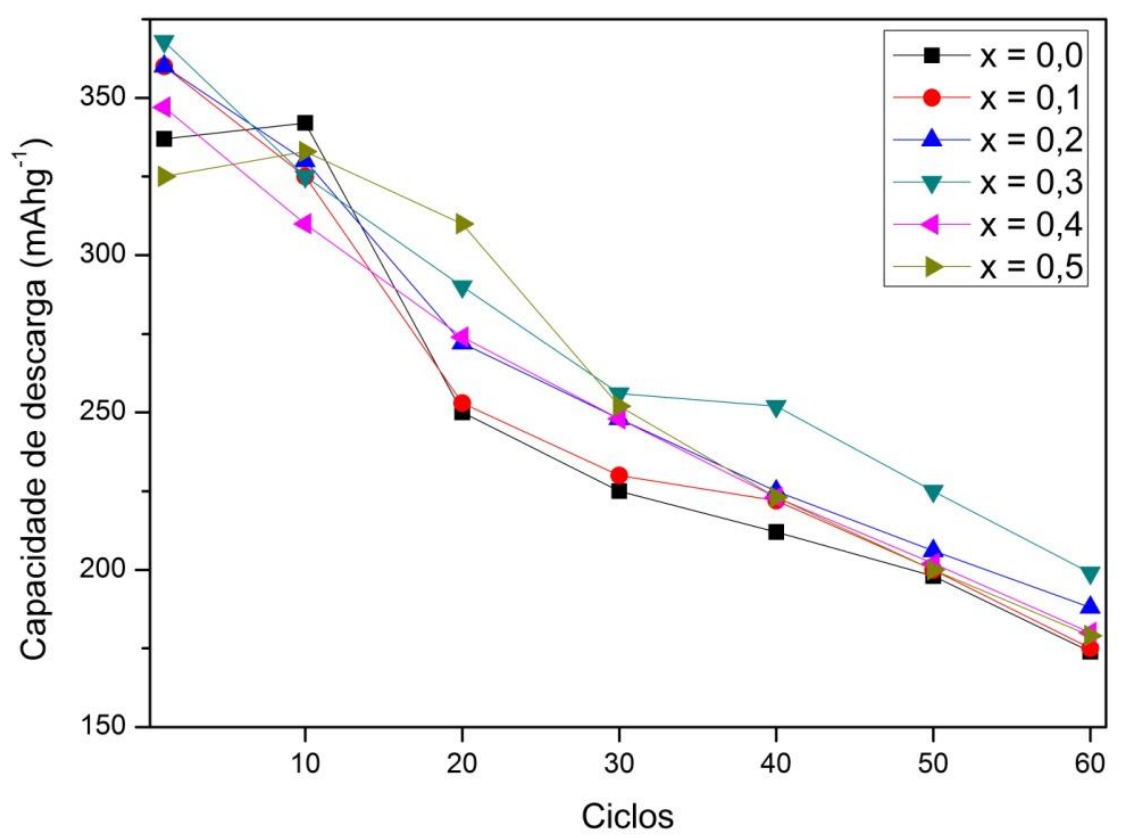

(a)

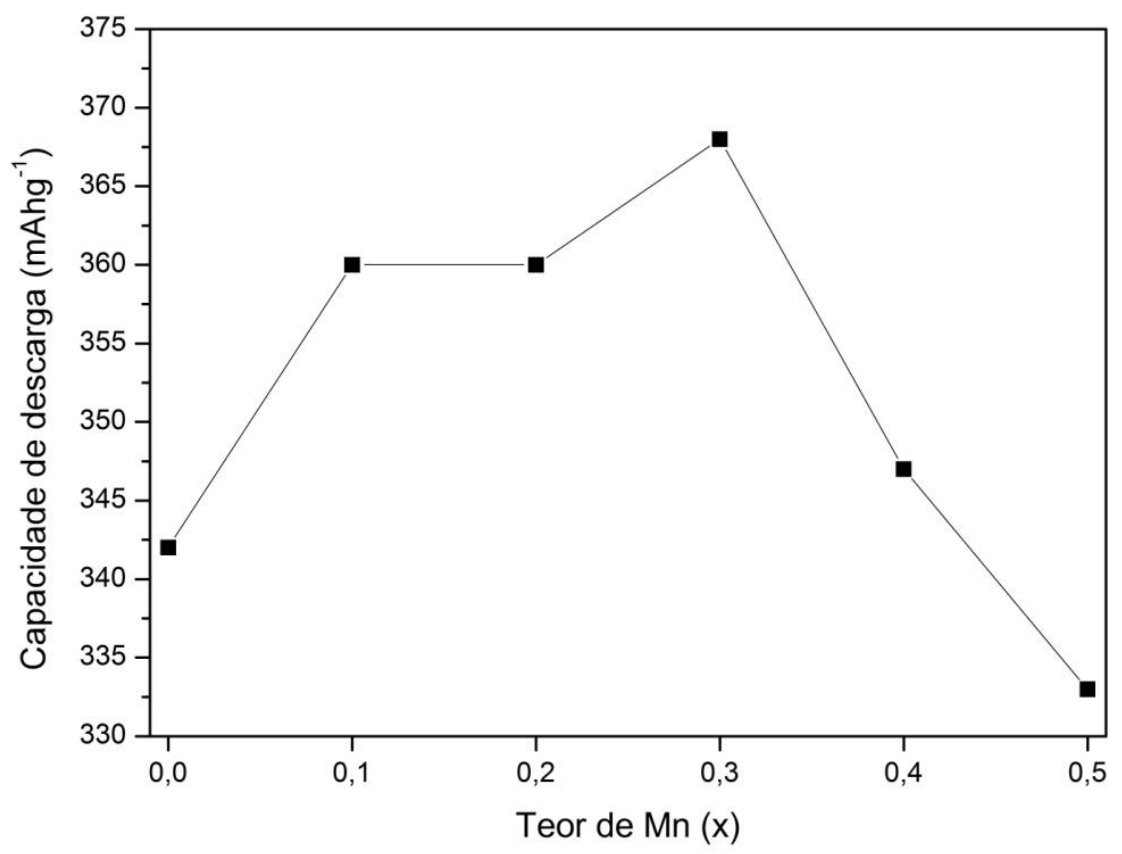

(b)

FIGURA 5 - Capacidades de descarga dos eletrodos negativos das ligas $\mathrm{La}_{0,7} \mathrm{Mg}_{0,3} \mathrm{Ni}_{2,55-x} \mathrm{Co}_{0,45} \mathrm{Mn}_{\mathrm{x}}(\mathrm{x}=0$ - 0,5); onde: (a) capacidade de descarga em função do número de ciclos e (b) capacidade de descarga máxima em função do teor de manganês [30]. 
Na TAB. 4 estão apresentadas as capacidades de descarga máxima $\left(\mathrm{C}_{\text {máx }}\right)$ e as capacidades de descarga no ciclo $\mathrm{n}^{\circ} 60\left(\mathrm{C}_{60}\right)$ obtidas para os eletrodos negativos das ligas $\mathrm{La}_{0,7} \mathrm{Mg}_{0,3} \mathrm{Ni}_{2,55-x} \mathrm{Co}_{0,45} \mathrm{Mn}_{\mathrm{x}}(\mathrm{x}=0$ - 0,5) [30].

TABELA 4 - Capacidades de descarga obtidas para as ligas

$$
\mathrm{La}_{0,7} \mathrm{Mg}_{0,3} \mathrm{Ni}_{2,55-\mathrm{x}} \mathrm{Co}_{0,45} \mathrm{Mn}_{\mathrm{x}}(\mathrm{x}=0 \text { - 0,5) [30]. }
$$

\begin{tabular}{cccc}
\hline $\mathrm{x}$ & $\mathrm{C}_{\text {máx }}\left(\mathrm{mAhg}^{-1}\right)$ & $\mathrm{C}_{60}\left(\mathrm{mAhg}^{-1}\right)$ & $\mathrm{C}_{60} / \mathrm{C}_{\text {máx }}(\%)$ \\
\hline 0,0 & 342 & 174 & 51,1 \\
0,1 & 360 & 175 & 48,7 \\
0,2 & 360 & 188 & 52,3 \\
0,3 & 368 & 199 & 54,1 \\
0,4 & 347 & 180 & 52,1 \\
0,5 & 333 & 174 & 54,0 \\
\hline
\end{tabular}

O efeito do manganês nas ligas ( $\left(\mathrm{La}_{0,7} \mathrm{Ce}_{0,2} \mathrm{Pr} 0,1\right) \mathrm{Ni} 2,6-\mathrm{x} \mathrm{Mn} \times \mathrm{Co}_{0,9}(\mathrm{x}=0,0$; $0,225 ; 0,45 ; 0,675 ; 0,90)$ mostraram resultados similares. A capacidade de descarga aumenta até uma determinada concentração de manganês e depois decai. A capacidade de descarga máxima obtida foi 352 mAhg-1 $(x=0,45)$, e depois diminui para 307 mAhg-1 para $x=0,9$ [33].

Estudos das ligas Lao,7Mgo,3 $\mathrm{Ni}_{2,975-x} \mathrm{Co0}_{5,525 \mathrm{Mn} \times}(\mathrm{x}=0-0,4)$ mostraram que há um aumento no coeficiente de difusão do hidrogênio causado pela expansão do volume da célula unitária. A capacidade de descarga máxima encontrada foi para a liga com $x=0,3$ (356 mAhg-1) [34].

\subsubsection{Efeito do cobalto}

O cobalto é um dos elementos de adição mais importantes utilizados de adição para a melhoria nas propriedades eletroquímicas de ligas à base de terras raras para eletrodos de baterias de $\mathrm{Ni}-\mathrm{HM}$, especialmente no prolongamento da vida útil (número de ciclos) das baterias. Estudos do efeito do cobalto em eletrodos a base de La-Mg-Ni têm sido extensivamente estudados [35-37]. 
Liao et al. estudaram o efeito da substituição do níquel pelo cobalto nas

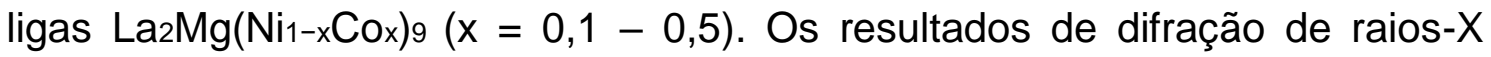
mostraram a presença da fase principal ( $\mathrm{La}, \mathrm{Mg}) \mathrm{Ni}_{3}$ (estrutura romboédrica tipo$\mathrm{PuNi}$ ) e duas fases em pequenas quantidades ( $\mathrm{LaNi}$ e $\mathrm{La}_{2} \mathrm{Ni}$ ). A capacidade de descarga das baterias mostrou um aumento de 400 mAhg-1 $(x=0)$ para 404 mAhg- $1(x=0,2)$. Para a liga com Co0,5 a capacidade de descarga diminuiu para 328 mAhg-1, porém apresentou melhor estabilidade cíclica. Este resultado foi explicado à baixa expansão da célula unitária quando se aumenta o teor de cobalto nas ligas, causando uma baixa taxa de decrepitação e corrosão das partículas durante a carga e descarga das baterias [36].

Liu et al. [35,37], mostraram o efeito da substituição do níquel pelo cobalto nas ligas $\mathrm{La} 0,7 \mathrm{Mg}_{0,3} \mathrm{Ni}_{3,4-x \mathrm{Mn} 0,1} \mathrm{Cox}_{\mathrm{x}}(\mathrm{x}=0-1,6)$. Com o aumento do teor de cobalto a capacidade de descarga máxima das baterias aumenta de 397 mAng $_{-1}(x=0)$ para 403 mAhg $_{-1}(x=0,75)$ e depois diminui para 380 mAhg $_{-1}(x$ $=1,6)$. Com altos teores de cobalto nas ligas a cinética eletroquímica diminui, devido à diminuição do coeficiente de difusão do hidrogênio.

A melhoria na estabilidade cíclica foi atribuída à baixa expansão do volume da célula unitária durante a hidrogenação/desidrogenação e o aumento da superfície de passivação durante a carga e descarga das baterias. A substituição adequada do Ni pelo Co aumenta a cinética eletroquímica dos eletrodos devido à concentração de Co e $\mathrm{Ni}$ na superfície das partículas da liga, e com consequente formação de um filme de $\mathrm{Ni}-\mathrm{Co}[35,37]$.

Na FIG. 6 (a) estão apresentados as capacidades de descarga em função do número de ciclos para os eletrodos negativos das ligas $\mathrm{La}_{0,7} \mathrm{Mg}_{0,3} \mathrm{Ni}_{3,4-x} \mathrm{Mn}_{0,1} \mathrm{Co}_{\mathrm{x}}(\mathrm{x}=0-1,6)$ e na FIG. 6 (b) estão mostradas as capacidades de descarga máxima obtidas em função do teor de cobalto nas ligas [37]. 


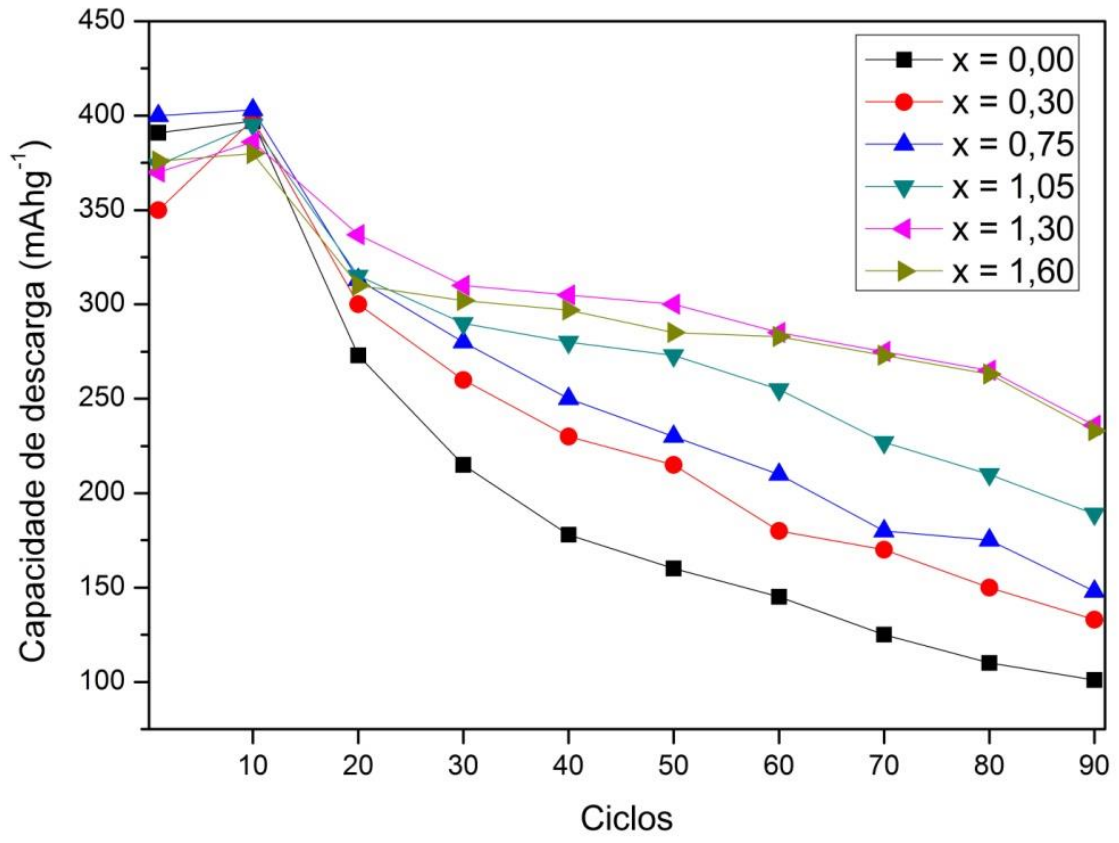

(a)

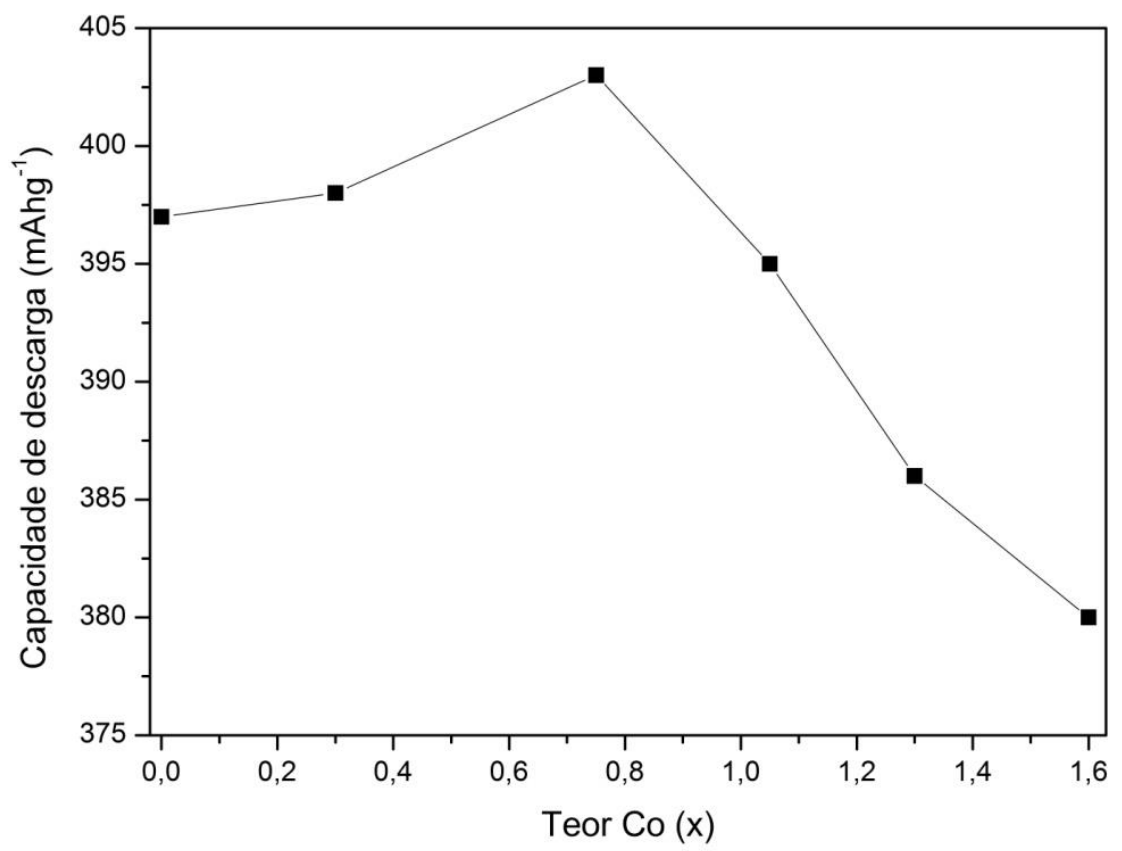

(b)

FIGURA 6 - Capacidades de descarga dos eletrodos negativos das ligas $\mathrm{La}_{0,7} \mathrm{Mg}_{0,3} \mathrm{Ni}_{3,4-x} \mathrm{Mn}_{0,1} \mathrm{Co}_{\mathrm{x}}(\mathrm{x}=0$ - 1,6); onde: (a) capacidade de descarga em função do número de ciclos e (b) capacidade de descarga máxima em função da teor de cobalto [37]. 
Na TAB. 5 estão apresentadas as capacidades de descarga máxima $\left(\mathrm{C}_{\text {máx }}\right)$ e as capacidades de descarga no ciclo $\mathrm{n}^{\circ} 90\left(\mathrm{C}_{90}\right)$ obtidas para os eletrodos negativos das ligas $\mathrm{La}_{0,7} \mathrm{Mg}_{0,3} \mathrm{Ni}_{3,4-x} \mathrm{Mn}_{0,1} \mathrm{Co}_{x}(x=0-1,6)$ [37].

TABELA 5 - Capacidades de descarga obtidas para as ligas

$$
\mathrm{La}_{0,7} \mathrm{Mg}_{0,3} \mathrm{Ni}_{3,4-x} \mathrm{Mn}_{0,1} \mathrm{Co}_{\mathrm{x}}(\mathrm{x}=0 \text { - 1,6) [37]. }
$$

\begin{tabular}{cccc}
\hline $\mathrm{x}$ & $\mathrm{C}_{\text {máx }}\left(\mathrm{mAhg}^{-1}\right)$ & $\mathrm{C}_{90}\left(\mathrm{mAhg}^{-1}\right)$ & $\mathrm{C}_{90} / \mathrm{C}_{\text {máx }}(\%)$ \\
\hline 0,00 & 397 & 101 & 25,5 \\
0,30 & 398 & 133 & 33,6 \\
0,75 & 403 & 148 & 36,9 \\
1,05 & 395 & 189 & 47,9 \\
1,30 & 386 & 236 & 61,3 \\
1,60 & 380 & 233 & 61,5 \\
\hline
\end{tabular}

\subsubsection{Efeito do alumínio}

Trabalhos envolvendo a substituição do Ni pelo Al (que não faz parte da família dos metais de transição) nas ligas à base de La-Mg-Ni mostram uma melhoria significativa na estabilidade cíclica das baterias de Ni-HM $[38,39]$.

Os estudos realizados nas ligas $\operatorname{La} 2 \mathrm{Mg}\left(\mathrm{Ni}_{1-x \mathrm{Al}}\right)_{9}(\mathrm{x}=0-0,05)$ mostraram a presença da fase principal, do tipo-PuNis, e pequenas quantidades da fase $\mathrm{La}_{2} \mathrm{Ni}$, citada como impureza. A capacidade de descarga das baterias mostrou decréscimo de 400 mAhg-1 $(\mathrm{x}=0)$ para $374 \mathrm{mAhg}_{-1}(\mathrm{x}=$ $0,02)$, atingindo um ponto mais baixo $\mathrm{ax}=0,05$ (221 mAhg-1) [38].

$\mathrm{Na}$ FIG. 7 (a) estão apresentados as capacidades de descarga em função do número de ciclos para os eletrodos negativos das ligas $\mathrm{La}_{2} \mathrm{Mg}\left(\mathrm{Ni}_{1-\mathrm{x}} \mathrm{Al} \mathrm{I}_{\mathrm{x}}\right)_{9}(\mathrm{x}=0-0,05)$ e na FIG. 7 (b) estão mostradas as capacidades de descarga máxima obtidas em função do teor de cobalto nas ligas [38]. 


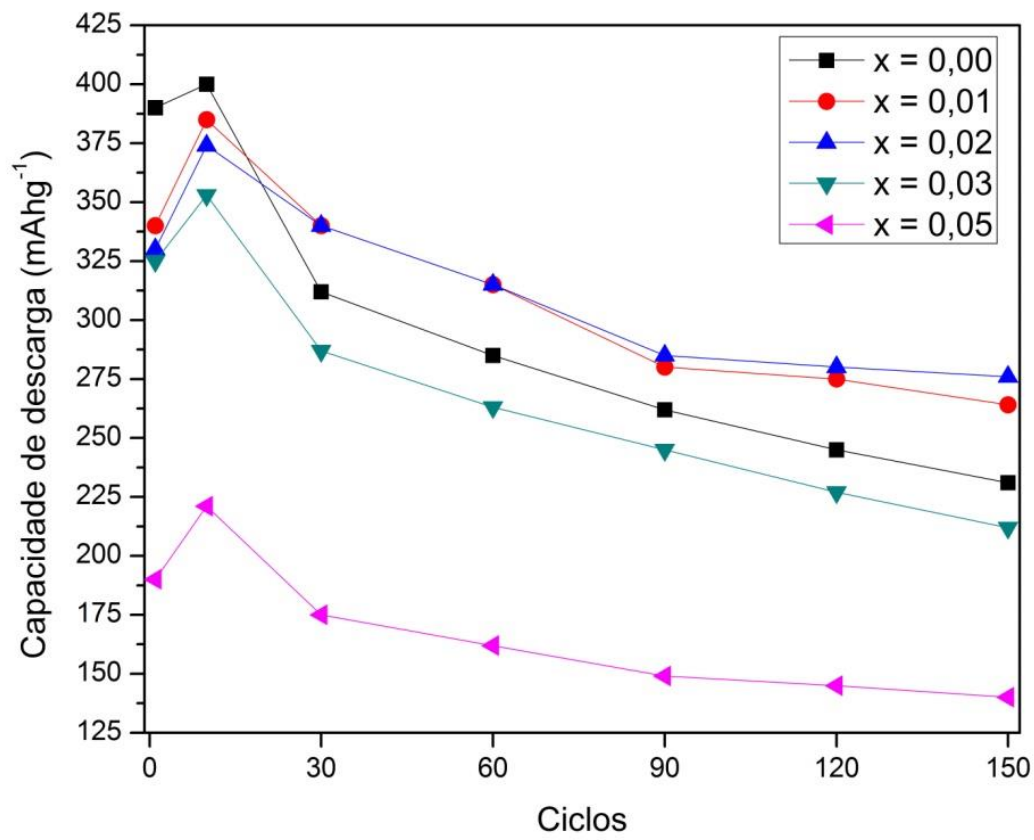

(a)

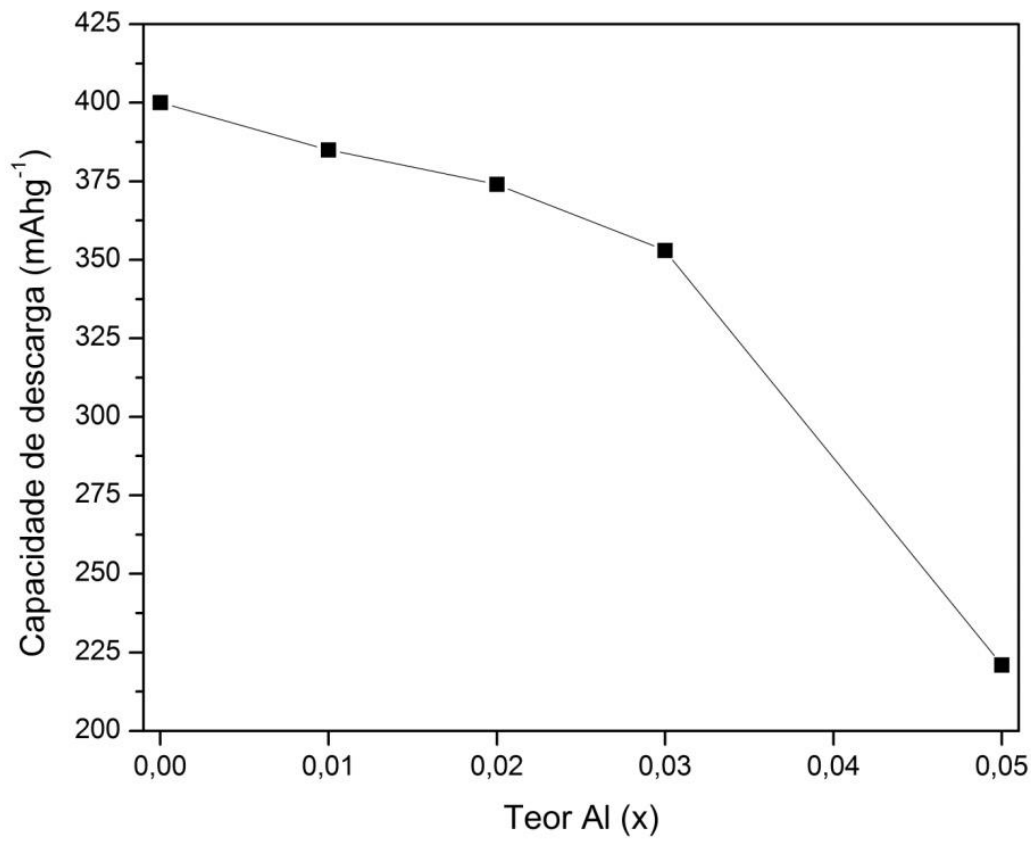

(b)

FIGURA 7 - Capacidades de descarga dos eletrodos negativos das ligas $\mathrm{La}_{2} \mathrm{Mg}\left(\mathrm{Ni}_{1-x} \mathrm{Al}_{\mathrm{x}}\right)_{9}(\mathrm{x}=0$ - 0,05); onde: (a) capacidade de descarga em função do número de ciclos e (b) capacidade de descarga máxima em função da teor de alumínio [38]. 
Na TAB. 6 estão apresentadas as capacidades de descarga máxima $\left(C_{\text {máx }}\right)$ e as capacidades de descarga no ciclo $n^{\circ} 150\left(C_{150}\right)$ obtidas para os eletrodos negativos das ligas $\mathrm{La}_{2} \mathrm{Mg}\left(\mathrm{Ni}_{1-\mathrm{x}} \mathrm{Al} \mathrm{I}_{\mathrm{x}}\right)_{9}(\mathrm{x}=0-0,05)$ [38].

TABELA 6 - Capacidades de descarga obtidas para as ligas $\operatorname{La}_{2} M g\left(\mathrm{Ni}_{1-\mathrm{x}} \mathrm{A} \mathrm{I}_{\mathrm{x}}\right)_{9}(\mathrm{x}$ $=0-0,05)[38]$.

\begin{tabular}{cccc}
\hline $\mathrm{x}$ & $\mathrm{C}_{\text {máx }}\left(\mathrm{mAhg}^{-1}\right)$ & $\mathrm{C}_{150}\left(\mathrm{mAhg}^{-1}\right)$ & $\mathrm{C}_{150} / \mathrm{C}_{\text {máx }}(\%)$ \\
\hline 0,00 & 400 & 231 & 57,7 \\
0,01 & 385 & 264 & 68,6 \\
0,02 & 374 & 276 & 73,8 \\
0,03 & 353 & 212 & 60,3 \\
0,05 & 221 & 140 & 63,5 \\
\hline
\end{tabular}

Pan et al. encontraram resultados semelhantes para as ligas

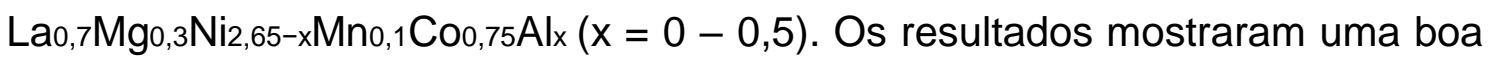
melhoria na estabilidade da capacidade de descarga após 100 ciclos a retenção de carga aumentou de $32 \%(x=0)$ para $74 \%(x=0,3)$ [39].

Liu et al. atribuíram o aumento da estabilidade cíclica à formação de uma camada de óxido de alumínio dificultando a corrosão e decrepitação das partículas durante os ciclos de carga/descarga. Porém, em grandes quantidades de alumínio esta camada de óxido dificulta a difusão do hidrogênio no interior da liga [40]. 


\subsection{Efeito do magnésio}

O magnésio tem sido reportado como um dos elementos mais promissores na utilização em ligas de armazenamento de hidrogênio, especialmente em aplicações veiculares. O magnésio metálico é bem acessível e de baixo custo. Além disso, os hidretos à base de $\mathrm{Mg}$ possuem boas propriedades, tais como a resistência ao calor, aumento da capacidade de descarga e facilidade de reciclagem após utilização [41]. Ligas à base de $\mathrm{Mg}$ possuem alta capacidade de armazenamento de hidrogênio e também é um metal bastante resistente e leve, aproximadamente $30 \%$ menos denso que 0 alumínio [42-44].

Em 1980, Oesterreicher e Bittner foram os primeiros a preparar ligas ternárias com substituição do La por $\mathrm{Mg}$ na liga LaNi2. As composições estudadas foram $\mathrm{La}_{1-\mathrm{x} M \mathrm{M} \times \mathrm{Ni} 2}(\mathrm{x}=0$ - 1) obtidas por forno de indução em atmosfera de argônio. Realizaram hidretação das ligas a $1 \mathrm{MPa}$ (10 bar) a temperatura ambiente e os resultados mostraram que $x=0,67$ foi o limite para que ocorresse a absorção de hidrogênio [45].

$\mathrm{O}$ desenvolvimento de novas ligas ternárias à base de $\mathrm{Mg}\left(\mathrm{RMg}_{2} \mathrm{Ni}_{9}\right)$, onde $\mathrm{R}=\mathrm{La}, \mathrm{Ce}, \mathrm{Pr}, \mathrm{Nd}, \mathrm{Sm}, \mathrm{Gd}$ e $\mathrm{Y}$, foram preparadas através da mistura dos compostos intermetálicos $\mathrm{RNi}_{5}$ com $\mathrm{MgNi}_{2}$ ou pela combinação direta dos elementos na razão atômica, $\mathrm{R}: \mathrm{Mg}: \mathrm{Ni}=1: 2: 9$ [45,46]. As ligas foram preparadas conforme as Eq. 1.4 e 1.5:

$$
\begin{gathered}
\mathrm{RNi}_{5}+2 \mathrm{MgNi}_{2} \stackrel{900^{\circ} \mathrm{C}-1100^{\circ} \mathrm{C}}{\longrightarrow} \mathrm{RMg}_{2} \mathrm{Ni}_{9} \\
\mathrm{R}+2 \mathrm{Mg}+9 \mathrm{Ni} \stackrel{900^{\circ} \mathrm{C}-1100^{\circ} \mathrm{C}}{\longrightarrow} \mathrm{RMg}_{2} \mathrm{Ni}_{9}
\end{gathered}
$$


O interesse no desenvolvimento de ligas ternária do tipo $\mathrm{R}-\mathrm{Mg}-\mathrm{Ni}(\mathrm{R}=$ elementos de terras raras) com formula geral $\mathrm{RMg}_{2} \mathrm{Ni}_{9}$ (tipo $\mathrm{PuNi}_{3}$ e estrutura romboédrica) foi devido a mesma apresentar melhor capacidade de estocagem de hidrogênio comparado com a liga $\mathrm{LaNi}_{5}$ [47-51].

Liao et al. [52,53] estudaram ligas ternárias com as composições LaxMg3-xNig $(x=1,0-2,2)$. Verificaram que com o aumento do La na liga há um aumento no volume da célula unitária. Verificaram também que os eletrodos negativos das ligas ricas em lantânio $(1,8-2,1)$ mostraram ser promissoras, incluindo alta capacidade de descarga ( 400 mAhg-1) e ativação inicial rápida, embora sua estabilidade cíclica tenha diminuído. Os resultados de difração de raios-X mostraram a presença de três fases: $\mathrm{LaMg}_{2} \mathrm{Ni}$, $\mathrm{LaNi}$ e $\mathrm{MgNiz}$. A fase principal, LaMgaNig, é hexagonal do tipo PuNiz e grupo espacial R-3m.

Zhang et al. [54] estudaram o efeito da substituição do lantânio pelo

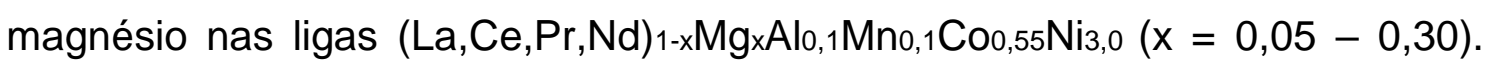
As fases determinadas por difração de raios- $X$ foram ( $L a, M g) N i z$ e LaNis. Com o incremento na concentração de magnésio nas ligas houve um aumentou de fração volumétrica da fase ( $\mathrm{La}, \mathrm{Mg}) \mathrm{Ni}$. A capacidade de descarga máxima das baterias aumentou de 355 mAhg-1 $(x=0,05)$ para 363 mAhg-1 $(x=0,20)$ e depois decaiu para 334 mAhg-1 $(x=0,30)$.

Na FIG. 8 está mostrada a relação entre a capacidade de descarga em função do número de ciclos das ligas (La,Ce,Pr,Nd) $)_{1-x} \mathrm{Mg}_{x} \mathrm{Al}_{0,1} \mathrm{Mn}_{0,1} \mathrm{Co}_{0,55} \mathrm{Ni}_{3,0}(\mathrm{x}$ $=0,05-0,30)[54]$.

Na FIG. 9 estão apresentadas as retenções da capacidade de descarga $\left(\mathrm{C}_{200} / \mathrm{C}_{\text {máx }}\right)$ em função do aumento do teor de magnésio nas ligas $(\mathrm{La}, \mathrm{Ce}, \mathrm{Pr}, \mathrm{Nd})_{1-x} \mathrm{Mg}_{x} \mathrm{Al}_{0,1} \mathrm{Mn}_{0,1} \mathrm{Co}_{0,55} \mathrm{Ni}_{3,0}(\mathrm{x}=0,05-0,30)$ [54]. 


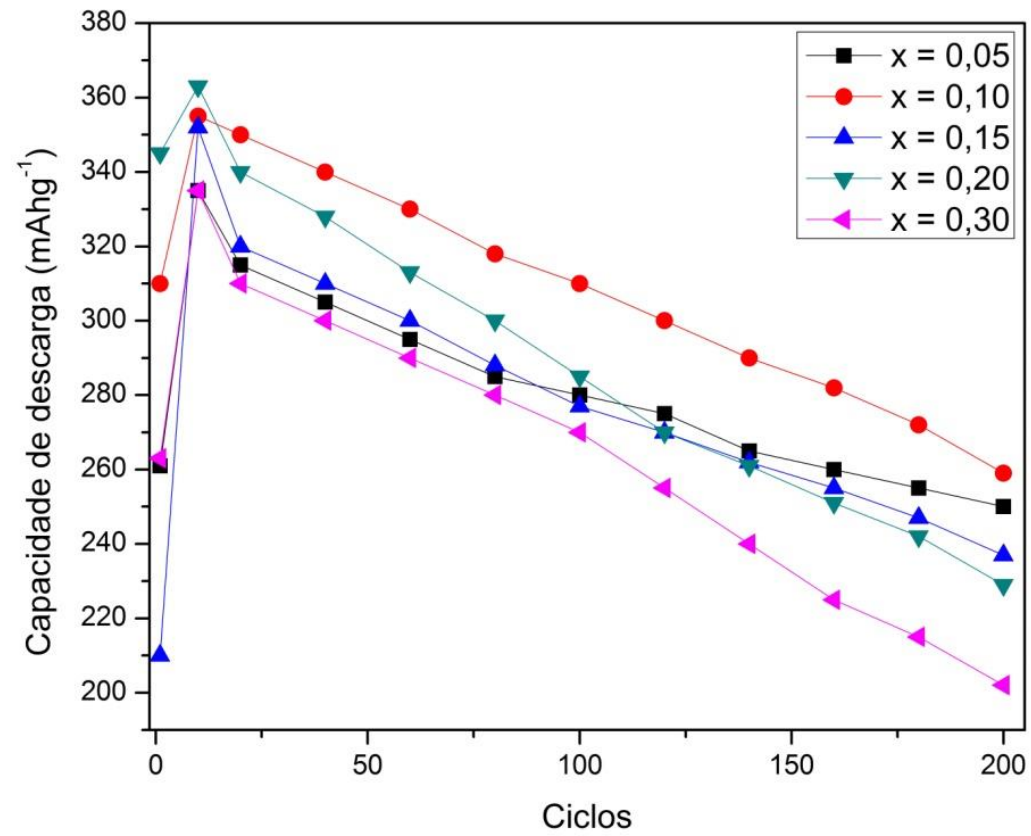

FIGURA 8 - Capacidade de descarga em função do número de ciclos dos eletrodos negativos produzidos com as ligas $(\mathrm{La}, \mathrm{Ce}, \mathrm{Pr}, \mathrm{Nd})_{1}$.

${ }_{x} \mathrm{Mg}_{x} \mathrm{Al}_{0,1} \mathrm{Mn}_{0,1} \mathrm{Co}_{0,55} \mathrm{Ni}_{3,0}(\mathrm{x}=0,05-0,30)$ [54].

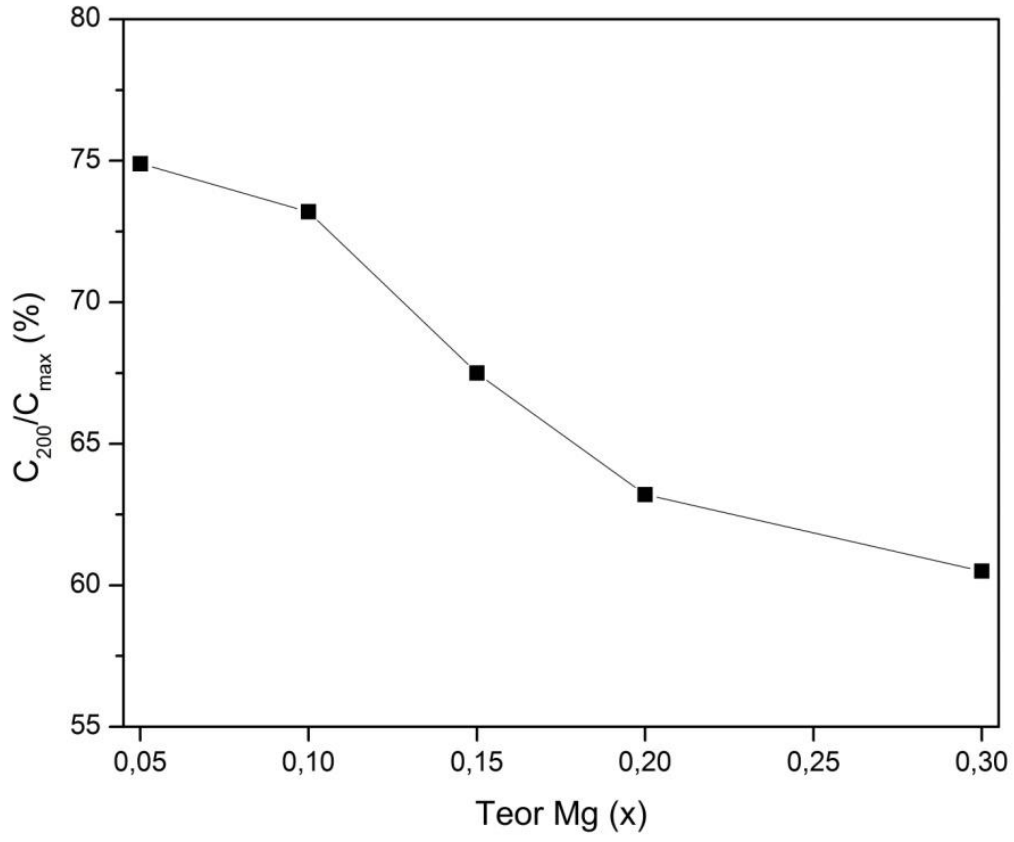

FIGURA 9 - Retenção da capacidade de descarga em função do aumento do teor de magnésio nas ligas ( $\mathrm{La}, \mathrm{Ce}, \mathrm{Pr}, \mathrm{Nd})_{1-x} \mathrm{Mg}_{x} \mathrm{Al}_{0,1} \mathrm{Mn}_{0,1} \mathrm{Co}_{0,55} \mathrm{Ni}_{3,0}(\mathrm{x}=0,05-$ $0,30)$. 
Os resultados obtidos da retenção da capacidade de descarga

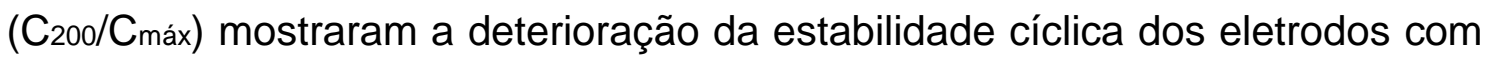
o aumento do teor de magnésio causados pela decrepitação e oxidação das partículas durante o carregamento e descarregamento das baterias. Em eletrólito alcalino de $\mathrm{KOH}$, o magnésio é oxidado formando $\mathrm{Mg}(\mathrm{OH})_{2}$. A formação deste hidróxido nas partículas das ligas leva à redução da capacidade de descarga nos eletrodos negativos a base de magnésio [54].

Muitos esforços têm sido feitos no sentido de melhorar o desempenho de hidretação/desidrogenação destas ligas, mas ainda há necessidade de pesquisa tem investigado o desempenho da absorção/dessorção eletroquímica de ligas baseadas em Mg em solução alcalina [55,56].

A oxidação da superfície do $\mathrm{Mg}$ formando hidróxido de magnésio $\left(\mathrm{Mg}(\mathrm{OH})_{2}\right)$, é o principal fator que reduz a capacidade de armazenamento de hidrogênio, além de dificultar o processo de hidrogenação. $\mathrm{O} \mathrm{Mg}(\mathrm{OH})_{2}$ forma sobre a superfície metálica da liga uma camada impermeável à absorção de hidrogênio, impedindo que o hidrogênio atravesse a superfície e se estoque no interior da liga. Portanto, para melhorar as propriedades e superar a limitação cinética das ligas baseadas em $\mathrm{Mg}$, o controle da oxidação das ligas é de fundamental importância. No intuito de reduzir o efeito da formação do $\mathrm{Mg}(\mathrm{OH})_{2}$, alguns autores [57-59] estudaram a incorporação do titânio em ligas amorfas de MgNi obtidas por moagem de alta energia (mechanical alloying) e de alta velocidade.

Han et al. estudaram a série de ligas $\mathrm{Mg}_{1-x} \mathrm{Ti}_{x} \mathrm{Ni}$ (onde $0,1 \leq \mathrm{x} \leq 0,3$ ). Os resultados mostraram uma melhoria no ciclo de vida da bateria fabricada com $x$ $=0,3$. Análises por espectroscopia de impedância eletroquímica (EIS) mostraram que a resistência de transferência de carga não aumentou com o avanço dos ciclos de carga e descarga [57].

$\mathrm{A}$ adição de paládio $(\mathrm{Pd})$ em ligas à base de $\mathrm{MgNi}$ têm sido também estudados [60,61]. Foi notado uma melhora nas propriedades eletroquímicas da liga $\mathrm{MgNi}$, quando $\mathrm{Pd}$ é adicionado como elemento de liga, pela eficácia deste elemento em diminuir a degradação das ligas decorrente da redução na formação do $\mathrm{Mg}(\mathrm{OH})_{2}$. Os autores estudaram o decaimento da capacidade de descarga das ligas com e sem paládio. A capacidade de descarga no $1^{\circ}$ ciclo 
resultou em $400 \mathrm{mAhg}^{-1}$ para as ligas $\mathrm{MgNi}$ e $(\mathrm{MgNi})_{90} \mathrm{Pd}_{10}$. Após o $10^{\circ}$ ciclo, a liga $\mathrm{MgNi}$ reduziu drasticamente sua capacidade para $100 \mathrm{mAh} / \mathrm{g}$, enquanto que, para a liga contendo Pd a capacidade foi de $300 \mathrm{mAhg}^{-1}$ [60].

\subsubsection{Tratamento térmico em ligas $A B_{5}$}

As propriedades eletroquímicas gerais do armazenamento de hidrogênio de ligas do tipo La-Mg-Ni-Co devem ser melhorados para a sua aplicação prática, em particular, sua estabilidade cíclica. $O$ tratamento térmico é um meio muito eficaz para melhorar as propriedades gerais das ligas de armazenamento de hidrogênio, tais como a capacidade máxima de descarga e estabilidade cíclica $[62,63]$. O tratamento térmico pode diminuir os defeitos cristalinos e aumentar a homogeneização da composição da liga e, conseqüentemente, aumentar a capacidade de descarga e estabilidade cíclica das baterias de $\mathrm{Ni}$ HM [62].

Para melhorar a estabilidade cíclica da liga $\mathrm{La} 0,7 \mathrm{Mg} 0,3 \mathrm{Ni}, 45 \mathrm{Co}, 75 \mathrm{Mno}_{1} \mathrm{Al}_{0,2}$ os autores estudaram o tratamento térmico a $900^{\circ} \mathrm{C}, 1000^{\circ} \mathrm{C}$ e $1100^{\circ} \mathrm{C}$ por 8 horas. As análises de difração de raios-X e Rietveld indicaram que a estrutura das ligas manteve a presença das duas principais fases após o tratamento térmico, ou seja, as fases ( $\mathrm{La}, \mathrm{Mg}) \mathrm{Ni}_{3} \mathrm{e}$ LaNis. Com o aumento da temperatura de tratamento térmico, os parâmetros de rede e os volumes da célula unitária, nas duas fases, aumentaram. Porém, houve variação no teor das duas fases, com a redução da fase $(\mathrm{La}, \mathrm{Mg}) \mathrm{Ni}_{3} \mathrm{e}$ conseqüentemente, aumento da fase LaNi5. Os estudos eletroquímicos indicaram melhorias na estabilidade cíclica devido à maior homogeneização da composição, mostrando um aumento de $65,5 \%$ (liga no estado bruto de fusão) para $75,0 \%$ (liga tratada termicamente a $1100^{\circ} \mathrm{C}$ ) na retenção da capacidade de descarga após 100 ciclos de carga e descarga. A capacidade de descarga máxima da liga no estado bruto de fusão (350 mAhg-1) aumentou para 370 mAhg-1 após tratamento térmico a $900^{\circ} \mathrm{C}$, reduzindo para $359 \mathrm{mAhg}-1$ a $1100^{\circ} \mathrm{C}$ [63].

Na FIG. 10 estão apresentados os resultados obtidos por Pan et al. da capacidade de descarga em função do número de ciclos [63]. 


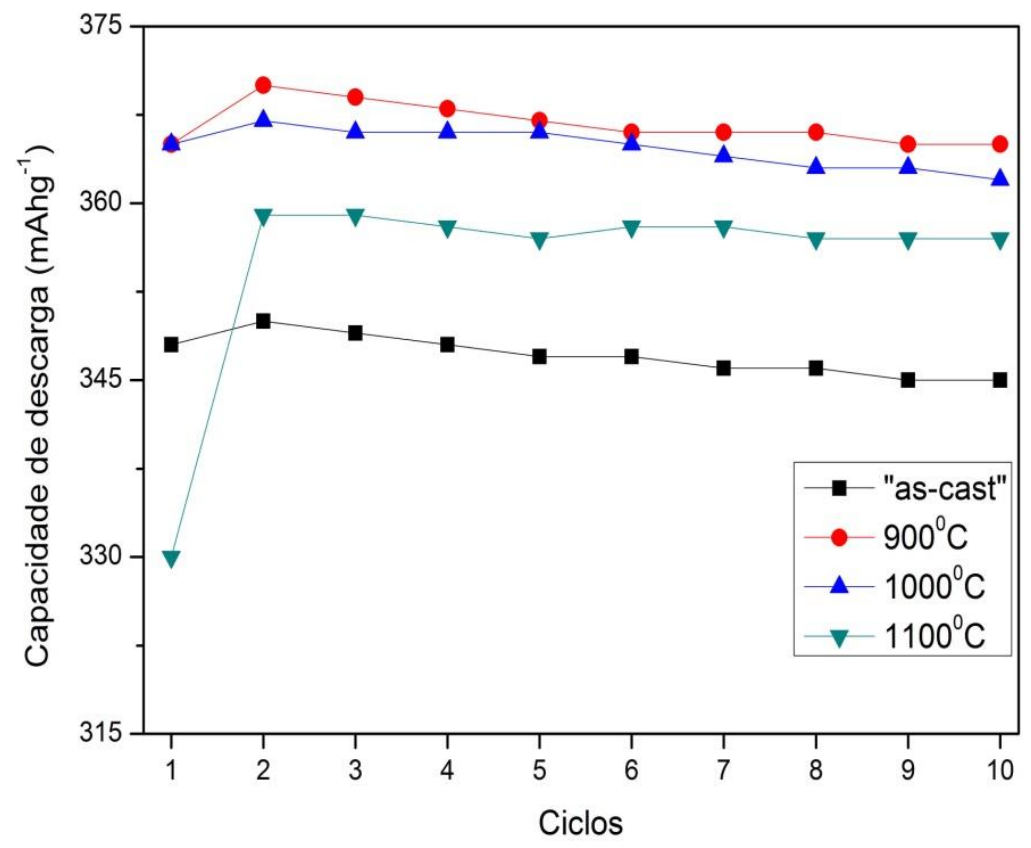

FIGURA 10 - Capacidade de descarga em função do número de ciclos dos eletrodos negativo produzido com a liga $\mathrm{La}_{0.7} \mathrm{Mg}_{0.3} \mathrm{Ni}_{2.45} \mathrm{Co}_{0.75} \mathrm{Mn}_{0.1} \mathrm{Al}_{0.2}$ [63].

Na TAB. 7 estão apresentadas as capacidades de descarga máxima $\left(\mathrm{C}_{\text {máx }}\right)$ e as capacidades de descarga no ciclo $\mathrm{n}^{\circ} 100\left(\mathrm{C}_{100}\right)$ obtidas para o eletrodo negativo da liga $\mathrm{La}_{0.7} \mathrm{Mg}_{0.3} \mathrm{Ni}_{2.45} \mathrm{Co}_{0.75} \mathrm{Mn}_{0.1} \mathrm{Al}_{0.2}$ sem e com tratamento térmico $\left(900^{\circ} \mathrm{C}, 1000^{\circ} \mathrm{C}\right.$ e $1100^{\circ} \mathrm{C}$ por 8 horas) [63].

TABELA 7 - Efeito do tratamento térmico na capacidade descarga no eletrodo negativo da liga $\mathrm{La}_{0.7} \mathrm{Mg}_{0.3} \mathrm{Ni}_{2.45} \mathrm{Co}_{0.75} \mathrm{Mn}_{0.1} \mathrm{Al}_{0.2}$ [63].

\begin{tabular}{cccc}
\hline $\begin{array}{c}\text { Temperatura de } \\
\text { tratamento térmico }\left({ }^{0} \mathrm{C}\right)\end{array}$ & $\mathrm{C}_{\text {máx }}\left(\mathrm{mAhg}^{-1}\right)$ & $\mathrm{C}_{100}\left(\mathrm{mAhg}^{-1}\right)$ & $\mathrm{C}_{100} / \mathrm{C}_{\text {máx }}(\%)$ \\
\hline 0 & 350 & 229 & 65,5 \\
900 & 370 & 249 & 67,5 \\
1000 & 367 & 264 & 72,1 \\
1100 & 359 & 269 & 75,0 \\
\hline
\end{tabular}




\subsection{Capacidade de descarga em baterias de Ni-HM}

As propriedades das baterias como: capacidade de descarga, ativação e estabilidade cíclica são dependentes das composições das ligas e suas características microestruturais.

Nas ultimas décadas o efeito da substituição dos elementos têm sido amplamente estudado com o objetivo principal de melhorar o desempenho e reduzir custos das baterias de $\mathrm{Ni}-\mathrm{HM}$.

A TAB. 8 mostra os principais elementos que foram estudados em baterias de $\mathrm{Ni}-\mathrm{HM}$ e a capacidade de descarga máxima obtida nas baterias. 
TABELA 8 - Capacidade máxima de descarga das principais ligas, a base de magnésio, com substituição dos elementos.

\begin{tabular}{|c|c|c|c|}
\hline Elementos & Ligas & $\begin{array}{l}\text { Capacidade máxima } \\
\text { de descarga }\left(\mathrm{mAhg}^{-1}\right)\end{array}$ & Ref. \\
\hline \multirow{3}{*}{$\operatorname{Pr}$} & $\mathrm{La}_{0,7} \mathrm{Mg}_{0,3} \mathrm{Ni}_{2,45} \mathrm{Co}_{0,75} \mathrm{Mn}_{0,1} \mathrm{Al}_{0,2}$ & 366 & \multirow{3}{*}{ [24] } \\
\hline & $\mathrm{La}_{0,55} \operatorname{Pr}_{0,15} \mathrm{Mg}_{0,3} \mathrm{Ni}_{2,45} \mathrm{Co}_{0,75} \mathrm{Mn}_{0,1} \mathrm{Al}_{0,2}$ & 356 & \\
\hline & $\mathrm{La}_{0,4} \mathrm{Pr}_{0,3} \mathrm{Mg}_{0,3} \mathrm{Ni}_{2,45} \mathrm{Co}_{0,75} \mathrm{Mn}_{0,1} \mathrm{Al}_{0,2}$ & 346 & \\
\hline \multirow{3}{*}{$\mathrm{Nd}$} & $\mathrm{La}_{0,7} \mathrm{Mg}_{0,3} \mathrm{Ni}_{2,45} \mathrm{Co}_{0,75} \mathrm{Mn}_{0,1} \mathrm{Al}_{0,2}$ & 377 & \multirow{3}{*}{ [25] } \\
\hline & $\mathrm{La}_{0,55} \mathrm{Nd}_{0,15} \mathrm{Mg}_{0,3} \mathrm{Ni}_{2,45} \mathrm{Co}_{0,75} \mathrm{Mn}_{0,1} \mathrm{Al}_{0,2}$ & 371 & \\
\hline & $\mathrm{La}_{0,4} \mathrm{Nd}_{0,3} \mathrm{Mg}_{0,3} \mathrm{Ni}_{2,45} \mathrm{Co}_{0,75} \mathrm{Mn}_{0,1} \mathrm{Al}_{0,2}$ & 357 & \\
\hline \multirow{3}{*}{$\mathrm{Ce}$} & $\mathrm{La}_{0,7} \mathrm{Mg}_{0,3} \mathrm{Ni}_{2,875} \mathrm{Mn}_{0,1} \mathrm{Co}_{0,525}$ & 382 & \multirow{3}{*}{ [26] } \\
\hline & $\mathrm{La}_{0,5} \mathrm{Ce}_{0,2} \mathrm{Mg}_{0,3} \mathrm{Ni}_{2,875} \mathrm{Mn}_{0,1} \mathrm{Co}_{0,525}$ & 295 & \\
\hline & $\mathrm{La}_{0,2} \mathrm{Ce}_{0,5} \mathrm{Mg}_{0,3} \mathrm{Ni}_{2,875} \mathrm{Mn}_{0,1} \mathrm{Co}_{0,525}$ & 48 & \\
\hline \multirow{3}{*}{$\mathrm{Ti}$} & $\mathrm{La}_{0,67} \mathrm{Mg}_{0,33} \mathrm{Ni}_{2,75} \mathrm{Co}_{0,25}$ & 384 & \multirow{3}{*}{ [29] } \\
\hline & $\mathrm{La}_{0,603} \mathrm{Ti}_{0,067} \mathrm{Mg}_{0,33} \mathrm{Ni}_{2,75} \mathrm{Co}_{0,25}$ & 359 & \\
\hline & $\mathrm{La}_{0,536} \mathrm{Ti}_{0,134} \mathrm{Mg}_{0,33} \mathrm{Ni}_{2,75} \mathrm{Co}_{0,25}$ & 321 & \\
\hline \multirow{3}{*}{$\mathrm{Zr}$} & $\mathrm{La}_{0,7} \mathrm{Mg}_{0,3} \mathrm{Ni}_{2,45} \mathrm{Co}_{0,75} \mathrm{Mn}_{0,1} \mathrm{Al}_{0,2}$ & 364 & \multirow{3}{*}{ [28] } \\
\hline & $\mathrm{La}_{0,66} \mathrm{Zr}_{0,04} \mathrm{Mg}_{0,3} \mathrm{Ni}_{2,45} \mathrm{Co}_{0,75} \mathrm{Mn}_{0,1} \mathrm{Al}_{0,2}$ & 343 & \\
\hline & $\mathrm{La}_{0,6} \mathrm{Zr}_{0,1} \mathrm{Mg}_{0,3} \mathrm{Ni}_{2,45} \mathrm{Co}_{0,75} \mathrm{Mn}_{0,1} \mathrm{Al}_{0,2}$ & 306 & \\
\hline \multirow{3}{*}{$\mathrm{Mn}$} & $\mathrm{La}_{0,7} \mathrm{Mg}_{0,3} \mathrm{Ni}_{2,55} \mathrm{Co}_{0,45}$ & 342 & \multirow{3}{*}{ [30] } \\
\hline & $\mathrm{La}_{0,7} \mathrm{Mg}_{0,3} \mathrm{Ni}_{2,25-x} \mathrm{Co}_{0,45} \mathrm{Mn}_{0,3}$ & 368 & \\
\hline & $\mathrm{La}_{0,7} \mathrm{Mg}_{0,3} \mathrm{Ni}_{2,05-x} \mathrm{Co}_{0,45} \mathrm{Mn}_{0,5}$ & 333 & \\
\hline \multirow{4}{*}{ Co } & $\mathrm{La}_{0,7} \mathrm{Mg}_{0,3} \mathrm{Ni}_{3,4} \mathrm{Mn}_{0,1}$ & 397 & \multirow{4}{*}{ [37] } \\
\hline & $\mathrm{La}_{0,7} \mathrm{Mg}_{0,3} \mathrm{Ni}_{2,65} \mathrm{Mn}_{0,1} \mathrm{Co}_{0,75}$ & 403 & \\
\hline & $\mathrm{La}_{0,7} \mathrm{Mg}_{0,3} \mathrm{Ni}_{2,25} \mathrm{Mn}_{0,1} \mathrm{Co}_{1,15}$ & 389 & \\
\hline & $\mathrm{La}_{0,7} \mathrm{Mg}_{0,3} \mathrm{Ni}_{1,8} \mathrm{Mn}_{0,1} \mathrm{Co}_{1,6}$ & 380 & \\
\hline \multirow{3}{*}{$\mathrm{Al}$} & $\mathrm{La}_{2} \mathrm{MgNi}_{9}$ & 400 & \multirow{3}{*}{ [38] } \\
\hline & $\mathrm{La}_{2} \mathrm{MgNi}_{8,82} \mathrm{Al}_{0,18}$ & 374 & \\
\hline & $\mathrm{La}_{2} \mathrm{MgNi}_{8,55} \mathrm{Al}_{0,45}$ & 221 & \\
\hline
\end{tabular}




\subsection{Efeitos da pulverização com hidrogênio}

Os efeitos da pulverização foram estudados em ligas $L_{0,7}$ ${ }_{x} \mathrm{Pr}_{0,3} \mathrm{Al}_{0,3} \mathrm{Mn}_{0,4} \mathrm{Co}_{0,5} \mathrm{Ni}_{3,8}$ ( $x=0$ a 0,7 ) como eletrodo negative de baterias de níquel hidreto metálico [64]. A hidrogenação das ligas foi realizada com duas pressões de hidrogênio (2 bar e 10 bar) e temperaturas (ambiente e $500^{\circ} \mathrm{C}$ ). a capacidade de descarga dos eletrodos negativos aumentou com a pulverização do eletrodo negativo, mas sua estabilidade cíclica diminui acarretando em uma perda do tempo de vida útil da bateria.

Na FIG. 11 está mostrada a capacidade de descarga em função do número de ciclos do eletrodo negativo fabricado com a liga $\mathrm{La}_{0,7} \mathrm{Pr}_{0,3} \mathrm{Al}_{0,3} \mathrm{Mn}_{0,4} \mathrm{Co}_{0,5} \mathrm{Ni}_{3,8}$ moída mecanicamente e hidrogenada a $1 \mathrm{MPa}$.

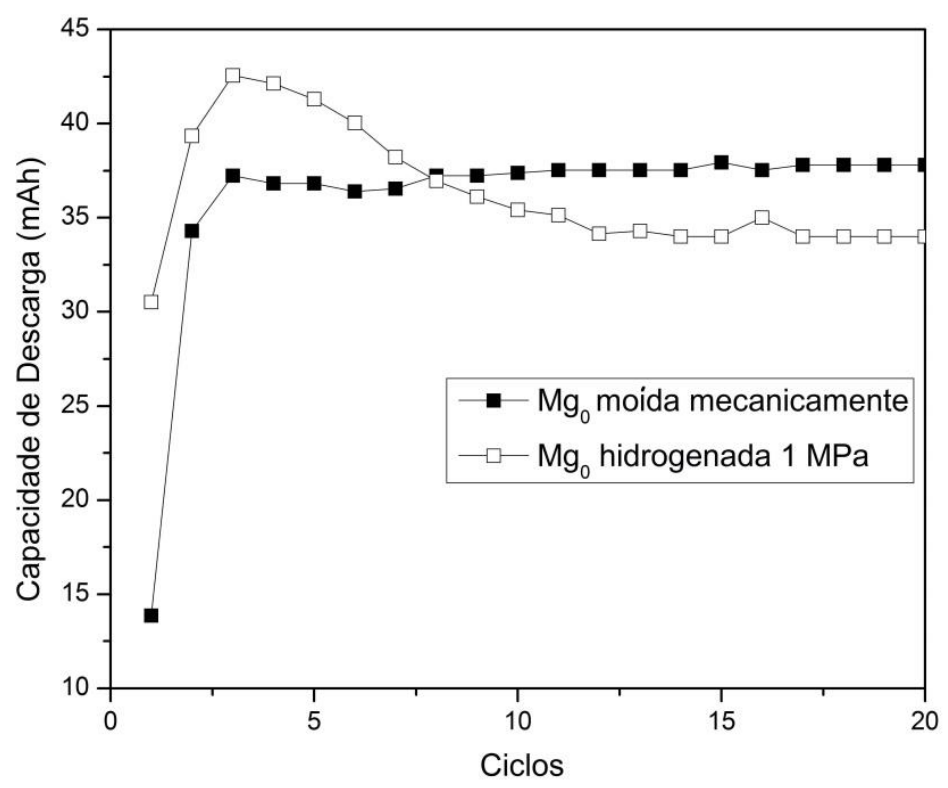

FIGURA 11 - Capacidade de descarga em função do número de ciclos para a liga $\mathrm{La}_{0,7} \mathrm{Pr}_{0,3} \mathrm{Al}_{0,3} \mathrm{Mn}_{0,4} \mathrm{Co}_{0,5} \mathrm{Ni}_{3,8}$ moída mecanicamente e hidrogenada a $1 \mathrm{Mpa}$ [64].

Os resultados mostraram que houve um aumento na capacidade de descarga máxima de $38 \mathrm{mAh}$ para $43 \mathrm{mAh}$ para bateria fabricada com a liga após hidrogenação. Porém, após 8 ciclos a capacidade de descarga é menor comparada a da liga moída mecanicamente, mostrando uma diminuição na estabilidade cíclica da bateria fabricada com a liga hidrogenada [64]. 
Na FIG. 12 está mostrada a capacidade de descarga em função do número de ciclos do eletrodo negativo fabricado com a liga $\mathrm{La}_{0,7} \mathrm{Mg}_{0,1} \mathrm{Pr}_{0,3} \mathrm{Al}_{0,3} \mathrm{Mn}_{0,4} \mathrm{Co}_{0,5} \mathrm{Ni}_{3,8}$ moída mecanicamente e hidrogenada a 1 MPa.

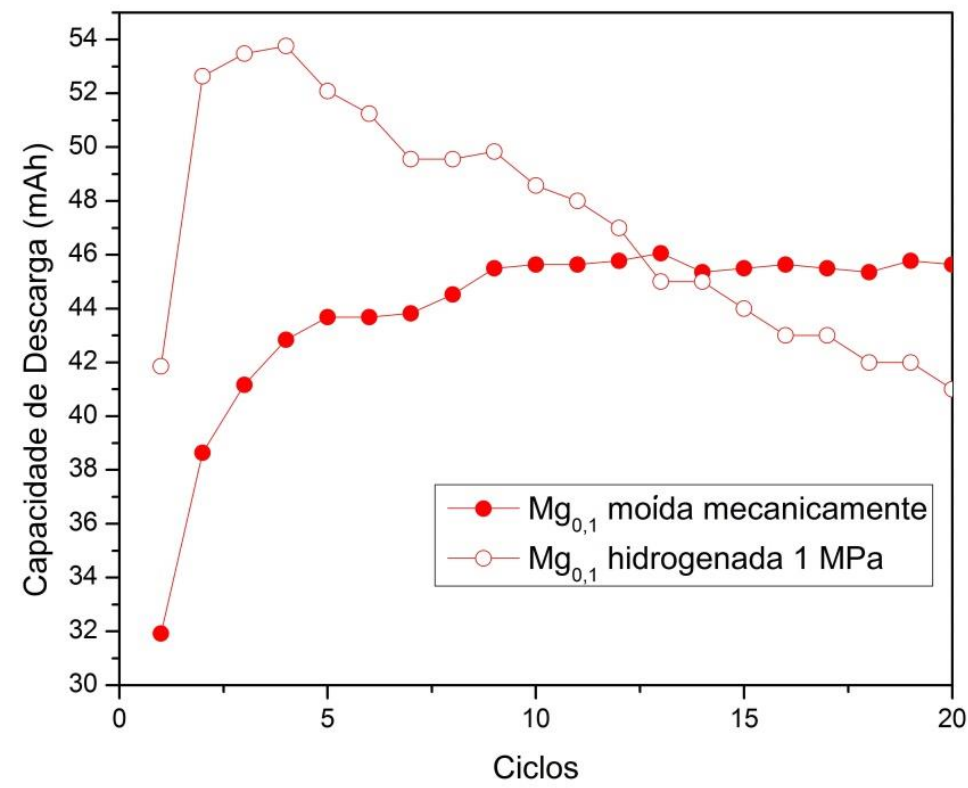

FIGURA 12 - Capacidade de descarga em função do número de ciclos para a liga $\mathrm{La}_{0,7} \mathrm{Mg}_{0,1} \mathrm{Pr}_{0,3} \mathrm{Al}_{0,3} \mathrm{Mn}_{0,4} \mathrm{Co}_{0,5} \mathrm{Ni}_{3,8}$ moída mecanicamente e hidrogenada a 1 MPa.

Os resultados obtidos foram semelhantes ao encontrado para a liga sem magnésio, o aumento da capacidade de descarga foi de $46 \mathrm{mAh}$ (liga moída mecanicamente) para $54 \mathrm{mAh}$ (liga hidrogenada). Porém a capacidade de descarga da bateria fabricada com a liga hidrogenada a $1 \mathrm{MPa}$ não se estabiliza.

Este fato, de alta capacidade de descarga inicial, pode estar relacionado à série de trincas nas partículas, que facilita a absorção do hidrogênio no interior da liga durante os primeiros ciclos, mas, por outro lado, aumenta a decriptação das partículas durante os ciclos de carga e descarga, diminuindo o tamanho de partículas e como consequência, uma queda drástica na capacidade de descarga $[65,66]$. 


\subsection{Nióbio}

Entre os metais refratários, o Nióbio é o mais leve prestando-se para a siderurgia, aeronáutica e largo emprego nas indústrias espacial e nuclear. $\mathrm{Na}$ necessidade de aços de alta resistência e baixa liga e de requisição de superligas indispensáveis para suportar altas temperaturas como ocorre nas turbinas de aviões a jato e foguetes, o nióbio adquire máxima importância. O Brasil detém $98 \%$ das reservas mundiais exploráveis de nióbio no mundo, e mais de $90 \%$ do total do minério presente no Planeta Terra. As Jazidas estão presentes em 3 cidades brasileiras: $61 \%$ proveniente de Araxá (MG), $21 \%$ das reservas em Catalão (GO) e outros $12 \%$ em São Gabriel da Cachoeira (AM).Outra reserva importante de minerais de Nióbio é do Canadá [67].

O nióbio, como agente refratário, é bem conhecido e empregado como agente refinador de grão em aços inoxidáveis, fazendo com que o aço produzido com esse metal seja mais resistente [9].

A influência do nióbio no refino de grão também é conhecida em ligas magnéticas à base de terras raras e metais de transição ( $\mathrm{Ne}-\mathrm{Fe}-\mathrm{B}$ e $\mathrm{Pr}-\mathrm{Fe}-\mathrm{B}$ ). Quando o nióbio é adicionado a essas ligas magnéticas ocorre um aumento da coercividade indutiva desses materiais [10].

O nióbio também já foi empregado com sucesso como agente de proteção da corrosão. Neste caso o nióbio foi utilizado em substituição ao níquel. Maior resistência à corrosão e maior eficiência de proteção foram obtidas para os revestimentos de fosfato de zinco em presença de niobatos (PZn-Nb), quando comparados com a camada tradicional em presença de níquel $(\mathrm{PZn}+\mathrm{Ni})[11]$. 


\section{PROCEDIMENTO EXPERIMENTAL}

Este trabalho foi realizado no Laboratório de Materiais Magnéticos e Elétricos, localizado no Centro de Ciências e Tecnologia de Materiais (CCTM) do Instituto de Pesquisas Energéticas e Nucleares (IPEN) e no Laboratório de Energias Renováveis da Universidade Politécnica de Valencia (UPV-Espanha). Os testes de corrosão foram realizados no Instituto de Biociências da Universidade Estadual Paulista Júlio de Mesquita Filho (UNESP-Botucatu). As ligas metálicas estudadas neste trabalho foram obtidas da LCM (Less Commom Metals) no estado bruto de fusão.

As composições químicas das ligas utilizadas no trabalho foram:

- $\quad \mathrm{La}_{0,7} \mathrm{Mg}_{0,3} \mathrm{Al}_{0,3} \mathrm{Mn}_{0,4} \mathrm{Co}_{0,5} \mathrm{Ni}_{3,8}$

- $\quad \mathrm{La}_{0,7} \mathrm{Mg}_{0,3} \mathrm{Al}_{0,3} \mathrm{Mn}_{0,4} \mathrm{Co}_{0,4} \mathrm{Nb}_{0,1} \mathrm{Ni}_{3,8}$

- $\quad \mathrm{La}_{0,7} \mathrm{Mg}_{0,3} \mathrm{Al}_{0,3} \mathrm{Mn}_{0,4} \mathrm{Co}_{0,3} \mathrm{Nb}_{0,2} \mathrm{Ni}_{3,8}$

- $\quad \mathrm{La}_{0,7} \mathrm{Mg}_{0,3} \mathrm{Al}_{0,3} \mathrm{Mn}_{0,4} \mathrm{Co}_{0,2} \mathrm{Nb}_{0,3} \mathrm{Ni}_{3,8}$

- $\quad \mathrm{La}_{0,7} \mathrm{Mg}_{0,3} \mathrm{Al}_{0,3} \mathrm{Mn}_{0,4} \mathrm{Co}_{0,1} \mathrm{Nb}_{0,4} \mathrm{Ni}_{3,8}$

- $\quad \mathrm{La}_{0,7} \mathrm{Mg}_{0,3} \mathrm{Al}_{0,3} \mathrm{Mn}_{0,4} \mathrm{Nb}_{0,5} \mathrm{Ni}_{3,8}$

- $\quad \mathrm{La}_{0,7} \mathrm{Mg}_{0,3} \mathrm{Al}_{0,3} \mathrm{Mn}_{0,4} \mathrm{Nb}_{0,8} \mathrm{Ni}_{3,0}$

- $\quad \mathrm{La}_{0,7} \mathrm{Mg}_{0,3} \mathrm{Al}_{0,3} \mathrm{Mn}_{0,4} \mathrm{Nb}_{1,0} \mathrm{Ni}_{2,8}$

- $\quad \mathrm{La}_{0,7} \mathrm{Mg}_{0,3} \mathrm{Al}_{0,3} \mathrm{Mn}_{0,4} \mathrm{Nb}_{1,8} \mathrm{Ni}_{2,0}$ 


\subsection{Caracterização das ligas metálicas}

\subsubsection{Microscopia eletrônica de varredura}

A microscopia eletrônica de varredura (MEV) foi utilizada para estudo da superfície dos materiais, permitindo a análise das ligas, na sua composição e morfologia das fases existentes.

Para realizar a caracterização microestrutural das ligas e determinar a composição das fases presentes, as amostras foram preparadas utilizando as técnicas convencionais de metalografia: embutimento em resina Epóxi, lixamento e polimento final das amostras para um posterior recobrimento. Foi utilizado um microscópio eletrônico de varredura (JOEL 5400) com EDS, como esta apresentado na FIG. 13.

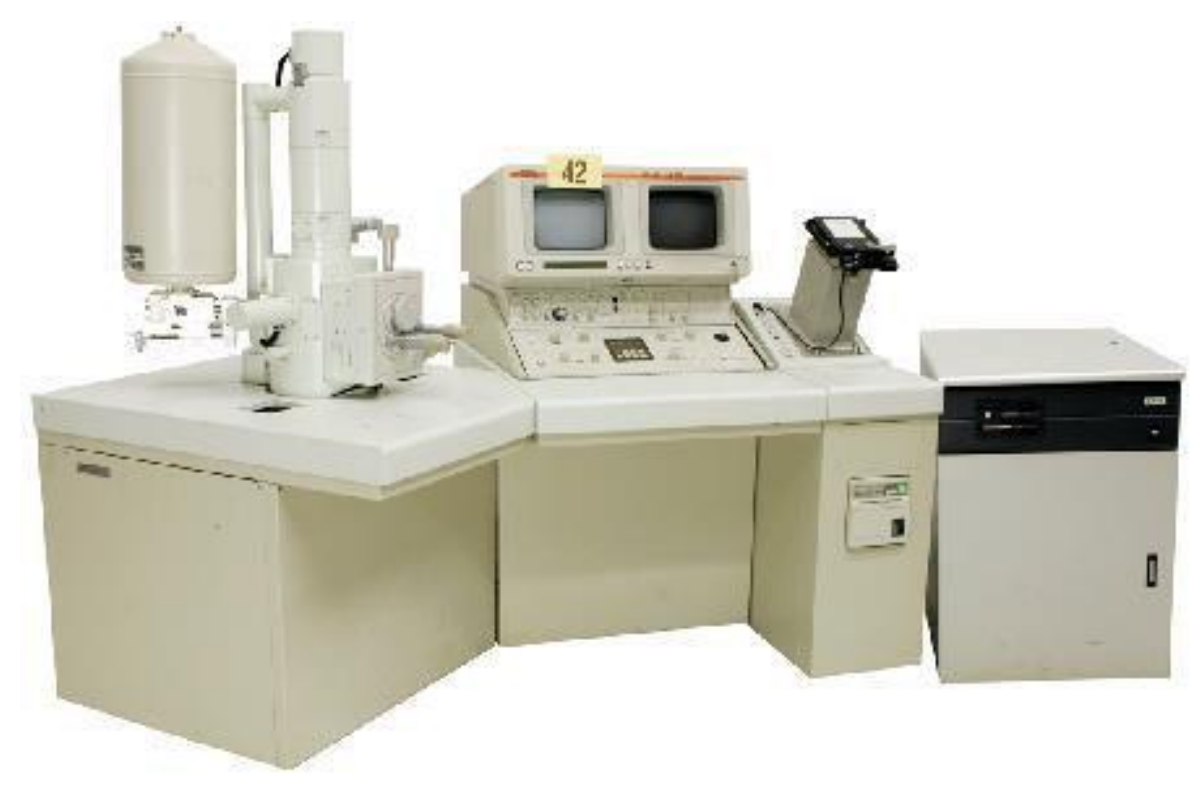

FIGURA 13 - Microscópio Eletrônico de Varredura (JOEL 5400). 


\subsubsection{Difração de raios-X}

Os ensaios foram realizados utilizando o equipamento Cubix modelo $\mathrm{HQ}$ (FIG. 14) no intervalo $10^{\circ} \leq 2 \theta \leq 100^{\circ}$ usando radiação CuKa (com taxa de varredura de $\left.1^{\circ} \mathrm{min}^{-1}\right)$. A identificação das fases foi realizada por meio do programa Crystallographica Search-Match (CSM). A quantificação de fases foi realizada através do programa PowderCell versão 2.3.

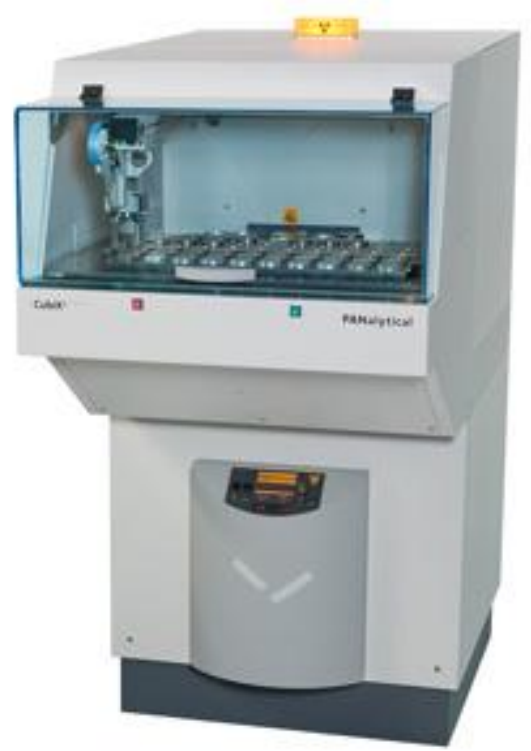

FIGURA 14 - Difratômetro de Raios-X (Cubix HQ).

\subsubsection{Distribuição do tamanho de partículas - CILAS}

Para a determinação do tamanho médio de partículas foi utilizado o equipamento CILAS 1064, com pirofosfato de sódio como agente dispersante e ultrassom por 3 minutos anterior a analise. 


\subsection{Pulverização das ligas metálicas}

Na FIG. 15 é mostrado o fluxograma utilizado para hidrogenação das ligas metálicas. A massa utilizada na hidrogenação foi de 5 gramas. A hidrogenação foi realizada utilizando uma pressão de $\mathrm{H}_{2}$ de 0,2 $\mathrm{MPa}$ (2 bar) e 0,9 MPa (9 bar).

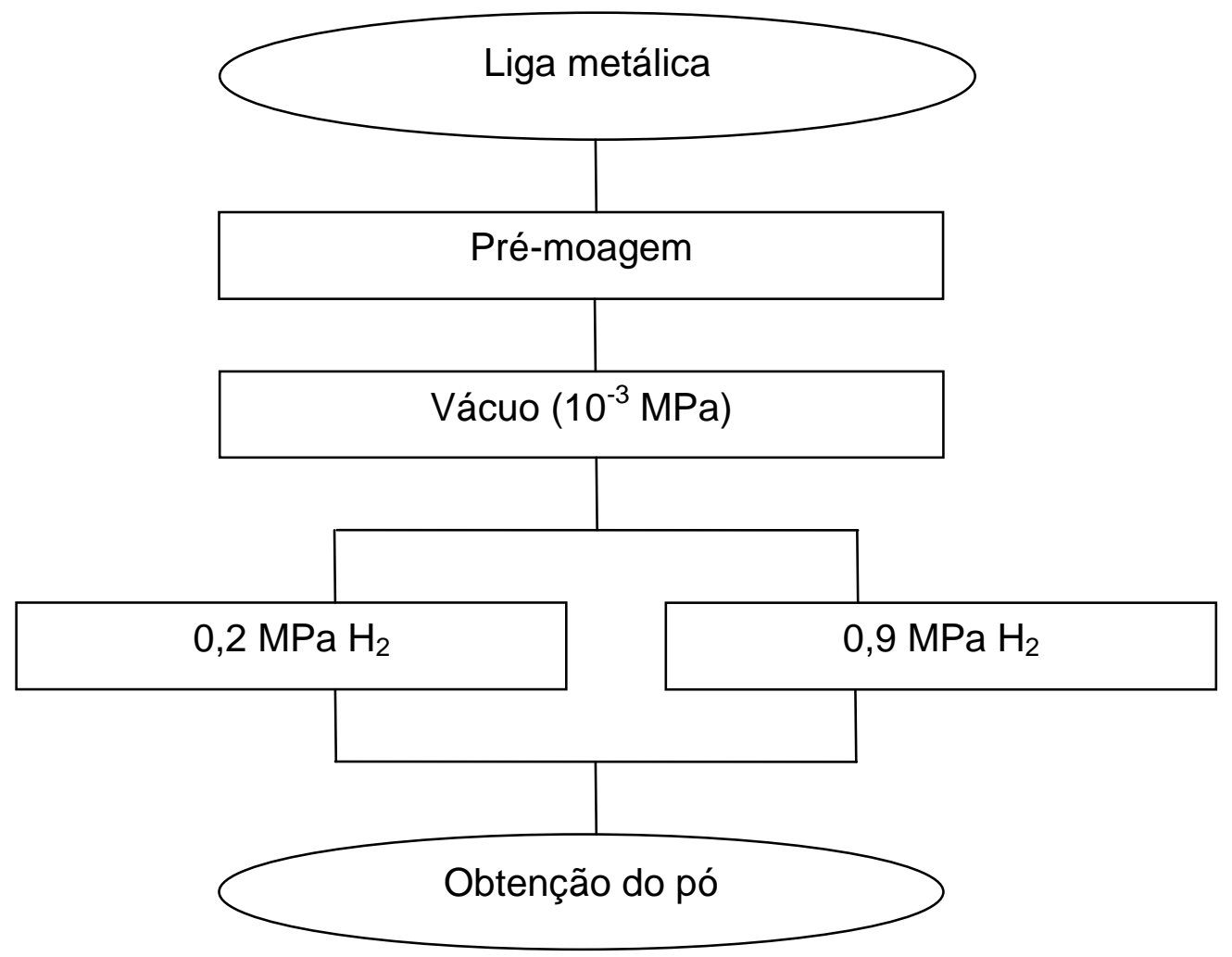

FIGURA 15 - Fluxograma utilizado na hidrogenação das ligas metálicas.

Na FIG. 16 (a) é apresentada a liga metálica no estado bruto de fusão e na FIG. 16 (b) 5 gramas da liga utilizada na hidrogenação. 

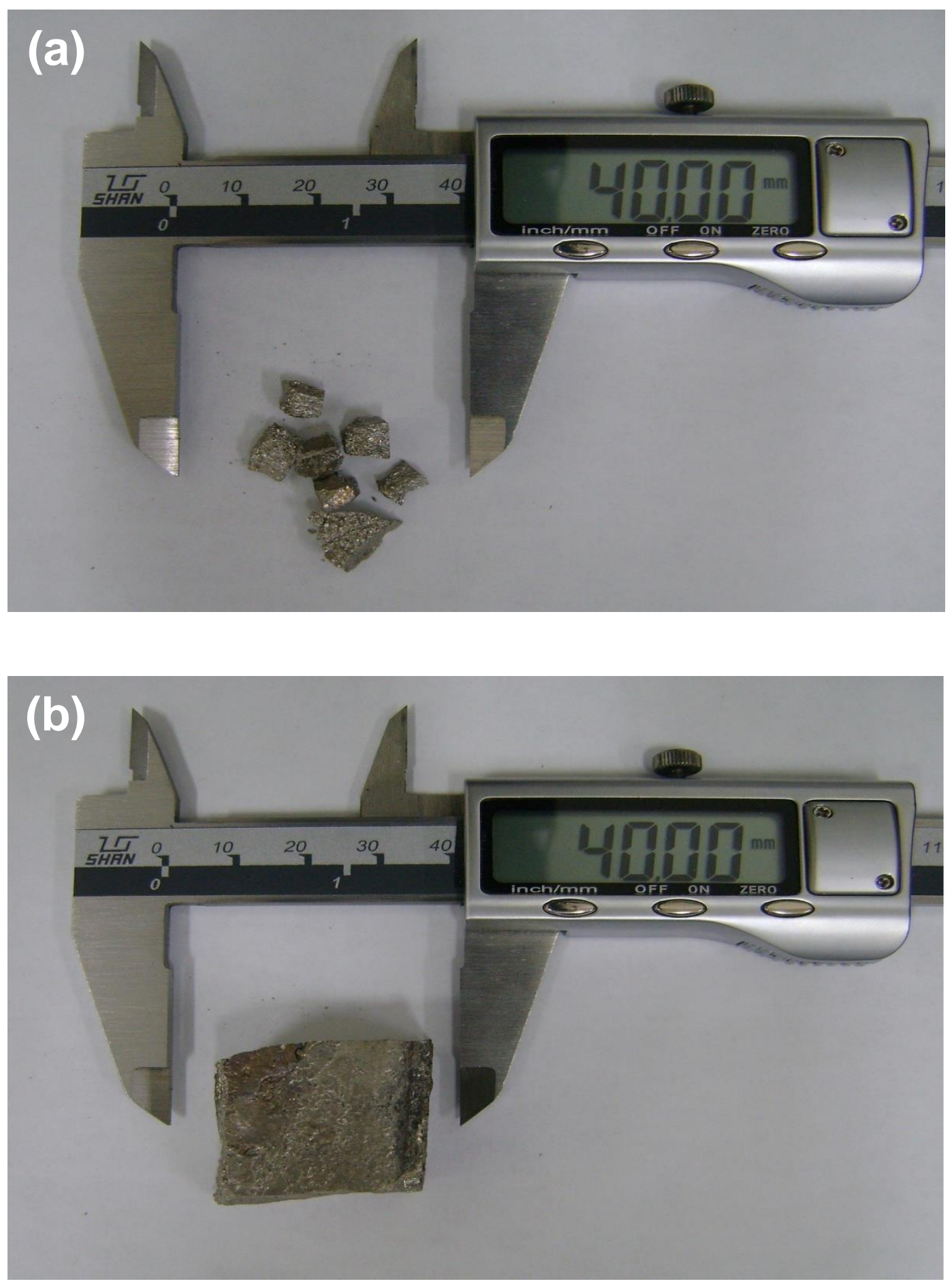

FIGURA 16 - (a) Liga metálica no estado bruto de fusão (b) $5 \mathrm{~g}$ da liga metálica utilizada na hidrogenação.

Para o processo de hidrogenação, a liga metálica é inserida em um cadinho de aço inox posicionado no interior de um vaso de pressurização. $O$ procedimento de hidrogenação foi realizado sem a presença da liga metálica, denominada branco, para comparação. 
Na FIG. 17 é apresentado o sistema utilizado para hidrogenação das ligas, constituído do vaso de hidrogenação de aço 316L, válvula de injeção de hidrogênio HyLok série NV, forno EDG modelo F-1800 e uma bomba de vácuo mecânica de dois estágios Edwards modelo E2M5 acoplado ao um medidor de pressão.

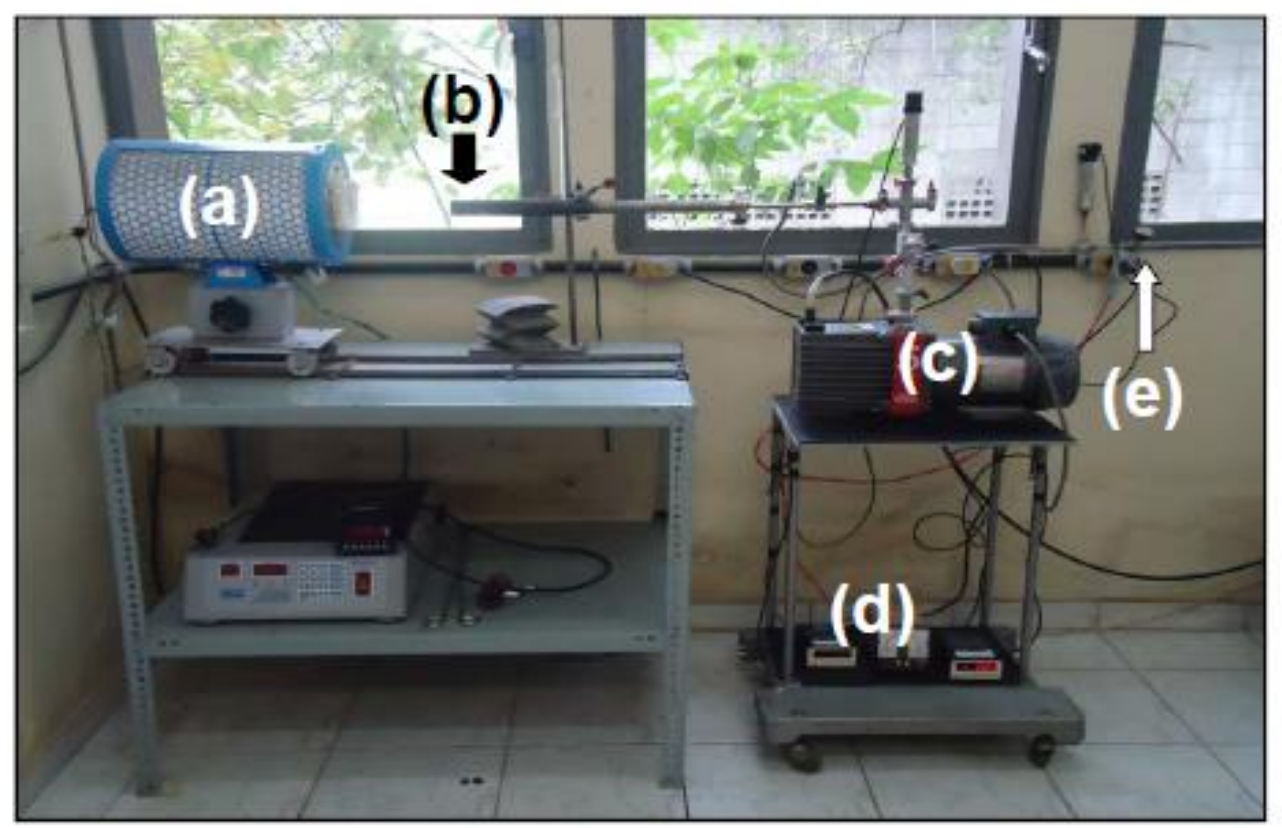

FIGURA 17 - Sistema de vácuo utilizado na hidrogenação das ligas, onde: (a) forno (EDG), (b) vaso de hidrogenação, (c) bomba de vácuo mecânica, (d) medidor Pirani e (e) válvula para injeção de hidrogênio. 


\subsection{Montagem das baterias de Ni-HM}

Para a montagem das baterias de Ni-HM foi utilizado às seguintes etapas, conforme mostrado na FIG. 18.

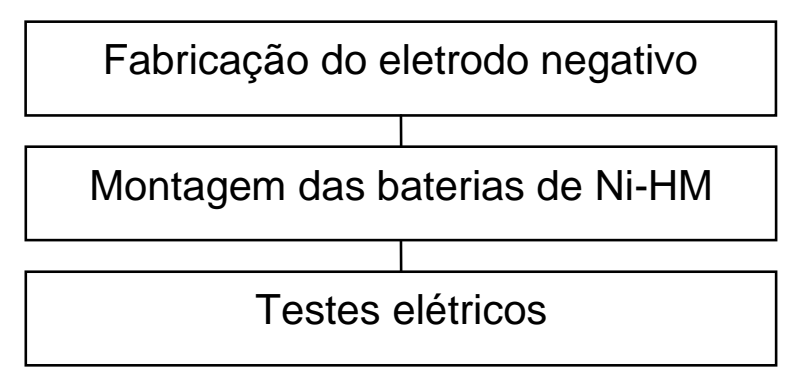

FIGURA 18 - Etapas para montagem das baterias de Ni-HM.

\subsubsection{Fabricação do eletrodo negativo}

O eletrodo negativo das baterias de $\mathrm{Ni}-\mathrm{HM}$ foi fabricado utilizando 140 mg da liga metálica, moída e classificada em uma peneira com abertura de $45 \mu \mathrm{m}$, e $140 \mathrm{mg}$ de uma mistura contendo $67 \%$ de carbono de alta área superficial (negro de fumo - Vulcan XC 72R) e 33\% do agente ligante politetrafluoretileno (PTFE, Teflon T30, Daikin). Na FIG. 19 são mostrados os materiais descritos [68].

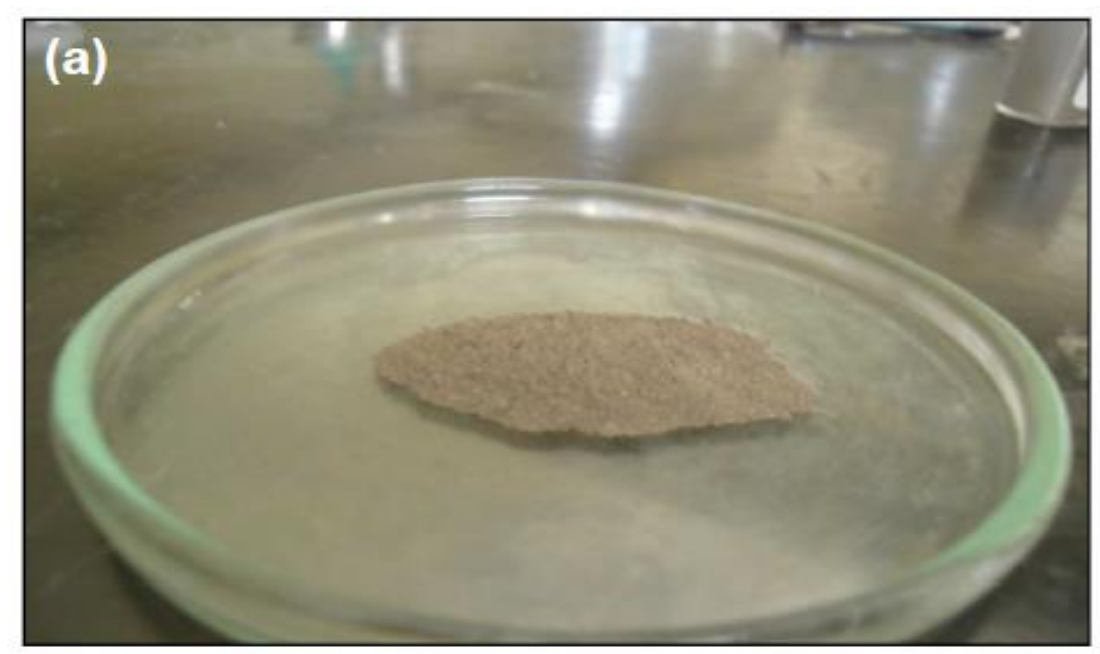



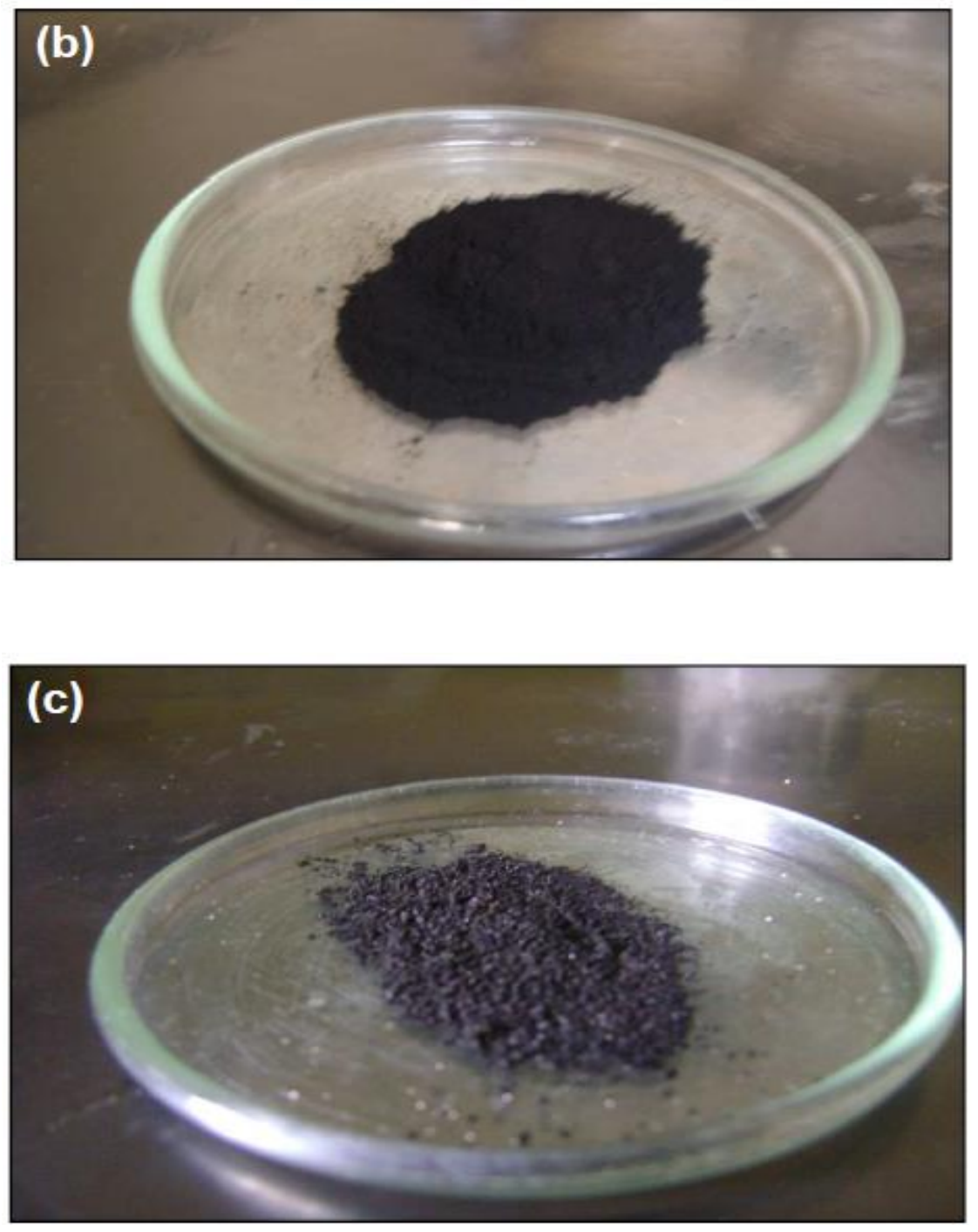

FIGURA 19 - Processo de fabricação do eletrodo negativo, onde: (a) pó da liga classificada $<45 \mu \mathrm{m}$, (b) mistura de $67 \%$ em massa de carbono de alta área superficial e 33\% em massa de PTFE e (c) mistura composta pela liga metálica, PTFE e carbono de alta área superficial.

\subsubsection{Montagem da bateria de Ni-HM}

O eletrodo positivo de $\mathrm{Ni}(\mathrm{OH})_{2}$ e 0 separador, utilizados no desenvolvimento deste trabalho, foram retirados de baterias de $\mathrm{Ni}-\mathrm{HM}$ comerciais da marca Sony modelo AA 2500 mAh. Tais materiais são mostrados na FIG. 20. 

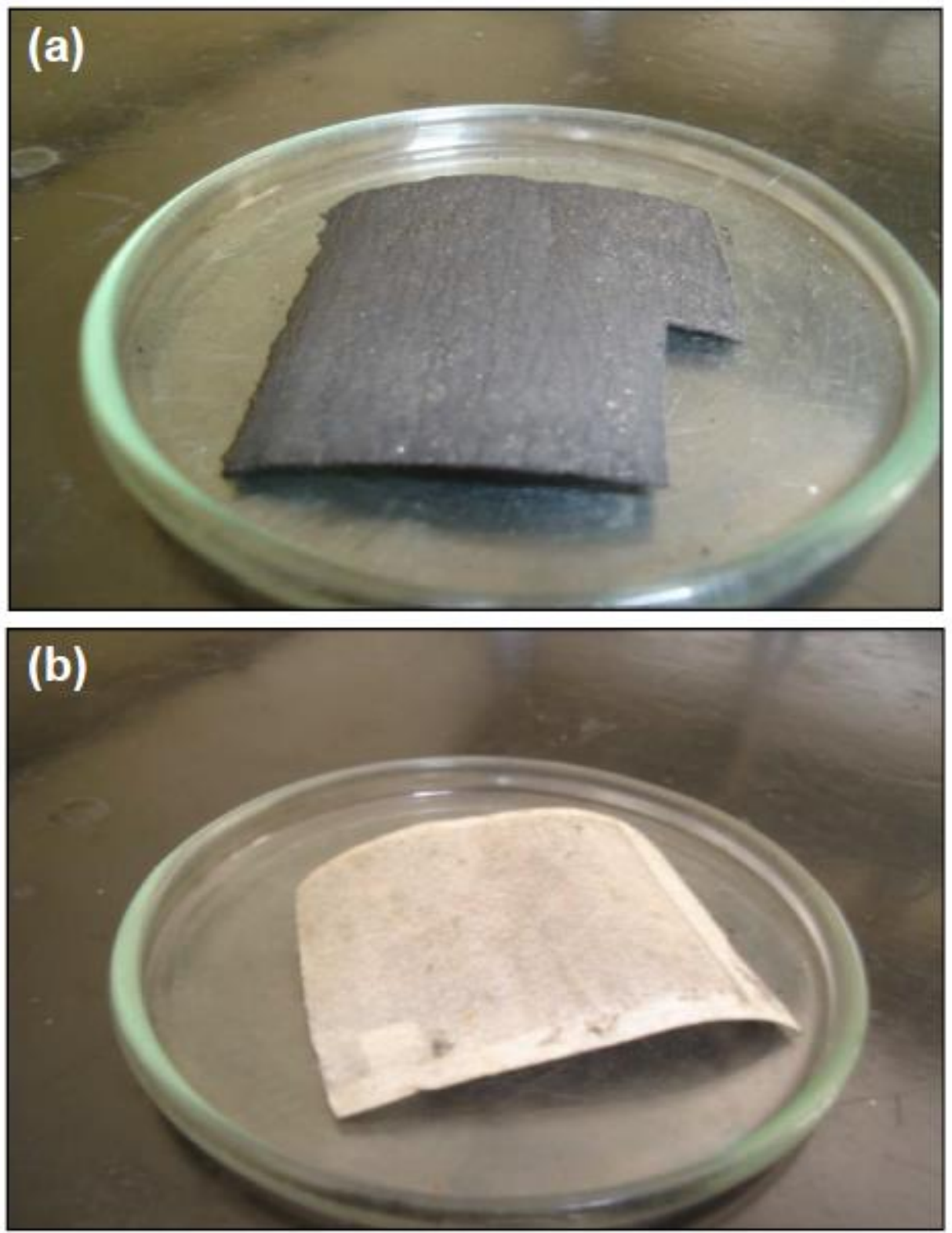

FIGURA 20 - (a) Eletrodo positivo de $\mathrm{Ni}(\mathrm{OH})_{2}$ (b) separador. Ambos foram retirados de baterias de $\mathrm{Ni}-\mathrm{HM}$ comerciais.

No separador é colocado o eletrólito que é uma solução composta de $\mathrm{KOH} 6 \mathrm{~mol} \mathrm{L-1.} \mathrm{A} \mathrm{quantidade} \mathrm{de} \mathrm{eletrólito} \mathrm{utilizada} \mathrm{foi} \mathrm{de} 0,25 \mathrm{ml}$ [68].

Após a prensagem do eletrodo negativo no molde de aço inox, o separador e o eletrodo positivo são recortados e colocados na bateria.

A utilização de vedações de polietileno foi necessária para selar as partes da bateria e evitar o curto-circuito interno. Na FIG. 21 são mostradas as regiões onde são colocadas as vedações. 


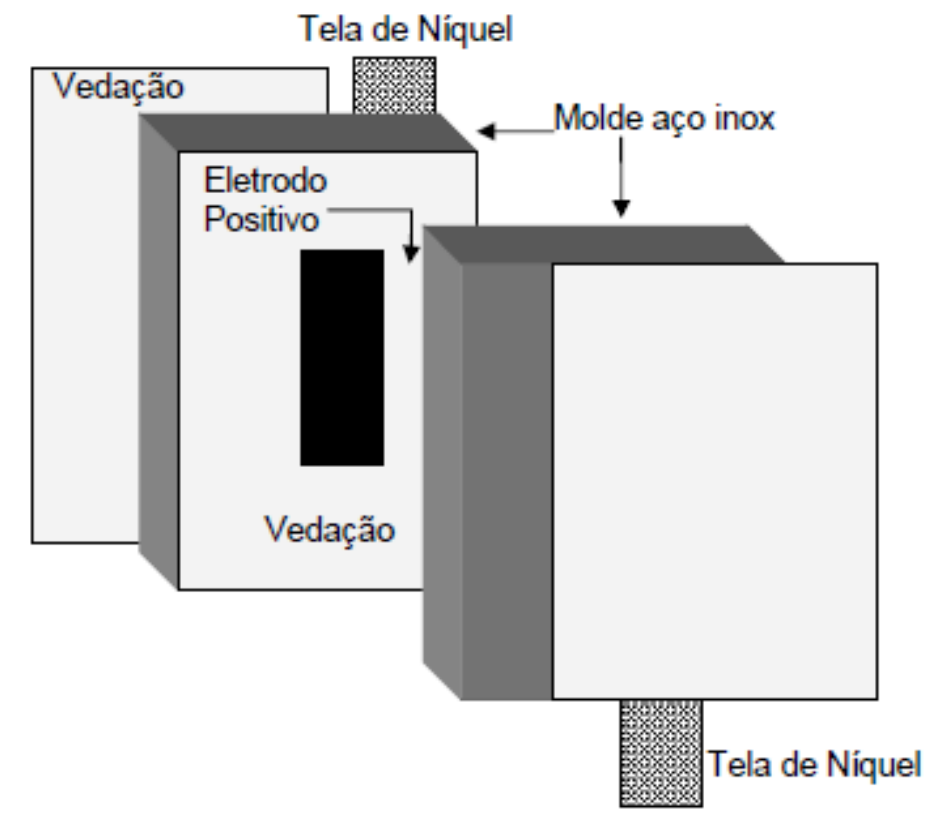

FIGURA 21 - Representação esquemática da região das vedações.

Na FIG. 22 (a - f) são apresentadas os as etapas de montagem das baterias seladas de Ni-HM. 


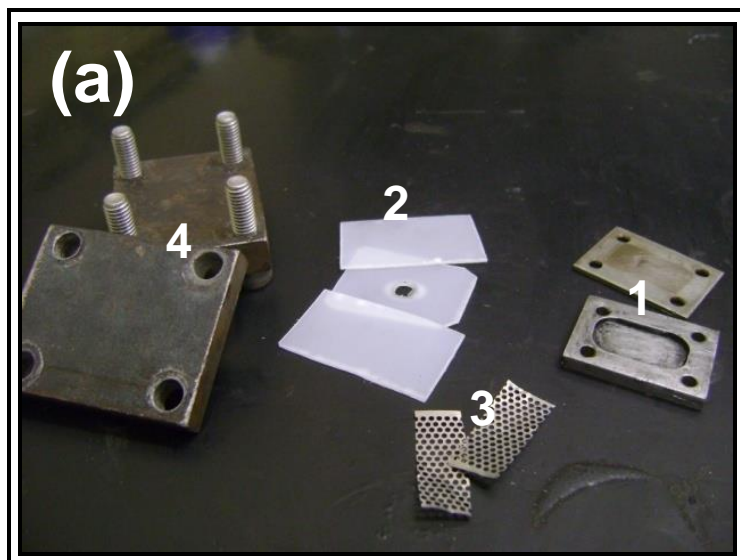

(a) 1 - molde aço inox, 2 - vedações, 3 - contatos de níquel, 4 - chapas para selagem

\section{(c)}

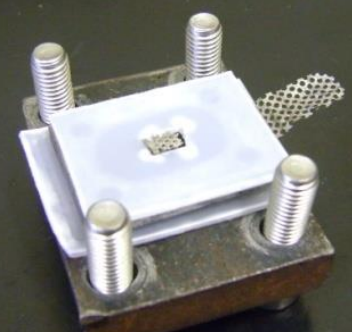

(b)

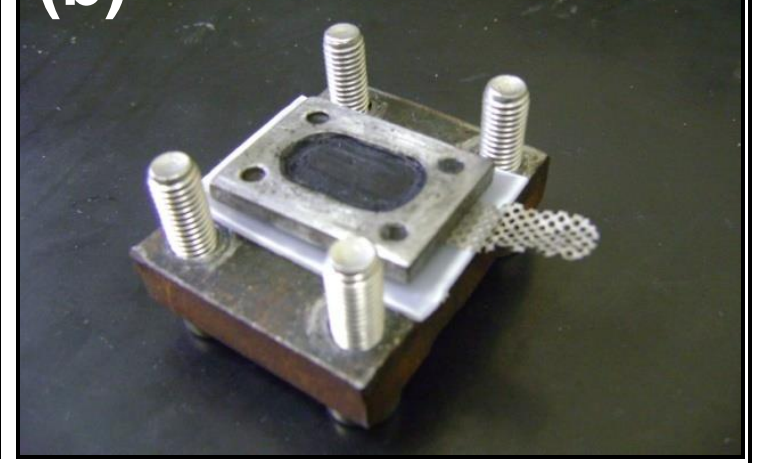

(b) Mistura (eletrodo negativo) prensada no molde e parte inferior da vedação e contato.

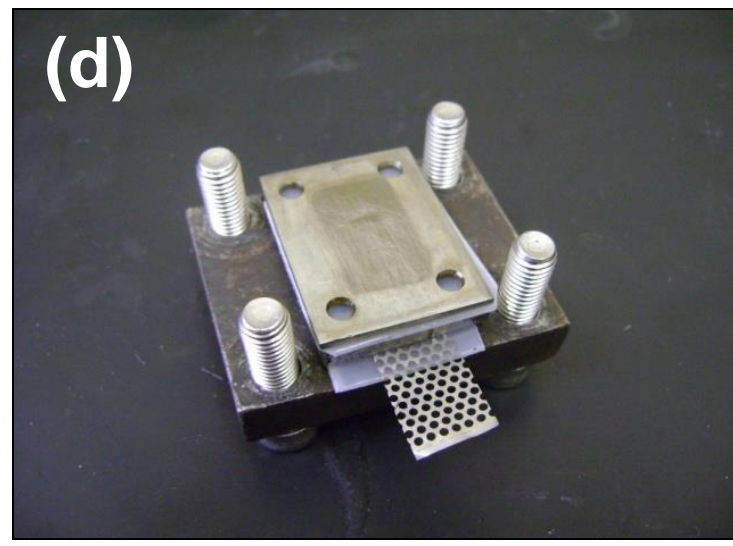

(d) Montagem da parte superior do

(c) Molde após montagem do separador, eletrólito, eletrodo positivo molde de aço inox. e vedação.

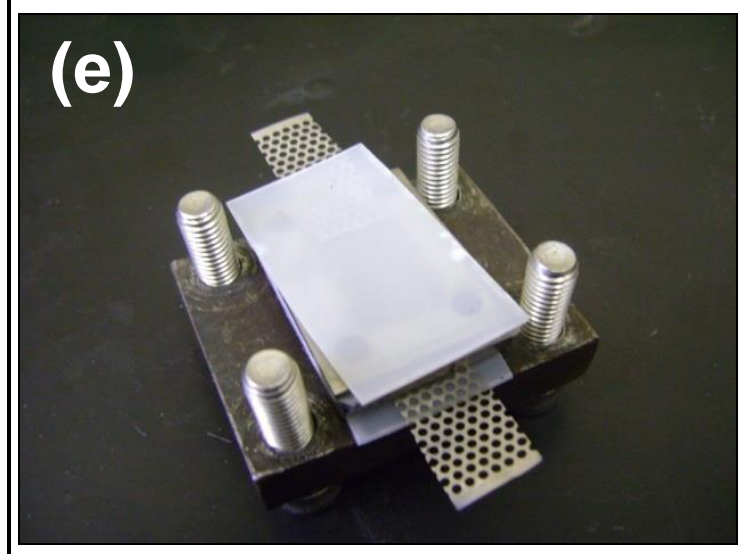

(e) Montage do contato de níquel e vedação.

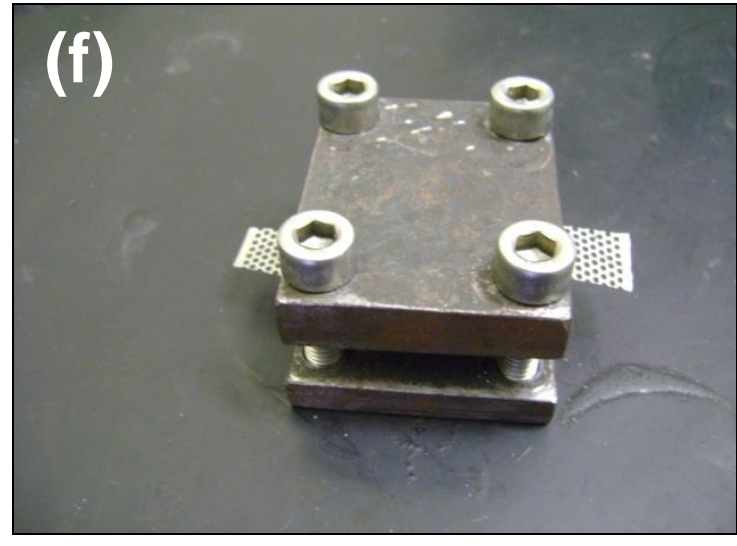

(f) Selagem da bateria FIGURA 22 - Etapas de montagem das baterias de Ni-HM. 


\subsection{Testes elétricos}

Para os experimentos de carga-descarga das baterias foi utilizado o analisador digital de quatro canais (Arbin BT4) conectado a um computador com o programa MTSPro versão 4.0, como mostrado na FIG. 23.

As medidas realizadas nas baterias de Ni-HM incluem a determinação da capacidade de descarga máxima das baterias e a durabilidade cíclica, ou seja, total de ciclos de carga/descarga. Foi utilizado uma densidade de corrente de carga de $100 \mathrm{mAg}^{-1}$ (14 mA durante 5 horas), densidade de corrente de descarga de $50 \mathrm{mAg}^{-1}(7 \mathrm{~mA})$ e um potencial de corte de 0,9 V. Para 0 experimento realizado em célula eletroquímica o potencial de corte foi $0,6 \mathrm{~V}$.
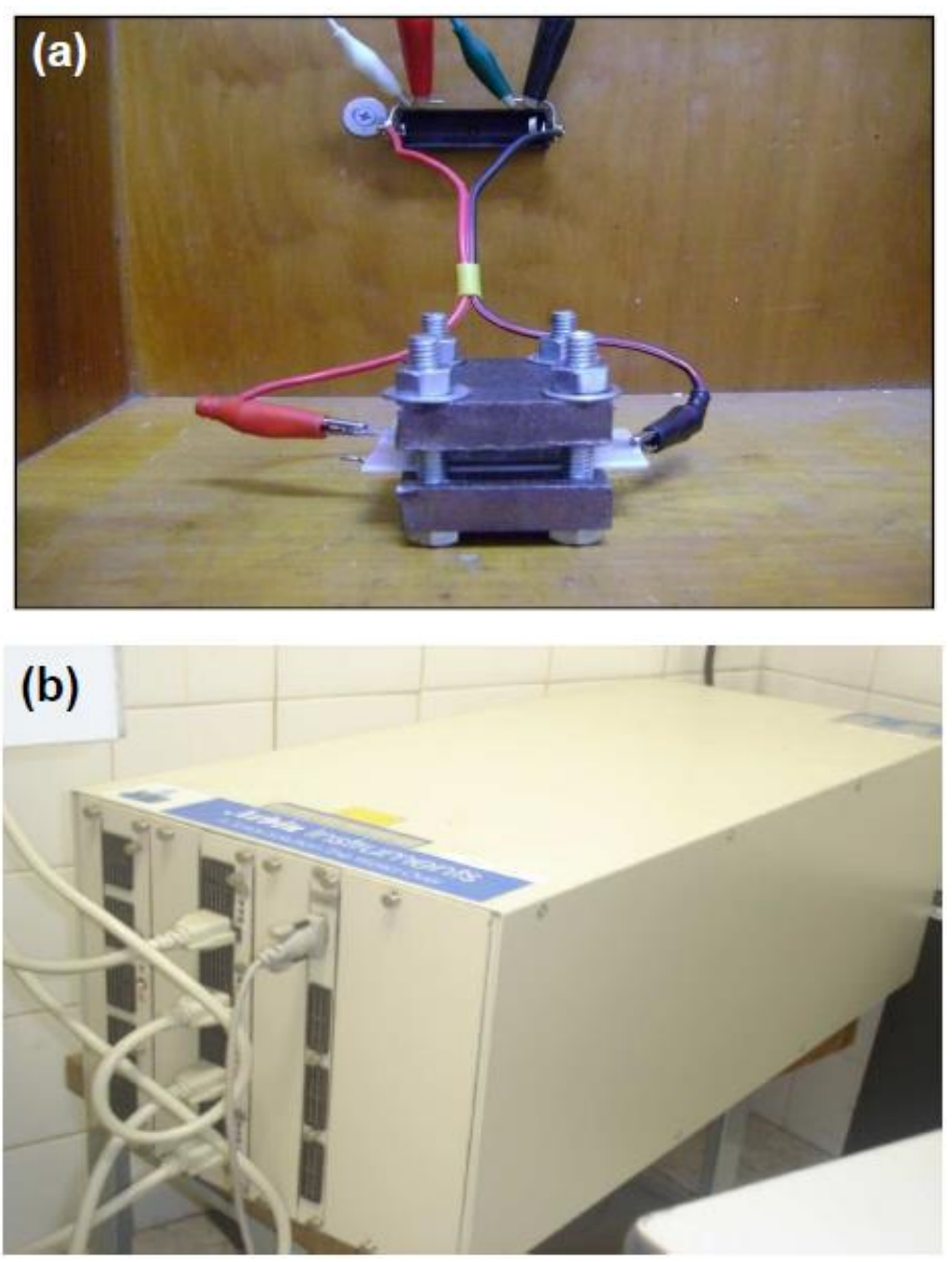

FIGURA 23 - Equipamento de testes elétricos, onde: (a) canal de medidas, (b) analisador digital de quatro canais (Arbin BT4). 


\subsubsection{Voltametria Cíclica e Resistência de Polarização}

Os voltamogramas cíclicos foram obtidos para os diferentes eletrodos preparados com as ligas a base de LaNi, fazendo-se varreduras no intervalo de $-400 \mathrm{mV}$ até $-1200 \mathrm{mV}$ a uma velocidade de varredura de potencial de $1 \mathrm{mV} . \mathrm{s}^{-1}$ , após o ciclo de caga e descarga das baterias e um potencial aberto (OCP) de 2 horas.

Os valores de resistência de polarização dos eletrodos foram obtidos através de micro polarizações lineares após os ciclos de carga e descarga. $O$ eletrodo é submetido a um potencial de circuito aberto (OCP) por 2 horas e após estabilização do mesmo é realizada uma varredura do potencial do eletrodo de $-5 \mathrm{mV}$ a $5 \mathrm{mV}$ em relação ao potencial de circuito aberto (OCP) a uma taxa de $0,1 \mathrm{mV} \cdot \mathrm{s}^{-1}$. Existe uma relação linear entre a sobre tensão $\eta$ e a corrente I. Essa relação é determinada a partir da forma linear da equação Butler-Volmer (Eq. 1.6) sendo essa equação válida em baixas tensões. A Resistência de polarização (Rp) é calculada a partir da inclinação da reta traçada da função $l=f(\eta)$ (Eq. 1.7) obtida na varredura de potencial.

$$
I=I_{0} \cdot \frac{F \cdot \eta}{R \cdot T}
$$

Onde:

$$
\begin{aligned}
& \boldsymbol{I}_{\boldsymbol{o}}=\text { Densidade de corrente } \\
& \boldsymbol{F}=\text { Constante de Faraday } \\
& \boldsymbol{R}=\text { Constante de gases perfeitos } \\
& \boldsymbol{T}=\text { Temperatura } \\
& \boldsymbol{R}_{\boldsymbol{p}}=\text { Resistência de Polarização }
\end{aligned}
$$

$$
\begin{aligned}
I_{0}=\frac{R \cdot \mathrm{T}}{F \cdot R_{p}} \\
R_{p}=\frac{R \cdot \mathrm{T}}{F \cdot I_{0}}
\end{aligned}
$$




\subsubsection{Potencial/Corrente de Corrosão}

O potencial de corrosão $\left(E_{\text {corr }}\right)$ e a corrente de corrosão ( $\left.I_{\text {corr }}\right)$ das ligas foram medidos através do potenciostato Solatron 1287. Uma das faces do eletrodo foi exposta a solução alcalina $(6 \mathrm{M} \mathrm{KOH})$, a outra face foi conectada com fio de cobre e protegida com resina epoxy, para evitar o contato com a solução. O experimento foi realizado utilizando sistema de três eletrodos, que consiste eletrodo de trabalho (liga de hidreto metálico), contra eletrodo (fio de platina, $50 \mathrm{~cm}$ de comprimento e $0,5 \mathrm{~mm}$ de diâmetro) e eletrodo de referencia $(\mathrm{Hg} / \mathrm{HgO})$ confeccionado em laboratório, obtendo potencial de $-928 \pm 1 \mathrm{mV}$ a $25^{\circ} \mathrm{C}$. Em todos os experimentos foi utilizado capilar de Luggin para reduzir a resistência por queda ôhmica. As curvas de polarização de Tafel foram obtidas aplicando potencial controlado de $5 \mathrm{mV} / \mathrm{s}$ de -500 até $1500 \mathrm{mV} / \mathrm{s}$ (vs. Potencial de circuito aberto). Na FIG. 24 é apresentado o modelo de célula eletroquímica com os eletrodos.

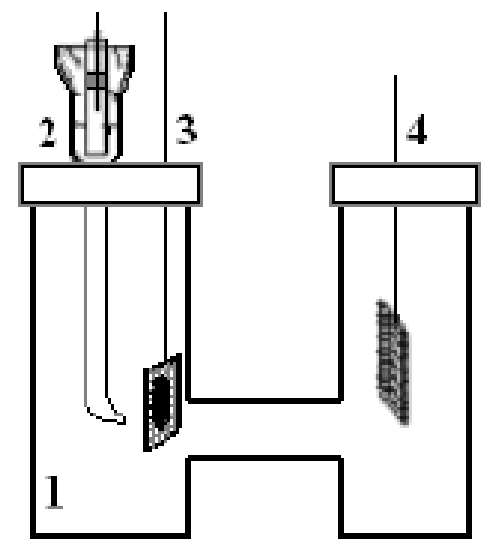

FIGURA 24 - Sistema experimental para estudo em célula eletroquímica; onde (1) representa a célula eletroquímica, (2) eletrodo de referência com $\mathrm{Hg} / \mathrm{HgO}$, (3) eletrodo de trabalho e (4) contra eletrodo (platina). 


\section{5 - RESULTADOS E DISCUSSÃO}

\section{1 - Caracterização Microestrutural das Ligas}

\subsection{1 - Composição das Ligas}

Nas TAB. 9 e 10 são apresentadas as análises químicas da série de ligas: $\mathrm{La}_{0,7} \mathrm{Mg}_{0,3} \mathrm{Al}_{0,3} \mathrm{Mn}_{0,4} \mathrm{Co}_{(0,5-\mathrm{x})} \mathrm{Nb}_{\mathrm{x}} \mathrm{Ni}_{3,8}$ (x= 0 a 0,5$)$ e $\mathrm{La}_{0,7} \mathrm{Mg}_{0,3} \mathrm{Al}_{0,3} \mathrm{Mn}_{0,4} \mathrm{Nb}$ $(0,5+x) \mathrm{Ni}_{(3,8--x)}(x=0,3 ; 0,5 ; 1,3)$, respectivamente. Nas tabelas estão os resultados das análises realizadas pelo fornecedor LCM (Less Commom Metals) por Espectrometria de Emissão Atômica por Plasma Acoplado Indutivamente (ICPAES - "Inductively Coupled Plasma - Atomic Emission Spectrometry").

TABELA 9 - Análises químicas das ligas: $\mathrm{La}_{0,7} \mathrm{Mg}_{0,3} \mathrm{Al}_{0,3} \mathrm{Mn}_{0,4} \mathrm{Co}_{(0,5-\mathrm{x})} \mathrm{Nb}_{\mathrm{x}} \mathrm{Ni}_{3,8}(\mathrm{X}=$ 0 a 0,5$)$; realizadas pelo fornecedor por (ICP-AES - "Inductively Coupled Plasma - Atomic Emission Spectrometry").

\begin{tabular}{|c|c|c|c|c|c|c|c|c|}
\hline \multirow{2}{*}{\multicolumn{2}{|c|}{ Composição Nominal (\%at) }} & \multicolumn{7}{|c|}{ Composição (\% peso) (erro $\pm 1 \%$ ) } \\
\hline & & La & Mg & Al & Mn & Co & $\mathrm{Nb}$ & $\mathbf{N i}$ \\
\hline $\mathrm{La}_{0,7} \mathrm{Mg}_{0,3} \mathrm{Al}_{0,3} \mathrm{Mn}_{0,4} \mathrm{Co}_{0,5} \mathrm{Ni}_{3,8}$ & Padrão & 25,12 & 1,88 & 2,09 & 5,68 & 7,61 & -- & 57,62 \\
\hline $\mathrm{La}_{0,7} \mathrm{Mg}_{0,3} \mathrm{Al}_{0,3} \mathrm{Mn}_{0,4} \mathrm{Co}_{0,4} \mathrm{Nb}_{0,1} \mathrm{Ni}_{3,8}$ & $\mathrm{Nb}_{0,1}$ & 24,90 & 1,87 & 2,07 & 5,63 & 6,04 & 2,38 & 57,12 \\
\hline $\mathrm{La}_{0,7} \mathrm{Mg}_{0,3} \mathrm{Al}_{0,3} \mathrm{Mn}_{0,4} \mathrm{Co}_{0,3} \mathrm{Nb}_{0,2} \mathrm{Ni}_{3,8}$ & $\mathrm{Nb}_{0,2}$ & 24,69 & 1,85 & 2,06 & 5,58 & 4,49 & 4,72 & 56,62 \\
\hline $\mathrm{La}_{0,7} \mathrm{Mg}_{0,3} \mathrm{Al}_{0,3} \mathrm{Mn}_{0,4} \mathrm{Co}_{0,2} \mathrm{Nb}_{0,3} \mathrm{Ni}_{3,8}$ & $\mathrm{Nb}_{0,3}$ & 24,47 & 1,84 & 2,04 & 5,53 & 2,97 & 7,02 & 56,14 \\
\hline $\mathrm{La}_{0,7} \mathrm{Mg}_{0,3} \mathrm{Al}_{0,3} \mathrm{Mn}_{0,4} \mathrm{Co}_{0,1} \mathrm{Nb}_{0,4} \mathrm{Ni}_{3,8}$ & $\mathrm{Nb}_{0,4}$ & 24,27 & 1,82 & 2,02 & 5,48 & 1,47 & 9,27 & 55,66 \\
\hline $\mathrm{La}_{0,7} \mathrm{Mg}_{0,3} \mathrm{Al}_{0,3} \mathrm{Mn}_{0,4} \mathrm{Nb}_{0,5} \mathrm{Ni}_{3,8}$ & $\mathrm{Nb}_{0,5}$ & 24,06 & 1,80 & 2,00 & 5,44 & -- & 11,50 & 55,20 \\
\hline
\end{tabular}


TABELA 10 - Análises químicas das ligas: $\mathrm{La}_{0,7} \mathrm{Mg}_{0,3} \mathrm{Al}_{0,3} \mathrm{Mn}_{0,4} \mathrm{Nb}{ }_{(0,5+x)} \mathrm{Ni}_{(3,8--x)}$ $(x=0,3 ; 0,5 ; 1,3)$; realizadas pelo fornecedor por (ICP-AES - "Inductively Coupled Plasma - Atomic Emission Spectrometry").

\begin{tabular}{|c|c|c|c|c|c|c|c|c|}
\hline \multirow{2}{*}{\multicolumn{2}{|c|}{ Composição Nominal (\%at) }} & \multicolumn{7}{|c|}{ Composição (\% peso) (erro $\pm 1 \%$ ) } \\
\hline & & La & $\mathrm{Ma}$ & Al & Mn & Co & $\mathbf{N b}$ & $\mathrm{Ni}$ \\
\hline $\mathrm{La}_{0,7} \mathrm{Mg}_{0,3} \mathrm{Al}_{0,3} \mathrm{Mn}_{0,4} \mathrm{Nb}_{0,5} \mathrm{Ni}_{3,8}$ & Padrão & 24,06 & 1,80 & 2,00 & 5,44 & - & 11,50 & 55,20 \\
\hline $\mathrm{La}_{0,7} \mathrm{Mg}_{0,3} \mathrm{Al}_{0,3} \mathrm{Mn}_{0,4} \mathrm{Co}_{0,4} \mathrm{Nb}_{\mathrm{c}}$ & $\mathrm{Nb}_{0}$ & 23,47 & 1,76 & 1,95 & 5,30 & - & 17,94 & 49,58 \\
\hline $\mathrm{La}_{0,7} \mathrm{Mg}_{0,3} \mathrm{Al}_{0,3} \mathrm{Mn}_{0,4} \mathrm{Co}_{0,3} \mathrm{Nb}_{1,0} \mathrm{Ni}_{2,8}$ & $\mathrm{Nb}_{1,0}$ & 23,09 & 1,73 & 1,92 & 5,22 & - & 22,06 & 45,99 \\
\hline $\mathrm{La}_{0,7} \mathrm{Mg}_{0,3} \mathrm{Al}_{0,3} \mathrm{Mn}_{0,4} \mathrm{Co}_{0,2} \mathrm{Nb}_{1,8} \mathrm{Ni}_{2,0}$ & $\mathrm{Nb}_{1,8}$ & 21,68 & 1,63 & 1,80 & 4,90 & & 37,28 & 32,71 \\
\hline
\end{tabular}

5.1.2 - Microscopia Eletrônica de Varredura (MEV) $\mathrm{La}_{0,7} \mathrm{Mg}_{0,3} \mathrm{Al}_{0,3} \mathrm{Mn}_{0,4} \mathrm{Co}_{(0,5-}$ ${ }_{x)} \mathrm{Nb}_{x} \mathrm{Ni}_{3,8}(\mathrm{x}=\mathrm{O}$ a 0,5$)$

As micrografias obtidas por MEV das ligas $\mathrm{La}_{0,7} \mathrm{Mg}_{0,3} \mathrm{Al}_{0,3} \mathrm{Mn}_{0,4} \mathrm{Co}_{(0,5-}$ x) $\mathrm{Nb}_{x} \mathrm{Ni}_{3,8}$ ( $x=0$ a 0,5 ) estão apresentadas nas FIG. 25 - 30, onde: (a) representa a visão geral e (b) detalhada. 


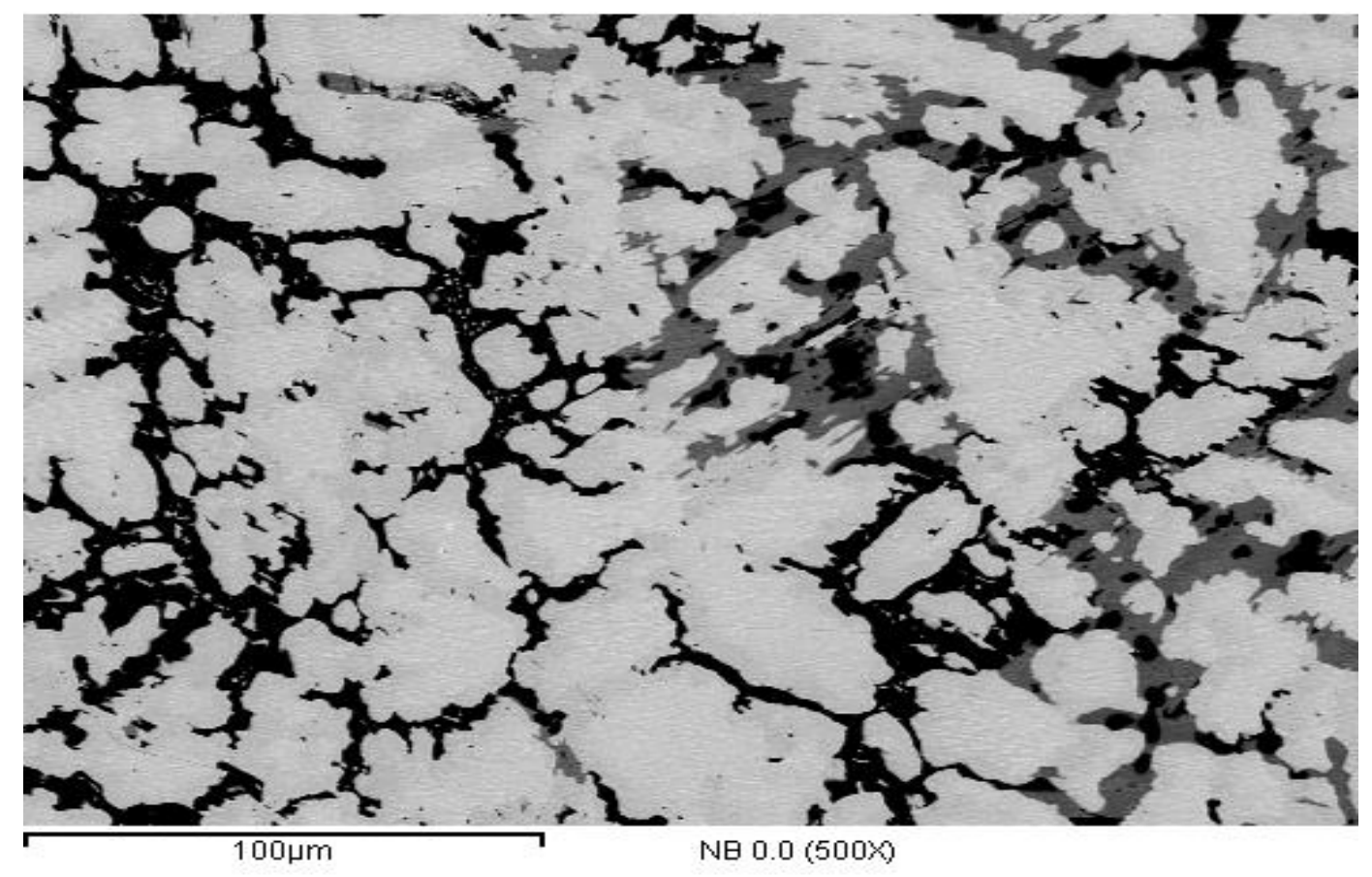

(a)

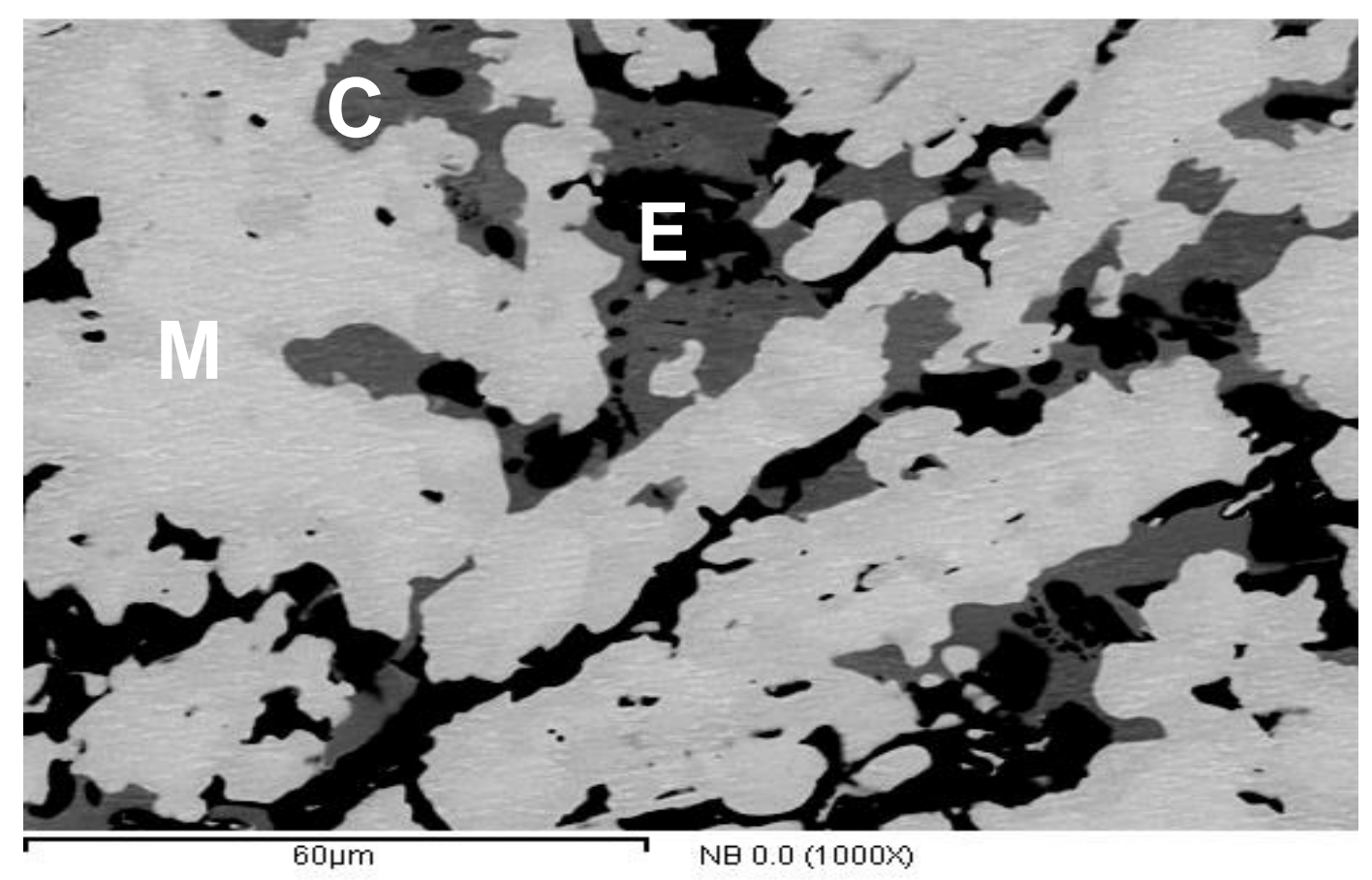

(b)

FIGURA 25 - Micrografias da liga $\mathrm{La}_{0,7} \mathrm{Mg}_{0,3} \mathrm{Al}_{0,3} \mathrm{Mn}_{0,4} \mathrm{Co}_{0,5} \mathrm{Ni}_{3,8}$; onde: (a) visão geral (500x) e (b) detalhada (1000x). 


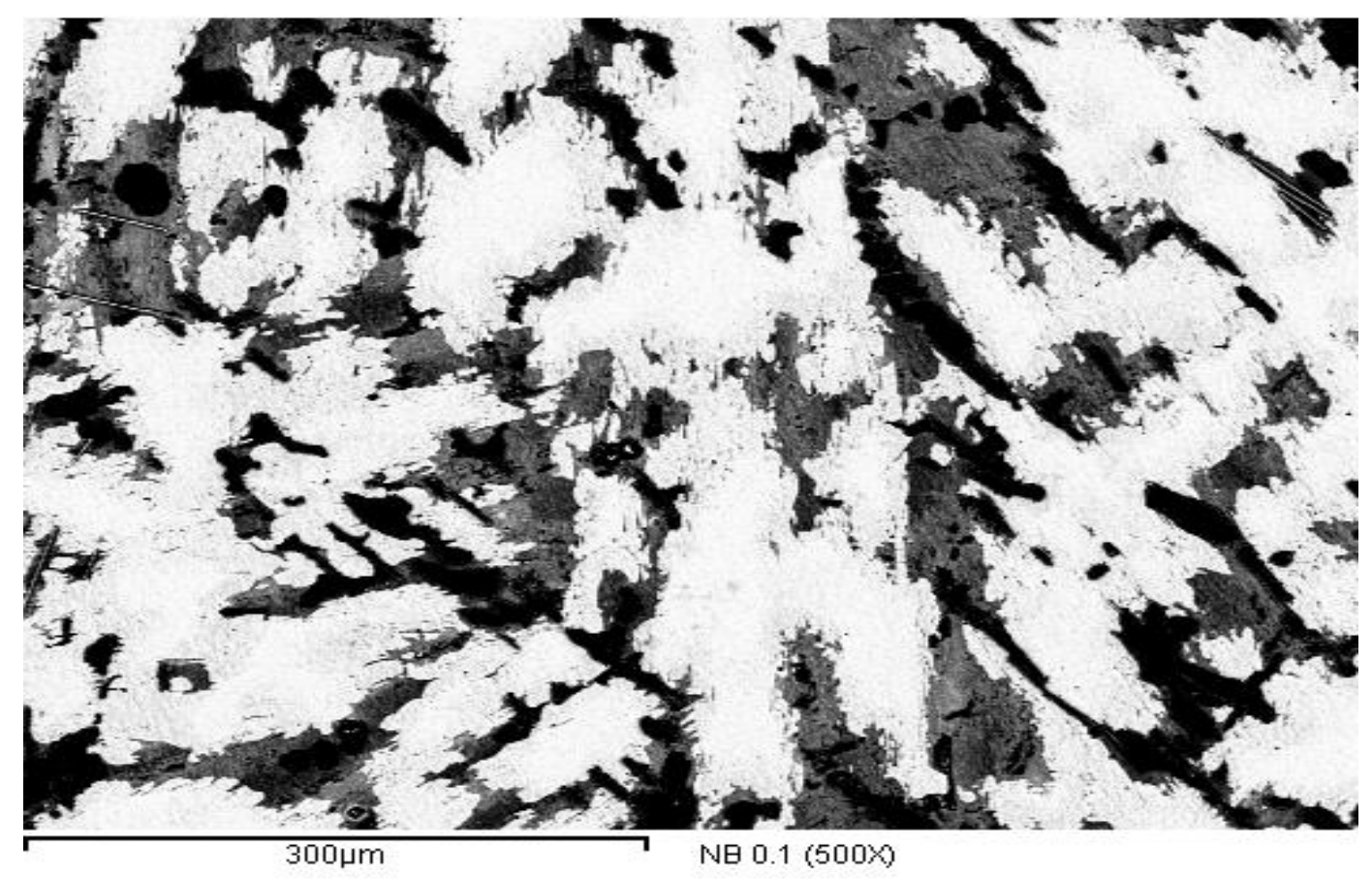

(a)

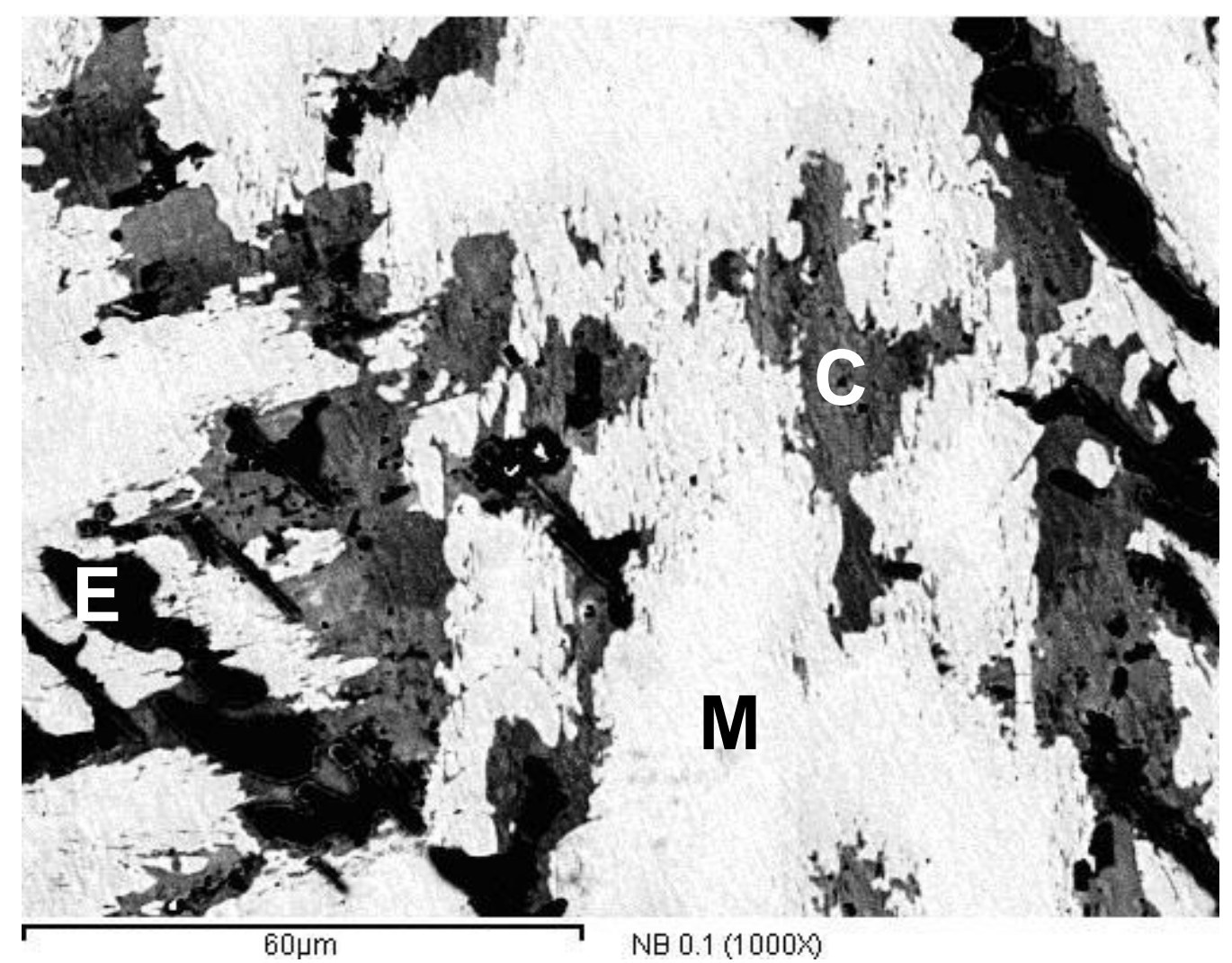

(b)

FIGURA 26 - Micrografias da liga $\mathrm{La}_{0,7} \mathrm{Mg}_{0,3} \mathrm{Al}_{0,3} \mathrm{Mn}_{0,4} \mathrm{Co}_{0,4} \mathrm{Nb}_{0,1} \mathrm{Ni}_{3,8}$; onde: (a) visão geral (500x) e (b) detalhada (1000x). 


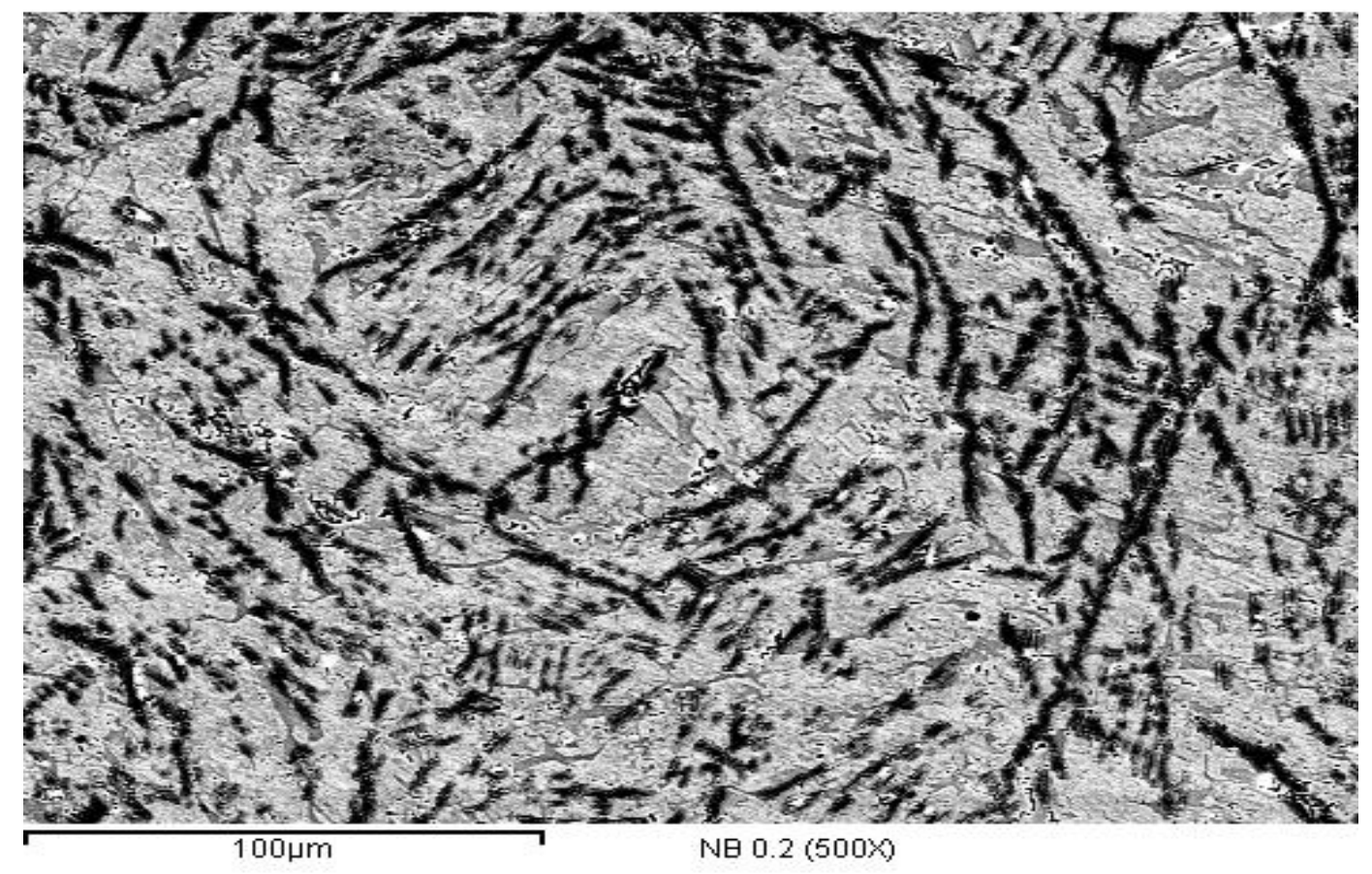

(a)

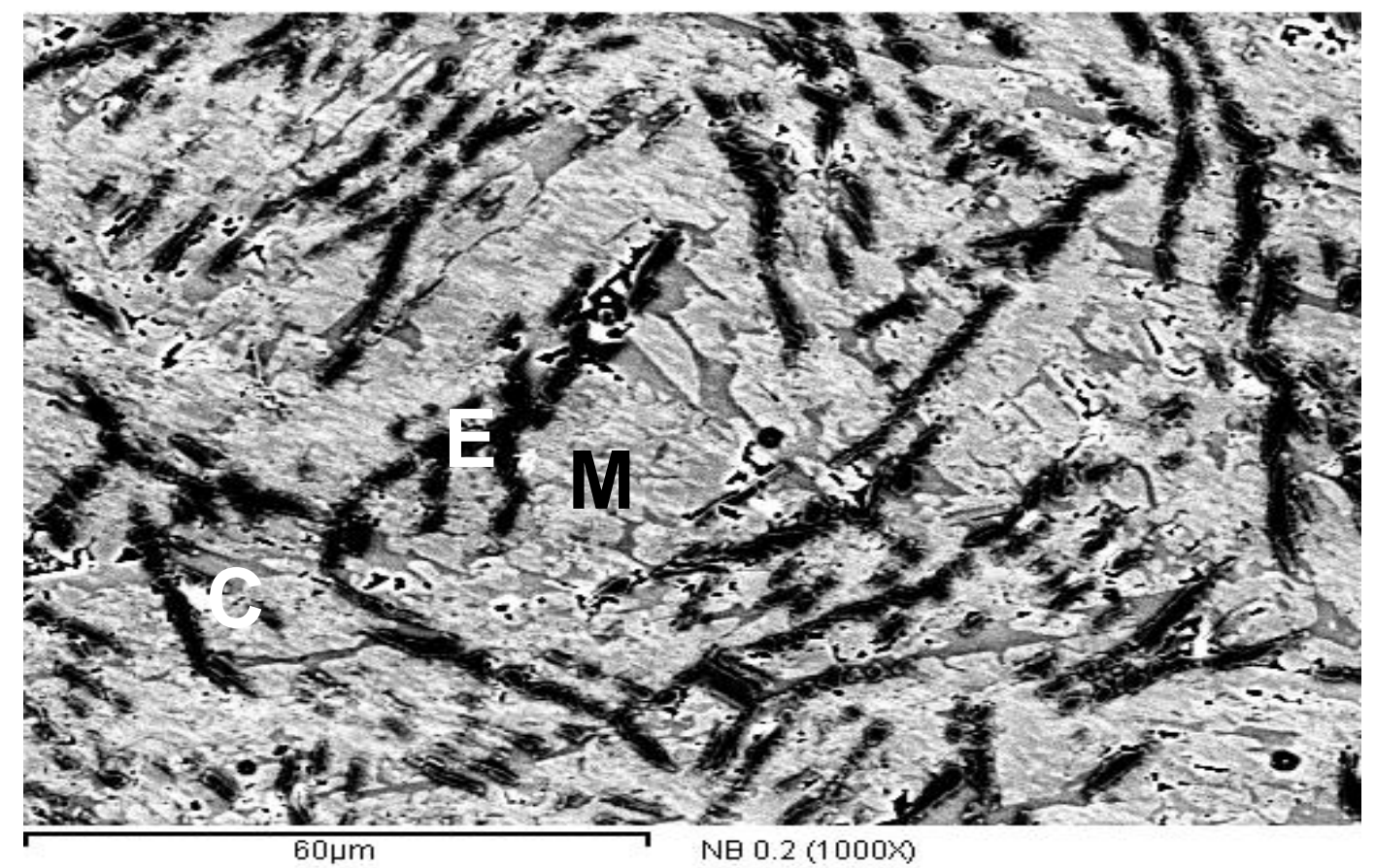

(b)

FIGURA 27 - Micrografias da liga $\mathrm{La}_{0,7} \mathrm{Mg}_{0,3} \mathrm{Al}_{0,3} \mathrm{Mn}_{0,4} \mathrm{Co}_{0,3} \mathrm{Nb}_{0,2} \mathrm{Ni}_{3,8}$; onde: (a) visão geral (500x) e (b) detalhada (1000x). 


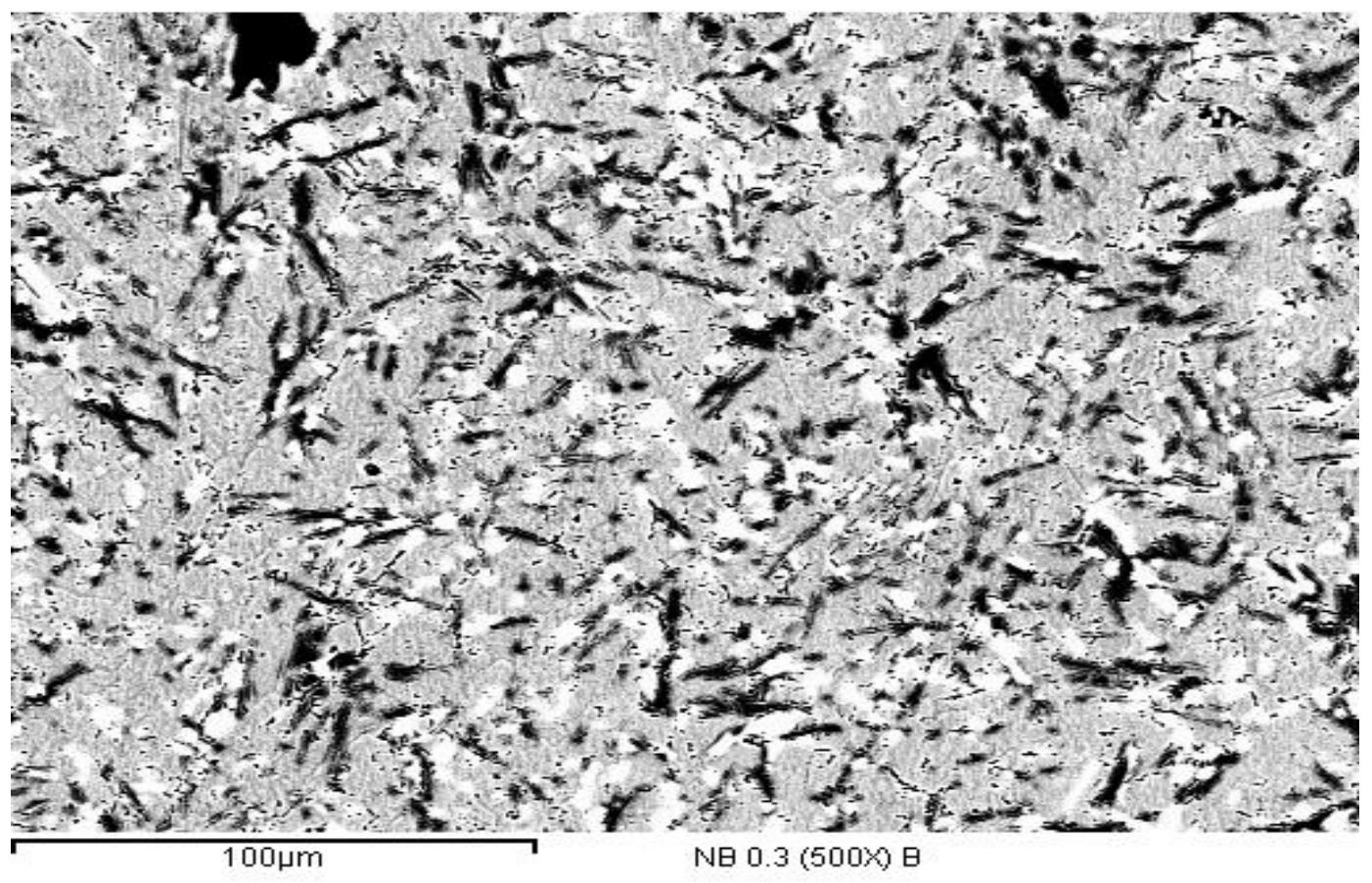

(a)

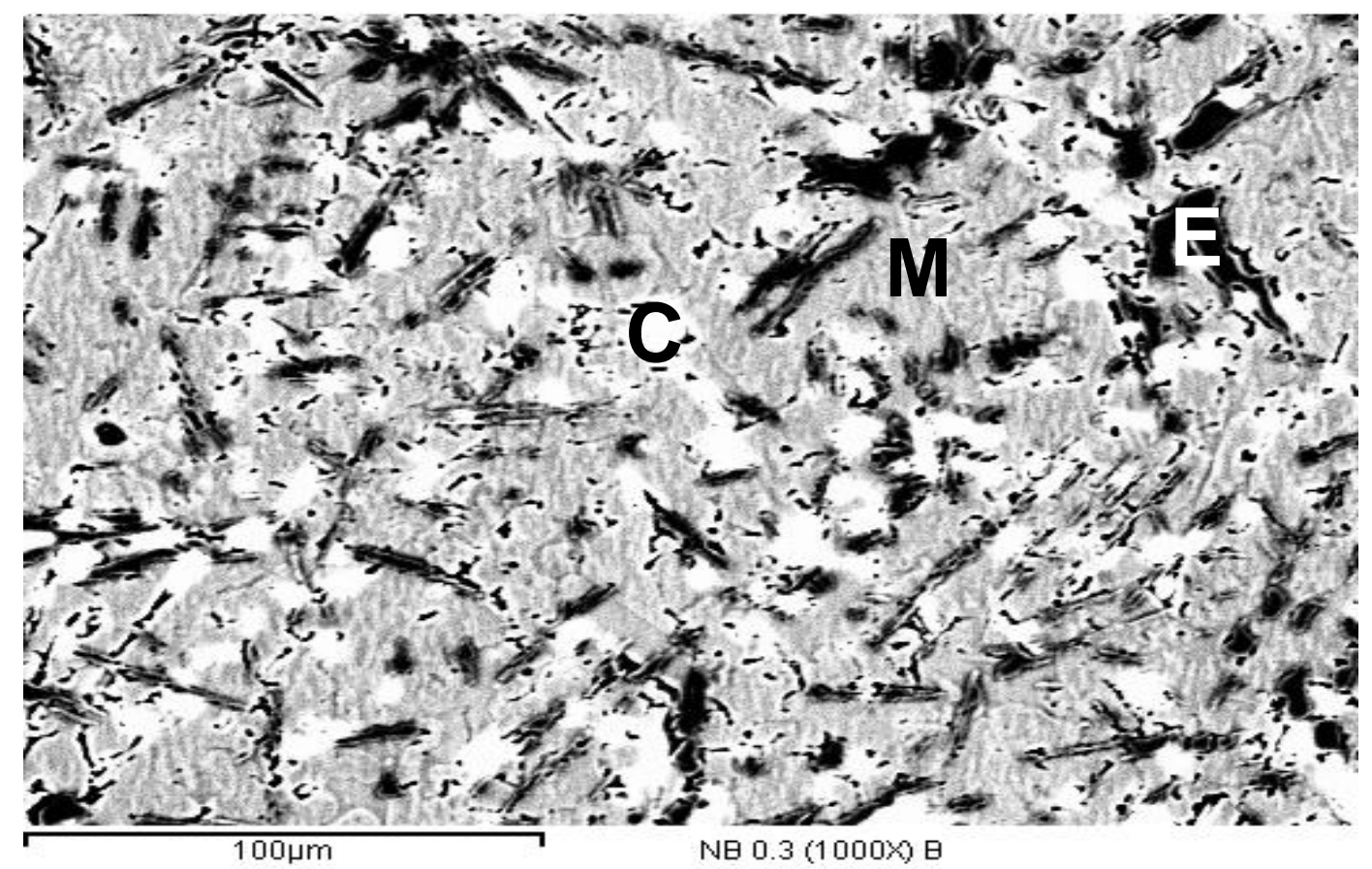

(b)

FIGURA 28 - Micrografias da liga $\mathrm{La}_{0,7} \mathrm{Mg}_{0,3} \mathrm{Al}_{0,3} \mathrm{Mn}_{0,4} \mathrm{Co}_{0,2} \mathrm{Nb}_{0,3} \mathrm{Ni}_{3,8}$; onde: (a) visão geral (500x) e (b) detalhada (1000x). 


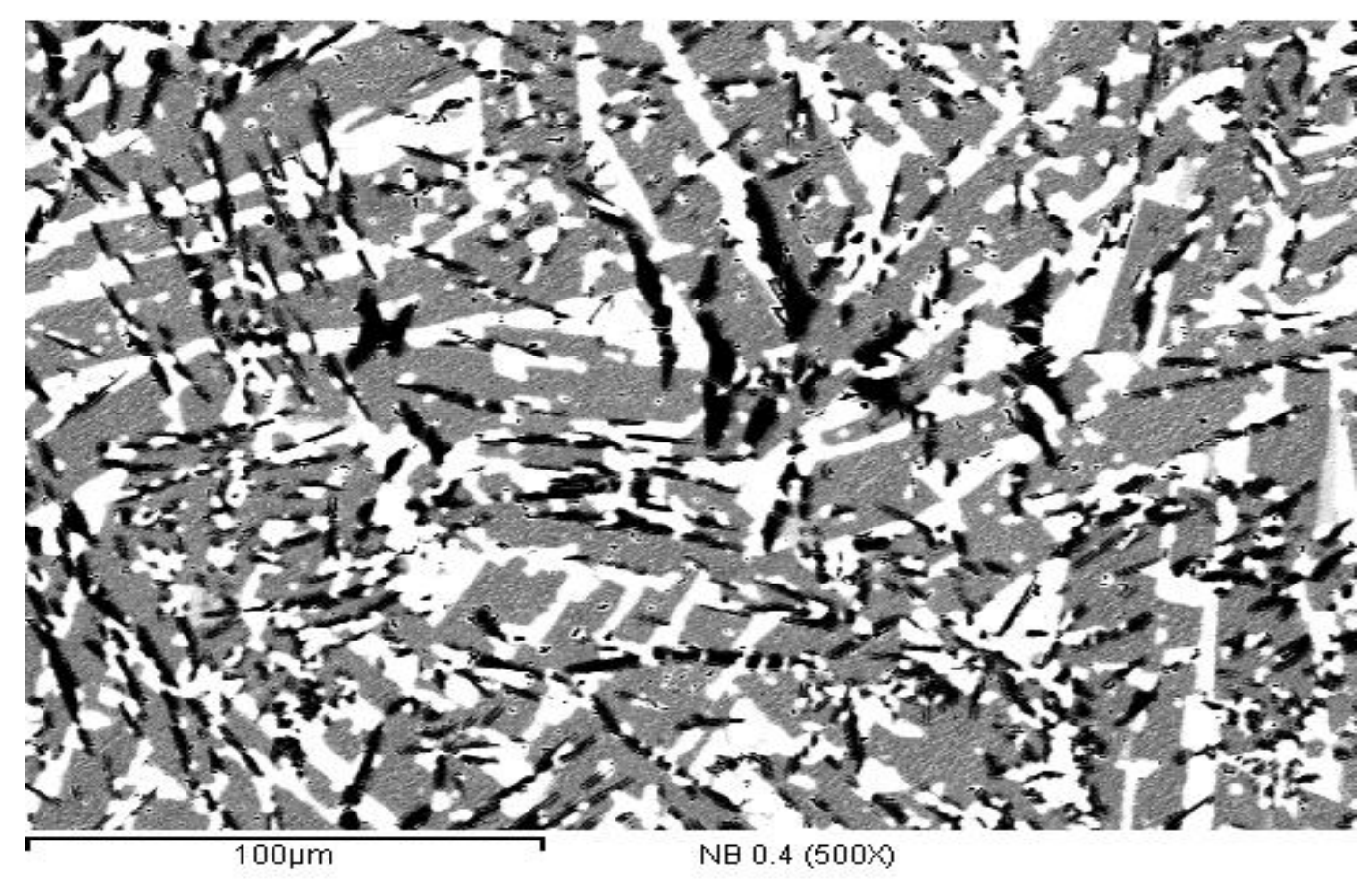

(a)

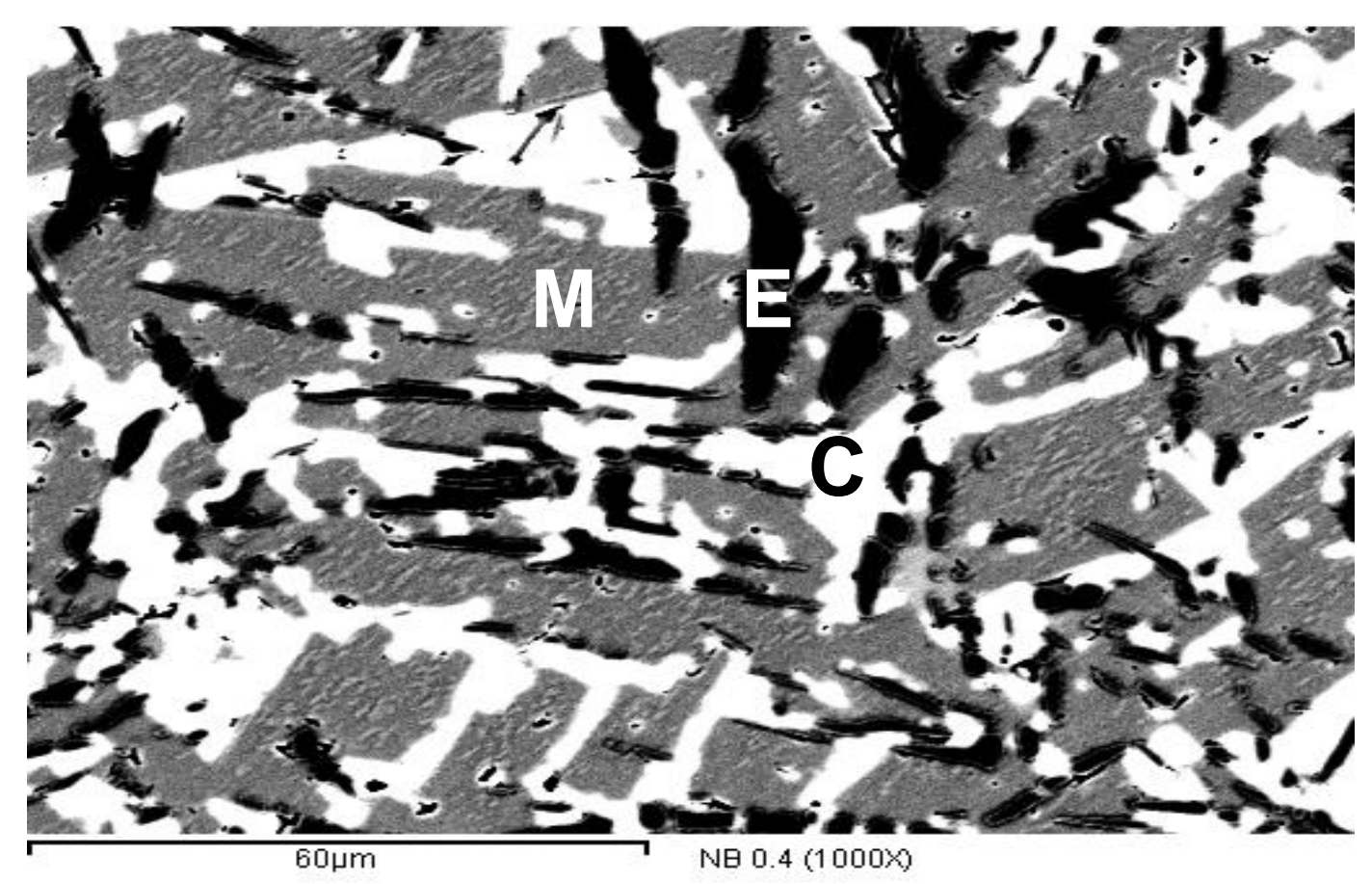

(b)

FIGURA 29 - Micrografias da liga $\mathrm{La}_{0,7} \mathrm{Mg}_{0,3} \mathrm{Al}_{0,3} \mathrm{Mn}_{0,4} \mathrm{Co}_{0,1} \mathrm{Nb}_{0,4} \mathrm{Ni}_{3,8}$; onde: (a) visão geral (500x) e (b) detalhada (1000x). 


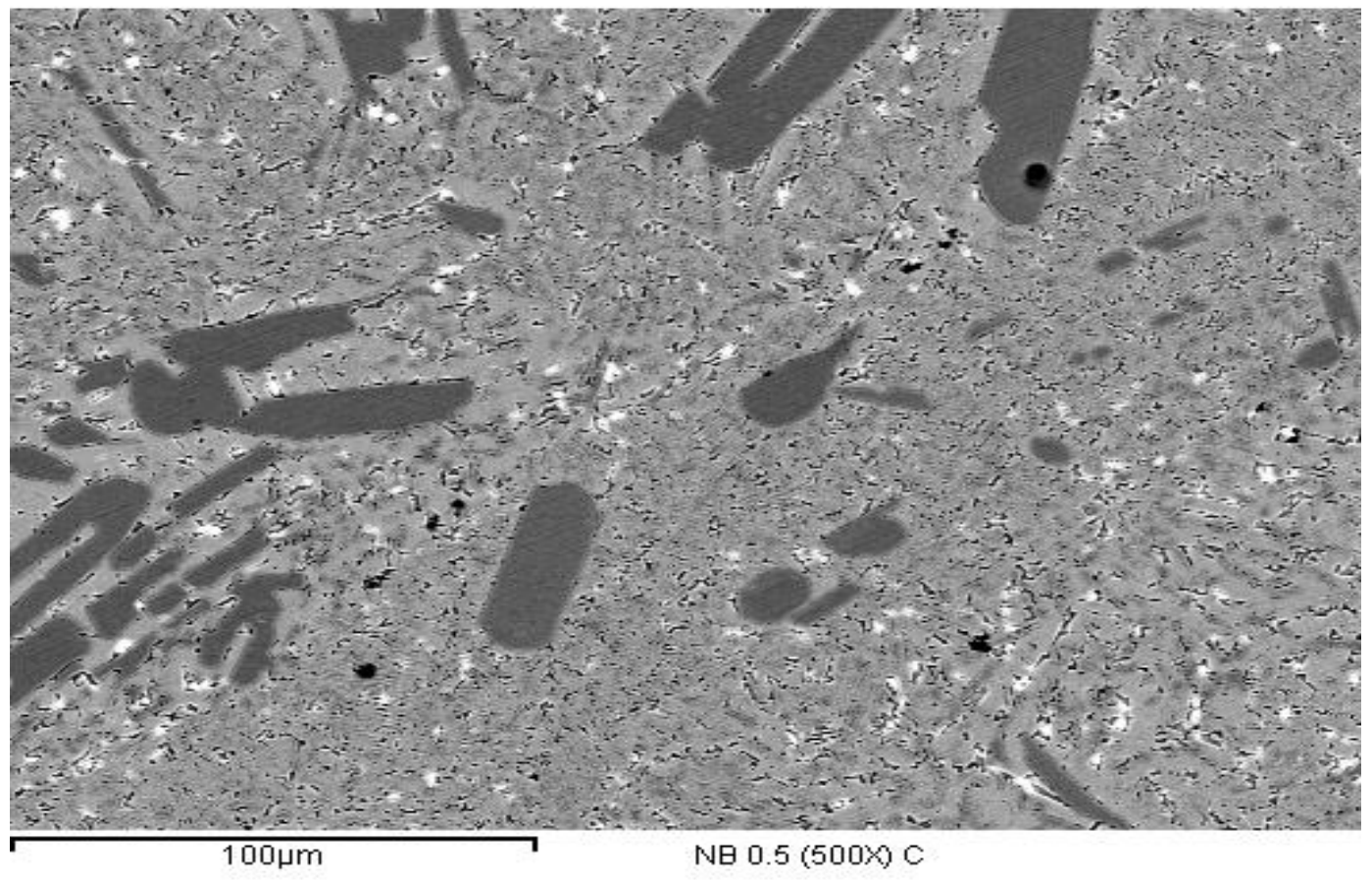

(a)

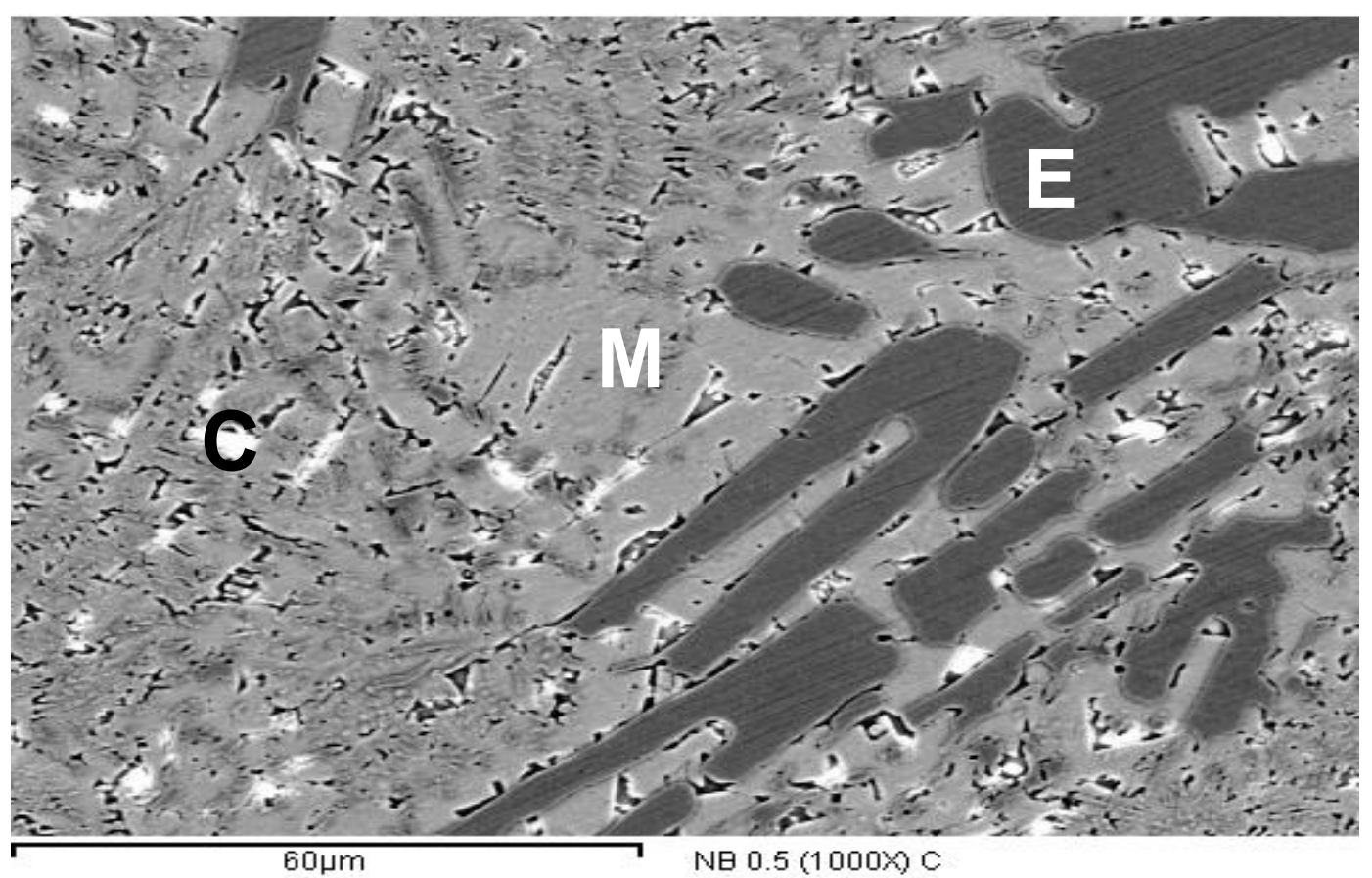

(b)

FIGURA 30 - Micrografias da liga $\mathrm{La}_{0,7} \mathrm{Mg}_{0,3} \mathrm{Al}_{0,3} \mathrm{Mn}_{0,4} \mathrm{Nb}_{0,5} \mathrm{Ni}_{3,8}$; onde: (a) visão geral (500x) e (b) detalhada (1000x). 
Foram observadas sempre três fases distintas nas micrografias: uma fase matriz $(M)$, uma fase clara $(C)$ e uma fase escura (E). Com o aumento do teor de $\mathrm{Nb}$ foi possível observar a mudança na composição atômica dos elementos dessas respectivas fases.

Na TAB. 11 - 13 estão apresentadas as análises por EDS das fases encontradas para as ligas $\mathrm{La}_{0,7} \mathrm{Mg}_{0,3} \mathrm{Al}_{0,3} \mathrm{Mn}_{0,4} \mathrm{Co}_{(0,5-\mathrm{x})} \mathrm{Nb}_{x} \mathrm{Ni}_{3,8}$ ( $\mathrm{x}=0$ a 0,5 ). Foram realizadas cinco medidas para cada fase, através destes valores foram calculadas as médias e o erro percentual.

TABELA 11- Composição da Fase Matriz (M) encontrada nas ligas $\mathrm{La}_{0,7} \mathrm{Mg}_{0,3} \mathrm{Al}_{0,3} \mathrm{Mn}_{0,4} \mathrm{Co}_{(0,5-x)} \mathrm{Nb}_{x} \mathrm{Ni}_{3,8}$ (x= 0 a 0,5).

\begin{tabular}{ccccccccc}
\hline \multirow{2}{*}{ Liga } & \multicolumn{7}{c}{ Composição Analisada (at.\%) Erro ( \pm 1\%) } & $\begin{array}{c}\text { Razão } \\
\text { (La,Mg):(Al, } \\
\text { Mn,Co,Ni) }\end{array}$ \\
\hline $\mathbf{S} / \mathbf{N b}$ & $\mathbf{L a}$ & $\mathbf{M g}$ & $\mathbf{A l}$ & $\mathbf{M n}$ & $\mathbf{C o}$ & $\mathbf{N b}$ & $\mathbf{N i}$ & $1: 5$ \\
\hline $\mathbf{N b}$ & $<1$ & 4,5 & 2,5 & 7,9 & -- & 69,5 & $1: 5$ \\
$\mathbf{N b}_{0,1}$ & 17,57 & -- & 1,74 & 2,64 & 6,71 & -- & 71,34 & $1: 5$ \\
$\mathbf{N b}_{0,3}$ & 18,09 & 1,45 & 2,85 & 5,42 & 4,31 & -- & 67,87 & $1: 5$ \\
$\mathbf{N b}_{0,4}$ & 18,35 & -- & 3,50 & 9,65 & 1,62 & -- & 66,88 & $1: 5$ \\
$\mathbf{N b}_{0,5}$ & 18,53 & -- & 4,62 & 9,79 & 1,01 & -- & 66,04 & $1: 5$ \\
\hline
\end{tabular}

TABELA 12 - Composição da Fase Escura $(E)$ encontrada nas ligas $\mathrm{La}_{0,7} \mathrm{Mg}_{0,3} \mathrm{Al}_{0,3} \mathrm{Mn}_{0,4} \mathrm{Co}_{(0,5-x)} \mathrm{Nb}_{x} \mathrm{Ni}_{3,8}$ (x= 0 a 0,5)

\begin{tabular}{|c|c|c|c|c|c|c|c|c|}
\hline \multirow{2}{*}{ Liga } & \multicolumn{7}{|c|}{ Composição Analisada (at.\%) Erro ( $\pm 1 \%$ ) } & \multirow{2}{*}{$\begin{array}{c}\text { Razão } \\
\text { (Nb ,Ni) }\end{array}$} \\
\hline & La & Mg & Al & Mn & Co & $\mathrm{Nb}$ & $\mathrm{Ni}$ & \\
\hline $\mathrm{S} / \mathrm{Nb}$ & 1,3 & -- & 9,6 & 15,4 & 15,5 & -- & 57,9 & -- \\
\hline $\mathrm{Nb}_{0,1}$ & 8,43 & 4,60 & 1,63 & 5,33 & 11,21 & 6,10 & 62,60 & -- \\
\hline $\mathrm{Nb}_{0,2}$ & 1,50 & -- & 1,23 & 2,43 & 14,45 & 16,68 & 63,70 & $\sim 1: 3,5$ \\
\hline $\mathrm{Nb}_{0,3}$ & $<1$ & -- & -- & $<1$ & 9,03 & 19,37 & 70,37 & $\sim 1: 3,5$ \\
\hline $\mathrm{Nb}_{0,4}$ & $<1$ & -- & $<1$ & 1,07 & 4,98 & 19,71 & 73,33 & $\sim 1: 3,5$ \\
\hline $\mathrm{Nb}_{0,5}$ & -- & -- & -- & -- & 1,2 & 19,4 & 79,3 & $\sim 1: 3,5$ \\
\hline
\end{tabular}


TABELA 13 - Composição da Fase Clara (C) encontrada nas ligas $\mathrm{La}_{0,7} \mathrm{Mg}_{0,3} \mathrm{Al}_{0,3} \mathrm{Mn}_{0,4} \mathrm{Co}_{(0,5-x)} \mathrm{Nb}_{x} \mathrm{Ni}_{3,8}$ ( $\mathrm{x}=0$ a 0,5).

\begin{tabular}{|c|c|c|c|c|c|c|c|c|}
\hline \multirow[t]{2}{*}{ Liga } & \multicolumn{7}{|c|}{ Composição Analisada (at.\%) Erro ( $\pm 1 \%$ ) } & \multirow{2}{*}{$\begin{array}{c}\text { Razão } \\
\text { (La,Mg):(Al,Mn, } \\
\text { Co,Ni) }\end{array}$} \\
\hline & La & Mg & Al & Mn & Co & $\mathrm{Nb}$ & $\mathbf{N i}$ & \\
\hline $\mathbf{S} / \mathrm{Nb}$ & 8,40 & 10,3 & 2,80 & 6,9 & 8,0 & -- & 63,30 & $1: 5$ \\
\hline $\mathrm{Nb}_{0,1}$ & 17,00 & 5,19 & 1,72 & 9,05 & $\overline{5,24}$ & -- & 64,80 & $1: 3,5$ \\
\hline $\mathrm{Nb}_{0,2}$ & 34,75 & 6,75 & 1,41 & 4,07 & 1,45 & -- & 51,56 & $1: 1$ \\
\hline $\mathrm{Nb}_{0,3}$ & 45,43 & 9,15 & -- & -- & $<1$ & -- & 45,28 & $1: 1$ \\
\hline $\mathrm{Nb}_{0,4}$ & 46,85 & 8,64 & -- & -- & -- & -- & 44,51 & $1: 1$ \\
\hline $\mathrm{Nb}_{0,5}$ & 38,10 & 8,30 & -- & 2,70 & -- & -- & 50,8 & $1: 1$ \\
\hline
\end{tabular}

A fase matriz (M) está presente em todas as ligas. Sua composição, apresentada na TAB. 11 apresentou uma razão de aproximadamente 1:5 para todas as ligas, o que provavelmente representa a fase $\mathrm{LaNi}_{5}$.

Com a substituição do cobalto pelo nióbio foi possível observar visualmente a diminuição da fase (C). As composições da fase cinza (C) apresentadas na TAB. 13 apresentaram a razão de aproximadamente 1:5 para a liga sem $\mathrm{Nb}$ (fase $\mathrm{LaNi}_{5}$ ), razão de 1:3,5 para a liga com $\mathrm{Nb}$ 0,2 (fase ( $\mathrm{La}, \mathrm{Mg}) \mathrm{Ni}_{3}$ e para as demais ligas razão de 1:1 (fase La:Ni).

A fase $E$, com alta concentração em Nióbio, surge na medida em que aumenta a concentração de $\mathrm{Nb}$ nas ligas. Sua composição, mostrada na TAB. 12, apresentou a razão de aproximadamente 1: 3,5, o que provavelmente representa a fase $\mathrm{NbNi}_{3}$. A formação desta fase deve-se ao Nióbio não substituir o cobalto nas ligas, principalmente na fase matriz. Além disso, foi possível observar que com o nióbio houve um refinamento do grão das ligas, como mostram as micrografias com menor aumento (500x; FIG. $25-30$ ). 


\subsection{3 - Difração de Raios - $X \mathrm{La}_{0,7} \mathrm{Mg}_{0,3} \mathrm{Al}_{0,3} \mathrm{Mn}_{0,4} \mathrm{Co}_{(0,5-\mathrm{x})} \mathrm{Nb}_{\mathrm{x}} \mathrm{Ni}_{3,8}(\mathrm{X}=\mathbf{0}$ a 0,5$)$}

Os dados cristalográficos são apresentados na Tabela $14 \mathrm{com}$ os valores dos parâmetros de rede e volume das fases obtidas por refinamento de todas as ligas. Os programas Crystallographica Search-Match (CSM) e PowderCell 2.3 foram usados para a determinação desses parâmetros. As Figuras 31-36 apresentam os difratogramas de raios $X$ das ligas $\mathrm{La}_{0,7} \mathrm{Mg}_{0,3} \mathrm{Al}_{0,3} \mathrm{Mn}_{0,4} \mathrm{Co}_{(0,5-x)} \mathrm{Nb}_{x} \mathrm{Ni}_{3,8} \quad(\mathrm{x}=0$ a $\quad$ a 0,5$)$. Quatro fases foram encontradas: LaNi ${ }_{5}$ e LaNi (Grupo Espacial: P6/mmm - PDF: 50-0777, PDF: 50 -0689),(La,Mg)Ni ${ }_{3}$ (SG: R-3m - PDF: 22-1124) e $\mathrm{NbNi}_{3}$ (Grupo Espacial: Pmmm - PDF: 65-589). Analisando esses dados foi observar uma diminuição do volume das fases $\mathrm{LaNi}$ e ( $\mathrm{La}, \mathrm{Mg}) \mathrm{Ni}_{3}$ e um aumento de volume da fase $\mathrm{NbNi}_{3}$ confirmado os dados coletados por MEV e EDS.

Tabela 14- Dados cristalográficos das ligas $\mathrm{La}_{0,7} \mathrm{Mg}_{0,3} \mathrm{Al}_{0,3} \mathrm{Mn}_{0,4} \mathrm{Co}_{(0,5-x)} \mathrm{Nb}_{x} \mathrm{Ni}_{3,8}$

$$
(x=0 \text { a } 0,5)
$$

\begin{tabular}{|c|c|c|c|c|}
\hline \multirow[t]{2}{*}{ Ligas } & \multirow[t]{2}{*}{ Fases } & \multicolumn{2}{|c|}{ Parâmetros (Å) } & \multirow{2}{*}{$\begin{array}{c}\text { Volume } \\
(\%)\end{array}$} \\
\hline & & $\mathbf{a}$ & C & \\
\hline \multirow[t]{2}{*}{$\mathrm{S} / \mathrm{Nb}$} & $\mathrm{LaNi}_{5}$ & 5.067 & 4.036 & 62,12 \\
\hline & $(\mathrm{La}, \mathrm{Mg}) \mathrm{Ni}_{3}$ & 5.065 & 24.341 & 37,88 \\
\hline \multirow[t]{3}{*}{$\mathrm{Nb} 0,1$} & $\mathrm{LaNi}_{5}$ & 5.072 & 4.037 & 59,47 \\
\hline & $(\mathrm{La}, \mathrm{Mg}) \mathrm{Ni}_{3}$ & 5.098 & 24.542 & 38,50 \\
\hline & $\mathrm{NbNi}_{3}$ & 5.104 & 4.558 & 2,03 \\
\hline \multirow{3}{*}{$\mathrm{Nb} 0,2$} & $\mathrm{LaNi}_{5}$ & 5.076 & 4.047 & 56,89 \\
\hline & LaNi & 3.838 & 4.553 & 39,03 \\
\hline & $\mathrm{NbNi}_{3}$ & 5.101 & 4.550 & 4,08 \\
\hline \multirow[t]{3}{*}{$\mathrm{Nb} 0,3$} & $\mathrm{LaNi}_{5}$ & 5.078 & 4.050 & 60,14 \\
\hline & LaNi & 3.837 & 4.552 & 32,88 \\
\hline & $\mathrm{NbNi}_{3}$ & 5.088 & 4.547 & 6,98 \\
\hline \multirow[t]{3}{*}{$\mathrm{Nb} 0,4$} & $\mathrm{LaNi}_{5}$ & 5.073 & 4.049 & 58,23 \\
\hline & LaNi & 3.832 & 4.559 & 32,03 \\
\hline & $\mathrm{NbNi}_{3}$ & 5.054 & 4.551 & 9,74 \\
\hline \multirow[t]{3}{*}{$\mathrm{Nb} 0,5$} & $\mathrm{LaNi}_{5}$ & 5.076 & 4.047 & 57,90 \\
\hline & LaNi & 3.831 & 4.595 & 29,87 \\
\hline & $\mathrm{NbNi}_{3}$ & 5.104 & 4.553 & 12,23 \\
\hline
\end{tabular}




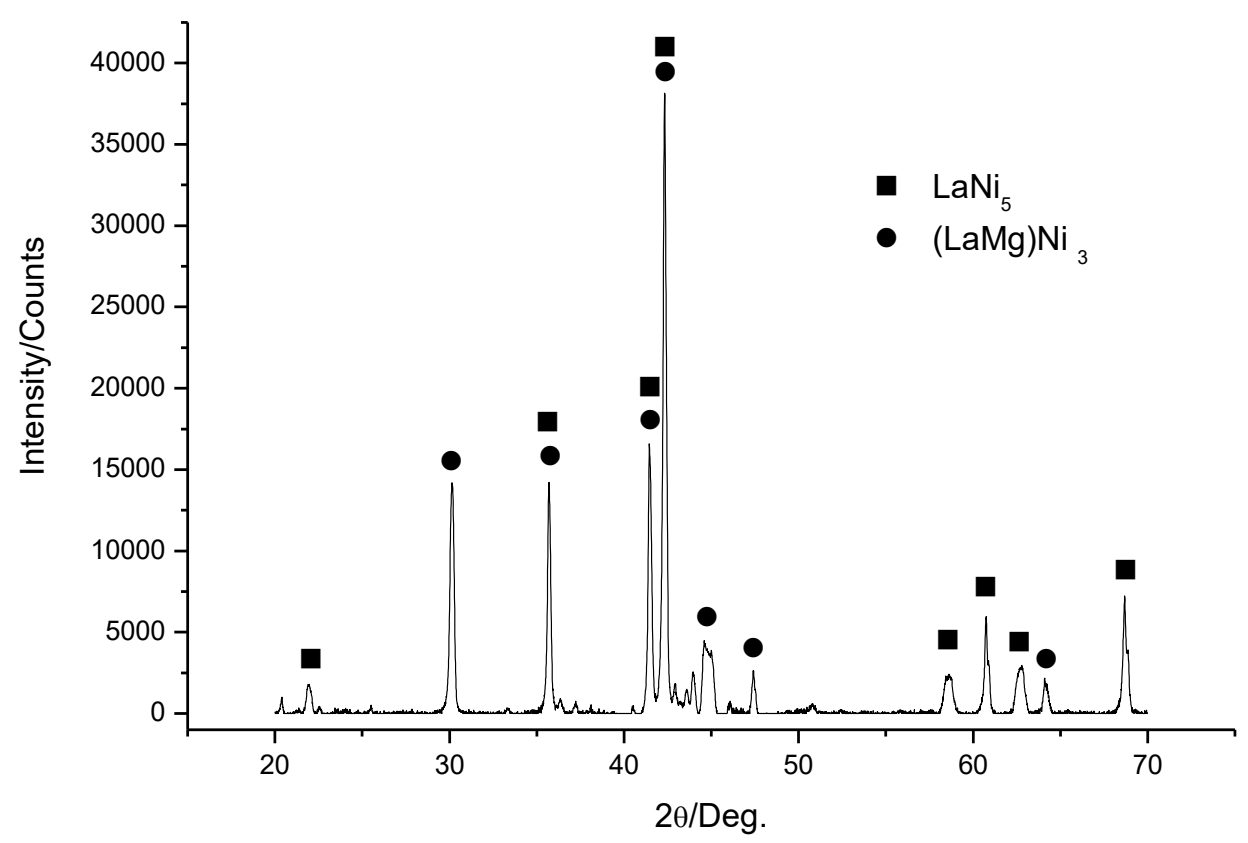

Figura 31 - Difratograma de raios $X$ da liga $\mathrm{La}_{0,7} \mathrm{Mg}_{0,3} \mathrm{Al}_{0,3} \mathrm{Mn}_{0,4} \mathrm{Co}_{0,5} \mathrm{Ni}_{3,8}$

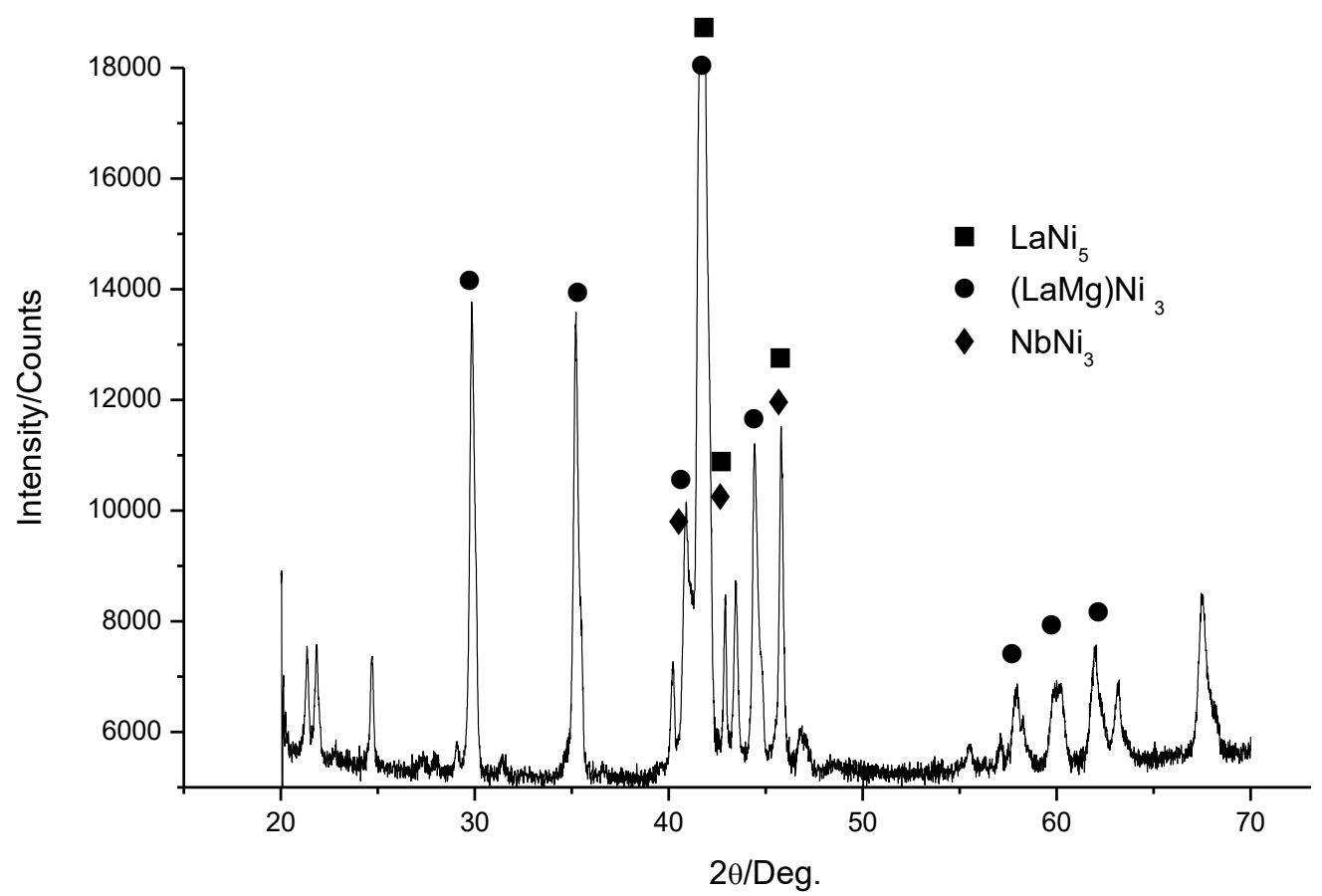

Figura 32 - Difratograma de raios $X-\mathrm{La}_{0,7} \mathrm{Mg}_{0,3} \mathrm{Al}_{0,3} \mathrm{Mn}_{0,4} \mathrm{Co}_{0,4} \mathrm{Nb}_{0,1} \mathrm{Ni}_{3,8}$ 


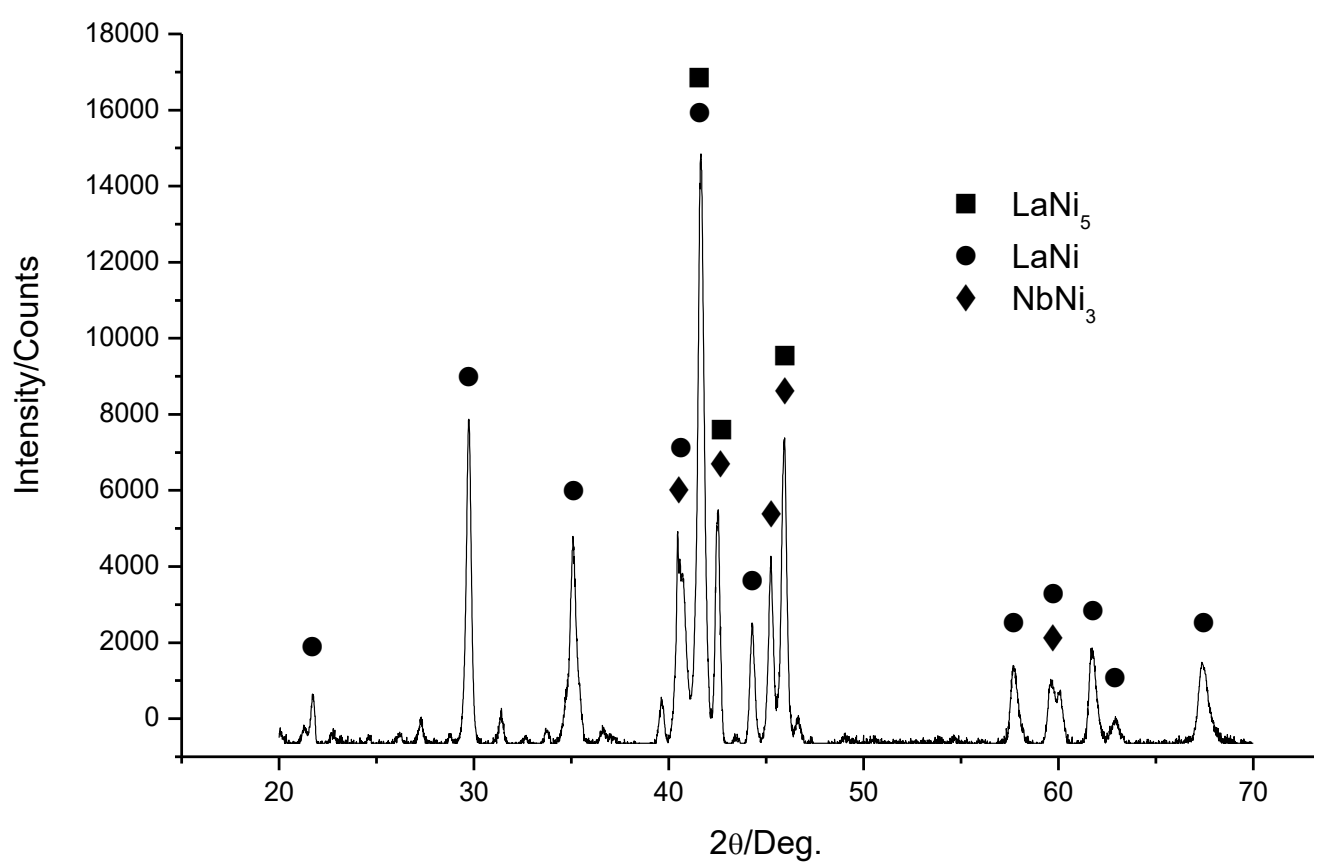

Figura 33- Difratograma de raios $\mathrm{X}$ - $\mathrm{La}_{0,7} \mathrm{Mg}_{0,3} \mathrm{Al}_{0,3} \mathrm{Mn}_{0,4} \mathrm{Co}_{0,3} \mathrm{Nb}_{0,2} \mathrm{Ni}_{3,8}$

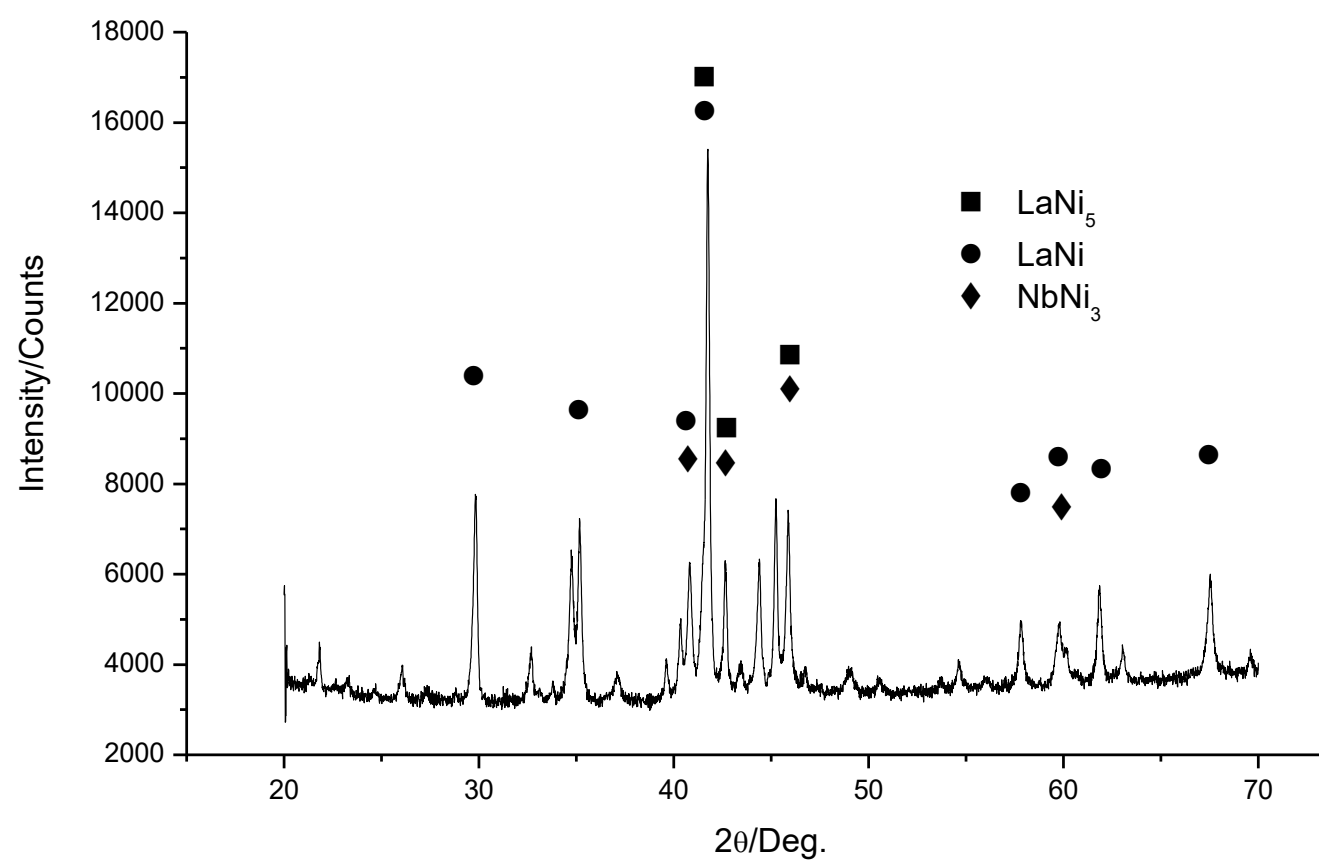

Figura 34 - Difratograma de raios $X$ - $\mathrm{La}_{0,7} \mathrm{Mg}_{0,3} \mathrm{Al}_{0,3} \mathrm{Mn}_{0,4} \mathrm{Co}_{0,2} \mathrm{Nb}_{0,3} \mathrm{Ni}_{3,8}$ 


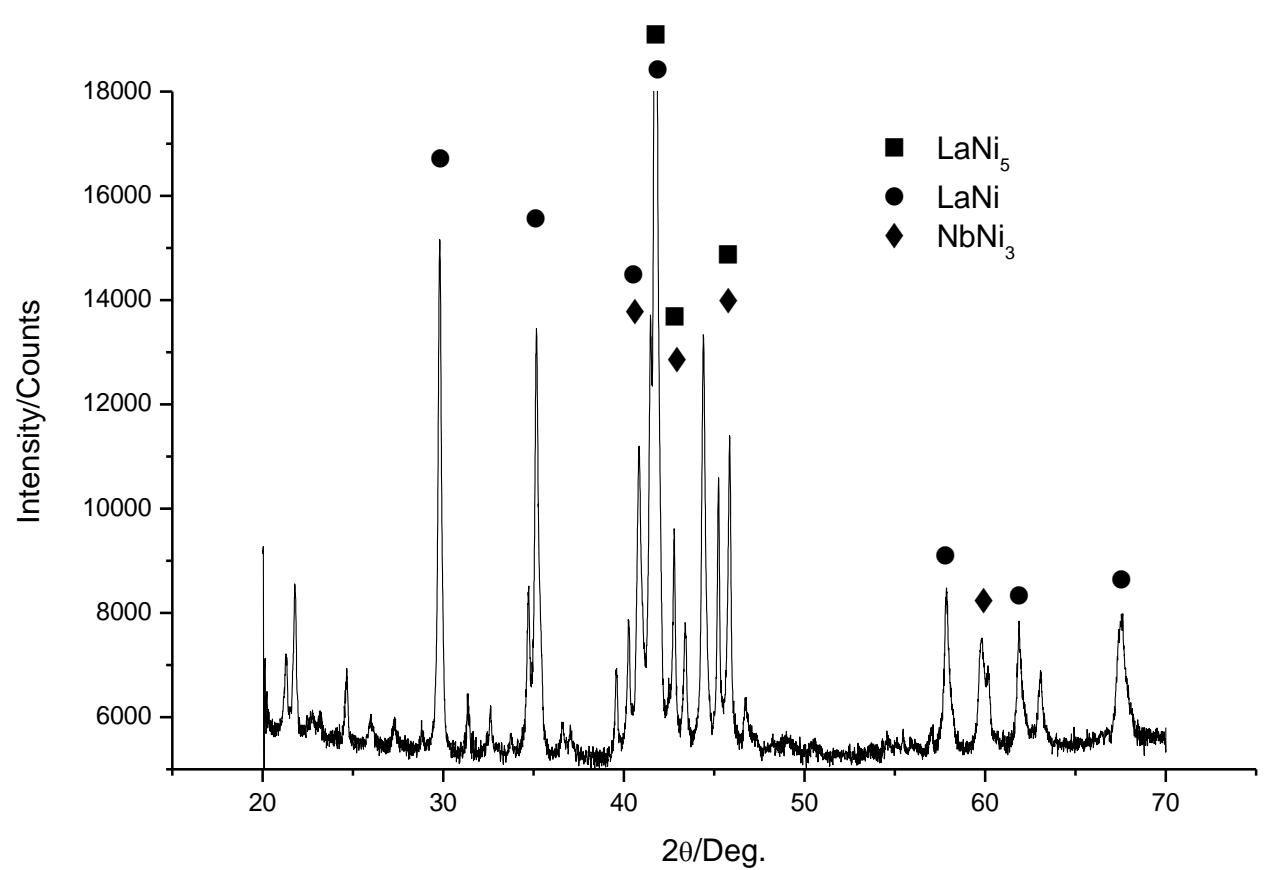

Figura 35 - Difratograma de raios $X-\mathrm{La}_{0,7} \mathrm{Mg}_{0,3} \mathrm{Al}_{0,3} \mathrm{Mn}_{0,4} \mathrm{Co}_{0,1} \mathrm{Nb}_{0,4} \mathrm{Ni}_{3,8}$

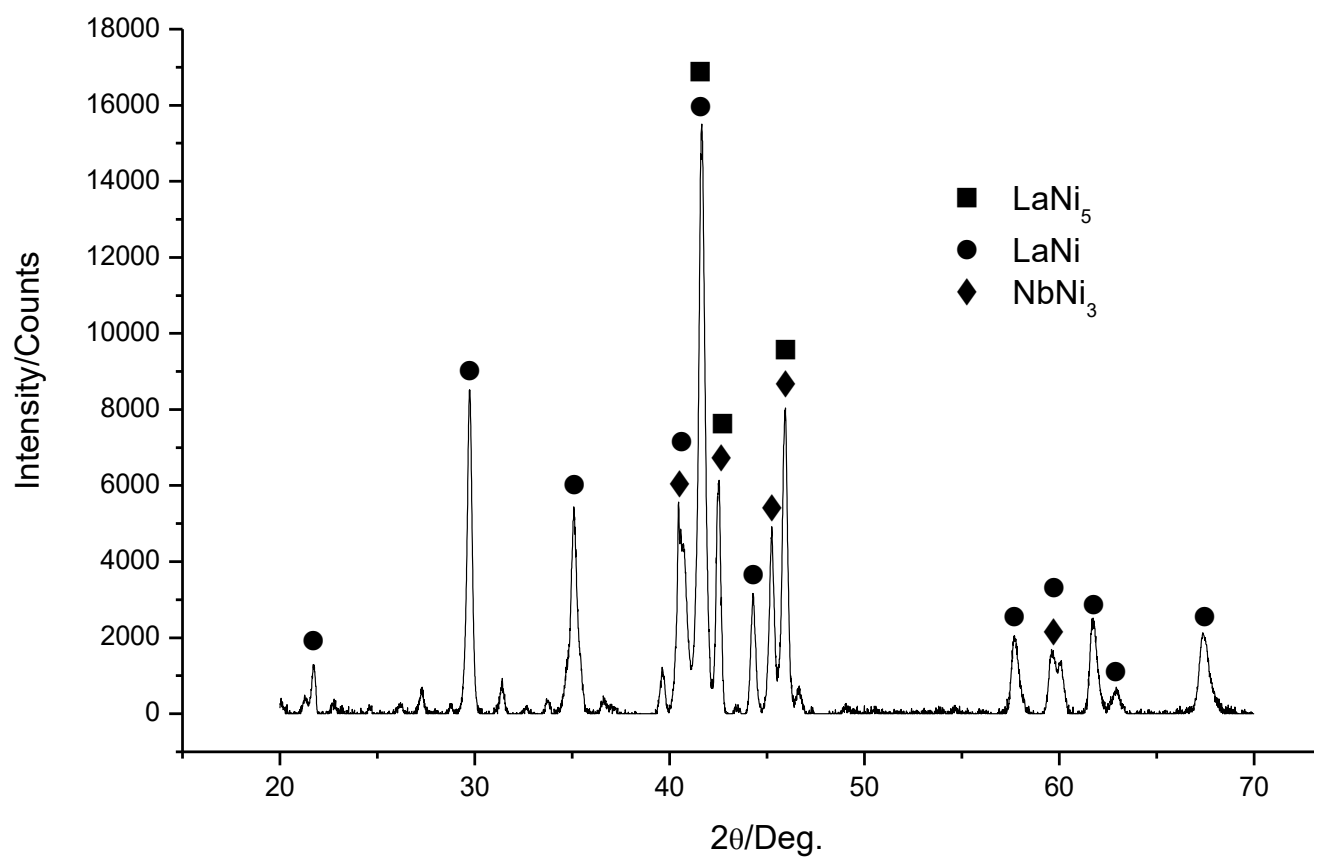

Figura 36 - Difratograma de raios $X$ - $\mathrm{La}_{0,7} \mathrm{Mg}_{0,3} \mathrm{Al}_{0,3} \mathrm{Mn}_{0,4} \mathrm{Nb}_{0,5} \mathrm{Ni}_{3,8}$ 


\subsection{4 - Microscopia Eletrônica de Varredura (MEV) $\mathrm{La}_{0,7} \mathrm{Mg}_{0,3} \mathrm{Al}_{0,3} \mathrm{Mn}_{0,4} \mathrm{Nb}$ $(0,5+\mathrm{x}) \mathrm{Ni}_{(3,8--\mathrm{x})}(\mathrm{x}=0,3 ; 0,5 ; 1,3)$}

As micrografias obtidas por MEV das ligas $\mathrm{La}_{0,7} \mathrm{Mg}_{0,3} \mathrm{Al}_{0,3} \mathrm{Mn}_{0,4} \mathrm{Nb}_{x} \mathrm{Ni}_{(3,8-x)}$ $(x=0,5 ; 0,8 ; 1,0 ; 1,8)$ estão apresentadas nas FIG. 37 - 48, onde: (a) representa a visão geral e (b) detalhada.

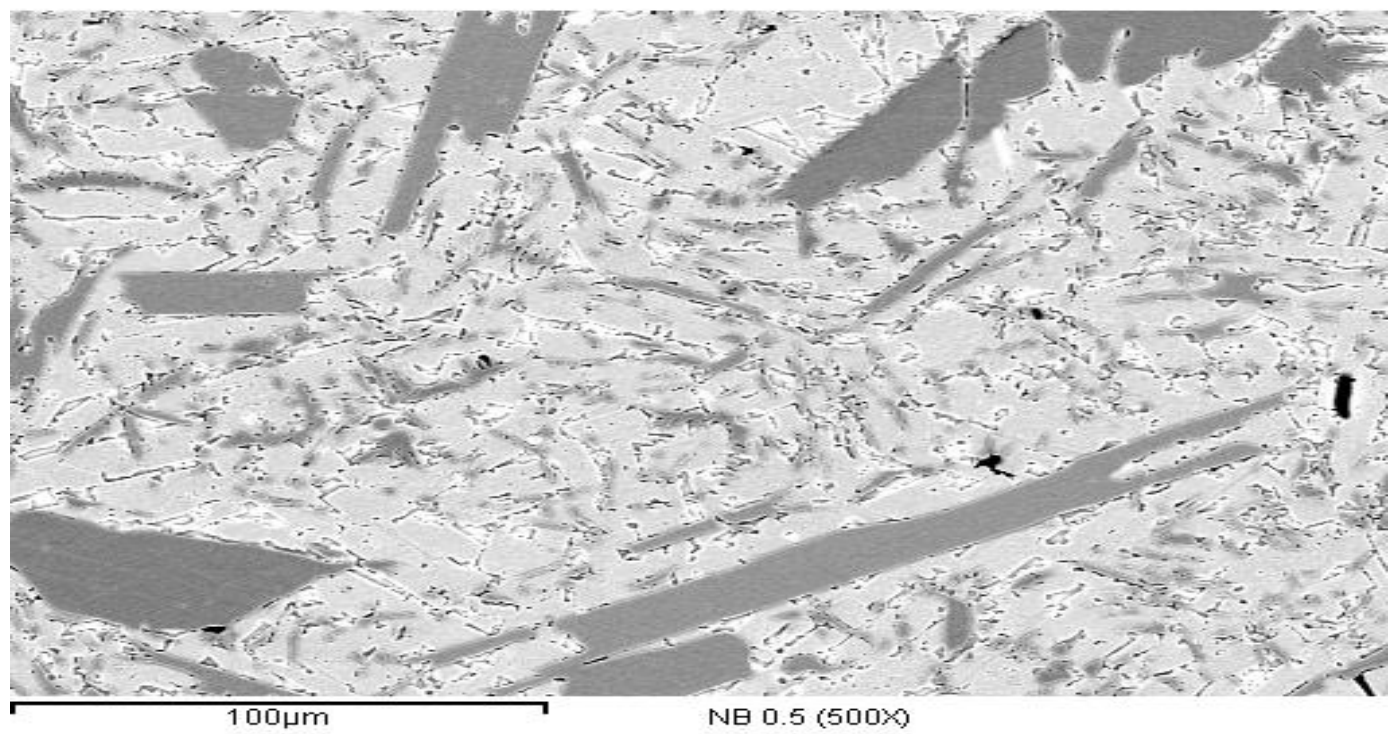

(a)

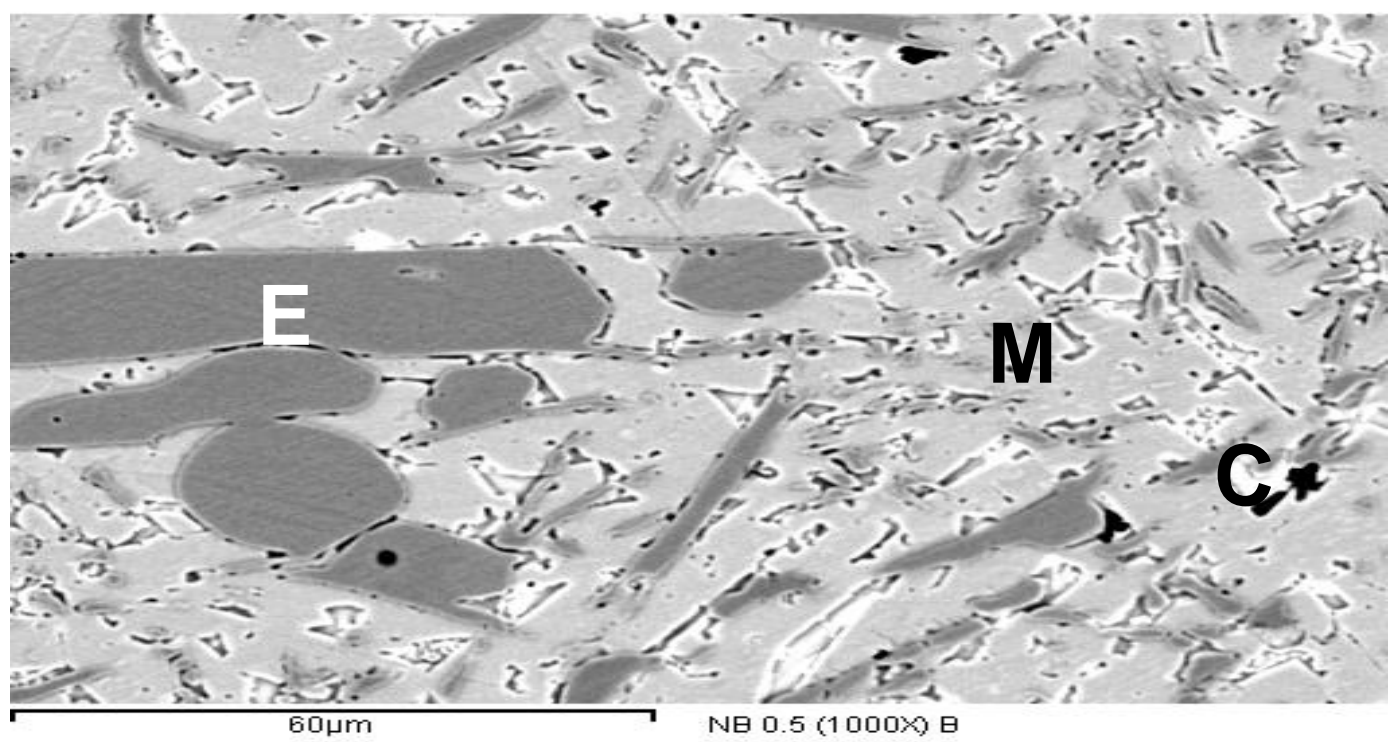

(b)

FIGURA 37 - Micrografias da liga $\mathrm{La}_{0,7} \mathrm{Mg}_{0,3} \mathrm{Al}_{0,3} \mathrm{Mn}_{0,4} \mathrm{Nb}_{0,5} \mathrm{Ni}_{3,8}$; onde: (a) visão geral (500x) e (b) detalhada (1000x). 


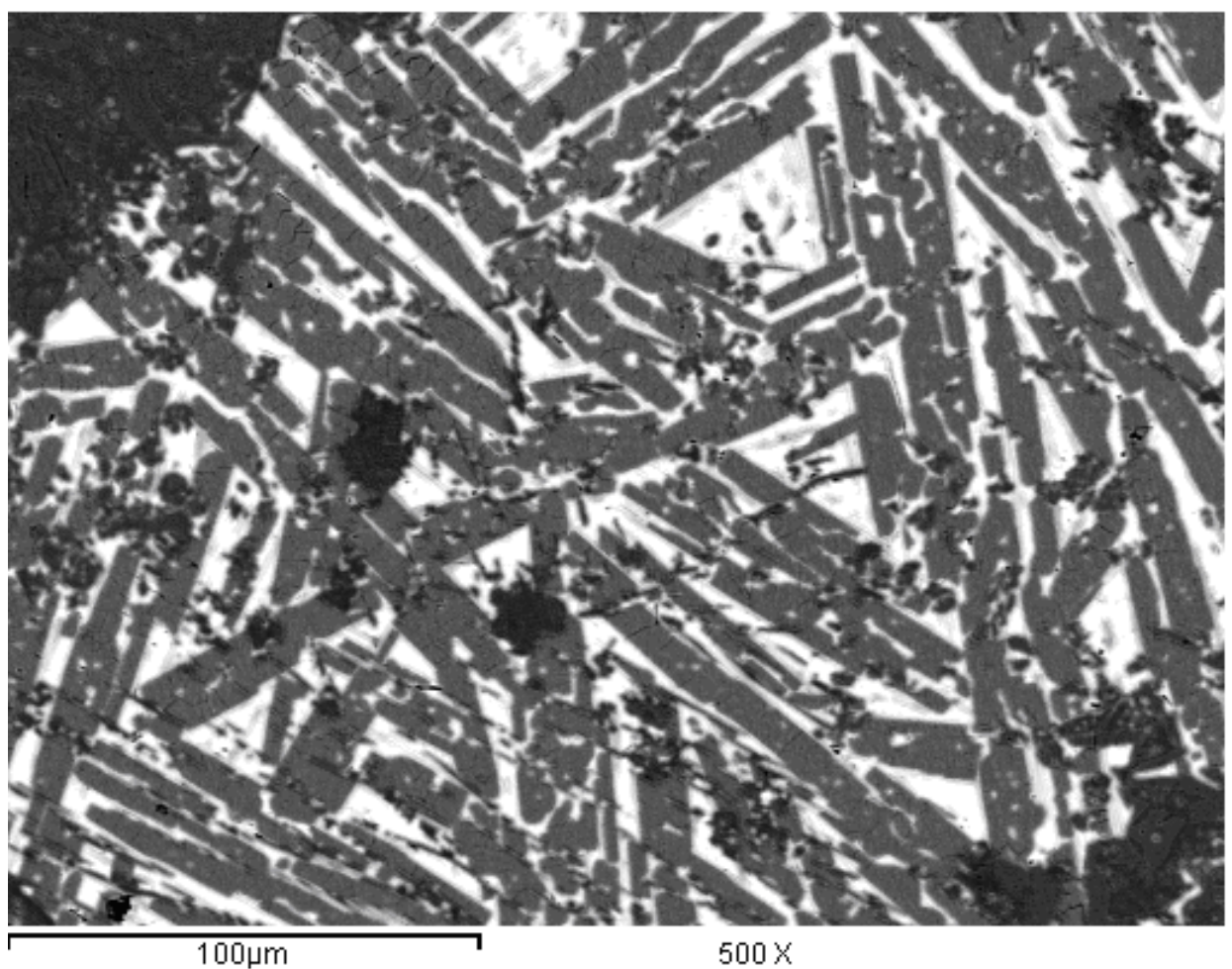

(a)

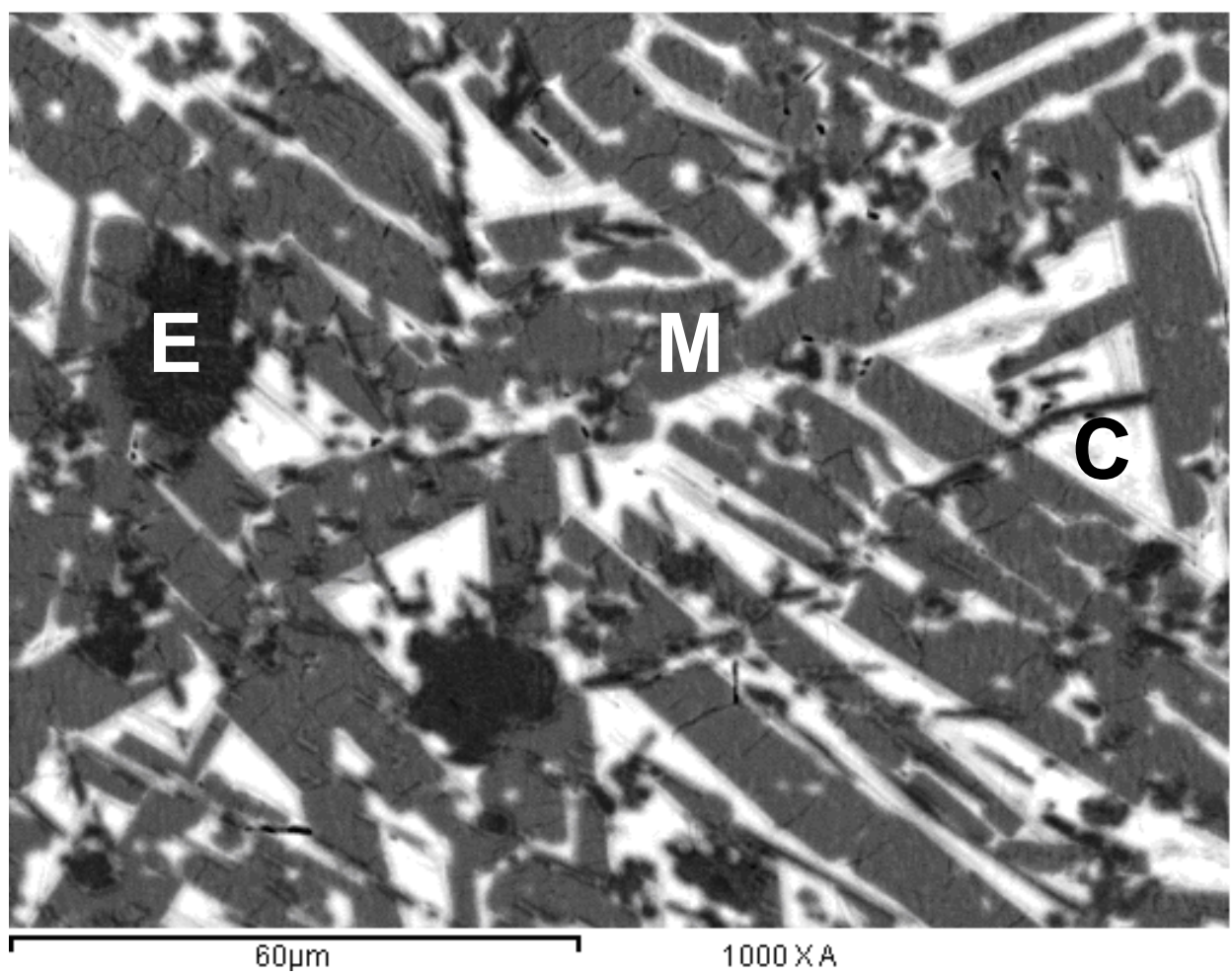

(b)

FIGURA 38 - Micrografias da liga $\mathrm{La}_{0,7} \mathrm{Mg}_{0,3} \mathrm{Al}_{0,3} \mathrm{Mn}_{0,4} \mathrm{Nb}_{0,8} \mathrm{Ni}_{3,0}$; onde: (a) visão geral (500x) e (b) detalhada (1000x). 


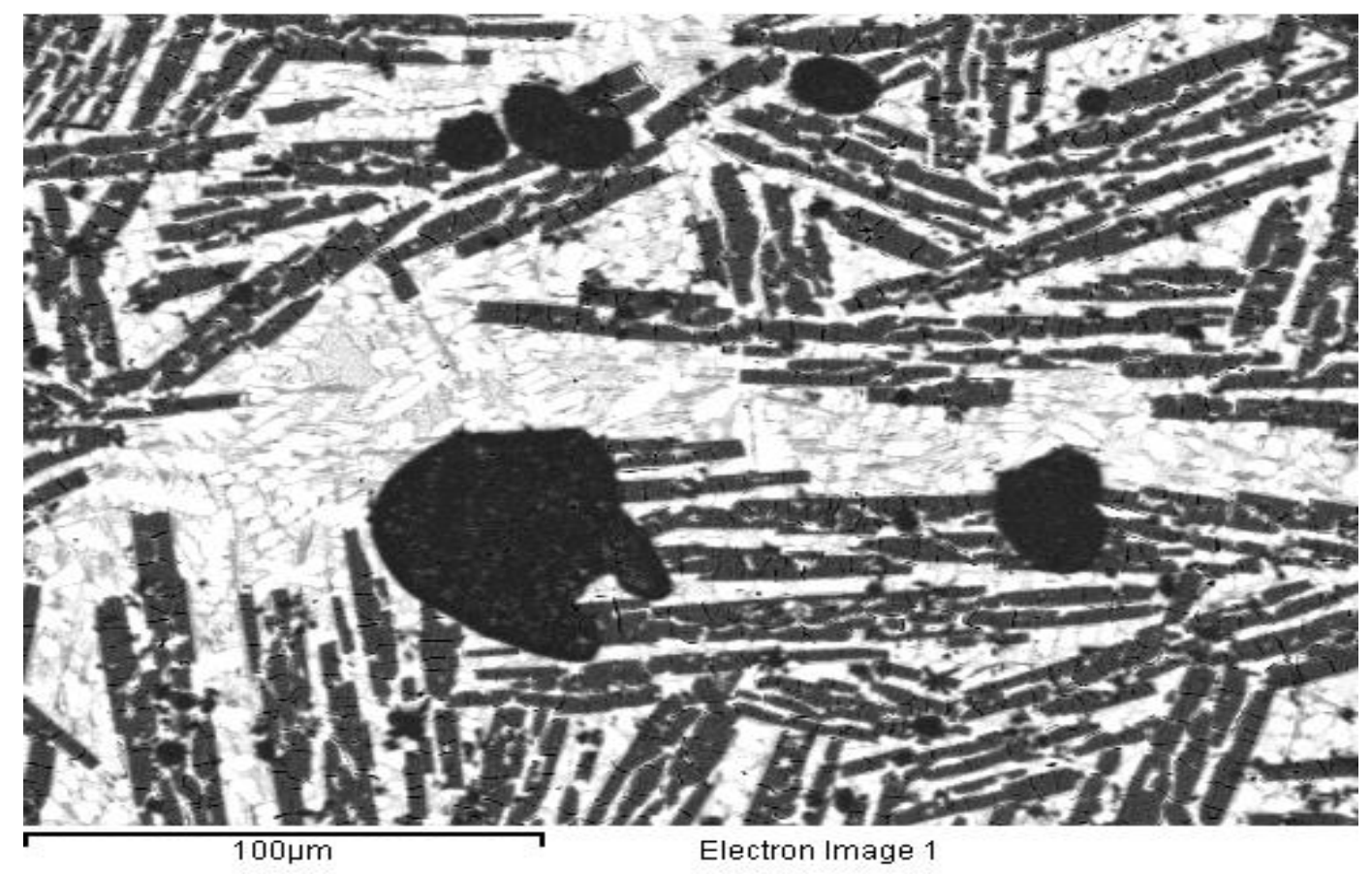

(a)

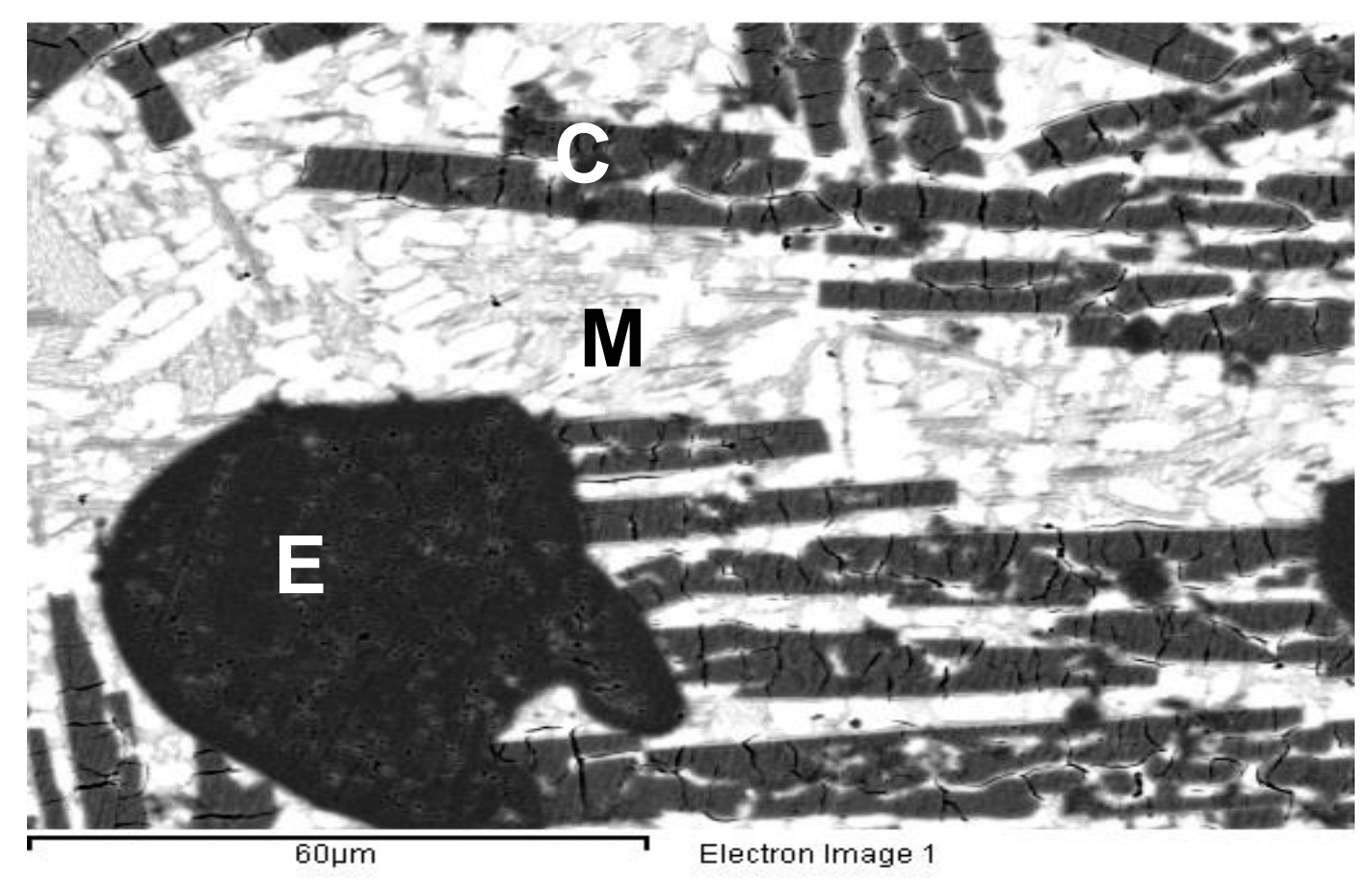

(b)

FIGURA 39 - Micrografias da liga $\mathrm{La}_{0,7} \mathrm{Mg}_{0,3} \mathrm{Al}_{0,3} \mathrm{Mn}_{0,4} \mathrm{Nb}_{1,0} \mathrm{Ni}_{2,8}$; onde: (a) visão geral (500x) e (b) detalhada (1000x). 


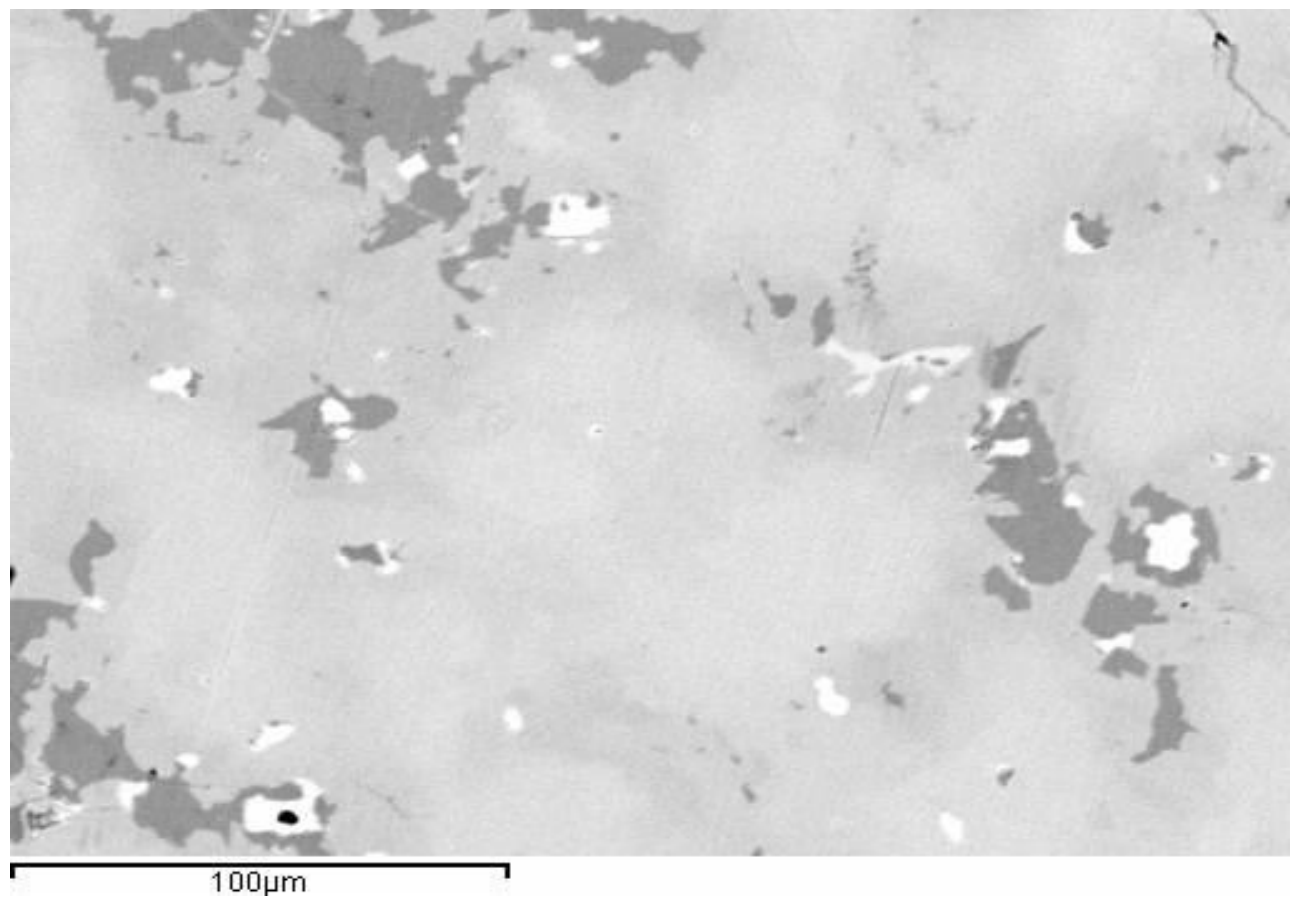

(a)

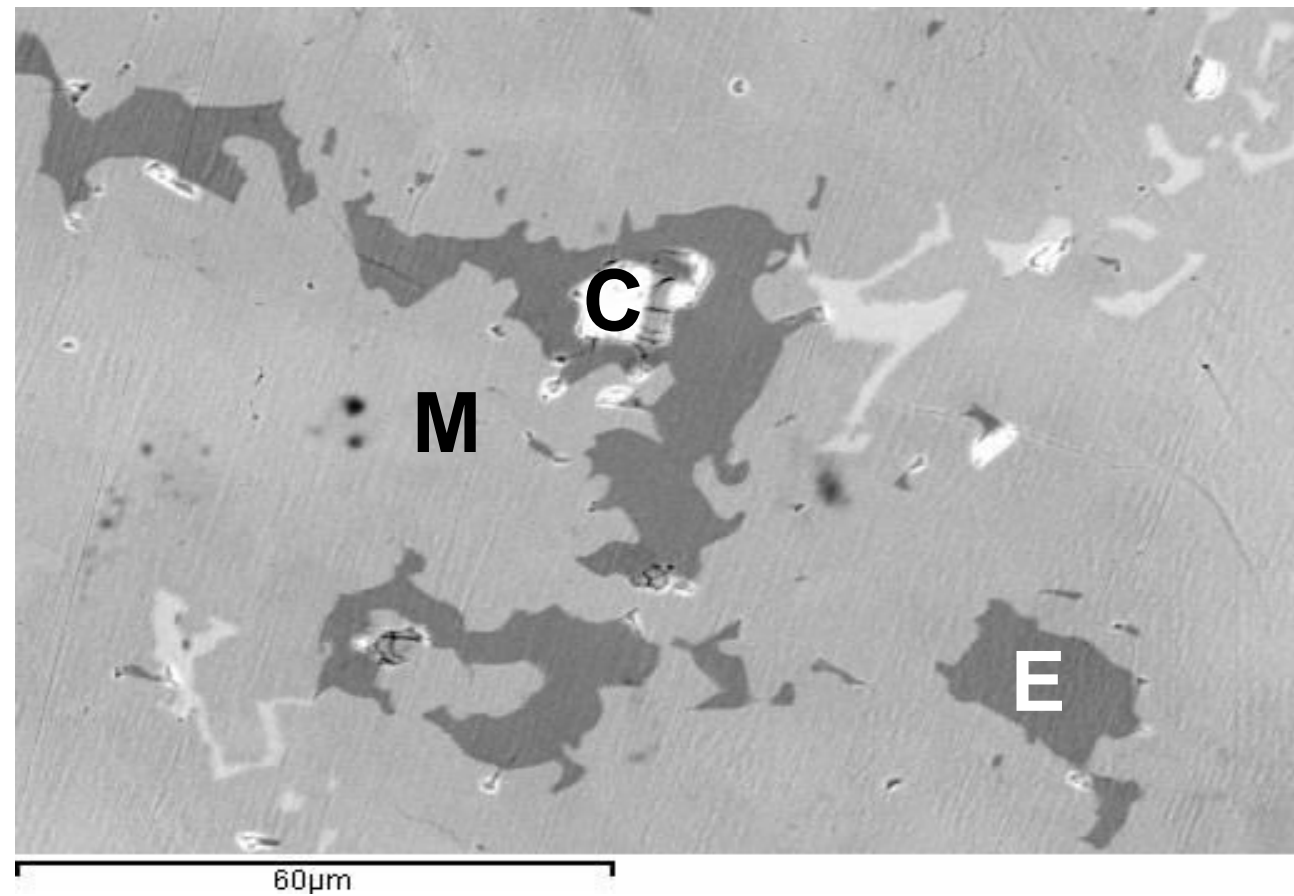

(b)

FIGURA 40 - Micrografias da liga $\mathrm{La}_{0,7} \mathrm{Mg}_{0,3} \mathrm{Al}_{0,3} \mathrm{Mn}_{0,4} \mathrm{Nb}_{1,8} \mathrm{Ni}_{2,0}$; onde: (a) visão geral (500x) e (b) detalhada (1000x). 
Foram observadas sempre três fases distintas nas micrografias: uma fase matriz (M), uma fase clara $(C)$ e uma fase escura (E), como também observado nas ligas com substituição de cobalto Com a substituição do Ni pelo $\mathrm{Nb}$ foi possível observar a mudança na composição atômica dos elementos dessas respectivas fases.

Na TAB. 15 - 17 estão apresentadas as análises por EDS das fases encontradas para as ligas $\mathrm{La}_{0,7} \mathrm{Mg}_{0,3} \mathrm{Al}_{0,3} \mathrm{Mn}_{0,4} \mathrm{Nb}_{(0,5+x)} \mathrm{Ni}_{(3,8--x)}(\mathrm{x}=0,3 ; 0,5 ; 1,3)$. Foram realizadas cinco medidas para cada fase, através destes valores foram calculadas as médias e o erro percentual.

TABELA 15 - Composição da Fase Matriz (M) encontrada nas ligas $\mathrm{La}_{0,7} \mathrm{Mg}_{0,3} \mathrm{Al}_{0,3} \mathrm{Mn}_{0,4} \mathrm{Nb}_{(0,5+x)} \mathrm{Ni}_{(3,8--x)}(\mathrm{x}=0,3 ; 0,5 ; 1,3)$.

\begin{tabular}{|c|c|c|c|c|c|c|c|c|}
\hline \multirow{2}{*}{ Liga } & \multicolumn{7}{|c|}{ Composição Analisada (at.\%) (Erro \pm 1$)$} & \multirow{2}{*}{$\begin{array}{c}\text { Razão } \\
\text { (La,Mg):(Al, } \\
\text { Mn,Nb,Ni) }\end{array}$} \\
\hline & La & $\mathbf{M g}$ & Al & Mn & Co & $\mathrm{Nb}$ & $\mathrm{Ni}$ & \\
\hline $\mathrm{Nb}_{0,5}$ & 18,05 & -- & 4,70 & 10,23 & -- & $<1$ & 66,74 & $1: 5$ \\
\hline $\mathrm{Nb}_{0,8}$ & 18,67 & -- & 4,87 & 9,34 & -- & -- & 67,12 & $1: 5$ \\
\hline $\mathrm{Nb}_{1,0}$ & 46,64 & -- & -- & -- & -- & -- & 45,80 & $1: 1$ \\
\hline $\mathrm{Nb}_{1,8}$ & -- & -- & 2,35 & 7,30 & -- & 41,85 & 48,50 & -- \\
\hline
\end{tabular}

TABELA 16 - Composição da Fase Escura (E) encontrada nas ligas $\mathrm{La}_{0,7} \mathrm{Mg}_{0,3} \mathrm{Al}_{0,3} \mathrm{Mn}_{0,4} \mathrm{Nb}_{(0,5+x)} \mathrm{Ni}_{(3,8--x)}(\mathrm{x}=0,3 ; 0,5 ; 1,3)$.

\begin{tabular}{ccccccccc}
\hline \multirow{2}{*}{ Liga } & \multicolumn{7}{c}{ Composição Analisada (at.\%) (Erro \pm 1 ) } & Razão \\
\cline { 2 - 7 } & La & $\mathbf{M g}$ & $\mathbf{A l}$ & $\mathbf{M n}$ & $\mathbf{C o}$ & $\mathbf{N b}$ & $\mathbf{N i}$ & (Nb ,Ni) \\
\hline $\mathbf{N b}_{0,5}$ & -- & -- & -- & -- & -- & 19,40 & 79,30 & $\sim 1: 3,5$ \\
$\mathbf{N b}_{0,8}$ & $<1$ & -- & -- & 8,18 & -- & 24,67 & 66,23 & $\sim 1: 3,5$ \\
$\mathbf{N b}_{1,0}$ & 1,16 & -- & 2,34 & 6,29 & -- & 27,28 & 62,93 & $\sim 1: 3,5$ \\
$\mathbf{N b}_{1,8}$ & -- & -- & 3,22 & 9,12 & -- & 31,85 & 55,82 & $\sim 1: 2$ \\
\hline
\end{tabular}


TABELA 17 - Composição da Fase Clara (C) encontrada nas ligas $\mathrm{La}_{0,7} \mathrm{Mg}_{0,3} \mathrm{Al}_{0,3} \mathrm{Mn}_{0,4} \mathrm{Nb}_{(0,5+x)} \mathrm{Ni}_{(3,8--x)}(\mathrm{x}=0,3 ; 0,5 ; 1,3)$.

\begin{tabular}{|c|c|c|c|c|c|c|c|c|}
\hline \multirow{2}{*}{ Liga } & \multicolumn{7}{|c|}{ Composição Analisada (at.\%) (Erro \pm 1$)$} & \multirow{2}{*}{$\begin{array}{c}\text { Razão } \\
(\mathrm{La}, \mathrm{Mg}):(\mathrm{Al}, \mathrm{Mn} \\
\mathrm{Nb}, \mathrm{Ni})\end{array}$} \\
\hline & La & Mg & Al & Mn & Co & $\mathrm{Nb}$ & $\mathbf{N i}$ & \\
\hline $\mathrm{Nb}_{0,5}$ & 38.1 & 8.30 & $\overline{--}$ & 2.70 & $\overline{--}$ & $\overline{--}$ & 50.80 & $1: 1$ \\
\hline $\mathrm{Nb}_{0,8}$ & 46.93 & 8.69 & -- & -- & -- & -- & 44.38 & $1: 1$ \\
\hline $\mathrm{Nb}_{1,0}$ & 52.03 & -- & -- & -- & -- & -- & 47.97 & $1: 1$ \\
\hline $\mathbf{N b}_{1,8}$ & 42.32 & 2.47 & -- & 2.58 & -- & -- & 52.63 & $1: 1$ \\
\hline
\end{tabular}

A composição da fase matriz (M), mostrada na TAB. 15, apresentou a razão de aproximadamente 1:5 para as ligas $N_{0,5}$ e $N_{0,8}$, o que provavelmente representa a fase $\mathrm{LaNi}_{5}$. Com o aumento do teor de $\mathrm{Nb}$ na liga a matriz muda para uma composição LaNi e com o teor de 1,8 at.\% de $\mathrm{Nb}$ a matriz muda para uma composição $\mathrm{NbNi}$ de razão 1:1.

Com a substituição do níquel pelo nióbio não foi possível observar visualmente o aumento da fase clara (C). As composições da fase clara (C) mostrada na TAB. 17 apresentaram a razão de aproximadamente 1:1, o que provavelmente representa a fase LaNi.

A fase $\mathrm{E}$, com alta concentração em $\mathrm{Nb}$, surge na medida em que aumenta a concentração de $\mathrm{Nb}$ nas ligas. Sua composição, mostrada na TAB. 13, apresentou a razão $\mathrm{Nb}: \mathrm{Ni}$ de aproximadamente $(1: 3,5)$, o que provavelmente representa a fase $\mathrm{NbNi}_{3}$. Com o teor de 1,8 at.\% de $\mathrm{Nb}$ e a mudança da fase matriz para uma composição $\mathrm{NbNi}$ de razão $1: 1$, a fase escura tem sua razão $\mathrm{Nb}: \mathrm{Ni}$ modificada para 1:2. 
5.1.5 - Difração de Raios - $X \operatorname{La}_{0,7} \mathrm{Mg}_{0,3} \mathrm{Al}_{0,3} \mathrm{Mn}_{0,4} \mathrm{Nb}_{(0,5+x)} \mathrm{Ni}_{(3,8-\mathrm{x})}(\mathrm{x}=0,3 ; 0,5$; 1,3)

Os dados cristalográficos são apresentados na Tabela $18 \mathrm{com}$ os valores dos parâmetros de rede e volume das fases obtidas por refinamento de todas as ligas. Os programas Crystallographica Search-Match (CSM) e PowderCell 2.3 foram usados para a determinação desses parâmetros.As Figuras 41 - 44 apresentam os difratogramas de raios $X$ das ligas $\left.\mathrm{La}_{0,7} \mathrm{Mg}_{0,3} \mathrm{Al}_{0,3} \mathrm{Mn}_{0,4} \mathrm{Nb} \quad{ }_{(0,5+x)} \mathrm{Ni}_{(3,8-} \quad-x\right) \quad(x=0,3 ; 0,5 ; 1,3)$. Quatro fases foram encontradas: LaNi $i_{5}$ e LaNi (Grupo Espacial: P6/mmm - PDF: 50-0777 , PDF: 50 -0689), $\mathrm{NbNi}$ e $\mathrm{NbNi}_{3}$ (Grupo Espacial: Pmmm - PDF: 65-589).Analisando esses dados foi observar uma diminuição do volume das fases $\mathrm{LaNi}_{5}$ e e um aumento de volume da fase $\mathrm{NbNi}_{3}$ confirmado os dados coletados por MEV e EDS.Além disso para o teor máximo de nióbio a matriz muda da composição $\mathrm{LaNi}_{5}$ para uma composição $\mathrm{NbNi}$.

Tabela 18- Dados cristalográficos das ligas $\mathrm{La}_{0,7} \mathrm{Mg}_{0,3} \mathrm{Al}_{0,3} \mathrm{Mn}_{0,4} \mathrm{Co}_{(0,5-x)} \mathrm{Nb}_{x} \mathrm{Ni}_{3,8}$

$$
(x=0 \text { a } 0,5) \text {. }
$$

\begin{tabular}{|c|c|c|c|c|}
\hline \multirow[t]{2}{*}{ Ligas } & \multirow[t]{2}{*}{ Fases } & \multicolumn{2}{|c|}{ Parâmetros (Å) } & \multirow{2}{*}{$\begin{array}{c}\text { Volume } \\
(\%)\end{array}$} \\
\hline & & $a$ & c & \\
\hline \multirow[t]{3}{*}{$\mathrm{Nb} 0,5$} & $\mathrm{LaNi}_{5}$ & 5.076 & 4.047 & 57,90 \\
\hline & LaNi & 3.831 & 4.595 & 29,87 \\
\hline & $\mathrm{NbNi}_{3}$ & 5.104 & 4.553 & 12,23 \\
\hline \multirow{3}{*}{$\mathrm{Nb} 0,8$} & $\mathrm{LaNi}_{5}$ & 5.074 & 4.049 & 53,88 \\
\hline & LaNi & 3.828 & 4.556 & 36,02 \\
\hline & $\mathrm{NbNi}_{3}$ & 5.097 & 4.448 & 18,26 \\
\hline \multirow{2}{*}{ Nb 1,0} & LaNi & 3.837 & 4.552 & 74,11 \\
\hline & $\mathrm{NbNi}_{3}$ & 5.083 & 4.541 & 25,89 \\
\hline \multirow[t]{3}{*}{ Nb 1,8} & $\mathrm{NbNi}$ & 5.024 & 4.033 & 51,71 \\
\hline & LaNi & 3.832 & 4.559 & 23,76 \\
\hline & $\mathrm{NbNi}_{3}$ & 5.088 & 4.547 & 24,53 \\
\hline
\end{tabular}




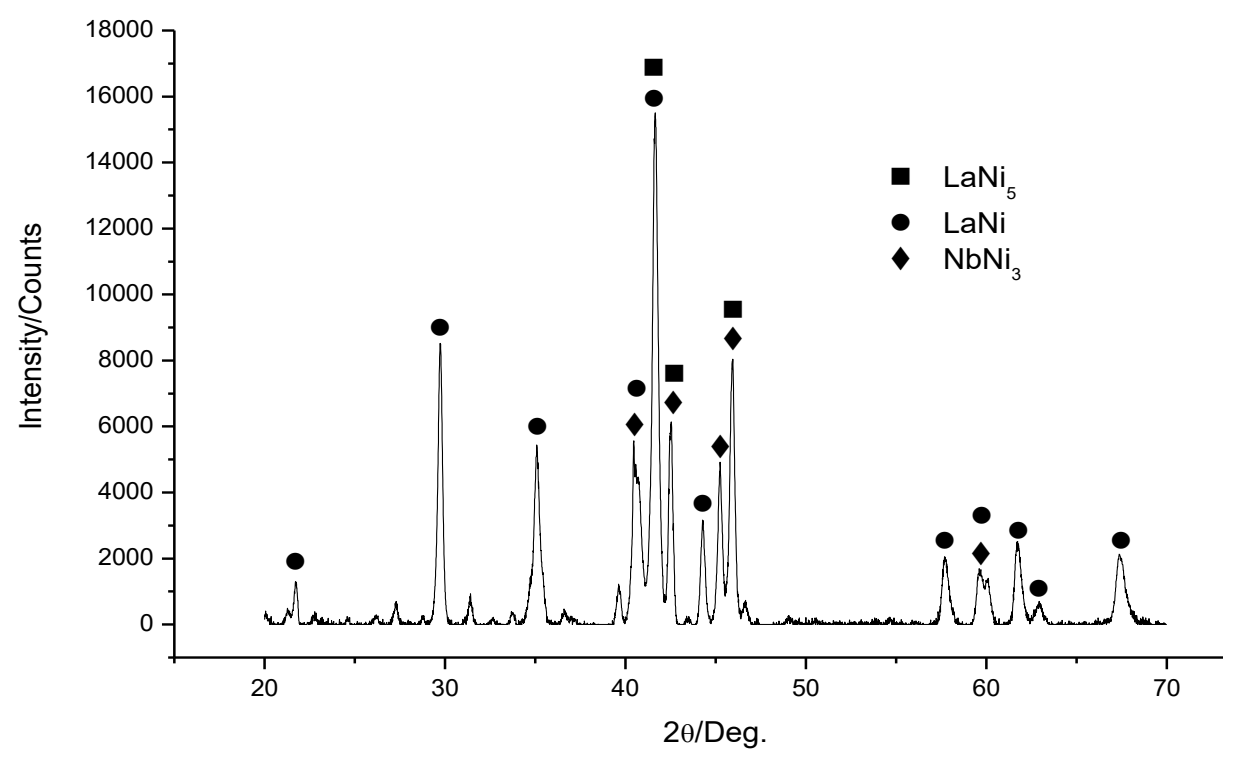

Figura 41 - Difratograma de raios $X-\mathrm{La}_{0,7} \mathrm{Mg}_{0,3} \mathrm{Al}_{0,3} \mathrm{Mn}_{0,4} \mathrm{Nb}_{0,5} \mathrm{Ni}_{3,8}$

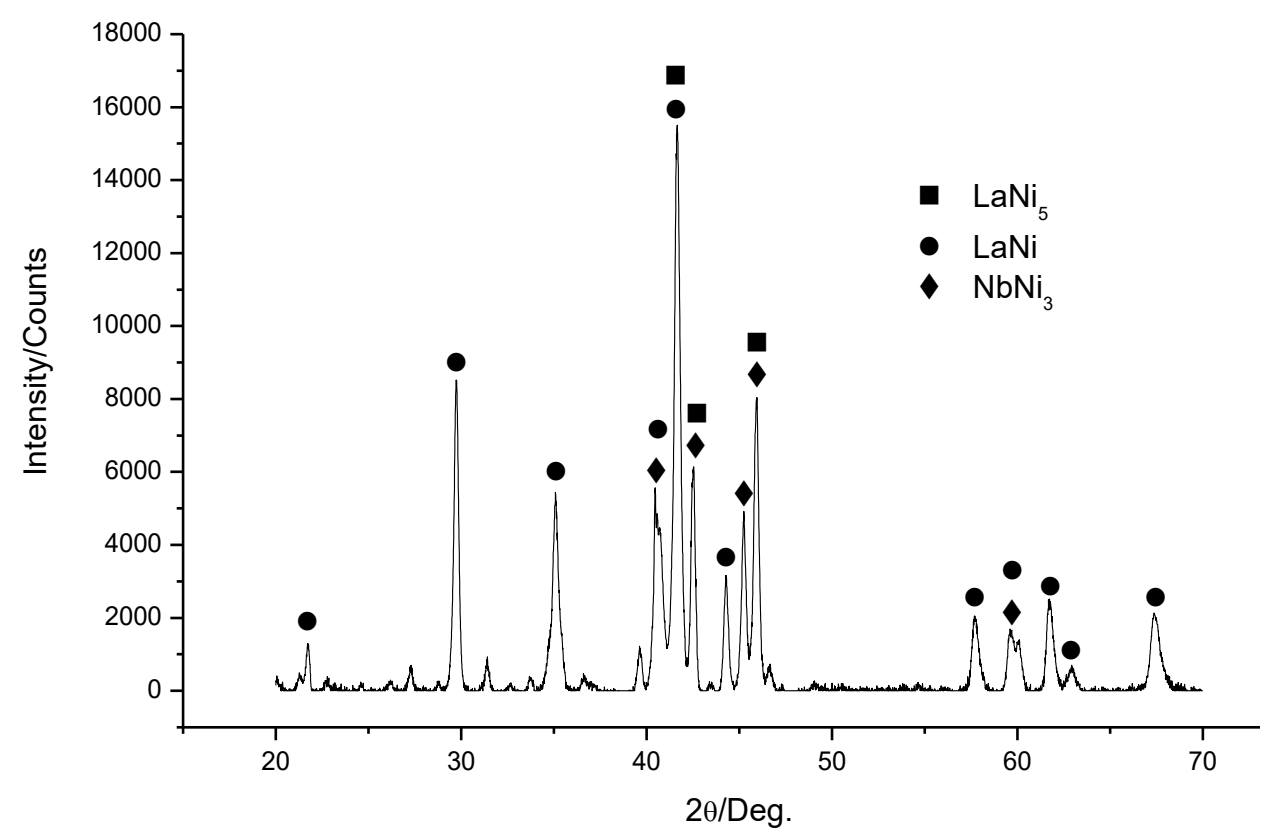

Figura 42 - Difratograma de raios $X-\mathrm{La}_{0,7} \mathrm{Mg}_{0,3} \mathrm{Al}_{0,3} \mathrm{Mn}_{0,4} \mathrm{Nb}_{0,8} \mathrm{Ni}_{3,0}$. 


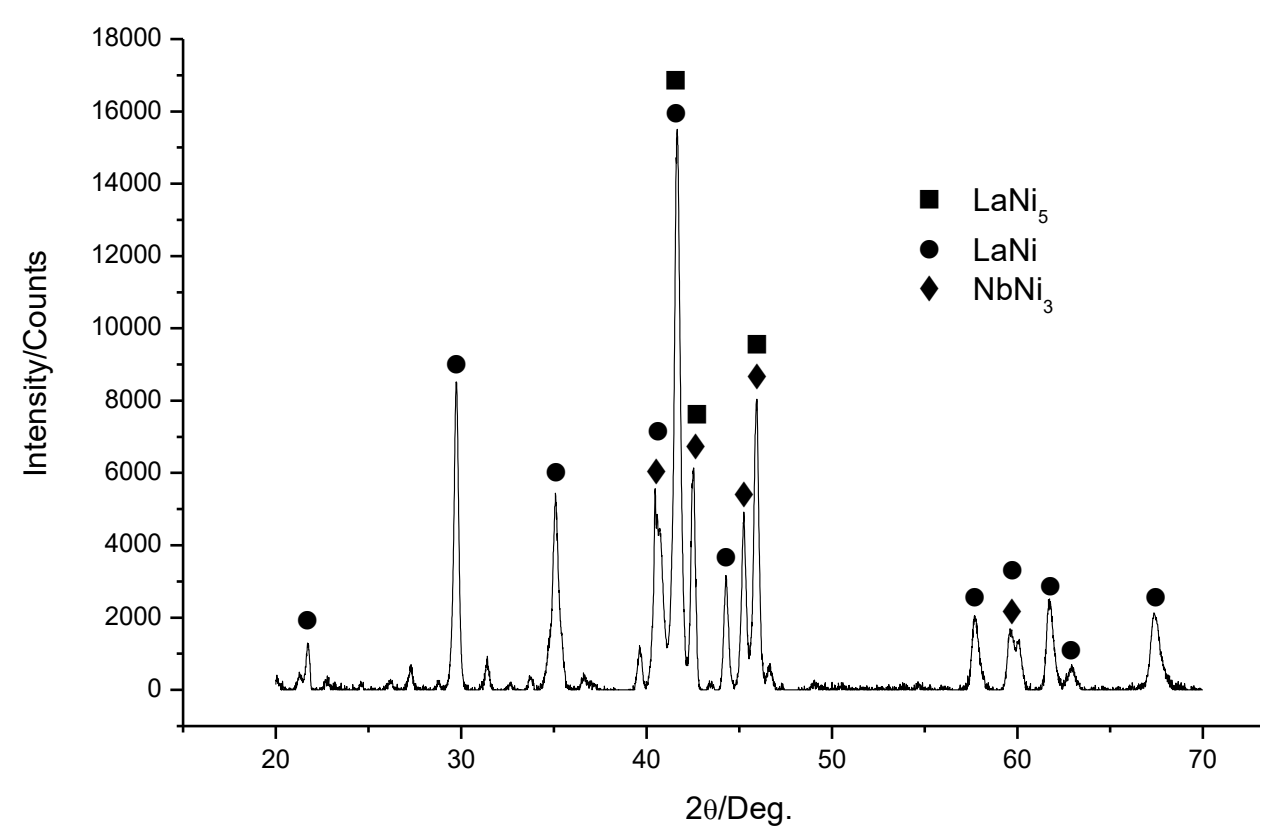

Figura 41 - Difratograma de raios $X$ - $\operatorname{La}_{0,7} \mathrm{Mg}_{0,3} \mathrm{Al}_{0,3} \mathrm{Mn}_{0,4} \mathrm{Nb}_{1,0} \mathrm{Ni}_{2,8}$

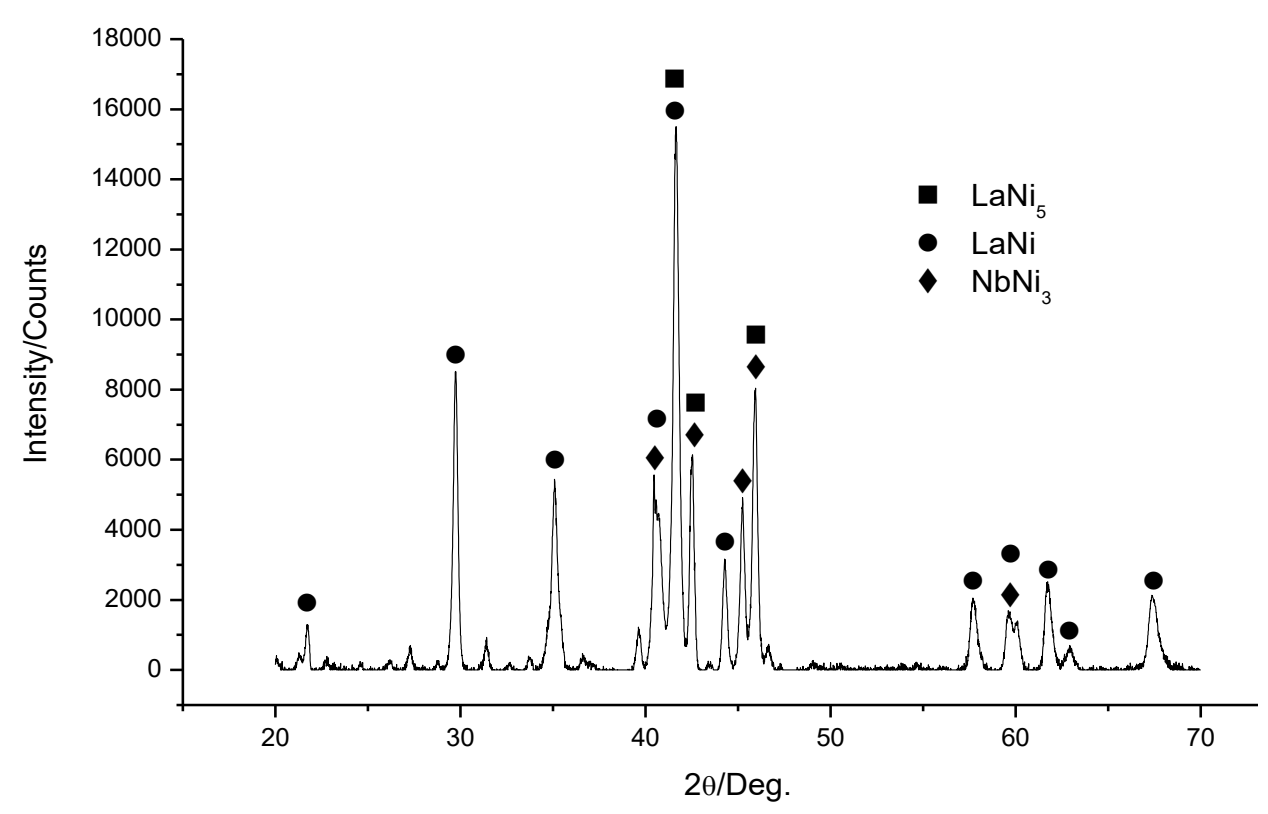

Figura 42 - Difratograma de raios $X$ - $\mathrm{La}_{0,7} \mathrm{Mg}_{0,3} \mathrm{Al}_{0,3} \mathrm{Mn}_{0,4} \mathrm{Nb}_{1,8} \mathrm{Ni}_{2,0}$ 


\subsection{Hidrogenação das ligas}

\subsubsection{Hidrogenação da série $\mathrm{La}_{0,7} \mathrm{Mg}_{0,3} \mathrm{Al}_{0,3} \mathrm{Mn}_{0,4} \mathrm{Co}_{(0,5-\mathrm{x})} \mathrm{Nb}_{\mathrm{x}} \mathrm{Ni}_{3,8}(\mathrm{x}=0$ a 0,5$)$}

Na FIG. 45 apresenta-se a curva da variação na absorção de hidrogênio em função do tempo das ligas $\mathrm{La}_{0,7} \mathrm{Mg}_{0,3} \mathrm{Al}_{0,3} \mathrm{Mn}_{0,4} \mathrm{Co}_{(0,5-\mathrm{x})} \mathrm{Nb}_{x} \mathrm{Ni}_{3,8}(\mathrm{x}=0$ a 0,5$)$ a uma pressão inicial de 0,2 $\mathrm{MPa}$ (2 bar) e a temperatura ambiente. Os resultados mostraram que todas as ligas apresentaram hidrogenação espontânea. A absorção de hidrogênio aumentou com a substituição parcial do nióbio pelo cobalto mais se manteve semelhante quanto à substituição foi completa.Todas as ligas foram pulverizadas nessa pressão.

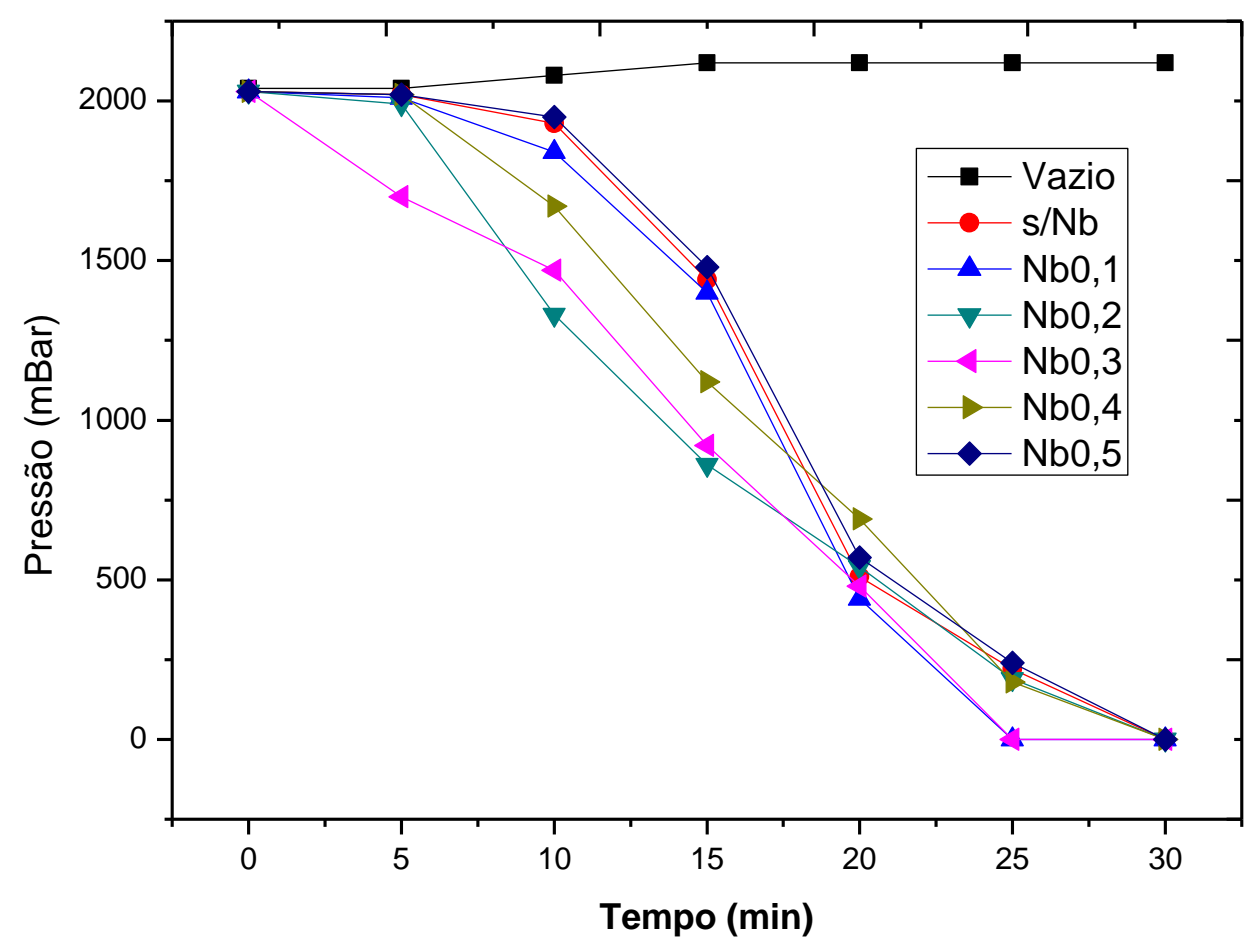

FIGURA 45 - Curvas da absorção de hidrogênio em função do tempo com pressão inicial de $0,2 \mathrm{MPa}$ (2 bar) das ligas $\mathrm{La}_{0,7} \mathrm{Mg}_{0,3} \mathrm{Al}_{0,3} \mathrm{Mn}_{0,4} \mathrm{Co}_{(0,5-x)} \mathrm{Nb}_{x} \mathrm{Ni}_{3,8}$ $(x=0$ a 0,5$)$. 
Com o aumento da pressão de hidrogênio para $1 \mathrm{MPa}(10 \mathrm{Bar})$ e a temperatura ambiente é possível observar alta absorção de hidrogenação espontânea para todas as ligas e o mesmo comportamento com relação ao a pressão de 0,2 $\mathrm{MPa}$ (2 bar). As curvas de absorção estão apresentadas na FIG.44. Com altos teores de nióbio as ligas não apresentaram absorção de $\mathrm{H}_{2}$ igual a liga sem nióbio. Com baixos teores a absorção foi maior e mais rápida.

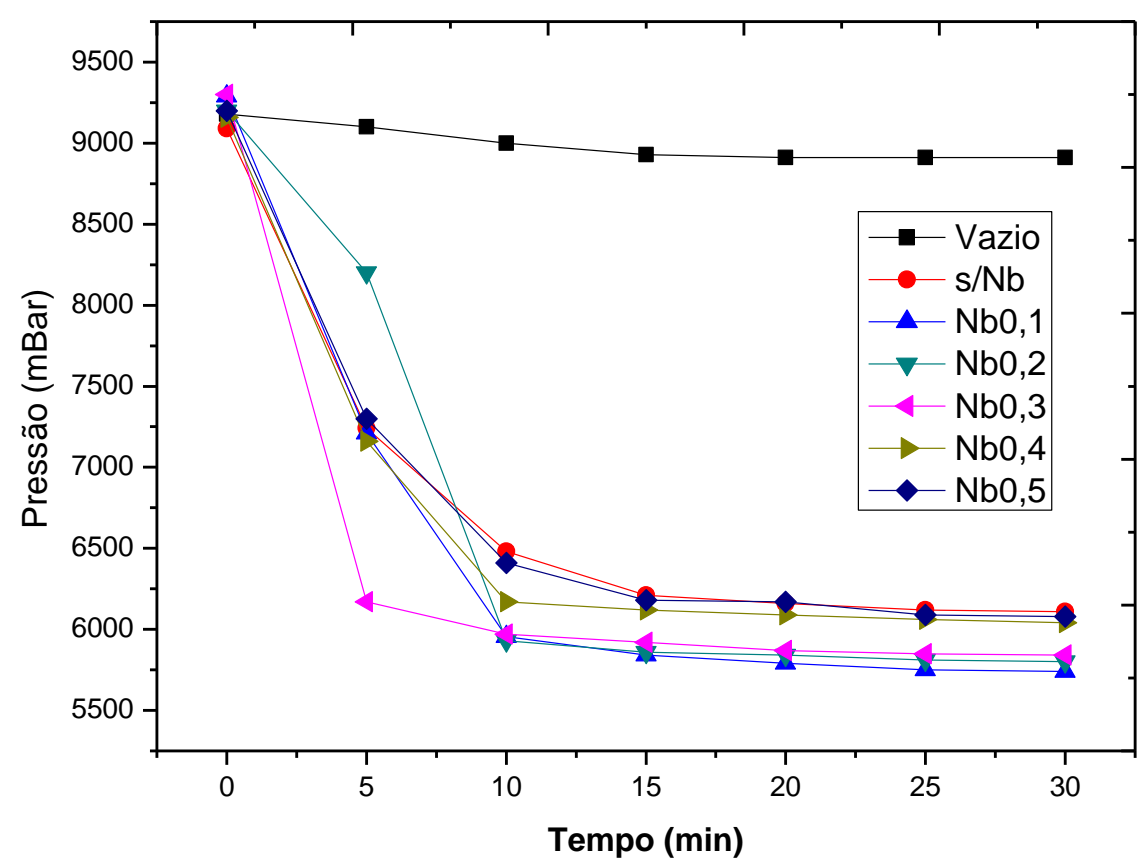

FIGURA 46 - Curvas da absorção de hidrogênio em função do tempo com pressão inicial de $1 \mathrm{MPa}$ (2 Bar) das ligas $\mathrm{La}_{0,7} \mathrm{Mg}_{0,3} \mathrm{Al}_{0,3} \mathrm{Mn}_{0,4} \mathrm{Co}_{(0,5-x)} \mathrm{Nb}_{x} \mathrm{Ni}_{3,8}$ $(x=0$ a 0,5$)$.

$\mathrm{Na}$ TAB. 19 apresentam-se todos os valores encontrados das hidrogenações com pressão inicial de $0,9 \mathrm{MPa}$ para as ligas $\mathrm{La}_{0,7} \mathrm{Mg}_{0,3} \mathrm{Al}_{0,3} \mathrm{Mn}_{0,4} \mathrm{Co}_{(0,5-x)} \mathrm{Nb}_{x} \mathrm{Ni}_{3,8}$ (x= 0 a 0,5$)$. 
Tabela 19 - Hidrogenações das ligas $\mathrm{La}_{0,7} \mathrm{Mg}_{0,3} \mathrm{Al}_{0,3} \mathrm{Mn}_{0,4} \mathrm{Co}_{(0,5-x)} \mathrm{Nb}_{x} \mathrm{Ni}_{3,8}(\mathrm{x}=0 \mathrm{a}$ 0,5) com pressão inicial de 0,9 MPa (9 bar).

\begin{tabular}{ccccc}
\hline Liga & $\begin{array}{c}\text { Pressão Inicial e Final } \\
(\sim 9000 \text { mBar })\end{array}$ & $\begin{array}{c}\Delta \mathbf{P} \\
(\mathbf{m B a r})\end{array}$ & $\begin{array}{c}\text { Tempo } \\
(\mathbf{m i n})\end{array}$ & Pulverização \\
\hline $\mathbf{S} / \mathbf{N b}$ & $9090-6110$ & 2980 & 15 & Sim \\
\hline $\mathbf{N b}_{0,1}$ & $9290-5740$ & 3550 & 10 & Sim \\
$\mathbf{N b}_{0,2}$ & $9200-5800$ & 3400 & 10 & Sim \\
$\mathbf{N b}_{0,3}$ & $9300-5840$ & 3460 & 5 & Sim \\
$\mathbf{N b}_{0,4}$ & $9160-6040$ & 3120 & 10 & Sim \\
$\mathbf{N b}_{0,5}$ & $9200-6080$ & 3120 & 15 & Sim \\
\hline
\end{tabular}

\subsubsection{Hidrogenação da série $\mathrm{La}_{0,7} \mathrm{Mg}_{0,3} \mathrm{Al}_{0,3} \mathrm{Mn}_{0,4} \mathrm{Nb}_{(0,5+x)} \mathrm{Ni}_{(3,8--x)}(x=0,3 ; 0,5$;} $1,3)$.

Na FIG. 47 (a) apresenta-se a curva da variação na absorção de hidrogênio em função do tempo das ligas $\mathrm{La}_{0,7} \mathrm{Mg}_{0,3} \mathrm{Al}_{0,3} \mathrm{Mn}_{0,4} \mathrm{Nb}_{(0,5+x)} \mathrm{Ni}_{(3,8--\mathrm{x})}(\mathrm{x}=$ 0,3;0,5;1,3) a uma pressão inicial de 0,2 MPa (2 bar) e a temperatura ambiente. Os resultados mostraram que todas as ligas apresentaram hidrogenação espontânea. A absorção de hidrogênio diminuiu com a substituição parcial do nióbio pelo níquel. A liga com teor de $\mathrm{Nb} 1,8 \%$ at. foi pulverizada parcialmente.

Com o aumento da pressão de hidrogênio para 0,9 MPa (9 Bar) e a temperatura ambiente é possível observar uma diminuição absorção de hidrogênio com o aumento do teor de $\mathrm{Nb}$. As curvas de absorção para a pressão de 0,9 MPa (9 Bar) estão apresentadas na FIG.47 (b). Com essa pressão todas as ligas foram pulverizadas. 


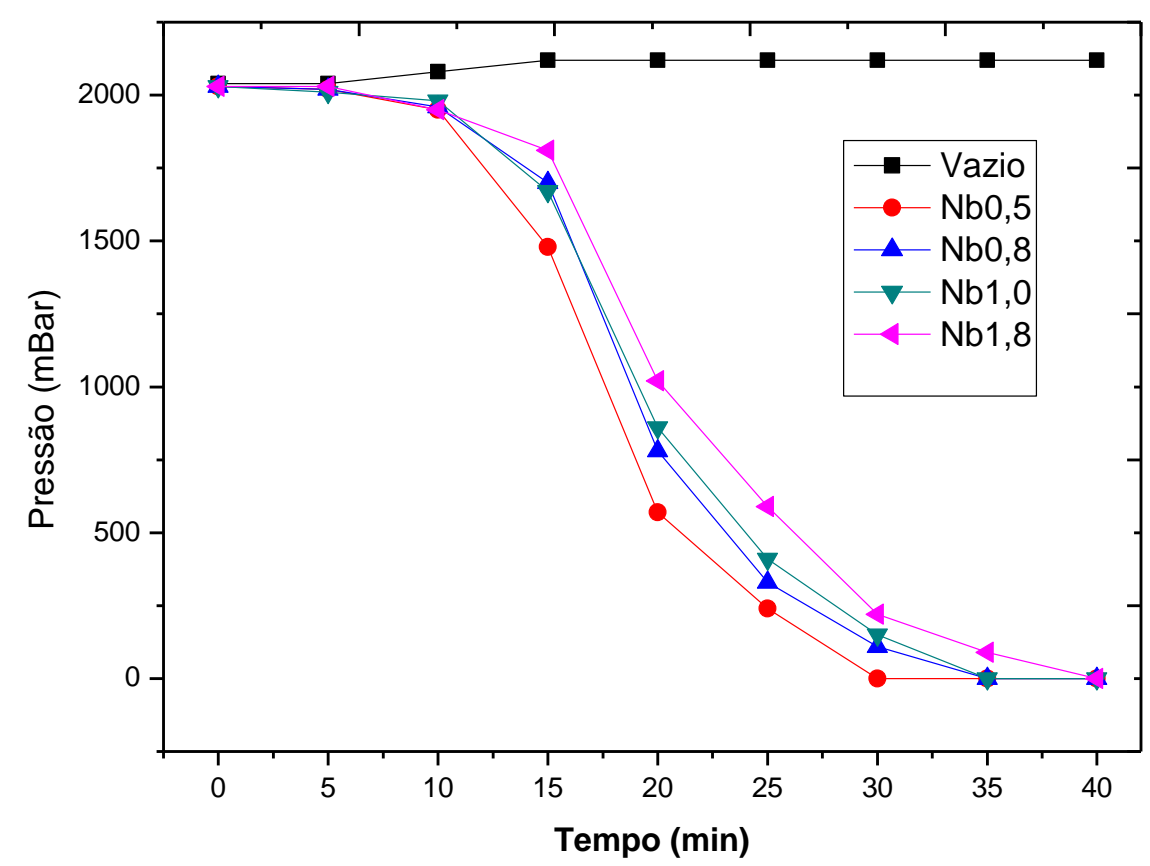

(a)

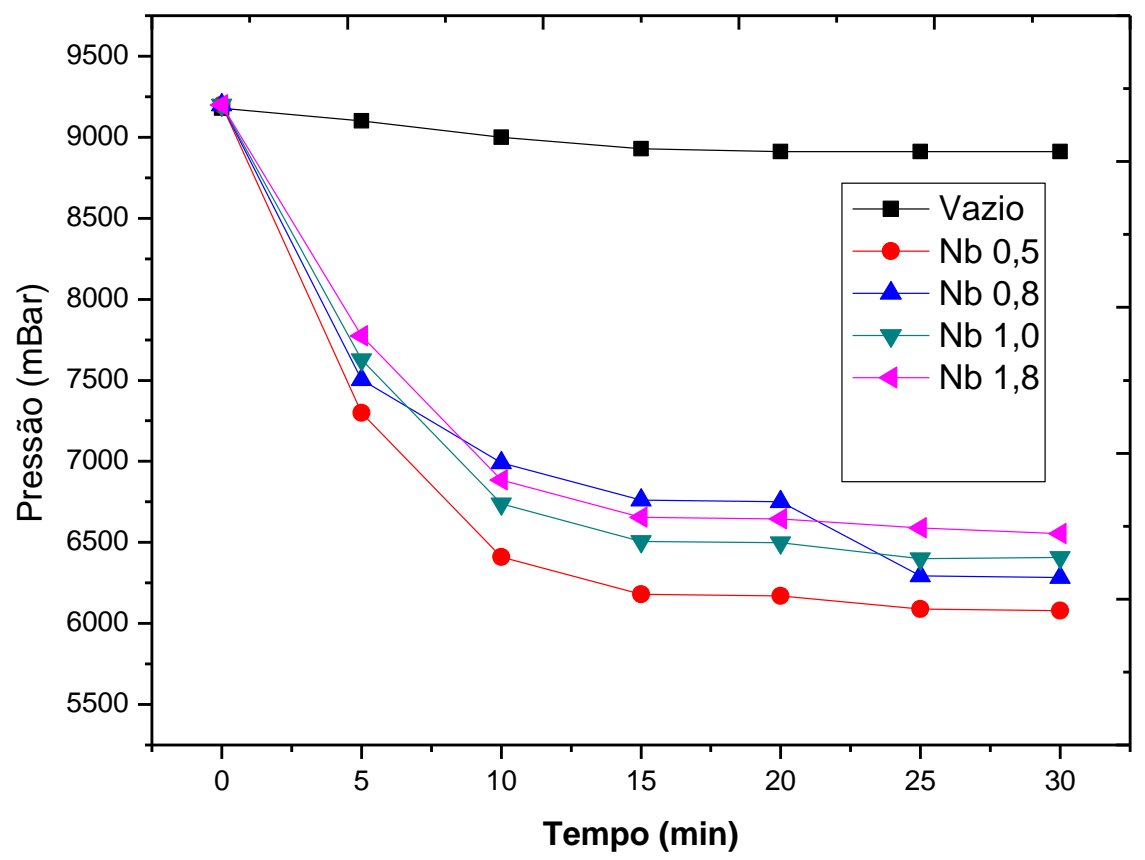

(b)

FIGURA 47 - Curvas da absorção de hidrogênio em função do tempo das ligas $\mathrm{La}_{0,7} \mathrm{Mg}_{0,3} \mathrm{Al}_{0,3} \mathrm{Mn}_{0,4} \mathrm{Nb}_{(0,5+\times)} \mathrm{Ni}_{(3,8-\mathrm{x})}(\mathrm{x}=$ 0,3;0,5;1,3); (a) pressão 0,2 MPa (2 bar) (b) $0,9 \mathrm{MPa}$ (9 Bar). 
$\mathrm{Na}$ TAB. 20 apresentam-se todos os valores encontrados das hidrogenações com pressão inicial de $0,9 \mathrm{MPa}$ para as ligas $\mathrm{La}_{0,7} \mathrm{Mg}_{0,3} \mathrm{Al}_{0,3} \mathrm{Mn}_{0,4} \mathrm{Nb}_{(0,5+x)} \mathrm{Ni}_{(3,8-\mathrm{x})}(\mathrm{x}=0,3 ; 0,5 ; 1,3)$.

Tabela 20 - Hidrogenações das ligas $\mathrm{La}_{0,7} \mathrm{Mg}_{0,3} \mathrm{Al}_{0,3} \mathrm{Mn}_{0,4} \mathrm{Nb}_{(0,5+x)} \mathrm{Ni}_{(3,8-x)}(\mathrm{x}=$ $0,3 ; 0,5 ; 1,3)$ com pressão inicial de $0,9 \mathrm{MPa}$ (9 bar).

\begin{tabular}{ccccc}
\hline Liga & $\begin{array}{c}\text { Pressão Inicial e Final } \\
(\sim 9000 \text { mBar })\end{array}$ & $\begin{array}{c}\Delta \mathbf{P} \\
(\mathbf{m B a r})\end{array}$ & $\begin{array}{c}\text { Tempo } \\
(\mathbf{m i n})\end{array}$ & Pulverização \\
\hline $\mathbf{N b}_{0,5}$ & $9200-6080$ & 3120 & 15 & sim \\
\hline $\mathbf{N b}_{0,8}$ & $9200-6284$ & 2916 & 25 & sim \\
\hline $\mathbf{N b}_{1,0}$ & $9200-6407$ & 2793 & 25 & sim \\
\hline $\mathbf{N b}_{1,8}$ & $9200-6553$ & 2647 & 25 & sim \\
\hline
\end{tabular}




\section{3 - Caracterização Eletroquímica}

5.3.1 Capacidade de Descarga - $\mathrm{La}_{0,7} \mathrm{Mg}_{0,3} \mathrm{Al}_{0,3} \mathrm{Mn}_{0,4} \mathrm{Co}_{(0,5-\mathrm{x})} \mathrm{Nb}_{\mathrm{x}} \mathrm{Ni}_{3,8}(\mathrm{x}=\mathbf{0}$ a 0,5)

Na FIG. 48 estão apresentados os valores de capacidade de descarga em função do número de ciclos iniciais (15 ciclos) das baterias de Ni-HM fabricadas com as ligas $\mathrm{La}_{0,7} \mathrm{Mg}_{0,3} \mathrm{Al}_{0,3} \mathrm{Mn}_{0,4} \mathrm{Co}_{(0,5-x)} \mathrm{Nb}_{x} \mathrm{Ni}_{3,8}(\mathrm{x}=0$ a 0,5$)$.

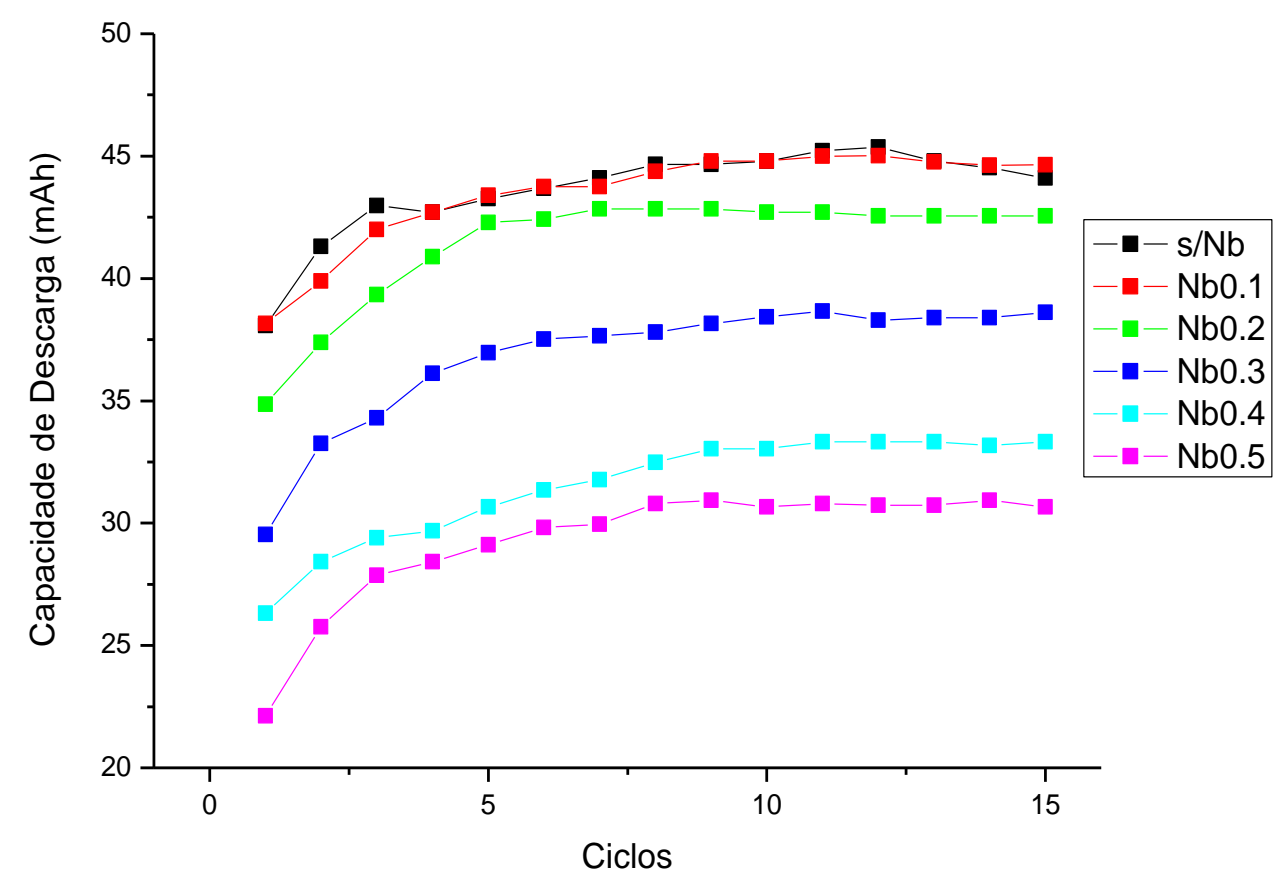

FIGURA 48 - Capacidade de descarga dos 15 ciclos iniciais das baterias fabricadas com as ligas $\mathrm{La}_{0,7} \mathrm{Mg}_{0,3} \mathrm{Al}_{0,3} \mathrm{Mn}_{0,4} \mathrm{Co}_{(0,5-\mathrm{x})} \mathrm{Nb}_{x} \mathrm{Ni}_{3,8}(\mathrm{x}=0$ a 0,5$)$.

$\mathrm{Na}$ FIG. 49 (a) e (b) estão apresentados os valores obtidos da capacidade de descarga máxima em relação ao aumento da concentração de nióbio nas ligas. Onde (a) mostra capacidade de descarga em mAh e (b) em $\mathrm{mAh} / \mathrm{g}$, foram calculados através da quantidade de material ativo no eletrodo negativo $(0,140 \mathrm{~g})$. 


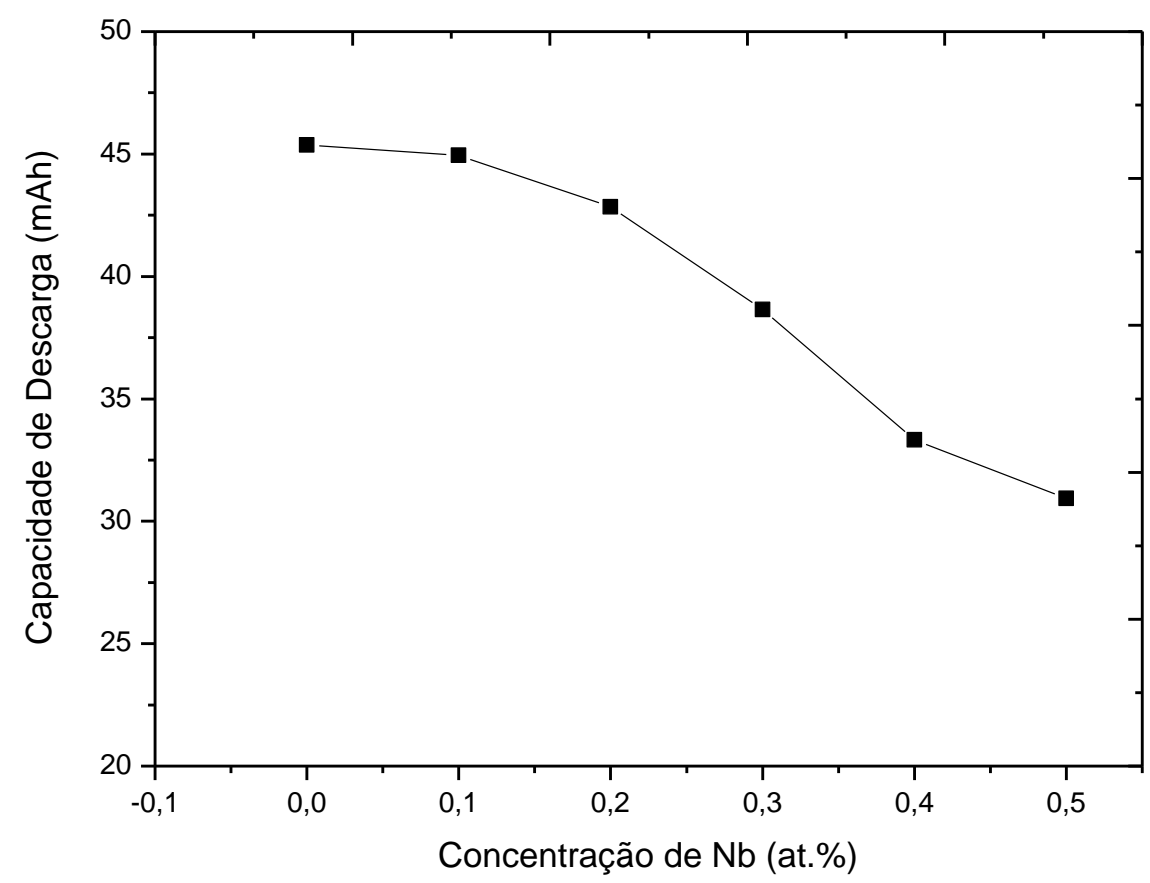

(a)

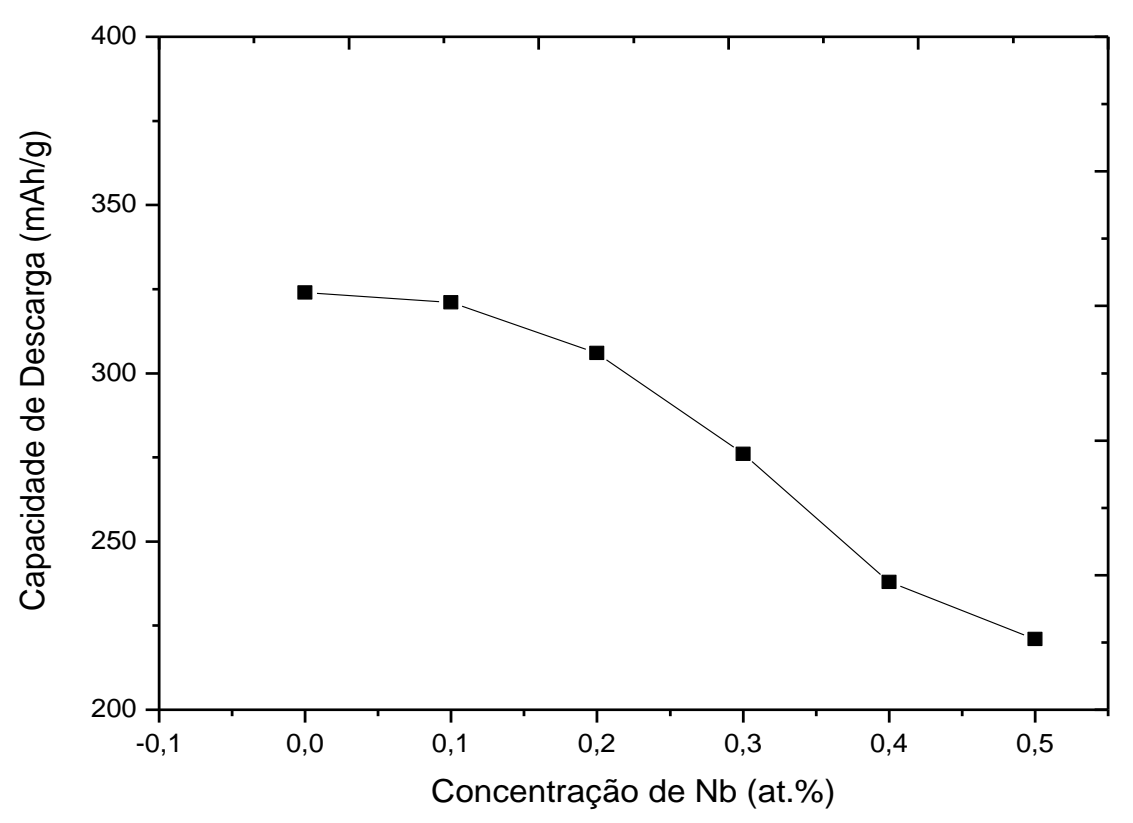

(b)

FIGURA 49 - Capacidade de descarga máxima obtidos das ligas as ligas $\mathrm{La}_{0,7} \mathrm{Mg}_{0,3} \mathrm{Al}_{0,3} \mathrm{Mn}_{0,4} \mathrm{Co}_{(0,5-x)} \mathrm{Nb}_{x} \mathrm{Ni}_{3,8}$ (x= 0 a 0,5) em função do aumento do teor de nióbio, onde: (a) mostra capacidade de descarga em mAh e (b) em mAh/g. 
A diminuição da capacidade de descarga, com o aumento do teor de $\mathrm{Nb}$ na liga e a completa substituição do Co das baterias pode ser atribuído ao aumento da concentração da fase $\mathrm{NbNi}_{3}$. Com o aumento do volume dessa fase, as fases $\mathrm{LaNi}_{5}$ e $(\mathrm{LaMg}) \mathrm{Ni}_{3}$,conhecidas por favorecerem 0 armazenamento de hidrogênio nesses materiais tiveram uma redução em volume na microestrutura. Uma boa capacidade de descarga e um bom desempenho de ativação estão relacionados, principalmente, com a disposição das fases na estrutura da liga e sua respectiva homogeneidade. Além disso, as regiões entre as fases fornecem ligações para a difusão de átomos de hidrogênio, acarretando em uma melhora significativa no desempenho de ativação das ligas [69].

Nas FIG. 50 estão apresentados os valores de capacidade de descarga em função do número de ciclos das baterias fabricadas com as ligas $\mathrm{La}_{0,7} \mathrm{Mg}_{0,3} \mathrm{Al}_{0,3} \mathrm{Mn}_{0,4} \mathrm{Co}_{(0,5-x)} \mathrm{Nb}_{x} \mathrm{Ni}_{3,8}(\mathrm{x}=0$ a 0,5$)$. O tempo de vida útil de cada bateria foi determinado adotando-se uma perda de (10\%) da capacidade de descarga máxima.

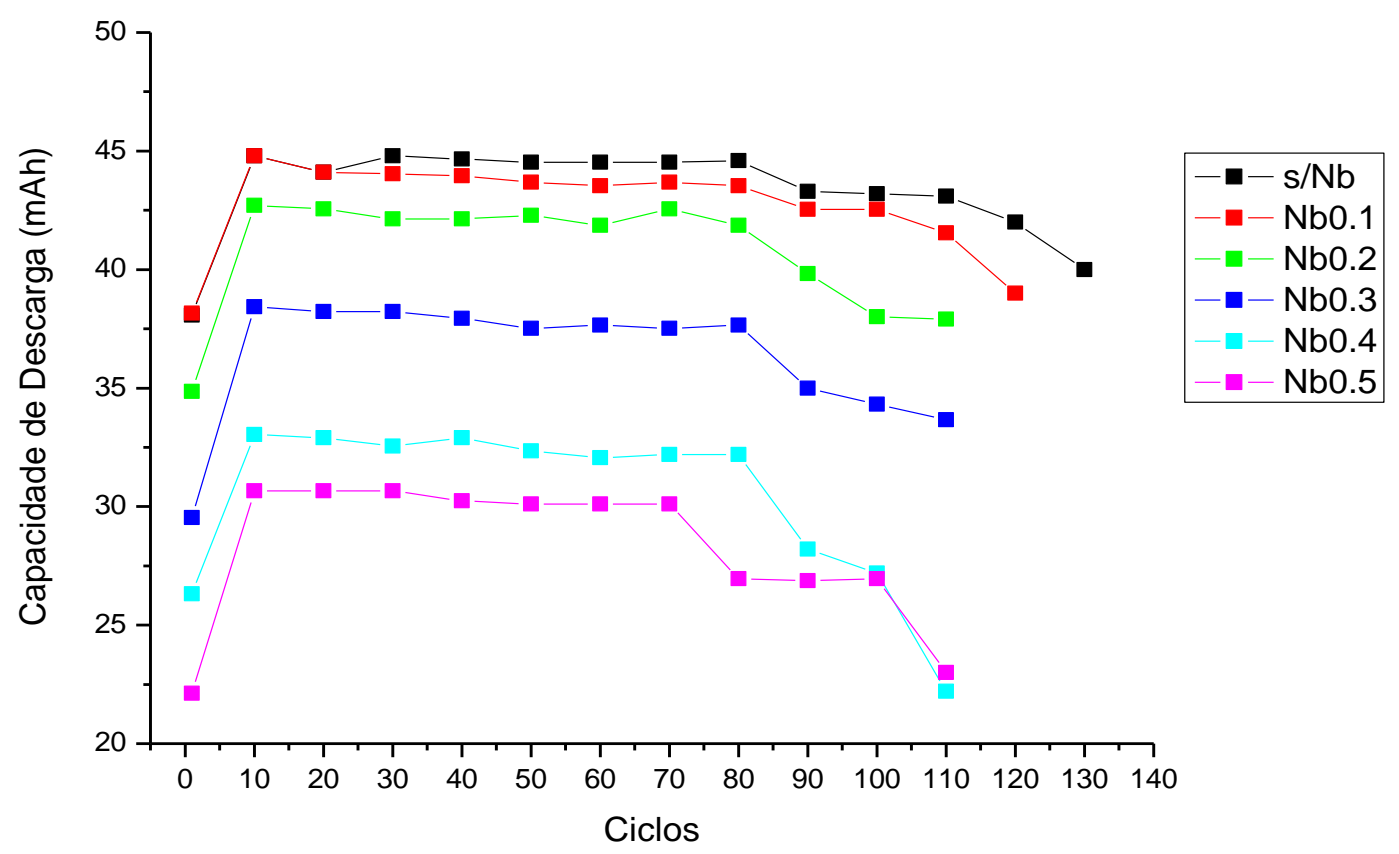

FIGURA 50 - Capacidade de descarga de todos os ciclos das baterias fabricadas com as ligas $\mathrm{La}_{0,7} \mathrm{Mg}_{0,3} \mathrm{Al}_{0,3} \mathrm{Mn}_{0,4} \mathrm{Co}_{(0,5-x)} \mathrm{Nb}_{x} \mathrm{Ni}_{3,8}(\mathrm{x}=0$ a 0,5$)$. 
Os resultados mostram que com a substituição total do cobalto pelo nióbio o número de ciclos das baterias diminui de $130 \mathrm{mAh}$ (liga sem $\mathrm{Nb}$ ) para aproximadamente $90 \mathrm{mAh}\left(\mathrm{Nb}_{0,5}\right)$. $\mathrm{Na}$ TAB. 21 estão apresentados os valores obtidos da FIG. 50.

TABELA 21 - Resultados das capacidades de descarga em relação ao tempo de vida dos eletrodos $\mathrm{La}_{0,7} \mathrm{Mg}_{0,3} \mathrm{Al}_{0,3} \mathrm{Mn}_{0,4} \mathrm{Co}_{(0,5-x)} \mathrm{Nb}_{x} \mathrm{Ni}_{3,8}(\mathrm{x}=0$ a 0,5$)$.

\begin{tabular}{ccccc}
\hline Liga & $\mathbf{C}_{\text {máx }}$ (mAh) & $\mathbf{C}_{\text {máx }}\left(\mathrm{mAhg}^{-1}\right)$ & $\mathbf{C}_{100}$ (mAh) & $\begin{array}{c}\text { Tempo de vida } \\
\text { (ciclos) }\end{array}$ \\
\hline $\mathbf{s / N b}$ & 45,36 & 324 & 43,31 & 128 \\
\hline $\mathbf{N b 0 , 1}$ & 44,94 & 321 & 42,54 & 114 \\
$\mathbf{N b 0 , 2}$ & 42,84 & 306 & 39,82 & 96 \\
$\mathbf{N b 0 , 3}$ & 38,64 & 276 & 37,66 & 91 \\
$\mathbf{N b 0 , 4}$ & 33,32 & 238 & 32,21 & 84 \\
$\mathbf{N b 0 , 5}$ & 30,94 & 221 & 26,96 & 83 \\
\hline
\end{tabular}

Os resultados obtidos mostram que o nióbio quando substitui o cobalto diminui drasticamente o tempo de vida útil das baterias, acarretando também baixos valores de capacidades de descarga. 


\subsubsection{Voltametria Cíclica - $\mathrm{La}_{0,7} \mathrm{Mg}_{0,3} \mathrm{Al}_{0,3} \mathrm{Mn}_{0,4} \mathrm{Co}_{(0,5-\mathrm{x})} \mathrm{Nb}_{\mathrm{x}} \mathrm{Ni}_{3,8}(\mathrm{x}=\mathbf{0}$ a 0,5$)$}

As Figuras 51 a 53 mostram os voltamogramas cíclicos obtidos para as ligas $\mathrm{La}_{0,7} \mathrm{Mg}_{0,3} \mathrm{Al}_{0,3} \mathrm{Mn}_{0,4} \mathrm{Co}_{(0,5-\mathrm{x})} \mathrm{Nb}_{\mathrm{x}} \mathrm{Ni}_{3,8}(\mathrm{x}=0$ a 0,5$)$ sem ciclos prévios e após 0 $25^{\circ}$ e $50^{\circ}$ ciclo de carga/descarga, partindo-se dos eletrodos descarregados, uma velocidade de varredura de potencial de $1 \mathrm{mV} \mathrm{s}^{-1}$ no intervalo de $-0,4 \mathrm{~V}$ a $1,2 \mathrm{~V}$ foi utilizada para a obtenção desses resultados.

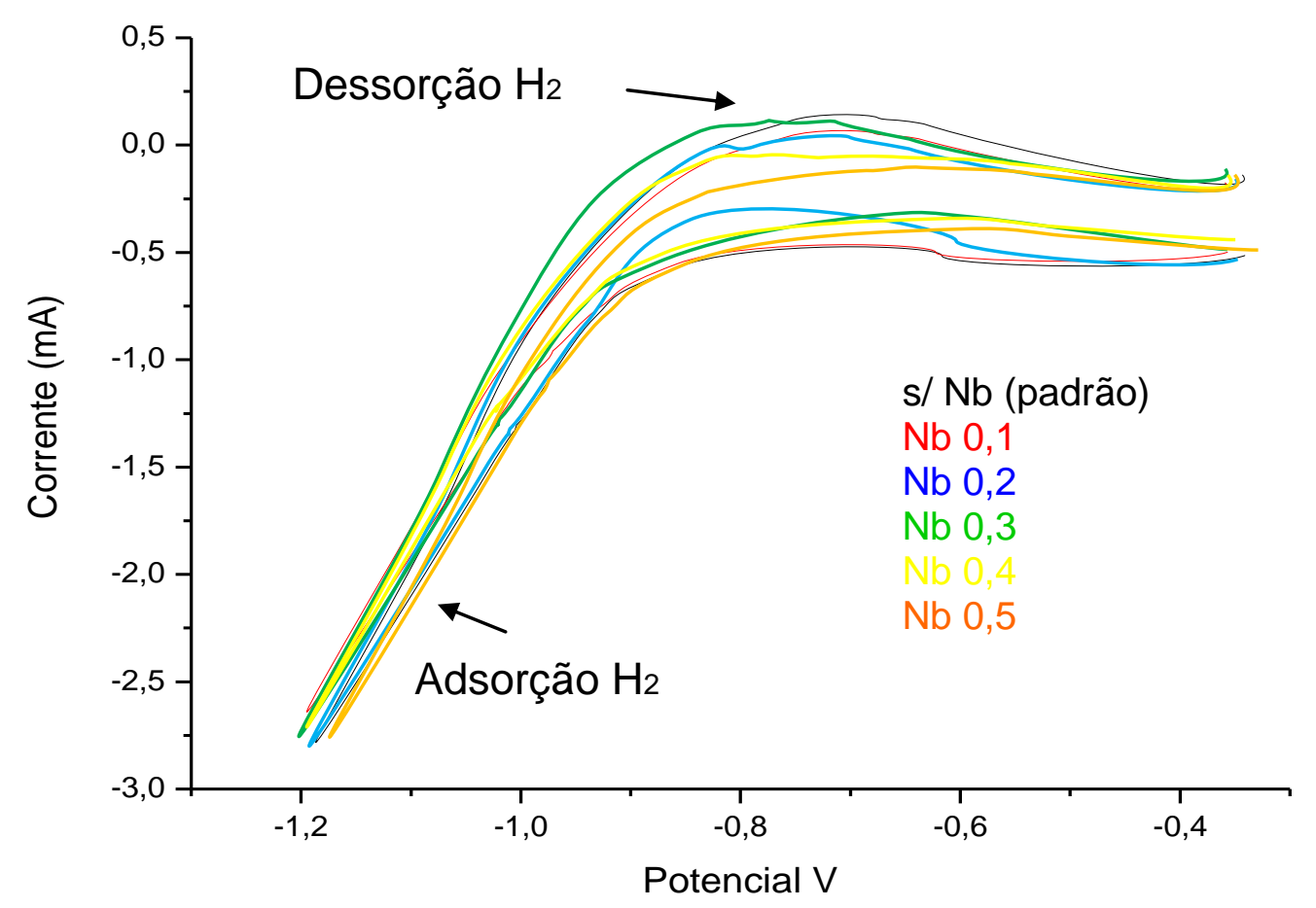

Figura 51 - Voltamogramas Cíclicos para as ligas $\mathrm{La}_{0,7} \mathrm{Mg}_{0,3} \mathrm{Al}_{0,3} \mathrm{Mn}_{0,4} \mathrm{Co}_{(0,5}$ ${ }_{x} \mathrm{Nb}_{x} \mathrm{Ni}_{3,8}(\mathrm{x}=0$ a 0,5$)$, sem ciclos prévios. 


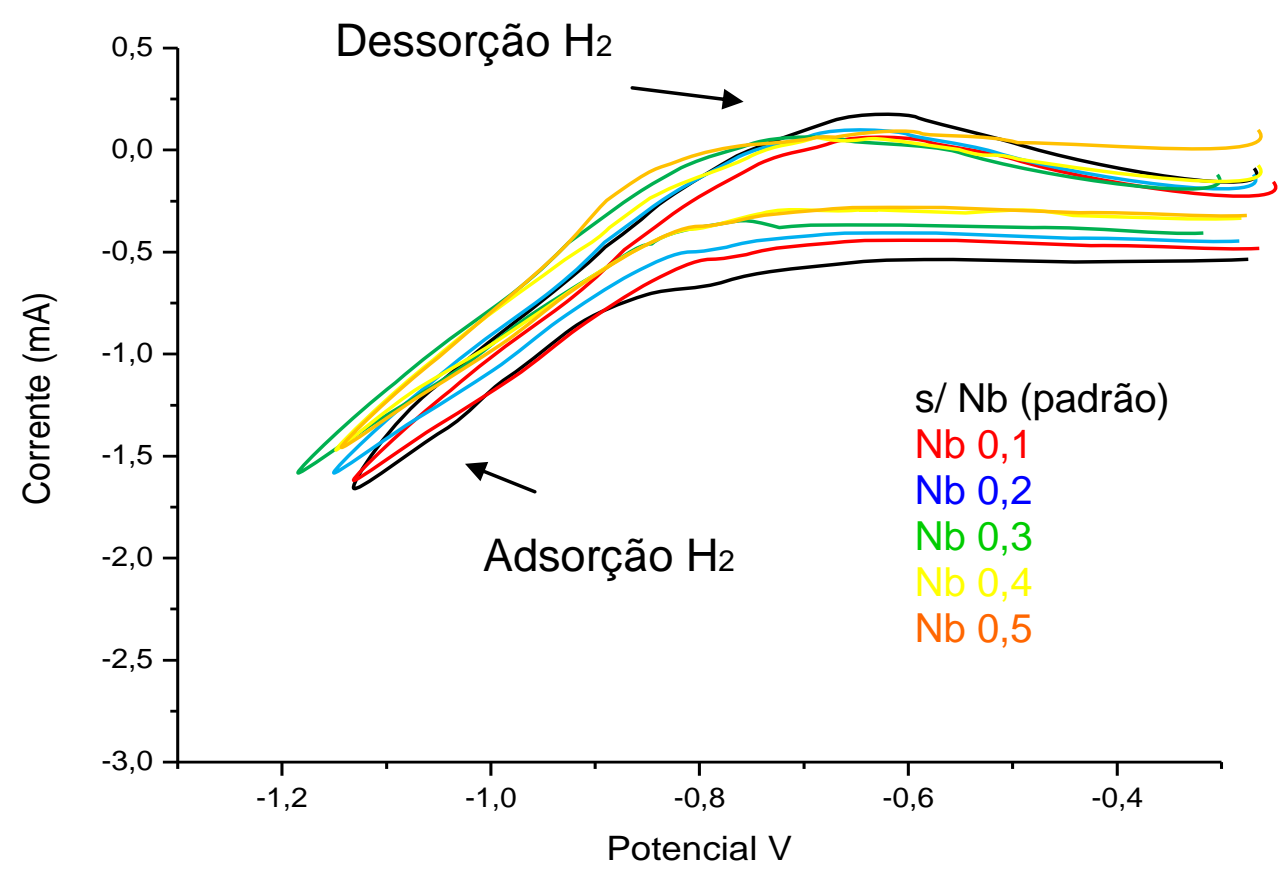

Figura 52 - Voltamogramas Cíclicos para as ligas $\mathrm{La}_{0,7} \mathrm{Mg}_{0,3} \mathrm{Al}_{0,3} \mathrm{Mn}_{0,4} \mathrm{Co}_{(0,5-}$ ${ }_{x)} \mathrm{Nb}_{x} \mathrm{Ni}_{3,8}$ ( $\mathrm{x}=0$ a 0,5), após 25 ciclos.

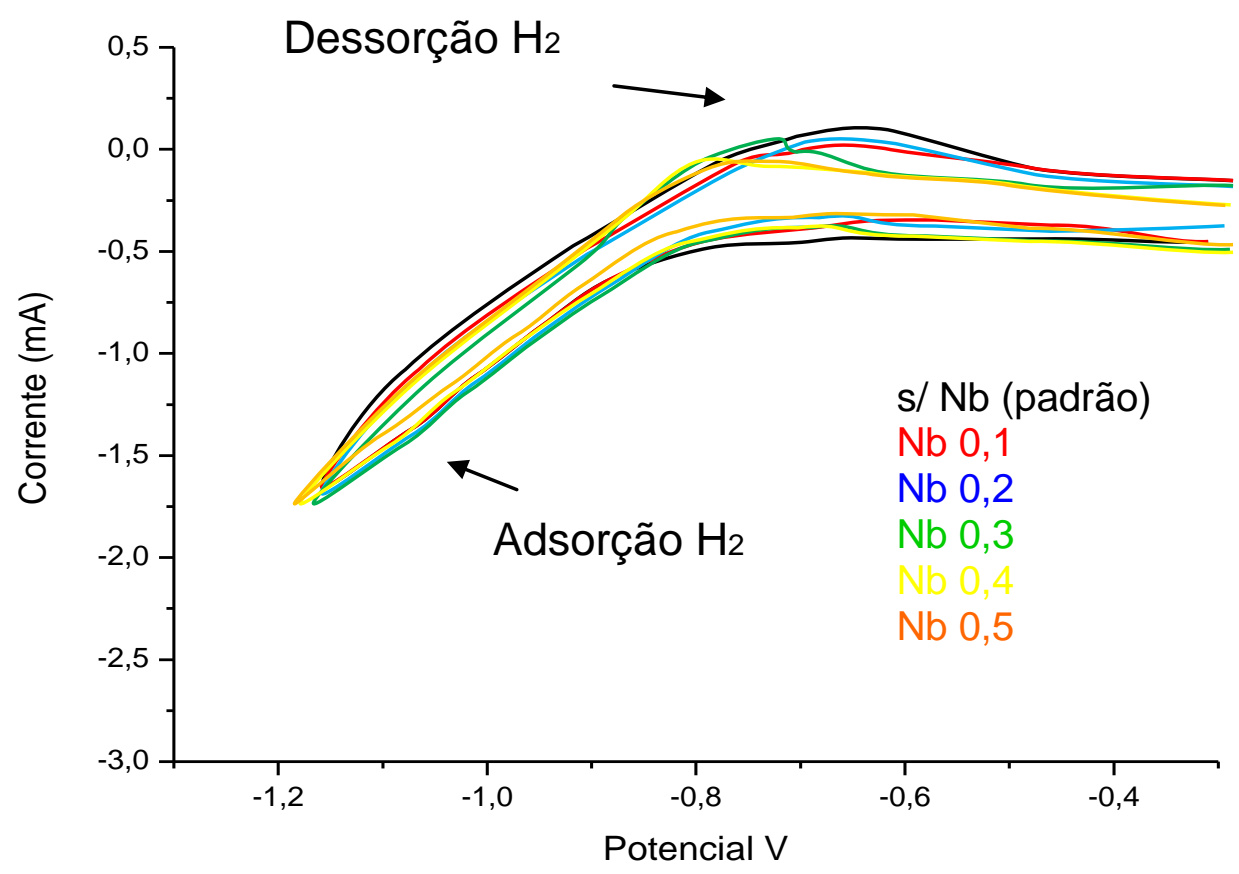

Figura 53 - Voltamogramas Cíclicos para as ligas $\mathrm{La}_{0,7} \mathrm{Mg}_{0,3} \mathrm{Al}_{0,3} \mathrm{Mn}_{0,4} \mathrm{Co}_{(0,5}$ ${ }_{x} \mathrm{Nb}_{x} \mathrm{Ni}_{3,8}(\mathrm{x}=0$ a 0,5), após 50 ciclos. 
Para todas as amostras após os diferentes ciclos de carga/descarga, durante a varredura de potencial no sentido catódico, observa-se um aumento no valor da corrente o qual é atribuído à ocorrência da reação de formação do hidreto. A dessorção de espécies de hidrogênio associado com o mecanismo de transferência de carga é observada durante a varredura reversa, no sentido anódico, onde aparece picos largos correspondentes a reação de desidretação.

Os voltamogramas cíclicos obtidos para as ligas não submetidas aos ciclos de carga e descarga indicam uma maior quantidade de hidrogênio absorvido, quando comparado com os demais casos. Nota-se uma progressiva diminuição das correntes catódica e anódica após todos os eletrodos terem sido submetidos aos sucessivos ciclos de carga/descarga. Isto se deve à perda de capacidade, que ocorre como consequência da oxidação de elementos como Mg e o Co na superfície das partículas, sendo este resultado consistente com os valores de capacidade de armazenamento de carga que foram apresentados anteriormente. Com o aumento dos ciclos as magnitudes das cargas envolvidas no processo de desidretação, são apreciavelmente inferiores em todas ligas, quando comparada com a liga sem $\mathrm{Nb}$. Tal comportamento é consistente com os resultados encontrados nas análises microestruturais, pois o nióbio refina a microestrutura e não substitui o Co na fase matriz.Além disso o aumento da concentração de $\mathrm{Nb}$ diminui a concentração das fases armazenadoras de hidrogênio. Como conseqüência, menor capacidade de armazenamento de carga com o avanço do número de ciclos foram obtidos para esses materiais, conforme foram apresentados nas Figs. 48 - 50. A comparação entre os perfis voltamétricos apresentados nas Figuras 51 - 53 evidenciam mudanças apreciáveis entre os comportamentos das ligas com e sem a presença de $\mathrm{Nb}$, fato que denota que a cinética dos processos envolvidos é prejudicada nessas situações. 
5.3.3 Resistência de Polarização - $\mathrm{La}_{0,7} \mathrm{Mg}_{0,3} \mathrm{Al}_{0,3} \mathrm{Mn}_{0,4} \mathrm{Co}_{(0,5-\mathrm{x})} \mathrm{Nb}_{\mathrm{x}} \mathrm{Ni}_{3,8}(\mathrm{x}=\mathbf{0}$ a 0,5)

Nas FIG. 54 estão apresentadas as curvas resultantes da média das micropolarizações realizadas na faixa de $-5 \mathrm{mv}$ até $5 \mathrm{mv}$ das baterias fabricadas com as ligas $\mathrm{La}_{0,7} \mathrm{Mg}_{0,3} \mathrm{Al}_{0,3} \mathrm{Mn}_{0,4} \mathrm{Co}_{(0,5-x)} \mathrm{Nb}_{x} \mathrm{Ni}_{3,8}(\mathrm{x}=0$ a 0,5 ) após 50 ciclos. Através da micropolarização é possível calcular a resistência de polarização de cada bateria.

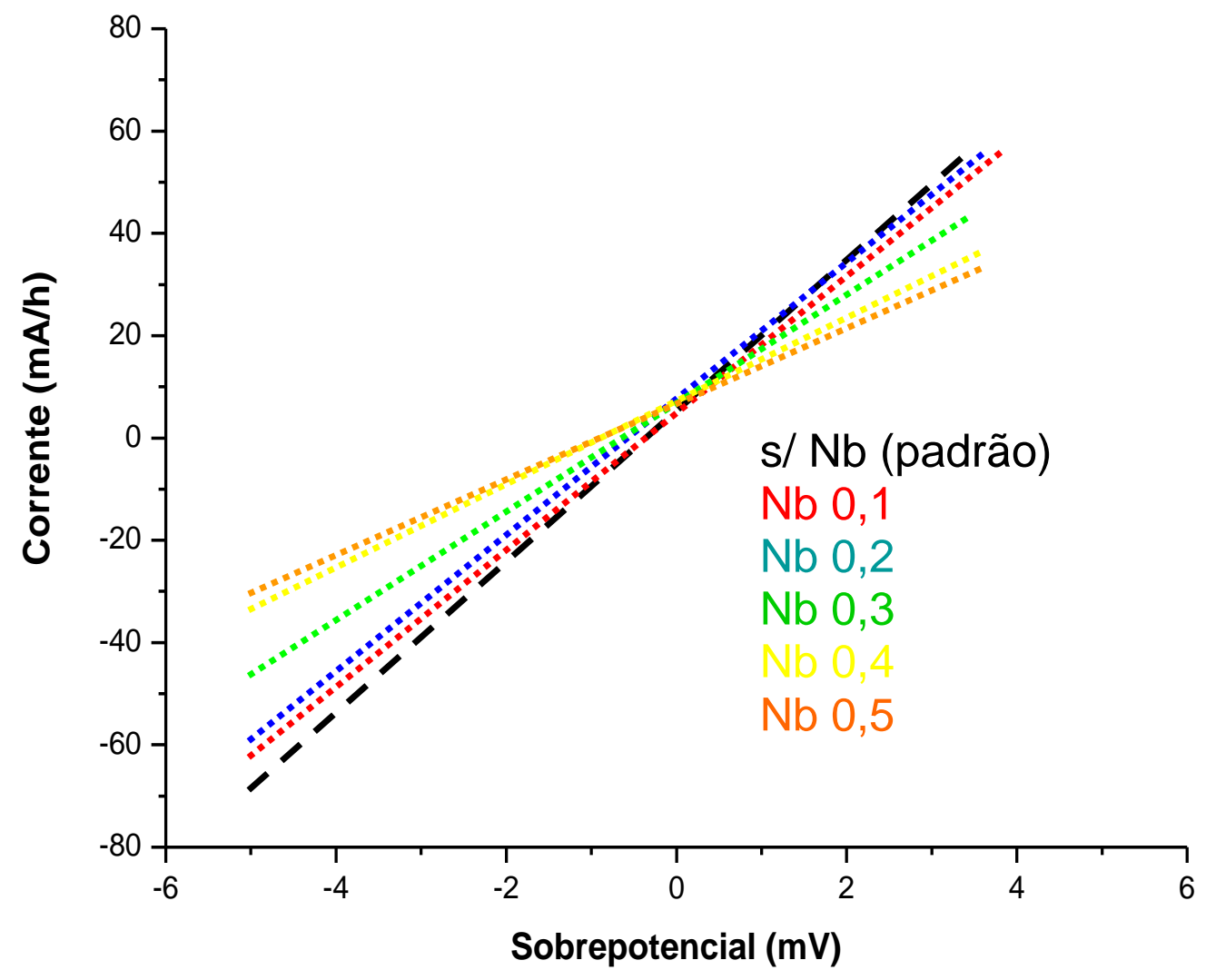

FIGURA 54 - Micropolarização média realizada na faixa de $-5 \mathrm{mv}$ até $5 \mathrm{mv}$ das ligas $\mathrm{La}_{0,7} \mathrm{Mg}_{0,3} \mathrm{Al}_{0,3} \mathrm{Mn}_{0,4} \mathrm{Co}_{(0,5-x)} \mathrm{Nb}_{x} \mathrm{Ni}_{3,8}(\mathrm{x}=0$ a 0,5) após 50 ciclos 
Foi possível observar que com o aumento do teor de $\mathrm{Nb}$ temos uma diminuição da corrente com a varredura no sentido anódico e catódico acarretando um aumento da resistência de polarização das baterias produzidas com esses tipos de ligas. A resistência de polarização de uma bateria é um dos fatores que limita sua durabilidade.

Na TAB. 22 estão apresentados os valores obtidos das resistências de polarização $(R p)$ iniciais, finais e a média para as baterias fabricadas com a liga

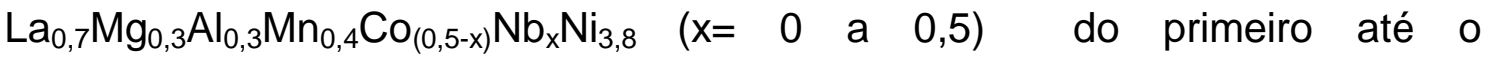
qüinquagésimo ciclo.

TABELA 22 - Resultados das resistências de polarização dos eletrodos produzidos com as ligas $\mathrm{La}_{0,7} \mathrm{Mg}_{0,3} \mathrm{Al}_{0,3} \mathrm{Mn}_{0,4} \mathrm{Co}_{(0,5-x)} \mathrm{Nb}_{x} \mathrm{Ni}_{3,8}$ ( $\mathrm{x}=0$ a 0,5$)$.

\begin{tabular}{cccc}
\hline Liga & $\begin{array}{c}\text { Rp Inicial }(\mathbf{m} \Omega) \\
\text { (0 ciclos) }\end{array}$ & $\begin{array}{c}\text { Rp Final }(\mathbf{m} \Omega) \\
\text { (50 ciclos) }\end{array}$ & $\begin{array}{c}\text { Rp Média }(\mathbf{m} \Omega) \\
(\mathbf{5 0} \text { ciclos })\end{array}$ \\
\hline $\mathbf{s / N b}$ & 690 & 786 & 708,5 \\
\hline $\mathbf{N b 0 , 1}$ & 713 & 779 & 755,8 \\
$\mathbf{N b 0 , 2}$ & 848 & 973 & 890,6 \\
$\mathbf{N b 0 , 3}$ & 1153 & 1278 & 1210,3 \\
$\mathbf{N b 0 , 4}$ & 1191 & 1282 & 1242,5 \\
$\mathbf{N b 0 , 5}$ & 1495 & 1674 & 1551,4 \\
\hline
\end{tabular}

Pelos valores obtidos verificou-se que com aumento dos ciclos houve um aumento considerável da resistência de polarização principalmente com os eletrodos contendo altos teores de $\mathrm{Nb}$. 
5.3.4 Capacidade de Descarga - $\mathrm{La}_{0,7} \mathrm{Mg}_{0,3} \mathrm{Al}_{0,3} \mathrm{Mn}_{0,4} \mathrm{Nb}_{(0,5+x)} \mathrm{Ni}_{(3,8--\mathrm{x})}(\mathrm{x}=\mathbf{0 , 3}$; $0,5 ; 1,3)$

Na FIG. 55 estão apresentados os valores de capacidade de descarga em função do número de ciclos iniciais (15 ciclos) das baterias de Ni-HM fabricadas com as ligas $\mathrm{La}_{0,7} \mathrm{Mg}_{0,3} \mathrm{Al}_{0,3} \mathrm{Mn}_{0,4} \mathrm{Nb}_{(0,5+x)} \mathrm{Ni}_{(3,8-\mathrm{x})}(\mathrm{x}=0,3 ; 0,5 ; 1,3)$.

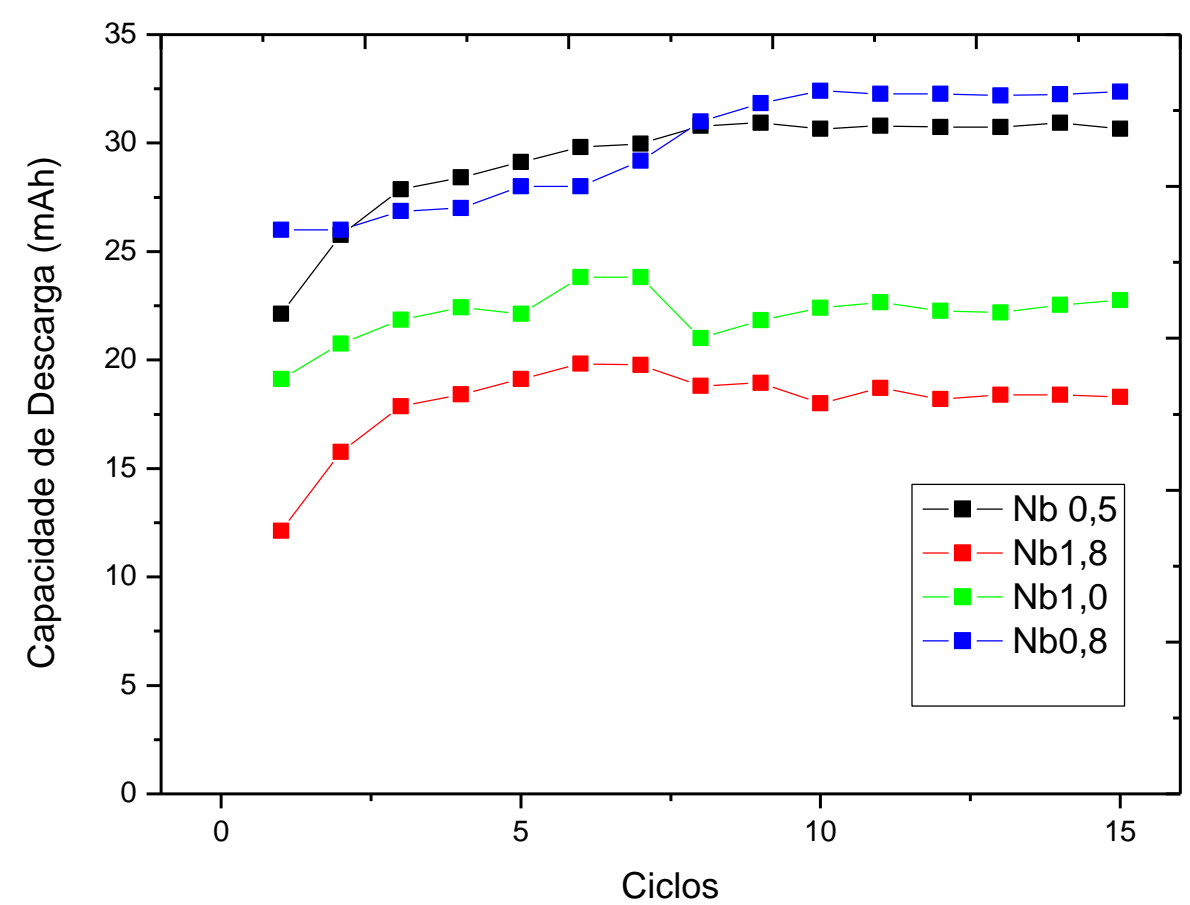

FIGURA 55 - Capacidade de descarga dos 15 ciclos iniciais das baterias fabricadas com as $\mathrm{La}_{0,7} \mathrm{Mg}_{0,3} \mathrm{Al}_{0,3} \mathrm{Mn}_{0,4} \mathrm{Nb}_{(0,5+x)} \mathrm{Ni}_{(3,8-x)}(\mathrm{x}=0,3 ; 0,5 ; 1,3)$.

$\mathrm{Na}$ FIG. 56 (a) e (b) estão apresentados os valores obtidos da capacidade de descarga máxima em relação ao aumento da concentração de nióbio nas ligas na substituição do níquel. Onde (a) mostra capacidade de descarga em mAh e (b) em $\mathrm{mAh} / \mathrm{g}$, foram calculados através da quantidade de material ativo no eletrodo negativo $(0,140 \mathrm{~g})$. 


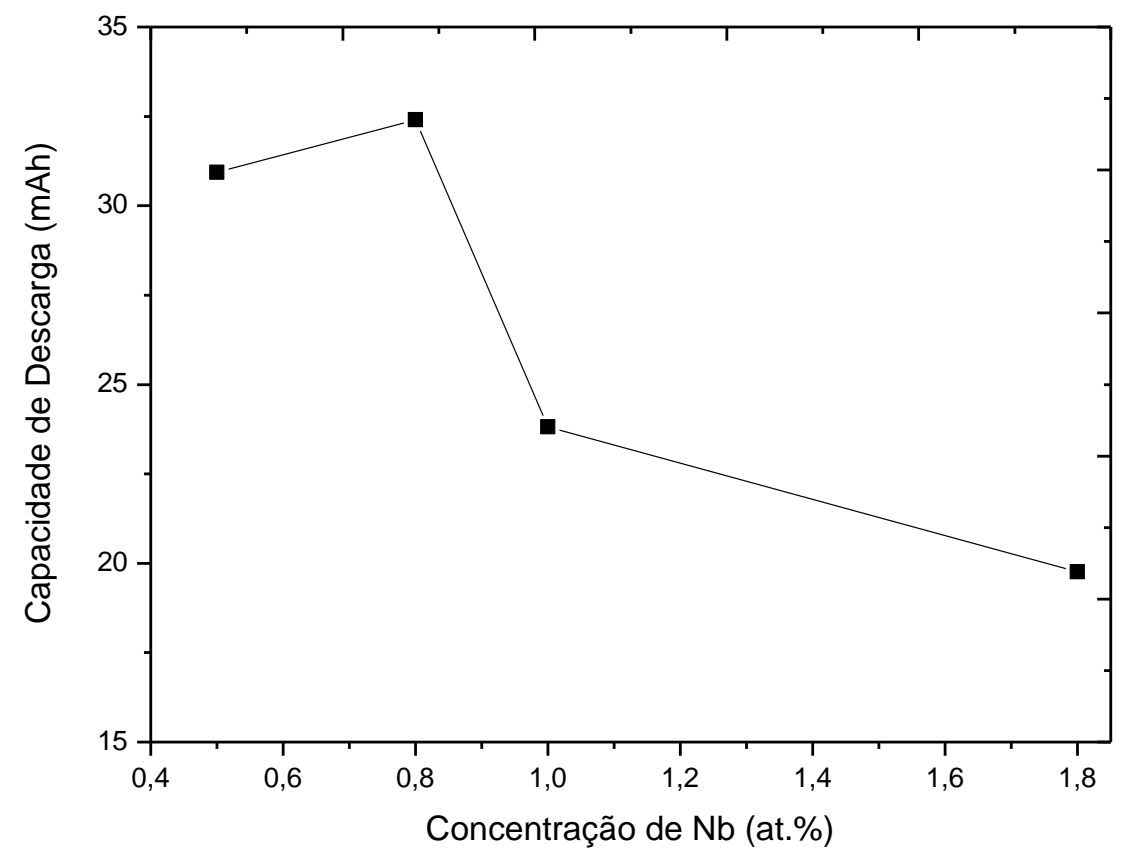

(a)

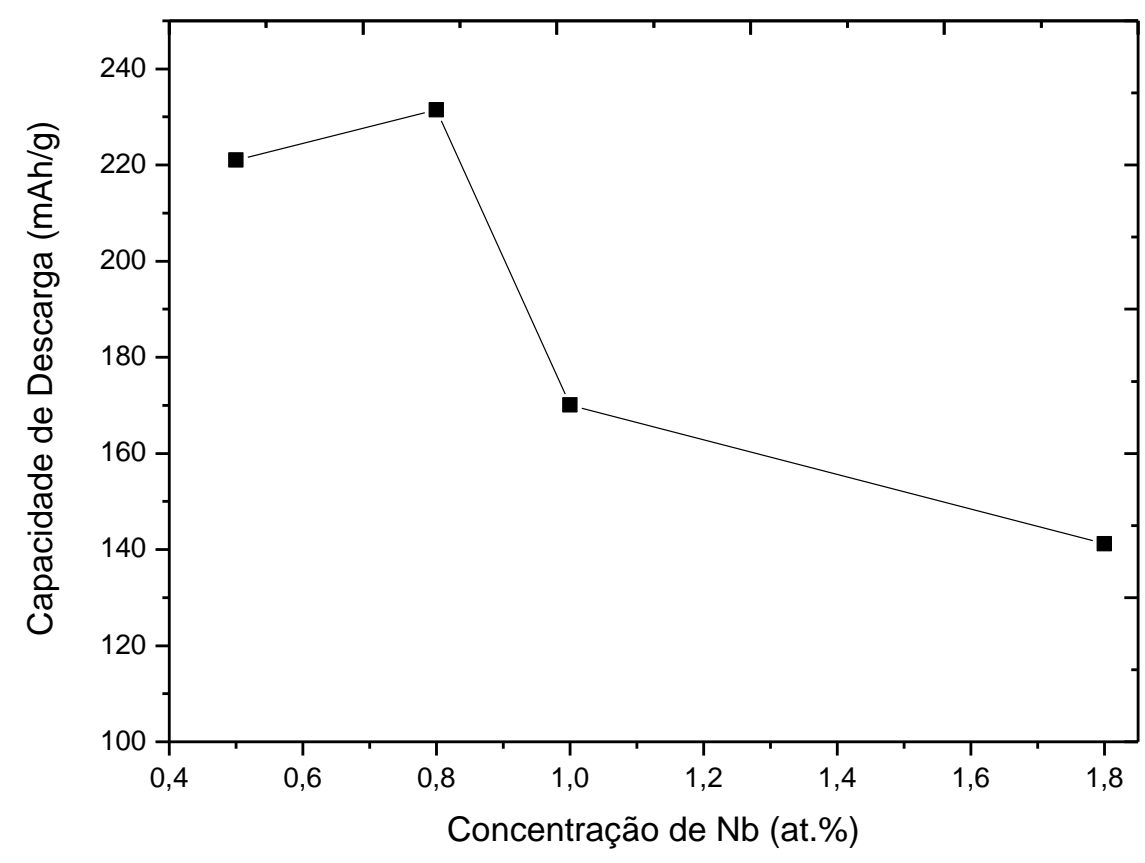

(b)

FIGURA 56 - Capacidade de descarga máxima obtidos das ligas as ligas $\mathrm{La}_{0,7} \mathrm{Mg}_{0,3} \mathrm{Al}_{0,3} \mathrm{Mn}_{0,4} \mathrm{Nb}_{(0,5+x)} \mathrm{Ni}_{(3,8-\mathrm{x})}(\mathrm{x}=0,3 ; 0,5 ; 1,3)$ em função do aumento do teor de nióbio, onde: (a) mostra capacidade de descarga em mAh e (b) em $\mathrm{mAh} / \mathrm{g}$. 
A diminuição da capacidade de descarga, com o aumento do teor de $\mathrm{Nb}$ na liga e a completa substituição do $\mathrm{Ni}$ das baterias pode ser atribuído ao aumento da concentração da fase $\mathrm{NbNi}_{3}$.Com o aumento do volume dessa fase, a fase $\mathrm{LaNi}_{5}$ conhecida por favorecer $\mathrm{o}$ armazenamento de hidrogênio tem sua concentração diminuída. Além disso a matriz das ligas com alto teor de $\mathrm{Nb}$ se transforma em uma composição NbNi de razão 1:1.

Nas FIG. 57 estão apresentados os valores de capacidade de descarga em função do número de ciclos das baterias fabricadas com as ligas $\mathrm{La}_{0,7} \mathrm{Mg}_{0,3} \mathrm{Al}_{0,3} \mathrm{Mn}_{0,4} \mathrm{Nb}_{(0,5+x)} \mathrm{Ni}_{(3,8--\mathrm{x})}(\mathrm{x}=0,3 ; 0,5 ; 1,3)$. O tempo de vida útil de cada bateria foi determinado adotando-se uma perda de (10\%) da capacidade de descarga máxima.

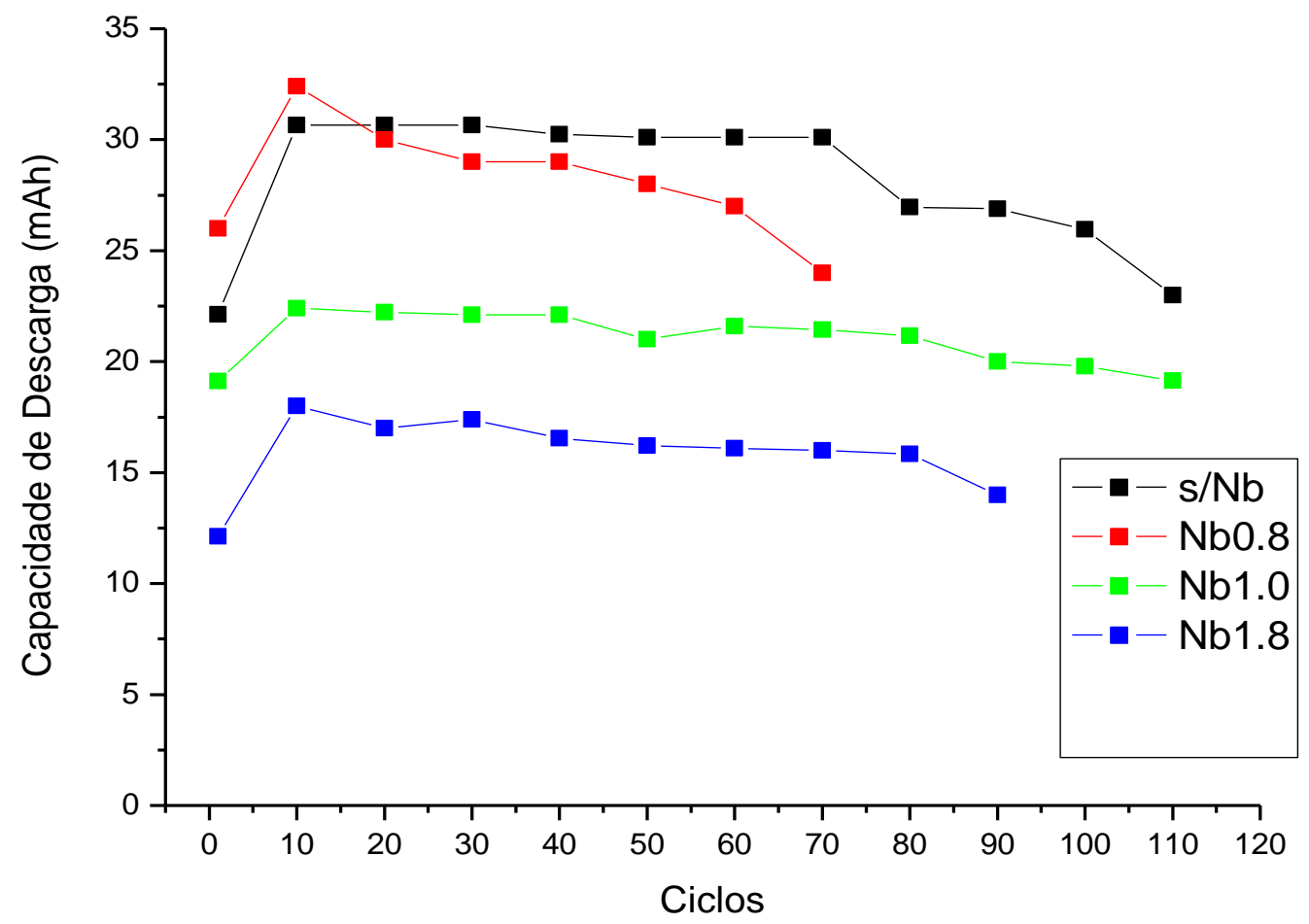

FIGURA 57 - Capacidade de descarga de todos os ciclos das baterias fabricadas com as ligas $\mathrm{La}_{0,7} \mathrm{Mg}_{0,3} \mathrm{Al}_{0,3} \mathrm{Mn}_{0,4} \mathrm{Nb}_{(0,5+x)} \mathrm{Ni}_{(3,8-x)}(\mathrm{x}=0,3 ; 0,5 ; 1,3)$. 
Os resultados mostram que com a substituição parcial do niquel pelo nióbio o número de ciclos das baterias se mantem aproximadamente o mesmo não havendo muitas variações. Na TAB. 23 estão apresentados os valores obtidos das FIG. 57.

TABELA 23 - Resultados das capacidades de descarga em relação ao tempo de vida dos eletrodos $\mathrm{La}_{0,7} \mathrm{Mg}_{0,3} \mathrm{Al}_{0,3} \mathrm{Mn}_{0,4} \mathrm{Nb}_{(0,5+x)} \mathrm{Ni}_{(3,8-\mathrm{x})}(\mathrm{x}=0,3 ; 0,5 ; 1,3)$.

\begin{tabular}{ccccc}
\hline Liga & $\mathbf{C}_{\text {máx }}(\mathrm{mAh})$ & $\mathbf{C}_{\text {máx }}\left(\mathrm{mAhg}^{-1}\right)$ & $\mathbf{C}_{100}$ (mAh) & Tempo de vida (ciclos) \\
\hline Nb0,5 & 30,94 & 221 & 26,96 & 83 \\
\hline $\mathbf{N b 0 , 8}$ & 32,41 & 231 & -- & 70 \\
$\mathbf{N b 1 , 0}$ & 23,81 & 170 & 19,15 & 90 \\
$\mathbf{N b 1 , 8}$ & 19,76 & 141 & -- & 80 \\
\hline
\end{tabular}


5.3.5 Voltametria Cíclica - $\mathrm{La}_{0,7} \mathrm{Mg}_{0,3} \mathrm{Al}_{0,3} \mathrm{Mn}_{0,4} \mathrm{Nb}_{(0,5+x)} \mathrm{Ni}_{(3,8-\mathrm{x})}(\mathrm{x}=0,3 ; 0,5 ; 1,3)$

As Figuras 58 a 60 mostram os voltamogramas cíclicos obtidos para as ligas $\mathrm{La}_{0,7} \mathrm{Mg}_{0,3} \mathrm{Al}_{0,3} \mathrm{Mn}_{0,4} \mathrm{Nb}_{(0,5+x)} \mathrm{Ni}_{(3,8-\mathrm{x})}(\mathrm{x}=0,3 ; 0,5 ; 1,3)$ sem ciclos prévios e após o $25^{\circ}$ e $50^{\circ}$ ciclo de carga/descarga, partindo-se dos eletrodos descarregados, uma velocidade de varredura de potencial de $1 \mathrm{mV} \mathrm{s}^{-1}$ no intervalo de $-0,4 \mathrm{~V}$ a $-1,2 \mathrm{~V}$ foi utilizada para a obtenção desses resultados.

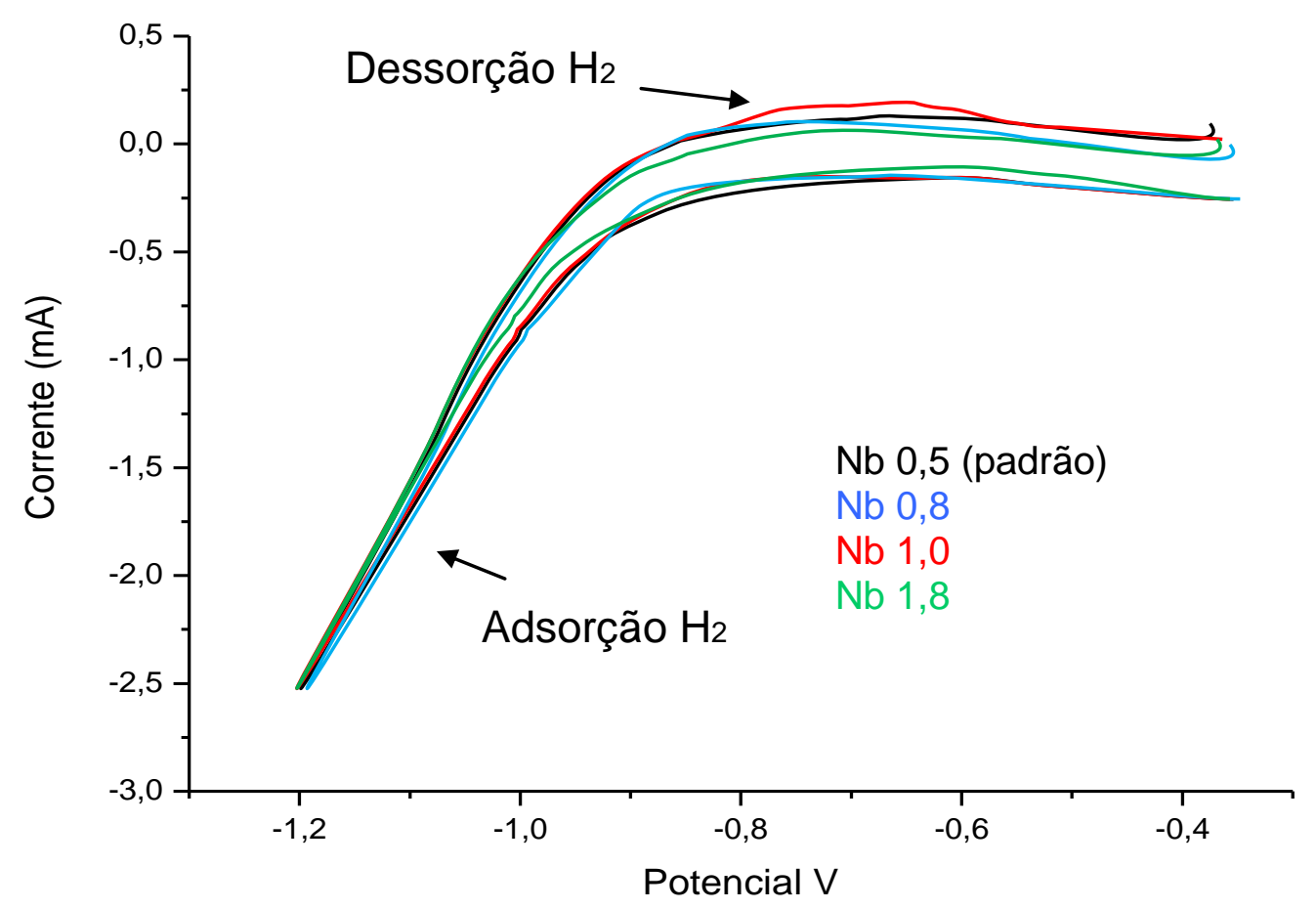

Figura 58 - Voltamogramas Cíclicos para as ligas

$\mathrm{La}_{0,7} \mathrm{Mg}_{0,3} \mathrm{Al}_{0,3} \mathrm{Mn}_{0,4} \mathrm{Nb}_{(0,5+x)} \mathrm{Ni}_{(3,8-x)}(\mathrm{x}=0,3 ; 0,5 ; 1,3)$, sem ciclos prévios. 


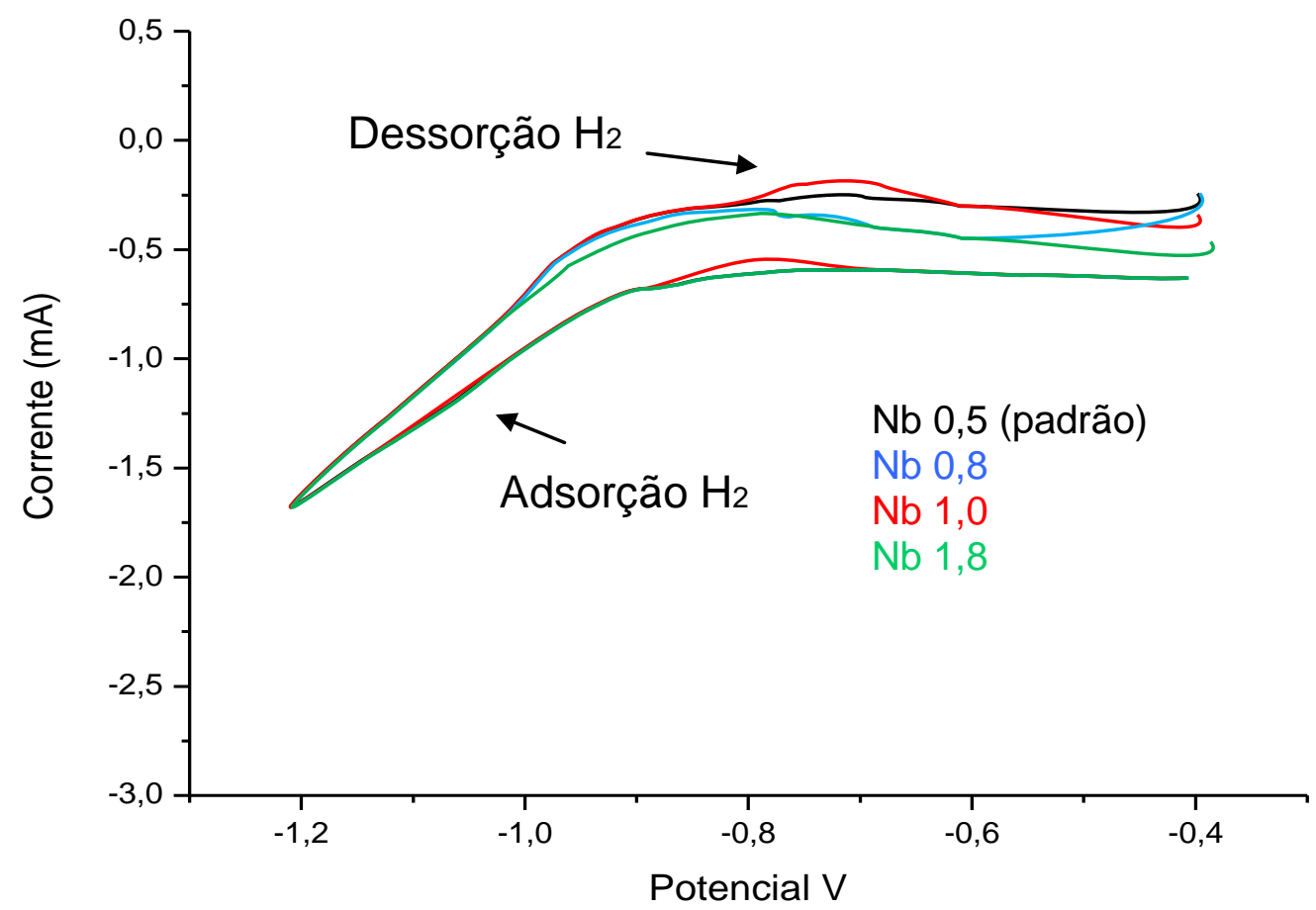

Figura 59 - Voltamogramas Cíclicos para as ligas

$\mathrm{La}_{0,7} \mathrm{Mg}_{0,3} \mathrm{Al}_{0,3} \mathrm{Mn}_{0,4} \mathrm{Nb}_{(0,5+x)} \mathrm{Ni}_{(3,8--x)}(\mathrm{x}=0,3 ; 0,5 ; 1,3)$, após 25 ciclos.

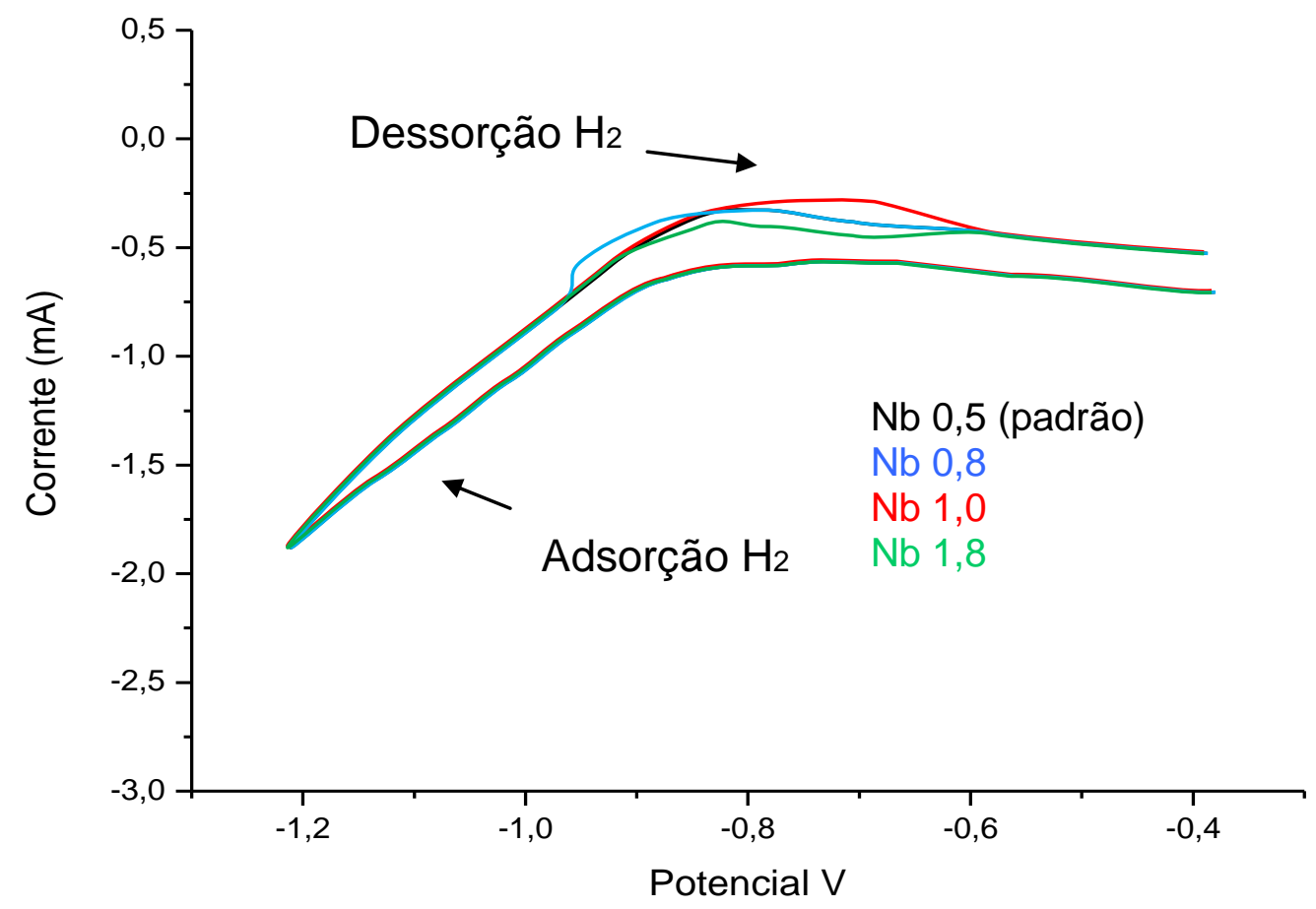

Figura 60 - Voltamogramas Cíclicos para as ligas

$\mathrm{La}_{0,7} \mathrm{Mg}_{0,3} \mathrm{Al}_{0,3} \mathrm{Mn}_{0,4} \mathrm{Nb}_{(0,5+x)} \mathrm{Ni}_{(3,8-\mathrm{x})}(\mathrm{x}=0,3 ; 0,5 ; 1,3)$, após 50 ciclos. 
Os voltamogramas cíclicos obtidos para as ligas não submetidas aos ciclos de carga e descarga, indicam uma menor quantidade de hidrogênio absorvido, quando comparadas com as ligas $\mathrm{La}_{0,7} \mathrm{Mg}_{0,3} \mathrm{Al}_{0,3} \mathrm{Mn}_{0,4} \mathrm{Co}_{(0,5-x)} \mathrm{Nb}_{x} \mathrm{Ni}_{3,8}$ $(x=0$ a 0,5$)$. Nota-se também uma progressiva diminuição das correntes catódica e anódica após todos os eletrodos terem sido submetidos aos sucessivos ciclos de carga/descarga. Tal comportamento é consistente com os resultados encontrados nas análises microestruturais, pois o nióbio refina a microestrutura e forma com o níquel uma composição $\mathrm{NbNi}$ na fase matriz. Essa fase tem grau de armazenamento de hidrogênio bem inferior em relação às fases $\mathrm{LaNi}$ e $\mathrm{LaNi}_{5}$. Como consequência, menor capacidade de armazenamento de carga com o avanço do número de ciclos tempo de vida baixos foram obtidos para esses materiais, conforme foi apresentado na FIG. 57. 
5.3.6 Resistência de Polarização - La $a_{0,7} \mathrm{Mg}_{0,3} \mathrm{Al}_{0,3} \mathrm{Mn}_{0,4} \mathrm{Nb}_{(0,5+x)} \mathrm{Ni}_{(3,8-\mathrm{x})}(\mathrm{x}=$ $0,3 ; 0,5 ; 1,3)$

Nas FIG. 61 estão apresentadas as curvas resultantes da média das micropolarizações realizadas na faixa de $-5 \mathrm{mv}$ até $5 \mathrm{mv}$ das baterias fabricadas com as ligas $\mathrm{La}_{0,7} \mathrm{Mg}_{0,3} \mathrm{Al}_{0,3} \mathrm{Mn}_{0,4} \mathrm{Nb}_{(0,5+x)} \mathrm{Ni}_{(3,8-\mathrm{x})}(\mathrm{x}=0,3 ; 0,5 ; 1,3)$ após 50 ciclos.

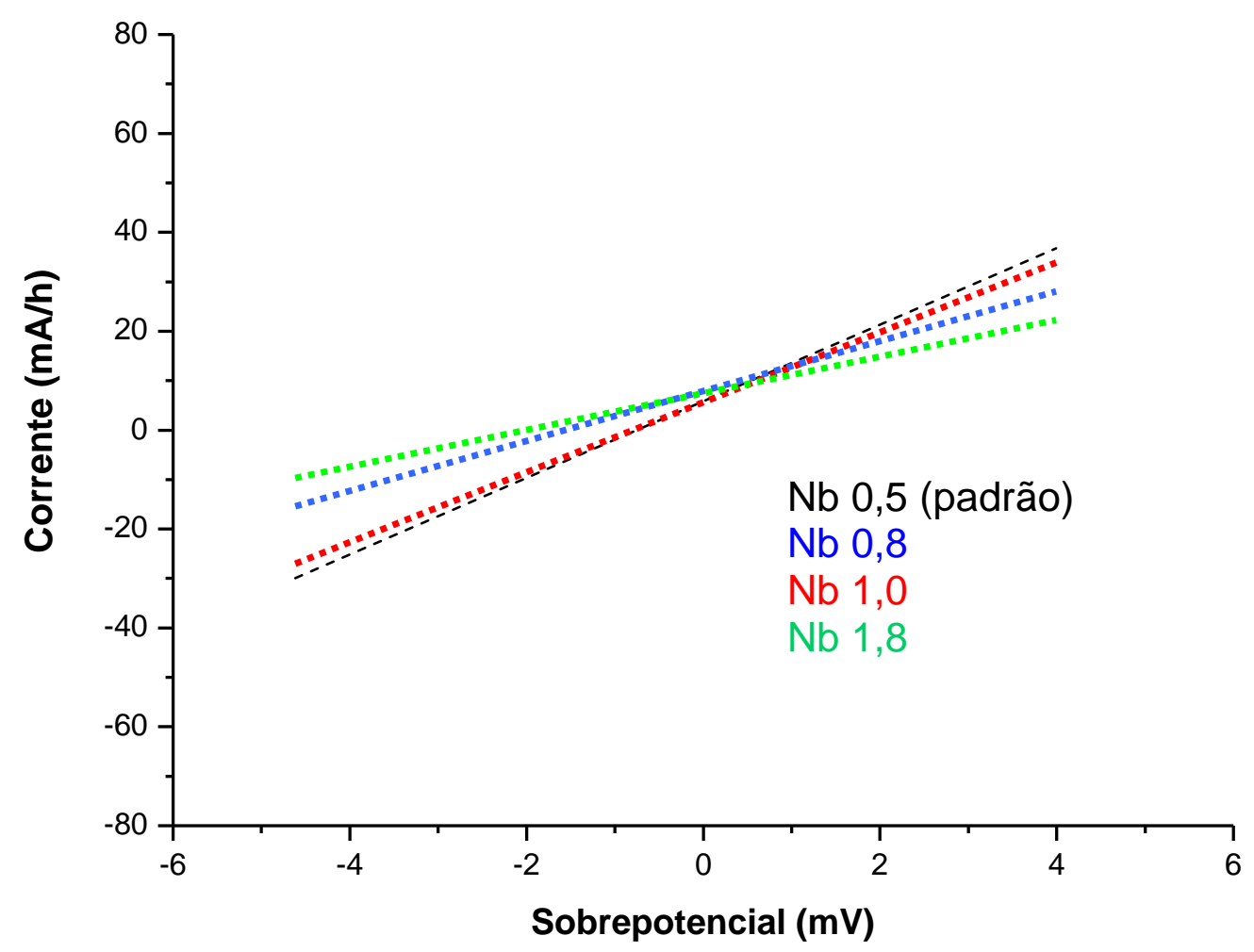

FIGURA 61 - Micropolarização média realizada na faixa de $-5 \mathrm{mv}$ até $5 \mathrm{mv}$ das ligas $\mathrm{La}_{0,7} \mathrm{Mg}_{0,3} \mathrm{Al}_{0,3} \mathrm{Mn}_{0,4} \mathrm{Nb}_{(0,5+x)} \mathrm{Ni}_{(3,8-\mathrm{x})}(\mathrm{x}=0,3 ; 0,5 ; 1,3)$ média após 50 ciclos.

Foi possível observar que com o aumento do teor de $\mathrm{Nb}$ temos uma diminuição da corrente com a varredura no sentido anódico e catódico acarretando um aumento da resistência de polarização das baterias produzidas com esses tipos de ligas, exatamente como ocorreu na substituição do Co pelo $\mathrm{Nb}$. A resistência de polarização de uma bateria é um dos fatores que limita sua durabilidade. 
Na TAB. 24 estão apresentados os valores obtidos das resistências de polarização (Rp) iniciais, finais e a média para as baterias fabricadas com a liga $\mathrm{La}_{0,7} \mathrm{Mg}_{0,3} \mathrm{Al}_{0,3} \mathrm{Mn}_{0,4} \mathrm{Nb}_{(0,5+x)} \mathrm{Ni}_{(3,8-\mathrm{x})} \quad(\mathrm{x}=0,3 ; 0,5 ; 1,3) \quad$ do primeiro até $\mathrm{O}$ quinquagésimo ciclo.

TABELA 24 - Resultados das resistências de polarização dos eletrodos produzidos com as ligas $\mathrm{La}_{0,7} \mathrm{Mg}_{0,3} \mathrm{Al}_{0,3} \mathrm{Mn}_{0,4} \mathrm{Nb}_{(0,5+x)} \mathrm{Ni}_{(3,8-\mathrm{x})}(\mathrm{x}=0,3 ; 0,5 ; 1,3)$.

\begin{tabular}{cccc}
\hline Liga & $\begin{array}{c}\text { Rp Inicial (m } \mathbf{)}) \\
\text { (0 ciclos) }\end{array}$ & $\begin{array}{c}\text { Rp Final }(\mathbf{m} \Omega) \\
\text { (50 ciclos) }\end{array}$ & $\begin{array}{c}\text { Rp Média }(\mathbf{m} \Omega) \\
\text { (50 ciclos) }\end{array}$ \\
\hline Nb0,5 & 1495 & 1674 & 1551,4 \\
Nb0,8 & 1467 & 1814 & 1745 \\
Nb1,0 & 1520 & 1689 & 1580 \\
Nb1,8 & 1693 & 1806 & 1783 \\
\hline
\end{tabular}

Pelos valores obtidos verificou-se que com aumento dos ciclos houve um aumento considerável da resistência de polarização principalmente com os eletrodos contendo altos teores de $\mathrm{Nb}$.A única exceção foi o eletrodo produzido com o teor 0,8 at.\%. de $\mathrm{Nb}$ que teve uma resistência média maior que $\mathrm{o}$ eletrodo produzido com o teor de 1,0 at.\% de Nb. Essa alta resistência de polarização foi provavelmente uma das causas do baixo tempo de vida do eletrodo produzido com a liga $\mathrm{La}_{0,7} \mathrm{Mg}_{0,3} \mathrm{Al}_{0,3} \mathrm{Mn}_{0,4} \mathrm{Nb}_{0,8} \mathrm{Ni}_{3,5}$. 


\subsection{Corrosão das ligas}

\subsubsection{Série $\mathrm{La}_{0,7} \mathrm{Mg}_{0,3} \mathrm{Al}_{0,3} \mathrm{Mn}_{0,4} \mathrm{Co}_{(0,5-x)} \mathrm{Nb}_{x} \mathrm{Ni}_{3,8}(x=0$ a 0,5$)$}

A FIG. 60 ilustra as curvas de polarização das ligas da série $\mathrm{La}_{0,7} \mathrm{Mg}_{0,3} \mathrm{Al}_{0,3} \mathrm{Mn}_{0,4} \mathrm{Co}_{(0,5-x)} \mathrm{Nb}_{x} \mathrm{Ni}_{3,8}(\mathrm{x}=0$ a 0,5) e a TAB. 25 mostra o potencial de corrosão ( $\left.E_{\text {corr }}\right)$ e a corrente de corrosão ( $\left.I_{\text {corr }}\right)$ para cada uma das ligas desta série.

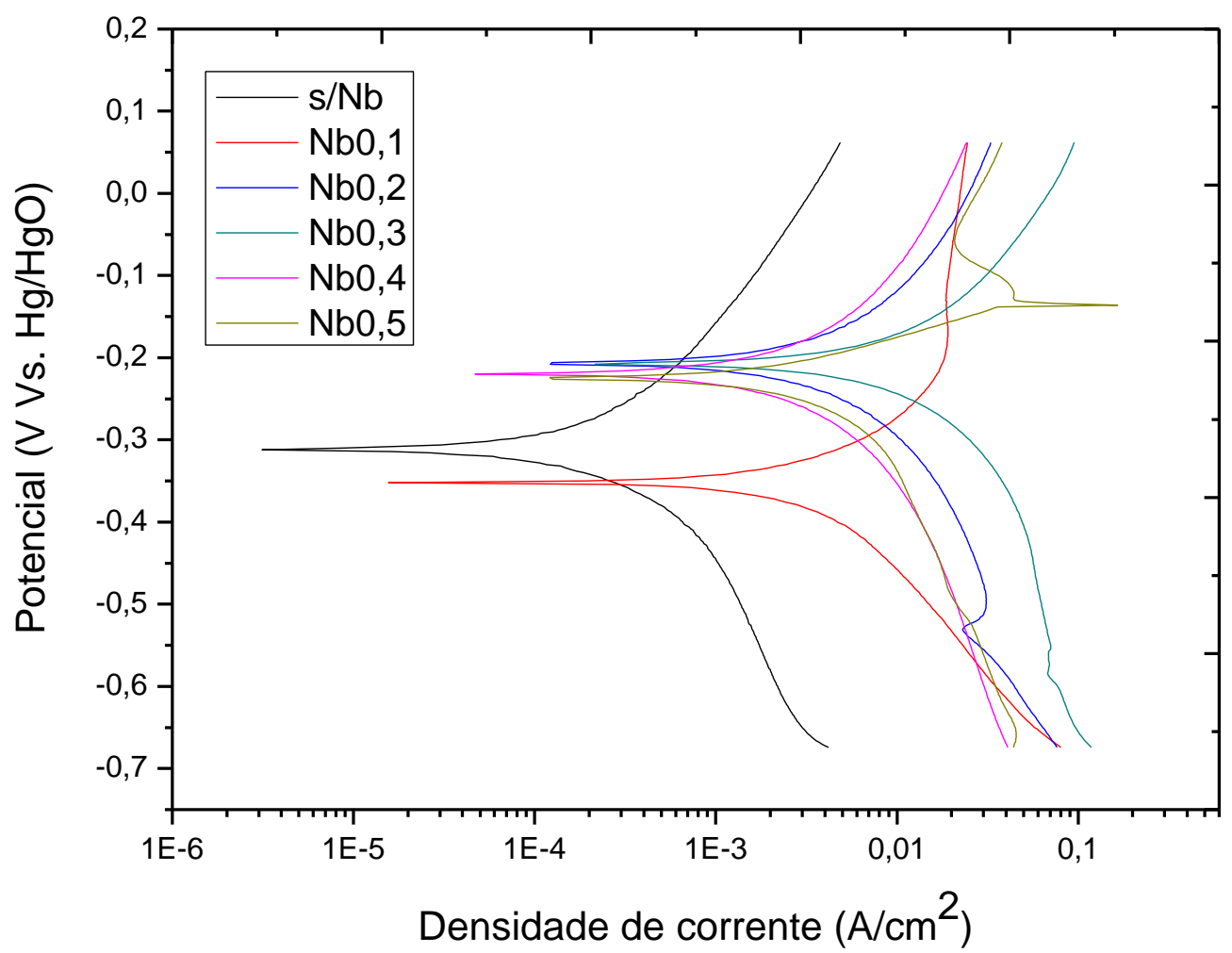

FIGURA 62 - Curvas de polarização das ligas $\mathrm{La}_{0,7} \mathrm{Mg}_{0,3} \mathrm{Al}_{0,3} \mathrm{Mn}_{0,4} \mathrm{Co}_{(0,5-}$ x) $\mathrm{Nb}_{x} \mathrm{Ni}_{3,8}(\mathrm{x}=0$ a 0,5$)$. 
TABELA 25 - Potencial e corrente de corrosão para as ligas $\mathrm{La}_{0,7} \mathrm{Mg}_{0,3} \mathrm{Al}_{0,3} \mathrm{Mn}_{0,4} \mathrm{Co}_{(0,5-x)} \mathrm{Nb}_{x} \mathrm{Ni}_{3,8}$ ( $\mathrm{x}=0$ a 0,5$)$.

\begin{tabular}{ccc}
\hline Liga & $\mathbf{E}_{\text {corr }}(\mathbf{V}$ vs. $\mathbf{H g} / \mathbf{H g O})$ & $\mathbf{I}_{\text {corr }}\left(\mu \mathbf{A} / \mathbf{c m}^{-2}\right)$ \\
\hline $\mathbf{s} / \mathbf{~ N b}$ & $-0,312$ & 63,24 \\
\hline $\mathbf{N b 0 , 1}$ & $-0,356$ & 87,76 \\
$\mathbf{N b 0 , 2}$ & $-0,192$ & 107,89 \\
$\mathbf{N b 0 , 3}$ & $-0,215$ & 129,43 \\
$\mathbf{N b 0 , 4}$ & $-0,224$ & 96,04 \\
$\mathbf{N b 0 , 5}$ & $-0,232$ & 120,04 \\
\hline
\end{tabular}

Através dos resultados obtidos foi possível observar a tendência do potencial de corrosão $\left(E_{c o r r}\right)$ a valores mais catódicos, este fenômeno é observado à medida que a concentração de nióbio aumenta nas ligas. Com o aumento do teor de $\mathrm{Nb}$, nota-se que o mecanismo do processo de oxidação é o mesmo que o da redução e ele não se altera em relação a liga que não contem $\mathrm{Nb}$.

Acredita-se que os pites formam-se devido à existência de pontos de maior fragilidade na camada passivante (defeitos de formação). Para a liga $\mathrm{Nb}_{0,5}$, a passivação ocorre em potenciais anódicos e a corrosão por pites é observada nesse mesmo potencial também. Para liga $\mathrm{Nb}_{0,5}$, a densidade de corrente é em geral maior em todo o intervalo de potencial estudado. A formação de pites, inicia em potenciais maiores que $-0,2 \mathrm{~V}$. Acima de $-0,1 \mathrm{~V}$, a formação de pites diminui.

A não linearidade no comportamento eletroquímico dos materiais dessa série pode ser devido a não homogeneidade na formação de liga conforme pode ser visto nos resultados de microscopia eletrônica de varredura e difração de raios-X dos capítulos anteriores.

A corrente corrosão ( $\left.I_{\text {corr }}\right)$ aumenta com a concentração de nióbio. De acordo com a literatura, o ciclo de vida do eletrodo negativo das baterias fabricadas com este tipo de ligas metálicas aumenta com o decréscimo da corrente de corrosão. 


\subsubsection{Série $\mathrm{La}_{0,7} \mathrm{Mg}_{0,3} \mathrm{Al}_{0,3} \mathrm{Mn}_{0,4} \mathrm{Nb}_{(0,5+x)} \mathrm{Ni}_{(3,8--\mathrm{x})}(\mathrm{x}=0,3 ; 0,5 ; 1,3)$}

A FIG. 63 ilustra as curvas de polarização das ligas da série cobre $\mathrm{La}_{0,7} \mathrm{Mg}_{0,3} \mathrm{Al}_{0,3} \mathrm{Mn}_{0,4} \mathrm{Nb}_{(0,5+x)} \mathrm{Ni}_{(3,8-\mathrm{x})} \quad(\mathrm{x}=0,3 ; 0,5 ; 1,3)$ e a TAB. 26 mostra 0 potencial de corrosão ( $\left.E_{\text {corr }}\right)$ e a corrente de corrosão ( $\left.I_{\text {corr }}\right)$ para cada uma das ligas desta série.

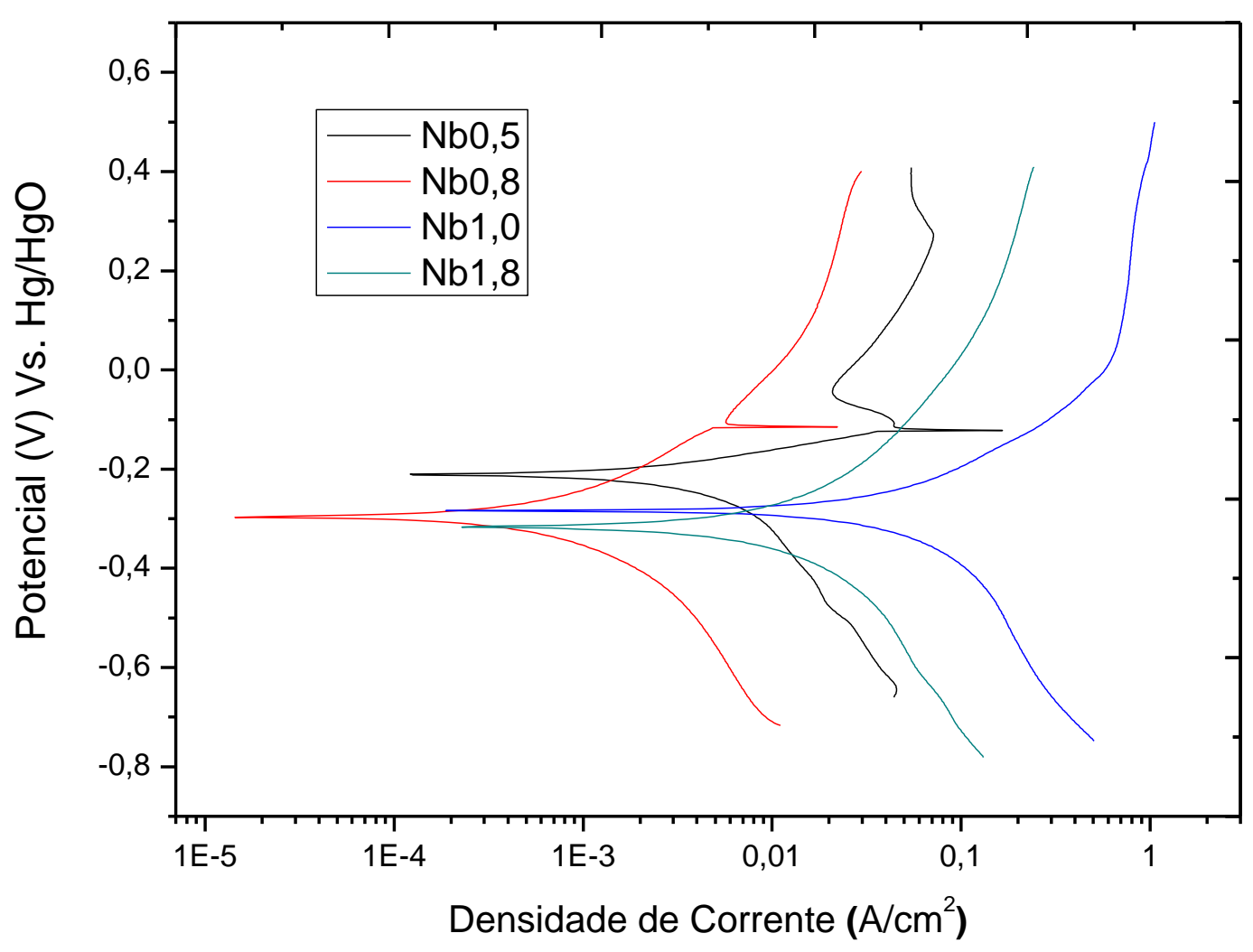

FIGURA 61 - Curvas de polarização das ligas $\mathrm{La}_{0,7} \mathrm{Mg}_{0,3} \mathrm{Al}_{0,3} \mathrm{Mn}_{0,4} \mathrm{Nb}_{(0,5+x)} \mathrm{Ni}_{(3,8--}$ x) $(x=0,3 ; 0,5 ; 1,3)$. 
TABELA 26 - Potencial e corrente de corrosão para as ligas $\mathrm{La}_{0,7} \mathrm{Mg}_{0,3} \mathrm{Al}_{0,3} \mathrm{Mn}_{0,4} \mathrm{Nb}_{(0,5+x)} \mathrm{Ni}_{(3,8-x)}(\mathrm{x}=0,3 ; 0,5 ; 1,3)$.

\begin{tabular}{ccc}
\hline Liga & $\mathbf{E}_{\text {corr }}(\mathbf{V}$ vs. $\mathbf{H g} / \mathbf{H g O})$ & $\mathrm{I}_{\text {corr }}\left(\mu \mathrm{A} / \mathbf{c m}^{-2}\right)$ \\
\hline $\mathbf{N b 0 , 5}$ & $-0,217$ & 74,29 \\
\hline $\mathbf{N b 0 , 8}$ & $-0,306$ & 109,87 \\
$\mathbf{N b 1 , 0}$ & $-0,286$ & 128,49 \\
$\mathbf{N b 1 , 8}$ & $-0,341$ & 116,54 \\
\hline
\end{tabular}

Através dos resultados obtidos foi possível observar a tendência do potencial de corrosão ( $\mathrm{E}_{\text {corr }}$ ) a valores mais anódicos com aumento do teor de $\mathrm{NB}$, mas apresentando resultados similares aos das ligas da série anterior. Todavia, em linhas gerais a adição de niobio torna o material menos resistente à corrosão $\left(E_{\text {corr }}\right.$ é tanto mais negativo com o aumento no teor de niobio bem como o i corr é maior). 


\section{5 - Tratamento Térmico}

Neste capítulo apresentam-se os resultados obtidos referentes ao processamento da liga $\mathrm{La}_{0,7} \mathrm{Mg}_{0,3} \mathrm{Al}_{0,3} \mathrm{Mn}_{0,4} \mathrm{Co}_{0,5} \mathrm{Ni}_{3,8}$ (Padrão), de forma a determinar a melhor condição de tratamento térmico $\left(600^{\circ} \mathrm{C}-1000^{\circ} \mathrm{C}\right)$ para $\mathrm{O}$ estudo das características dos eletrodos negativos com melhores propriedades elétricas. A liga $\mathrm{La}_{0,7} \mathrm{Mg}_{0,3} \mathrm{Al}_{0,3} \mathrm{Mn}_{0,4} \mathrm{Co}_{0,5} \mathrm{Ni}_{3,8}$ foi submetida a uma série de tratamentos térmicos $\left(700-1000^{\circ} \mathrm{C}\right)$ sob vácuo entre $10^{-4}$ e $10^{-5} \mathrm{mbar}$ por 8 horas. O tratamento térmico só é utilizado quando houver uma melhora substancial nas propriedades elétricas. Isto se deve ao fato de o custo de processamento se elevar consideravelmente com a introdução desta etapa. 0 tratamento térmico, sob vácuo em alta temperatura por um tempo prolongado, com grandes quantidades de material não é empregado industrialmente a menos eu isto possa ser repassado ao custo da bateria.

\subsubsection{Microscopia Eletrônica de Varredura (MEV)}

As micrografias obtidas por MEV da liga $\mathrm{La}_{0,7} \mathrm{Mg}_{0,3} \mathrm{Al}_{0,3} \mathrm{Mn}_{0,4} \mathrm{Co}_{0,5} \mathrm{Ni}_{3,8}$ $\left(600^{\circ} \mathrm{C}-1000^{\circ} \mathrm{C}\right)$ estão apresentadas nas FIG. 64 - 67, onde: (a) representa a visão geral (500x) e (b) detalhada (750x - 2000x). 


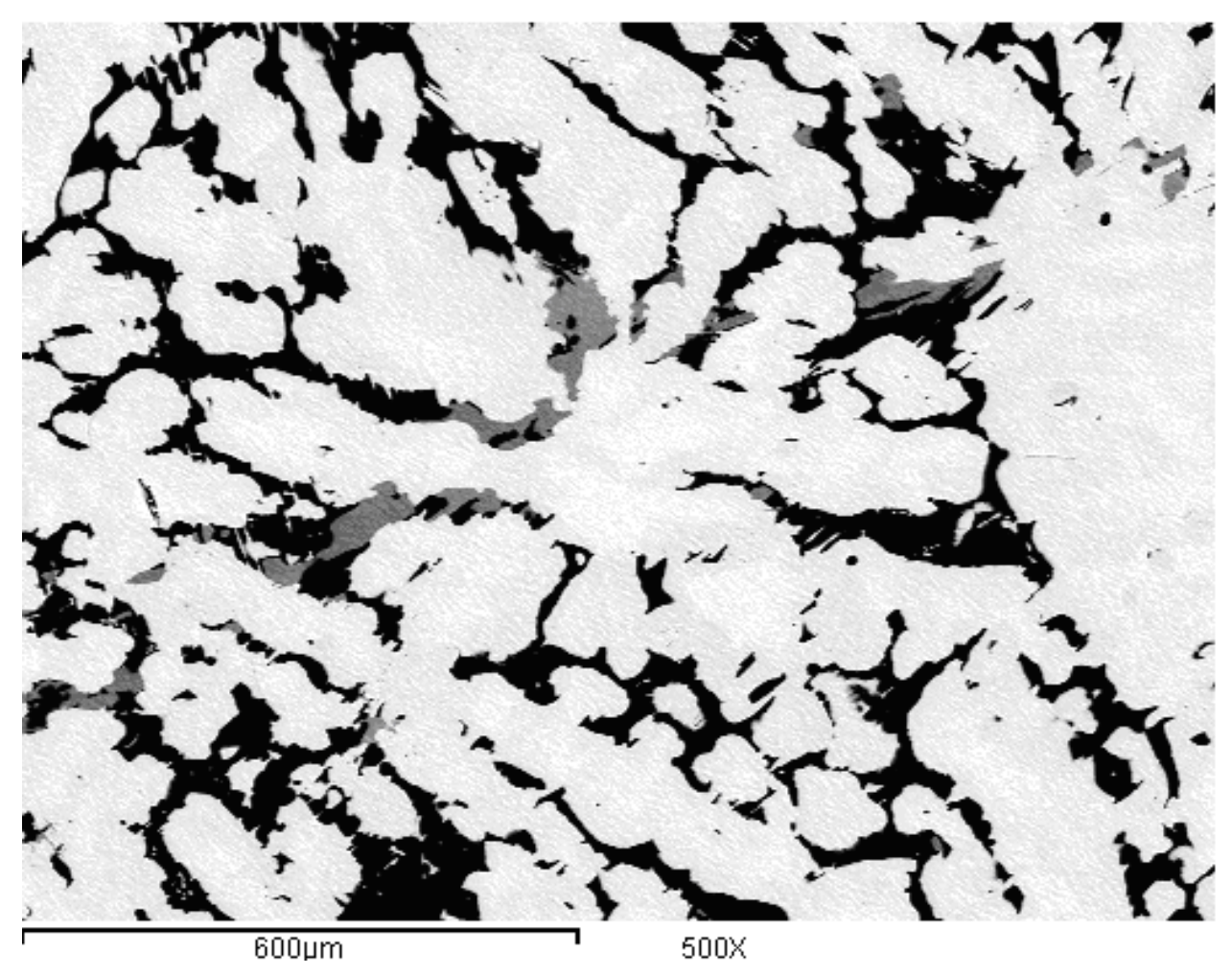

(a)

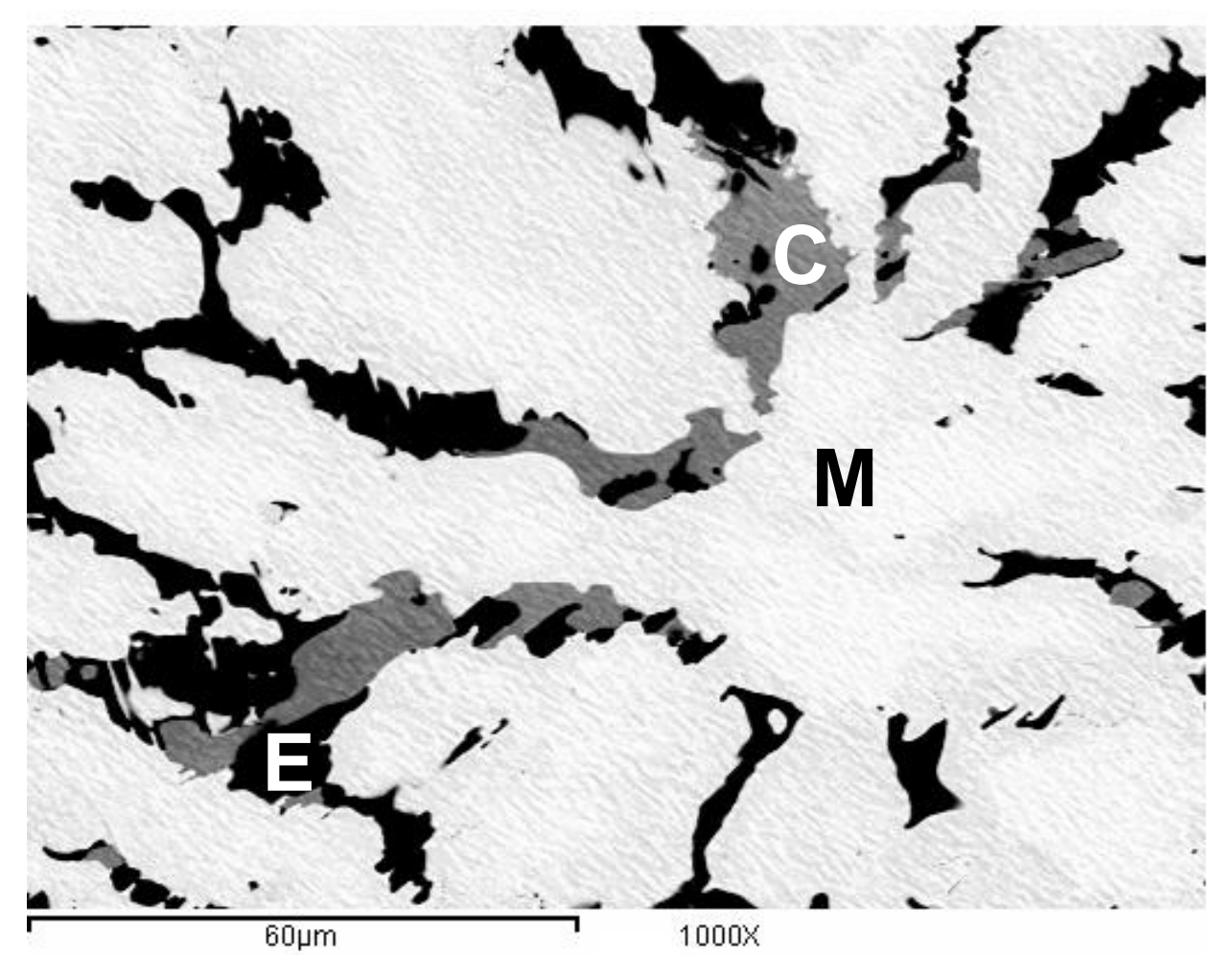

(b)

Figura $65-\mathrm{La}_{0,7} \mathrm{Mg}_{0,3} \mathrm{Al}_{0,3} \mathrm{Mn}_{0,4} \mathrm{Co}_{0,5} \mathrm{Ni}_{3,8}\left(700^{\circ} \mathrm{C}\right)$. 


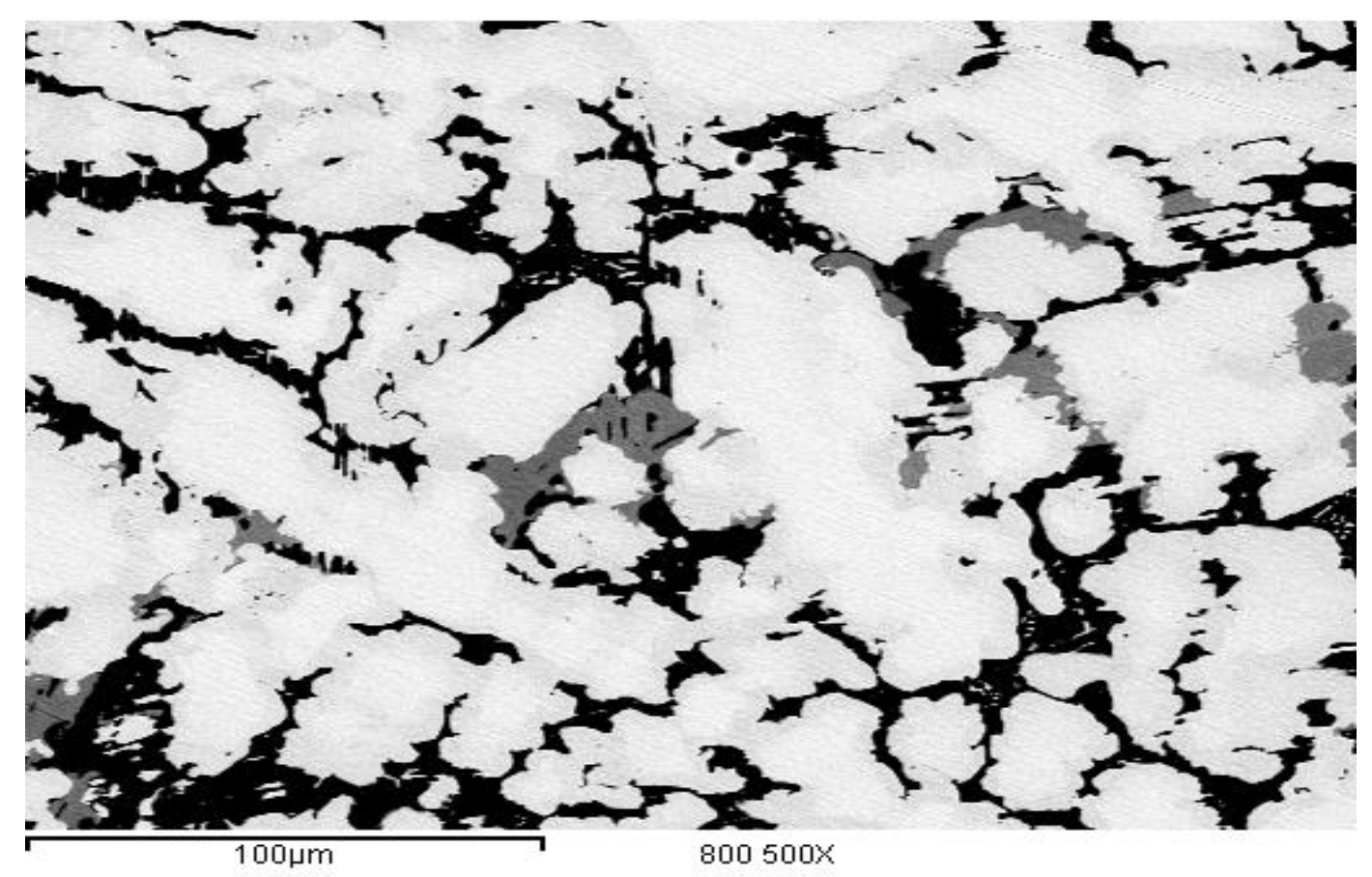

(a)

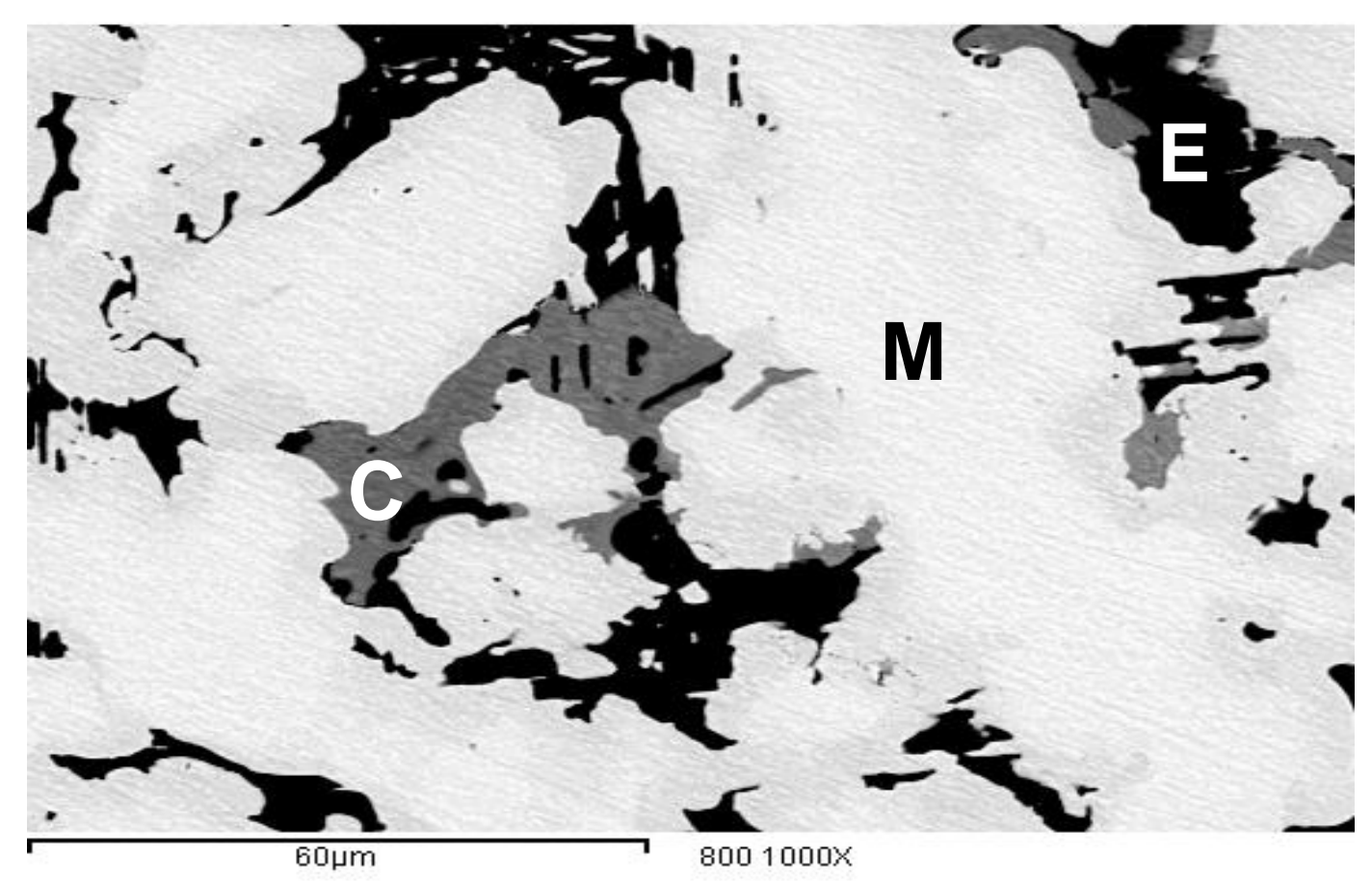

(b)

Figura 66 - $\mathrm{La}_{0,7} \mathrm{Mg}_{0,3} \mathrm{Al}_{0,3} \mathrm{Mn}_{0,4} \mathrm{Co}_{0,5} \mathrm{Ni}_{3,8}$ (800으 ). 


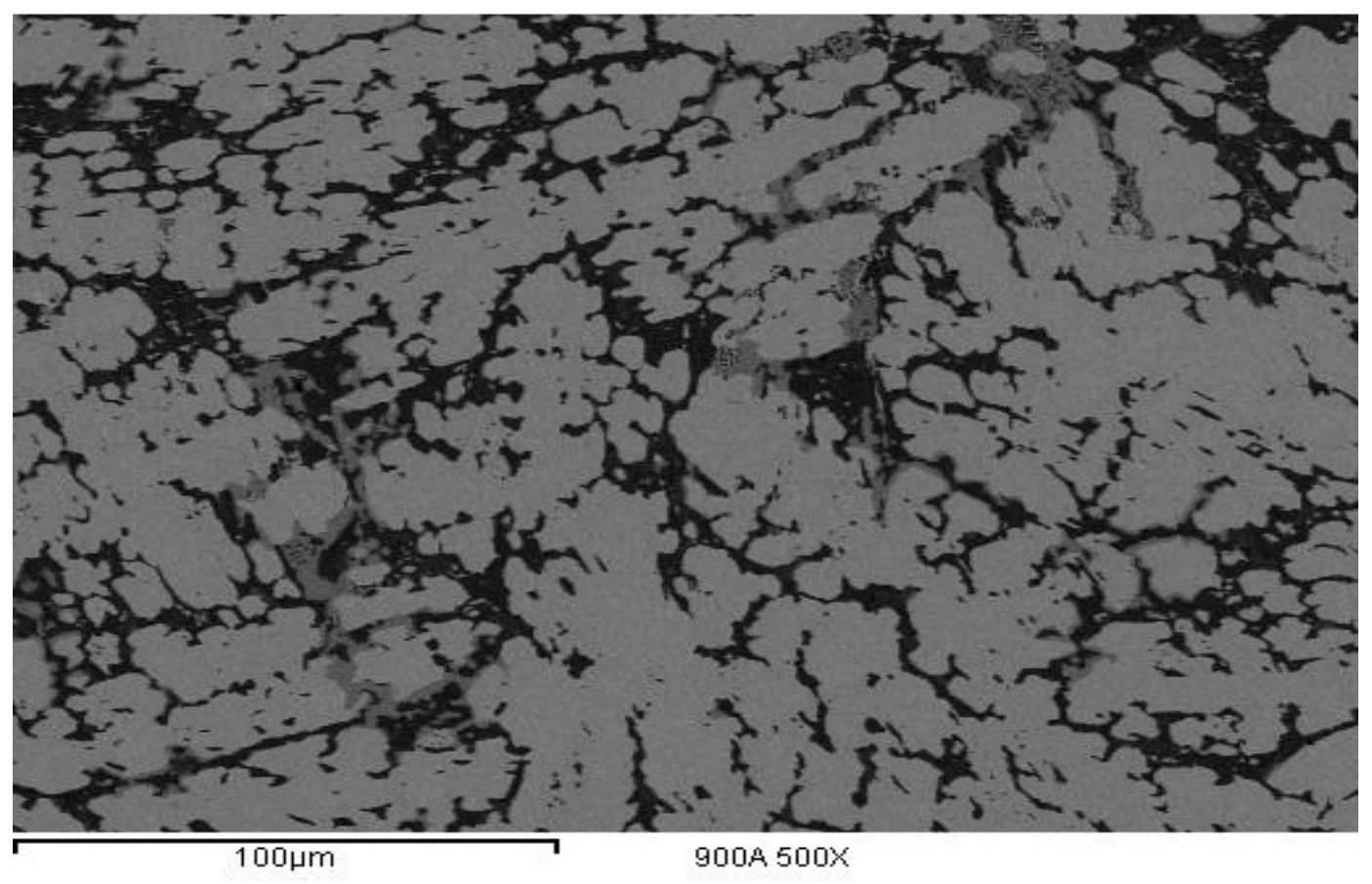

(a)

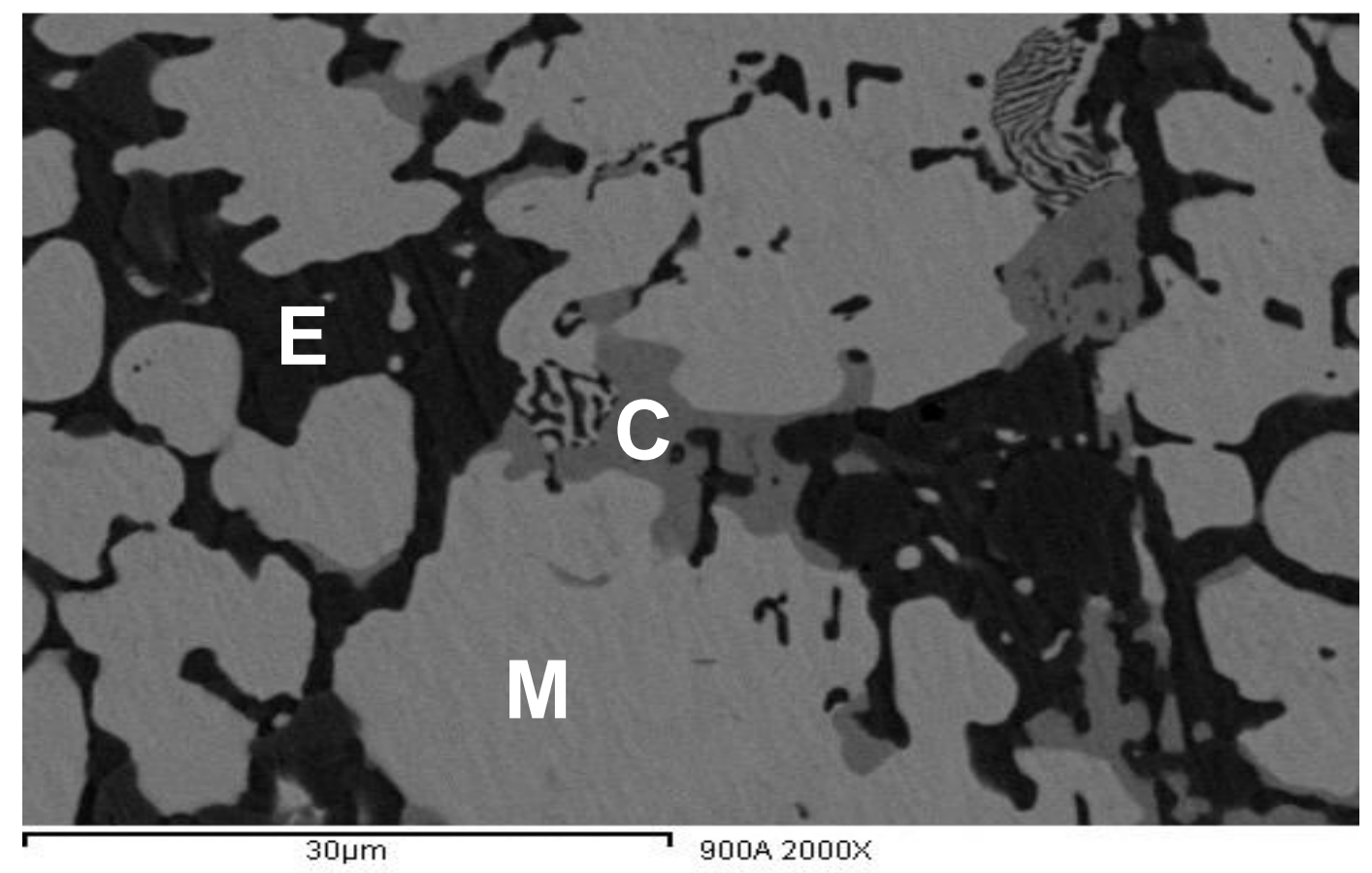

(b)

Figura $67-\mathrm{La}_{0,7} \mathrm{Mg}_{0,3} \mathrm{Al}_{0,3} \mathrm{Mn}_{0,4} \mathrm{Co}_{0,5} \mathrm{Ni}_{3,8}\left(900^{\circ} \mathrm{C}\right)$. 


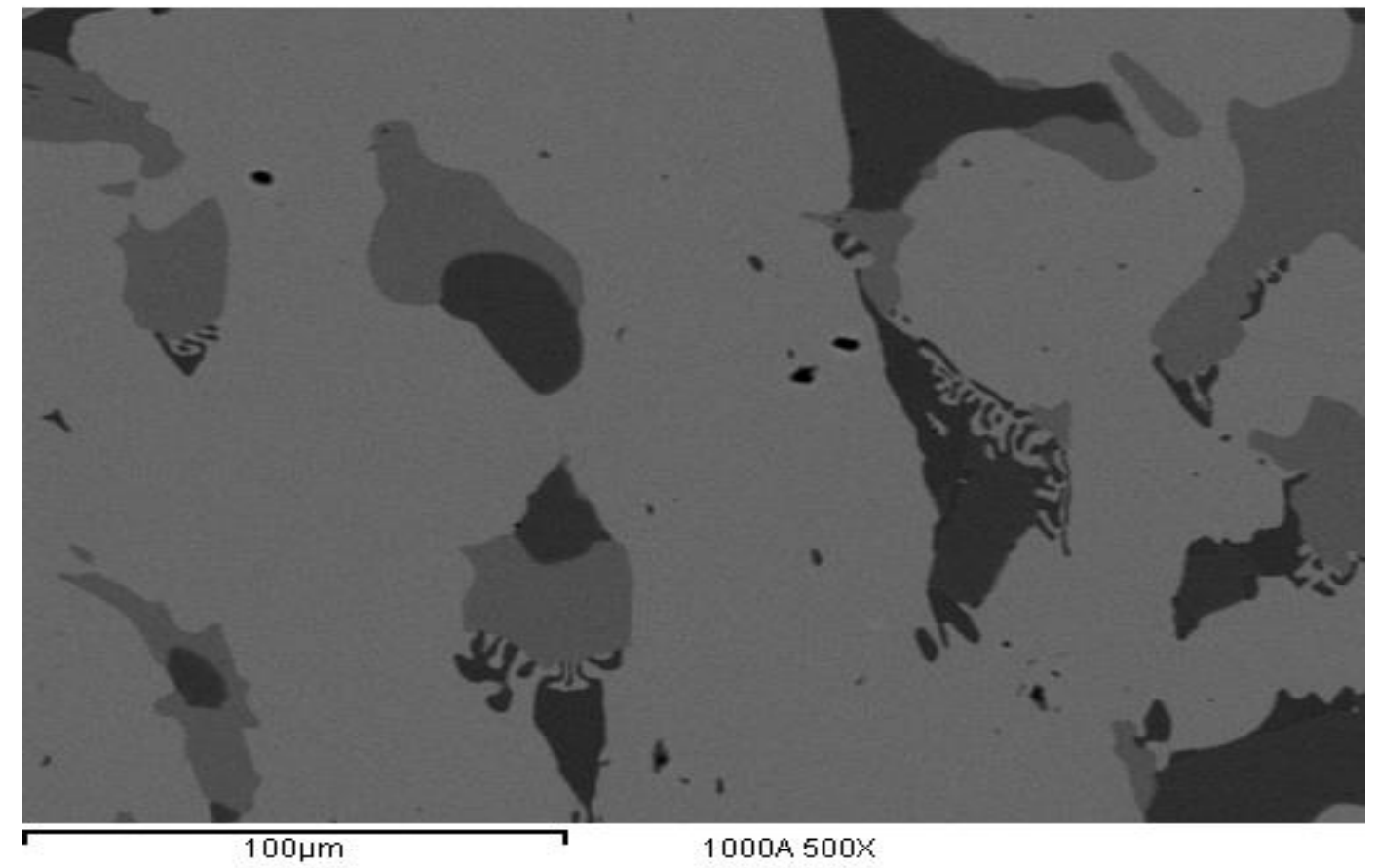

(a)

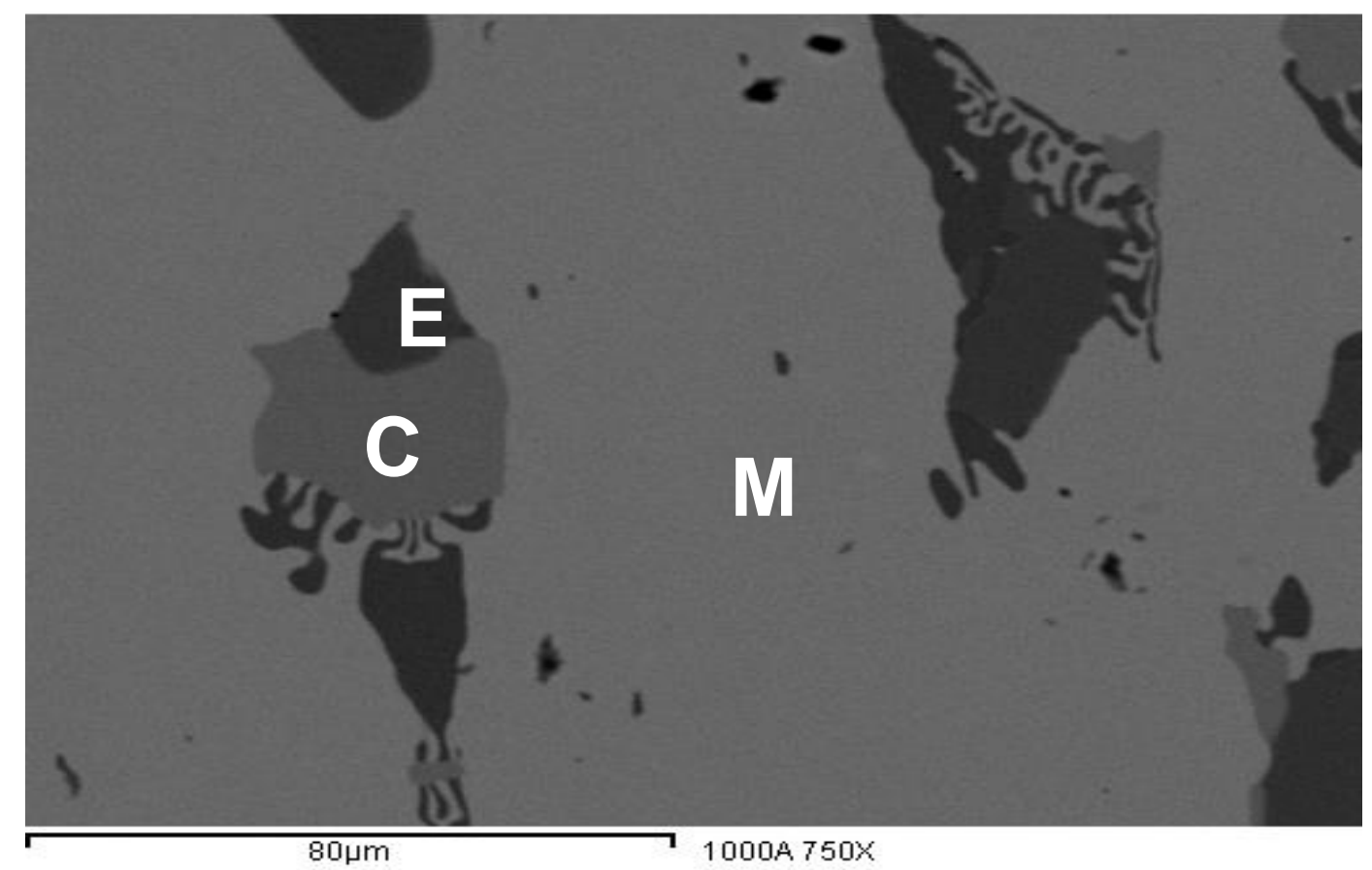

(b)

Figura 68 - $\mathrm{La}_{0,7} \mathrm{Mg}_{0,3} \mathrm{Al}_{0,3} \mathrm{Mn}_{0,4} \mathrm{Co}_{0,5} \mathrm{Ni}_{3,8}$ (1000ํㅡ ) 
Foram observadas três fases em todas as análises: a fase matriz $M$ (similar à fase $\mathrm{LaNi}_{5}$ - região branca com baixo teor de $\mathrm{Mg}$ ), a fase escura $\mathrm{E}$ (AlMnCoNi com alto teor de $\mathrm{Ni}$, sem $\mathrm{La}$ e $\mathrm{Mg}$ ) e a a fase cinza (C) (La,Mg)(Al,Mn,Co,Ni) $)_{x}(\mathrm{x} \sim$ entre 3 e 4$)$ com baixo teor de La ( 1\% at.). $\mathrm{Na}$ TAB. 27 - 29 estão apresentadas as análises por EDS das fases encontradas para as ligas $\mathrm{La}_{0,7} \mathrm{Mg}_{0,3} \mathrm{Al}_{0,3} \mathrm{Mn}_{0,4} \mathrm{Co}_{0,5} \mathrm{Ni}_{3,8}$ antes e após os respectivos tratamentos térmicos realizados. Foram realizadas cinco medidas para cada fase, através destes valores foram calculado as médias e os desvios padrões.

TABELA 27 - Composição da Fase Matriz encontrada na liga $\mathrm{La}_{0,7} \mathrm{Mg}_{0,3} \mathrm{Al}_{0,3} \mathrm{Mn}_{0,4} \mathrm{Co}_{0,5} \mathrm{Ni}_{3,8}$ com e sem Tratamento Térmico.

\begin{tabular}{|c|c|c|c|c|c|c|c|}
\hline \multirow{2}{*}{ Temperatura } & \multicolumn{6}{|c|}{ Composição Analisada (at.\%) } & \multirow{2}{*}{$\begin{array}{c}\text { Estequiometria } \\
\text { (La,Mg): } \\
\text { (Al,Mn,Co,Ni) }\end{array}$} \\
\hline & La & Mg & $\mathrm{Al}$ & Mn & Co & $\mathrm{Ni}$ & \\
\hline $\mathrm{S} / \mathrm{TT}$ & 15,4 & $<1$ & 4,5 & 2,5 & 7,9 & 69,5 & $1: 5$ \\
\hline $700 \div \mathrm{C}$ & 15,1 & $<1$ & 4,9 & 4,4 & 7,8 & 67,5 & $1: 5$ \\
\hline $800^{\circ} \mathrm{C}$ & 14,6 & $<1$ & 4,4 & 4,7 & 8,1 & 67,3 & $1: 5$ \\
\hline $900^{\circ} \mathrm{C}$ & 14,8 & 1,2 & 5,1 & 5,0 & 7,8 & 65,9 & $1: 5$ \\
\hline $1000^{\circ} \mathrm{C}$ & 15,4 & $<1$ & 4,3 & 5,0 & 7,9 & 67,2 & $1: 5$ \\
\hline
\end{tabular}

TABELA 28 - Composição da Fase Escura encontrada na liga $\mathrm{La}_{0,7} \mathrm{Mg}_{0,3} \mathrm{Al}_{0,3} \mathrm{Mn}_{0,4} \mathrm{Co}_{0,5} \mathrm{Ni}_{3,8}$ com e sem Tratamento Térmico.

\begin{tabular}{|c|c|c|c|c|c|c|c|}
\hline \multirow[t]{2}{*}{ Temperatura } & \multicolumn{6}{|c|}{ Composição Analisada (at.\%) } & \multirow{2}{*}{$\begin{array}{l}\text { Estequiometria } \\
\text { (Al: Mn,Co,Ni) }\end{array}$} \\
\hline & La & Mg & Al & Mn & Co & $\mathbf{N i}$ & \\
\hline $\mathrm{S} / \mathrm{TT}$ & 1,3 & - & 9,6 & 15,4 & 15,5 & 57,9 & $1: 1,7 ; 1,7 ; 6,1$ \\
\hline $700^{\circ} \mathrm{C}$ & 1,9 & - & 8,7 & 15,4 & 15,2 & 58,6 & $1: 1,7 ; 1,7 ; 6,7$ \\
\hline $800^{\circ} \mathrm{C}$ & 1,3 & 1,0 & 7,7 & 18,1 & 20,2 & 51,5 & $1: 2,3 ; 2,6 ; 6,6$ \\
\hline $900^{\circ} \mathrm{C}$ & $<1$ & 1,1 & 9,5 & 16,6 & 17,7 & 54,2 & $1: 1,7 ; 1,8 ; 5,7$ \\
\hline $1000^{\circ} \mathrm{C}$ & 1,2 & - & 9,8 & 15,9 & 16,1 & 56,9 & $1: 1,6 ; 1,6 ; 5,7$ \\
\hline
\end{tabular}


TABELA 29 - Composição da Fase Clara encontrada na liga

$\mathrm{La}_{0,7} \mathrm{Mg}_{0,3} \mathrm{Al}_{0,3} \mathrm{Mn}_{0,4} \mathrm{Co}_{0,5} \mathrm{Ni}_{3,8}$ com e sem Tratamento Térmico.

\begin{tabular}{|c|c|c|c|c|c|c|c|}
\hline \multirow{2}{*}{ Temperatura } & \multicolumn{6}{|c|}{ Composição Analisada (at.\%) } & \multirow{2}{*}{$\begin{array}{c}\text { Estequiometria } \\
\qquad(\mathrm{La}, \mathrm{Mg}): \\
(\mathrm{Al}, \mathrm{Mn}, \mathrm{Co}, \mathrm{Ni})\end{array}$} \\
\hline & La & Mg & Al & Mn & Co & $\mathrm{Ni}$ & \\
\hline $\mathrm{S} / \mathrm{TT}$ & 8,4 & 10,3 & 2,8 & 6,9 & 8,0 & 63,3 & $1: 5$ \\
\hline $700^{\circ} \mathrm{C}$ & 1,5 & 17,8 & 1,6 & 11,2 & 8,6 & 59,1 & $1: 4,1$ \\
\hline $800^{\circ} \mathrm{C}$ & $<1$ & 21,4 & - & 11,5 & 8,1 & 57,9 & $1: 3,6$ \\
\hline $900^{\circ} \mathrm{C}$ & 3,6 & 20,1 & 1,7 & 10,3 & 8,2 & 55,9 & $1: 3,2$ \\
\hline $1000 \div C$ & 2,2 & 20,0 & - & 10,4 & 8,0 & 59,2 & $1: 3,5$ \\
\hline
\end{tabular}

As micrografias apresentadas nas figuras de 65 a 68 , da liga $\mathrm{La}_{0,7} \mathrm{Mg}_{0,3} \mathrm{Al}_{0,3} \mathrm{Mn}_{0,4} \mathrm{Co}_{0,5} \mathrm{Ni}_{3,8}$ antes e após os tratamentos térmicos, revelam uma estrutura multifásica composta por três fases, descritas no parágrafo anterior. Observou-se que acima da temperatura de $700^{\circ} \mathrm{C}$, a concentração da fase clara $(C)$ foi alterada. $O$ aumento da fase clara $(C)$ provavelmente não alterou a quantidade da fase $\mathrm{LaNi}_{5}(\mathrm{M})$ encontrada na microestrutura. As análises de EDS também mostraram que a fase $(\mathrm{La}, \mathrm{Mg}) \mathrm{Ni}_{\mathrm{x}}(\mathrm{x} \sim$ entre 3 e 4 , região cinza escura) é muito heterogênea e o conteúdo dos principais elementos ( $\mathrm{Mg}, \mathrm{Al}, \mathrm{Mn}, \mathrm{Co}, \mathrm{Ni}$ ) variou consideravelmente. Isso pode ser atribuído à condição inicial destas ligas. Essa informação condiz com estudos anteriores, onde foi mostrado que, em uma liga $\mathrm{La}_{0,7} \mathrm{Mg}_{0,3} \mathrm{Al}_{0,2} \mathrm{Mn}_{0,1} \mathrm{Co}_{0,75} \mathrm{Ni}_{2,45}$ tratada termicamente em alta temperatura foi essencial para conseguir uma composição homogênea. Análises de raios $X$ e de Rietveld revelaram que as principais fases encontradas em todas as ligas foram: (La, $\mathrm{Mg}) \mathrm{Ni}_{3}$ e $\mathrm{LaNi}_{5}$. Esses estudos também relataram que a capacidade de descarga e do ciclo de vida aumentaram após o tratamento térmico da liga, mas a cinética eletroquímica dos eletrodos diminuiu após este tratamento [63].

O tratamento térmico (em alto vácuo e em alta temperatura) aumenta o custo de produção do eletrodo. Por isso, esse tratamento térmico deve ser usado somente se 0 aumento da capacidade de descarga compensar 0 
aumento no custo de processamento. $\mathrm{Na}$ literatura, a liga $\mathrm{La}_{0,7} \mathrm{Mg}_{0,3} \mathrm{Al}_{0,2} \mathrm{Mn}_{0,1} \mathrm{Co}_{0,75} \mathrm{Ni}_{2,45}$ sem tratamento térmico mostrou uma capacidade máxima de descarga de 350,9 mAh/g (e esse valor aumentou para apenas $370,0 \mathrm{mAh} / \mathrm{g}$ com tratamento térmico a $900^{\circ} \mathrm{C}$ por 8 horas.

\subsection{2 - Difração de Raios X}

A Figura 69 mostra os difratogramas de raios $X$ da liga $\mathrm{La}_{0,7} \mathrm{Mg}_{0,3} \mathrm{Al}_{0,3} \mathrm{Mn}_{0,4} \mathrm{Co}_{0,5} \mathrm{Ni}_{3,8}$ não tratada e tratada termicamente em diferentes temperaturas. Duas fases foram encontradas: $\mathrm{LaNi}_{5}$ (Grupo Espacial: P6/mmm - PDF: 50-0777), (La,Mg)Ni ${ }_{3}$ (Grupo Espacial: R-3m - PDF: 22-1124).

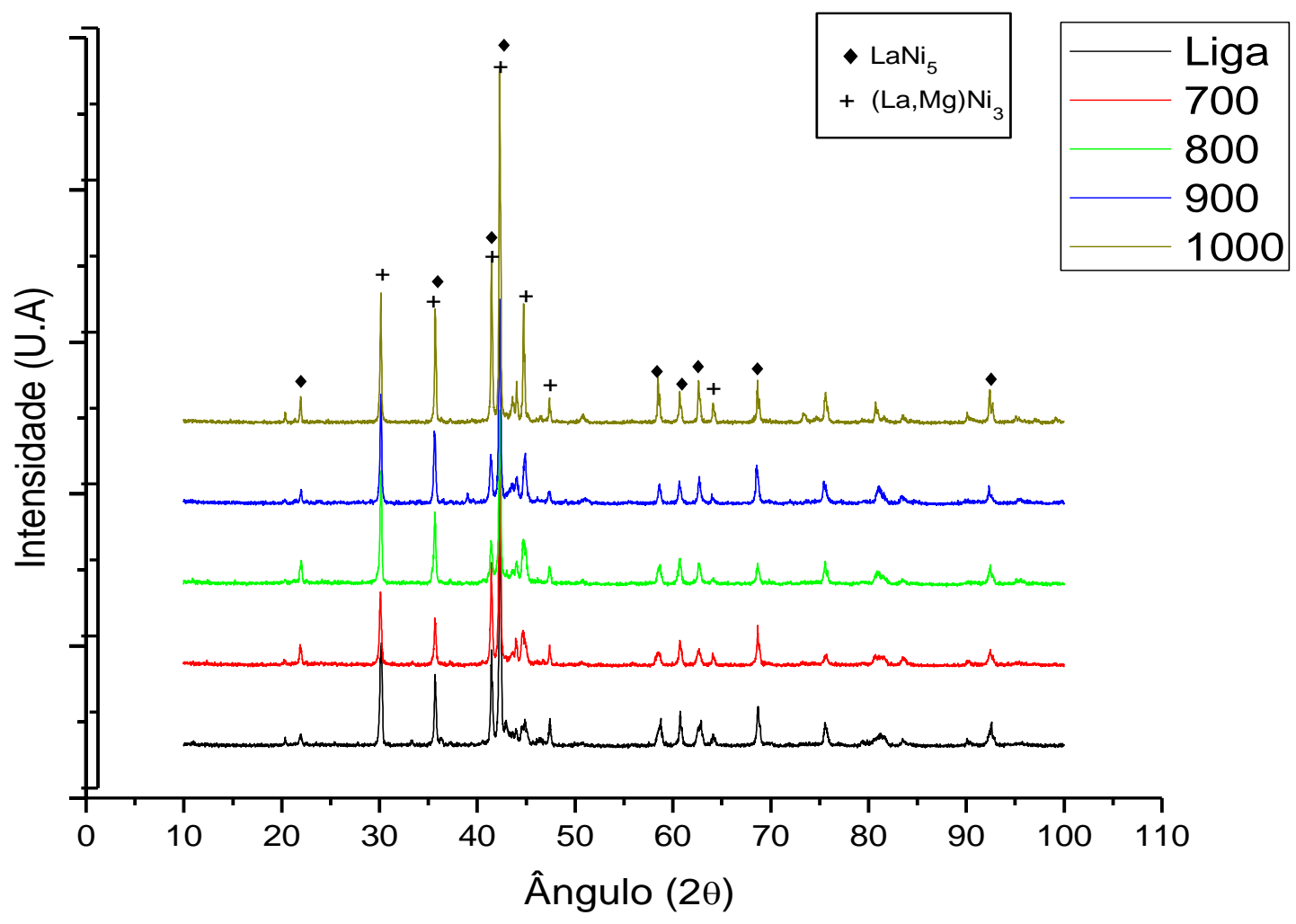

FIGURA 69 - Espectros de difração de raios $X$ da liga $\mathrm{La}_{0,7} \mathrm{Mg}_{0,3} \mathrm{Al}_{0,3} \mathrm{Mn}_{0,4} \mathrm{Co}_{0,5} \mathrm{Ni}_{3,8}$ sem e com tratamento térmico. 
As diferenças observadas nos difratogramas das ligas tratadas com a liga sem tratamento podem ser atribuídas a substituições atômicas nas fases decorrentes da presença de $\mathrm{Al}, \mathrm{Mg}, \mathrm{Mn}$ e Co . Não há muitas diferenças entre os difratogramas da liga e da liga tratada a $700^{\circ} \mathrm{C}$. Isso indicou que $\mathrm{O}$ tratamento realizado a essa temperatura não alterou a intensidade dos picos das fases existentes e não proporcionou um aumento da cristalinidade do material. Os difratogramas nas temperaturas de $800^{\circ} \mathrm{C}$ e $900^{\circ} \mathrm{C}$ também estão muito semelhantes. No difratograma na temperatura de $1000^{\circ} \mathrm{C}$ foi possível observar um aumento significativo da intensidade das fases ( $\mathrm{La}, \mathrm{Mg}) \mathrm{Ni}_{3}$ e $\mathrm{LaNi}_{5}$ $\left(2 \theta=36^{\circ}, 43^{\circ}, 44^{\circ}, 46^{\circ}\right)$ e um estreitamento dos picos de difração, indicando um aumento da cristalinidade. Analisando as micrografias (Figuras 65 a 68) e os difratogramas (Figura 69) pode-se deduzir que houve uma maior homogeneização das fases e crescimento dos grãos.

\subsubsection{Caracterização Elétrica}

\subsubsection{Capacidade de Descarga}

A Figura 70 apresenta o perfil de capacidade de descarga em função do número de ciclos de carga/descarga, do $1^{\circ}$ ao $50^{\circ}$, para os eletrodos formados pela liga $\mathrm{La}_{0,7} \mathrm{Mg}_{0,3} \mathrm{Al}_{0,3} \mathrm{Mn}_{0,4} \mathrm{Co}_{0,5} \mathrm{Ni}_{3,8}$ tratada termicamente. Nestes cinquenta ciclos iniciais os eletrodos atingiram a capacidade máxima e também mantiveram praticamente constantes suas capacidades de descarga após suas respectivas ativações. As capacidades médias de cada eletrodo também estão indicadas na Tabela 30. 


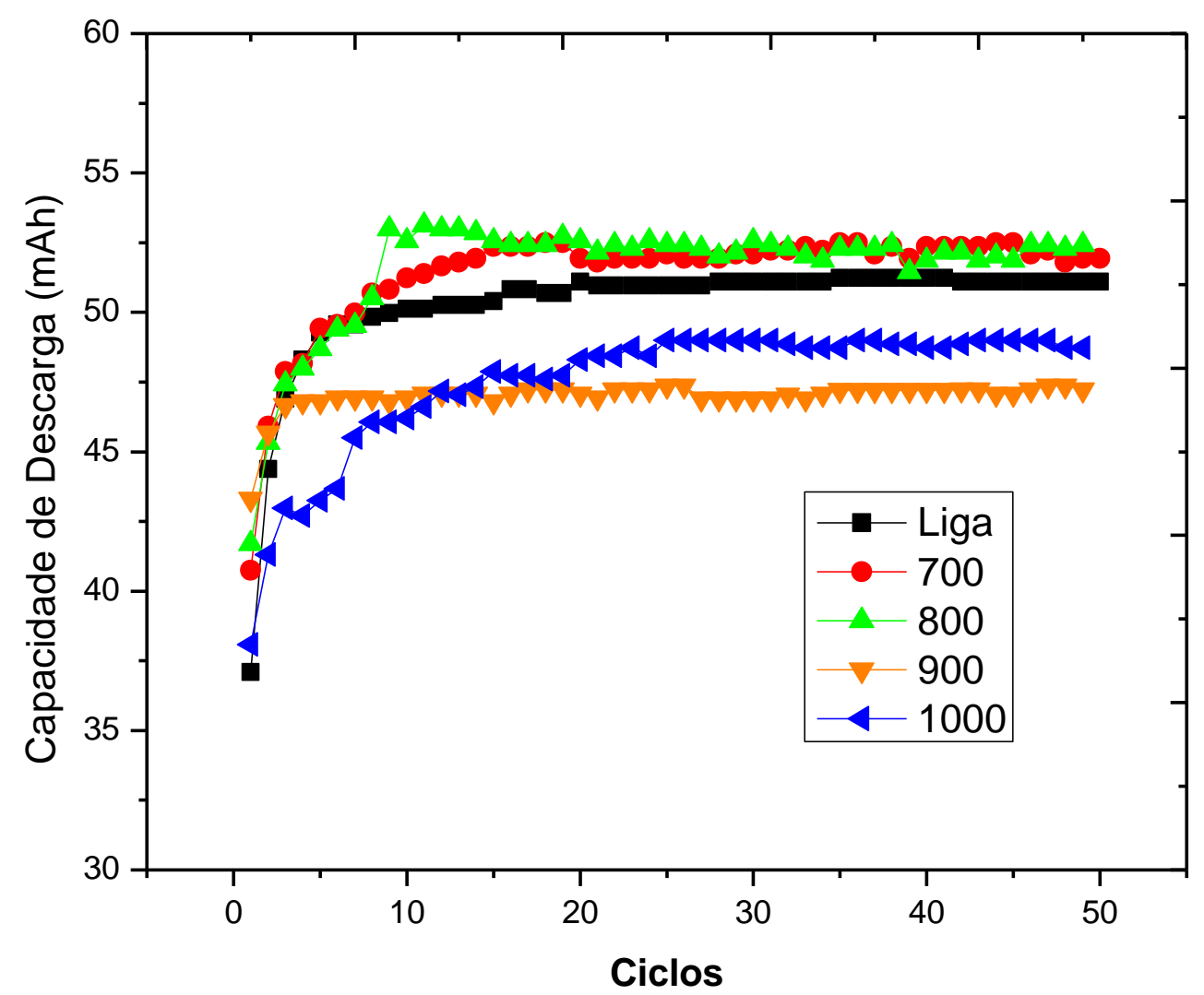

Figura 70 - Capacidade de descarga para a liga $\mathrm{La}_{0,7} \mathrm{Mg}_{0,3} \mathrm{Al}_{0,3} \mathrm{Mn}_{0,4} \mathrm{Co}_{0,5} \mathrm{Ni}_{3,8}$ antes e após os tratamentos térmicos.

TABELA 30 - Resultados das capacidades de descarga em relação ao tempo de vida dos eletrodos $\mathrm{La}_{0,7} \mathrm{Mg}_{0,3} \mathrm{Al}_{0,3} \mathrm{Mn}_{0,4} \mathrm{Co}_{0,5} \mathrm{Ni}_{3,8}$ tratados termicamente.

\begin{tabular}{|c|c|c|c|c|}
\hline Temp $\left({ }^{\circ} \mathbf{C}\right)$ & $C_{\text {máx }}(m A h)$ & $\mathrm{C}_{\text {máx }}\left(\mathrm{mAhg} \mathrm{g}^{-1}\right)$ & $\mathrm{C}_{50}$ (mAh) & $C_{\text {méd }}(m A h)$ \\
\hline $\mathrm{S} / \mathrm{TT}$ & 51,24 & 3660 & 51,1 & 50,26 \\
\hline 700 & 52,5 & 375 & 51,94 & 51,38 \\
\hline 800 & 53,13 & 379 & 52,43 & 51,94 \\
\hline 900 & 47,36 & 338 & 47,21 & 46,09 \\
\hline 1000 & 49,2 & 351 & 48,72 & 47,48 \\
\hline
\end{tabular}


Analisando os perfis de capacidade de armazenamento de carga dos eletrodos formados pela liga $\mathrm{La}_{0,7} \mathrm{Mg}_{0,3} \mathrm{Al}_{0,3} \mathrm{Mn}_{0,4} \mathrm{Co}_{0,5} \mathrm{Ni}_{3,8}$ tratada termicamente podemos observar que não houve aumento nos valores de capacidade média de descarga dos eletrodos produzidos nas temperaturas de $900^{\circ} \mathrm{C}$ (Cméd: 46 $\mathrm{mAh}$ ) e $1000^{\circ} \mathrm{C}$ (Cméd: 47,46 mAh) em relação ao eletrodo produzido sem o tratamento térmico (Cméd: 50,26 mAh). A diferença encontrada no baixo desempenho de capacidade de carga / descarga do eletrodo de $900^{\circ} \mathrm{C}$ pode ser explicada levando em consideração a alteração das suas microestruturas em relação às fases existentes. Nas micrografias (Figuras 10 e 11) ocorreu uma mudança na estrutura de fases da liga. A concentração da fase clara (C) vai diminuindo e consequentemente vai aumentando a concentração da fase escura (E). Essa mudança de concentração desestabilizou a região que limita a área das estruturas mencionadas anteriormente, diminuindo a homogeneidade do material e consequentemente, a capacidade dos eletrodos produzidos nessas temperaturas.

A fase (La,Mg) $\mathrm{Ni}_{x}$ é conhecida por ter uma capacidade de armazenamento de hidrogênio maior que a fase $\mathrm{LaNi}_{5}$. No eletrodo produzido na temperatura de $1000 \stackrel{\circ}{\circ}$ o processo de transformação de fase não havia ainda sido concluído como é possível observar na micrografia obtida por MEV, mas o aumento da intensidade das fases ( $\mathrm{La}, \mathrm{Mg}) \mathrm{Ni}_{3}$ e $\mathrm{LaNi}_{5}$ nos espectros de difração de raios $X$ indicou um aumento da cristalinidade e que o equilíbrio entre as fases do material estava melhor, contribuindo em um aumento expressivo na capacidade média desse eletrodo em relação ao eletrodo de 900 $\stackrel{\circ}{ } \mathrm{C}$.

Com relação aos eletrodos de $700{ }^{\circ} \mathrm{C}$ e $800{ }^{\circ} \mathrm{C}$ houve um pequeno aumento em sua capacidade média de descarga (Cméd: 51,38 mAh e 51,96 mAh) em comparação ao eletrodo da liga não tratado termicamente (Cméd: 50,26 mAh). Essa variação positiva da capacidade pode ser explicada apenas por um pequeno aumento da homogeneidade da liga, já que analisando e observando as microestruturas e os espectros dos dois materiais não encontramos diferenças significativas. 


\subsection{Caracterização da liga - $\mathrm{La}_{0,7} \mathrm{Mg}_{0,3} \mathrm{Al}_{0,3} \mathrm{Mn}_{0,4} \mathrm{Co}_{0,4} \mathrm{Nb}_{0,1} \mathrm{Ni}_{3,8}$}

Neste capitulo apresentam-se os resultados obtidos referentes ao processamento da liga $\mathrm{La}_{0,7} \mathrm{Mg}_{0,3} \mathrm{Al}_{0,3} \mathrm{Mn}_{0,4} \mathrm{Co}_{0,5} \mathrm{Nb}_{0,1} \mathrm{Ni}_{3,8}$ (liga que teve os melhores resultados na caracterização elétrica), de forma analisar o seu comportamento na melhor condição de tratamento térmico $\left(800^{\circ} \mathrm{C}\right)$ e analisar também seu comportamento como material pulverizado em uma bateria em comparação aos resultados obtidos com a liga padrão $\mathrm{La}_{0,7} \mathrm{Mg}_{0,3} \mathrm{Al}_{0,3} \mathrm{Mn}_{0,4} \mathrm{Co}_{0,5} \mathrm{Ni}_{3,8}$.

\subsubsection{Capacidade de descarga $\mathrm{La}_{0,7} \mathrm{Mg}_{0,3} \mathrm{Al}_{0,3} \mathrm{Mn}_{0,4} \mathrm{Co}_{0,4} \mathrm{Nb}_{0,1} \mathrm{Ni}_{3,8}\left(800^{\circ} \mathrm{C}\right)$}

A FIG. 71 apresenta o perfil de capacidade de descarga em função do numero de ciclos de carga/descarga, do $1^{\circ} \mathrm{ao} 50^{\circ}$, para o eletrodo formado pela liga $\mathrm{La}_{0,7} \mathrm{Mg}_{0,3} \mathrm{Al}_{0,3} \mathrm{Mn}_{0,4} \mathrm{Co}_{0,4} \mathrm{Nb}_{0,1} \mathrm{Ni}_{3,8}$ tratada termicamente a $800^{\circ} \mathrm{C}$ em comparação com a mesma liga não tratada termicamente. Nestes cinquenta ciclos iniciais os eletrodos atingiram a capacidade máxima e também mantiveram praticamente constantes suas capacidades de descarga.

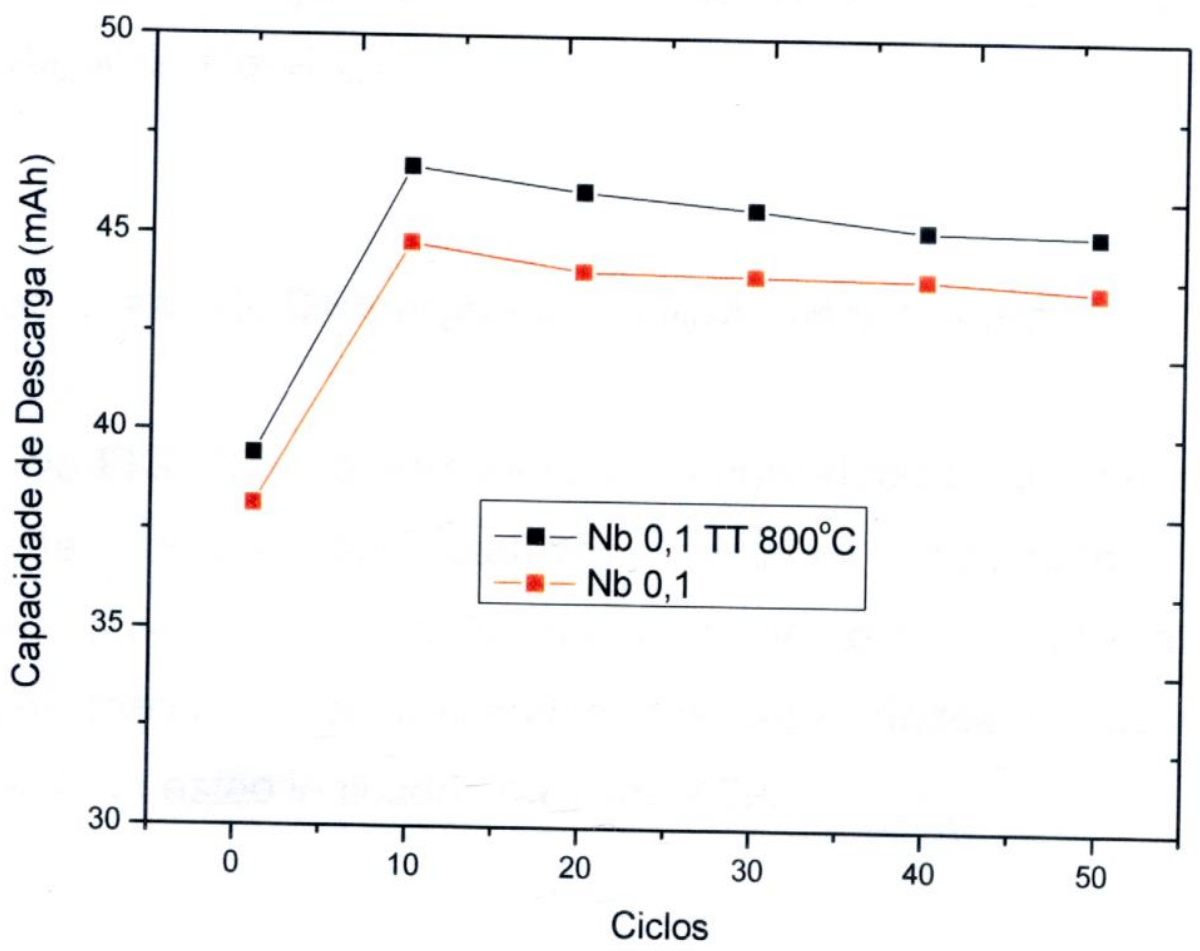

FIGURA 71 - Capacidade de descarga para a liga

$\mathrm{La}_{0,7} \mathrm{Mg}_{0,3} \mathrm{Al}_{0,3} \mathrm{Mn}_{0,4} \mathrm{Co}_{0,4} \mathrm{Nb}_{0,1} \mathrm{Ni}_{3,8}$ antes e após o tratamento térmico $\left(800^{\circ} \mathrm{C}\right)$. 
As capacidades médias e os resultados das capacidades de descarga de cada eletrodo também estão indicados na TAB. 31.

TABELA 31 - Resultados das capacidades de descarga da liga $\mathrm{La}_{0,7} \mathrm{Mg}_{0,3} \mathrm{Al}_{0,3} \mathrm{Mn}_{0,4} \mathrm{Co}_{0,4} \mathrm{Nb}_{0,1} \mathrm{Ni}_{3,8}$ sem tratamento térmico e tratada termicamente a $800^{\circ} \mathrm{C}$.

\begin{tabular}{|c|c|c|c|c|}
\hline Temp $\left({ }^{\circ} \mathrm{C}\right)$ & $C_{\text {máx }}(m A h)$ & $C_{\text {máx }}\left(m A h g^{-1}\right)$ & $\mathrm{C}_{50}$ (mAh) & $C_{\text {méd }}(\mathrm{mAh})$ \\
\hline $\mathrm{Nb0,1(S/TT)}$ & 44,94 & 321 & 43,68 & 43,12 \\
\hline $\mathrm{Nb} 0,1\left(800^{\circ} \mathrm{C}\right)$ & 46,71 & 333 & 45,18 & 44,70 \\
\hline
\end{tabular}

Analisando os perfis de capacidade de armazenamento de carga do eletrodo formado pela liga $\mathrm{La}_{0,7} \mathrm{Mg}_{0,3} \mathrm{Al}_{0,3} \mathrm{Mn}_{0,4} \mathrm{Co}_{0,4} \mathrm{Nb}_{0,1} \mathrm{Ni}_{3,8}$ tratada termicamente podemos observar que houve aumento nos valores de capacidade de descarga (Cmax: 46,71 mAh) em relação ao eletrodo não tratado termicamente (Cmax: 44,94 mAh). Essa melhora de capacidade ocorreu devido a um aumento da homogeneidade da liga como foi apresentado com os resultados da liga $\mathrm{La}_{0,7} \mathrm{Mg}_{0,3} \mathrm{Al}_{0,3} \mathrm{Mn}_{0,4} \mathrm{Co}_{0,5} \mathrm{Ni}_{3,8}$.

\subsubsection{Capacidade de descarga $\mathrm{La}_{0,7} \mathrm{Mg}_{0,3} \mathrm{Al}_{0,3} \mathrm{Mn}_{0,4} \mathrm{Co}_{0,4} \mathrm{Nb}_{0,1} \mathrm{Ni}_{3,8}$ (Pulverizada)}

Na FIG. 72 está apresentada a capacidade de descarga em função do numero de ciclos do eletrodo negativo fabricado com a liga $\mathrm{La}_{0,7} \mathrm{Mg}_{0,3} \mathrm{Al}_{0,3} \mathrm{Mn}_{0,4} \mathrm{Co}_{0,5} \mathrm{Ni}_{3,8}$ moída mecanicamente e pulverizada a 0,9 Mpa. As capacidades médias e os resultados das capacidades de descarga de cada eletrodo também estão indicados na TAB. 32. 


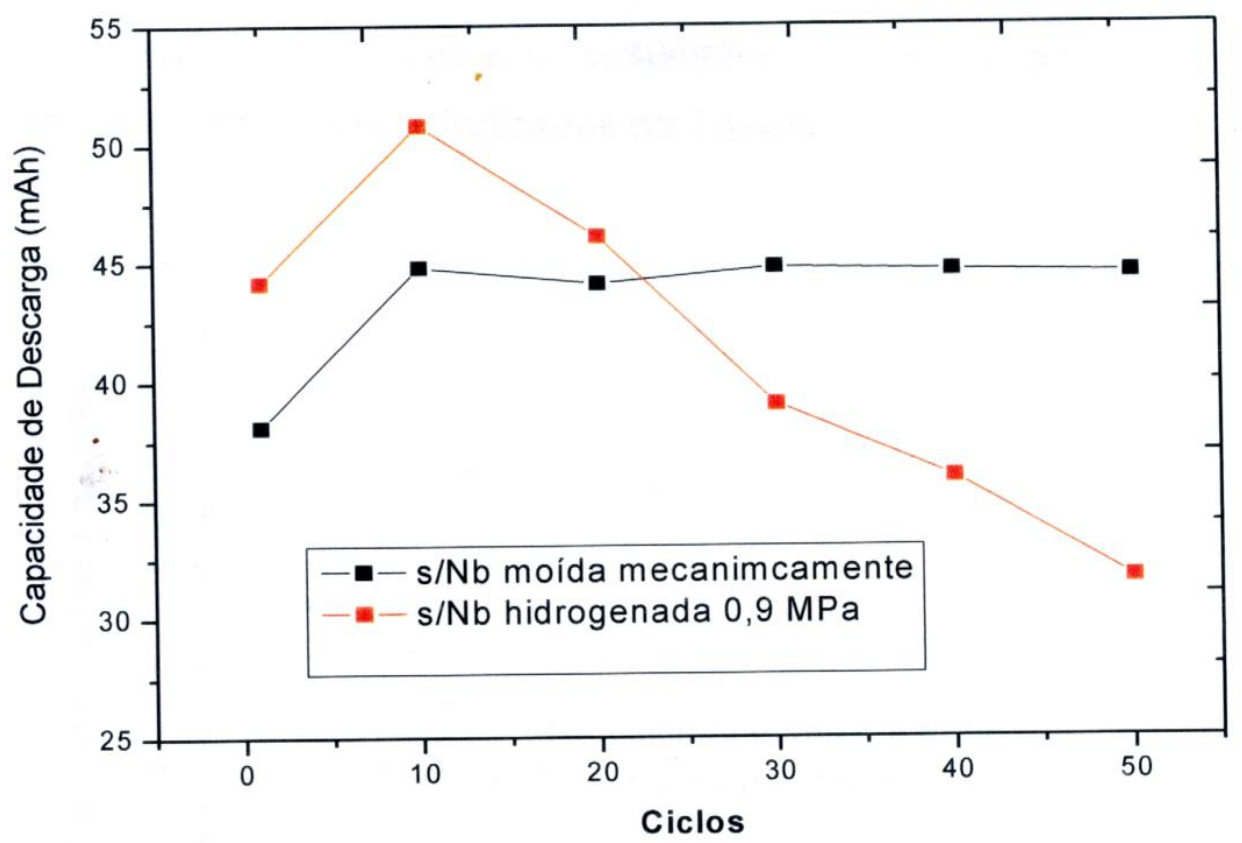

FIGURA 72 - Capacidade de descarga em função do numero de ciclos para a liga $\mathrm{La}_{0,7} \mathrm{Mg}_{0,3} \mathrm{Al}_{0,3} \mathrm{Mn}_{0,4} \mathrm{Co}_{0,5} \mathrm{Ni}_{3,8}$ moída mecanicamente e hidrogenada a 0,9 Mpa.

TABELA 32 - Capacidade de descarga em função do numero de ciclos para a liga $\mathrm{La}_{0,7} \mathrm{Mg}_{0,3} \mathrm{Al}_{0,3} \mathrm{Mn}_{0,4} \mathrm{Co}_{0,5} \mathrm{Ni}_{3,8}$ moída mecanicamente e hidrogenada a 0,9 Mpa.

\begin{tabular}{ccccc}
\hline Liga & $\mathbf{C}_{\text {máx }}$ (mAh) & $\mathbf{C}_{\text {máx }}\left(\right.$ mAhg $\left.^{-1}\right)$ & $\mathbf{C}_{50}$ (mAh) & $\mathbf{C}_{\text {méd }}$ (mAh) \\
\cline { 1 - 3 } $\mathbf{s} / \mathbf{N b}$ & 45,36 & 324 & 44,52 & 43,49 \\
\cline { 1 - 3 } $\mathbf{s} / \mathbf{N b}$ (0,9 Mpa) & 50,84 & 363 & 31,68 & 41,28 \\
\hline
\end{tabular}

Os resultados mostraram que houve um aumento na capacidade de descarga máxima de 45,36 mAh para 50,84 mAh para a bateria fabricada com a liga após a hidrogenação. Porém, após 25 ciclos a capacidade de descarga é menor comparada a da liga moída mecanicamente, mostrando uma diminuição na estabilidade cíclica da bateria fabricada com a liga hidrogenada.

Na FIG. 73 está mostrada a capacidade de descarga em função do numero de ciclos do eletrodo negativo fabricado com a liga $\mathrm{La}_{0,7} \mathrm{Mg}_{0,3} \mathrm{Al}_{0,3} \mathrm{Mn}_{0,4} \mathrm{Co}_{0,4} \mathrm{Nb}_{0,1} \mathrm{Ni}_{3,8}$ moída mecanicamente e hidrogenada a 0,9 
Mpa. As capacidades médias e os resultados das capacidades de descarga de cada eletrodo também estão indicados na TAB. 33.

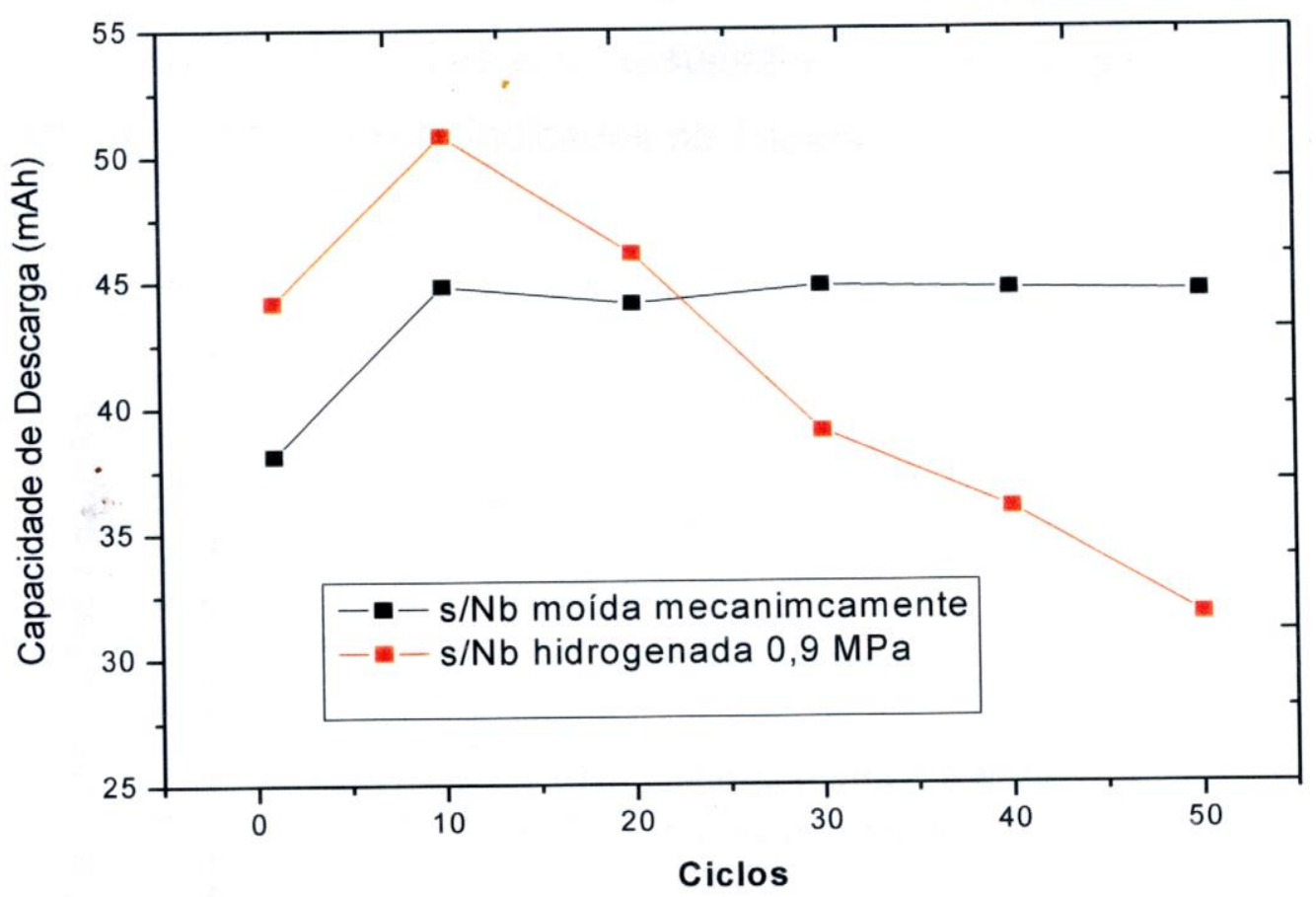

FIGURA 73 - Capacidade de descarga em função do numero de ciclos para a liga $\mathrm{La}_{0,7} \mathrm{Mg}_{0,3} \mathrm{Al}_{0,3} \mathrm{Mn}_{0,4} \mathrm{Co}_{0,4} \mathrm{Nb}_{0,1} \mathrm{Ni}_{3,8}$ moída mecanicamente e hidrogenada a 0,9 Mpa.

TABELA 33 - Capacidade de descarga em função do numero de ciclos para a liga $\mathrm{La}_{0,7} \mathrm{Mg}_{0,3} \mathrm{Al}_{0,3} \mathrm{Mn}_{0,4} \mathrm{Co}_{0,4} \mathrm{Nb}_{0,1} \mathrm{Ni}_{3,8}$ moída mecanicamente e hidrogenada a 0,9 Mpa.

\begin{tabular}{ccccc}
\hline Liga & $\mathbf{C}_{\text {máx }}$ (mAh) & $\mathbf{C}_{\text {máx }}\left(\mathrm{mAhg}^{-1}\right)$ & $\mathbf{C}_{\text {50 }}$ (mAh) & $\mathbf{C}_{\text {méd }}(\mathrm{mAh})$ \\
\cline { 1 - 3 } $\mathbf{N b 0 , 1}$ & 44,94 & 321 & 43,68 & 43,12 \\
\hline Nb0,1 (0,9Mpa) & 49,87 & 356 & 33,52 & 40,82 \\
\hline
\end{tabular}

Os resultados obtidos foram semelhantes ao encontrado para a liga sem nióbio, o aumento da capacidade de descarga foi de 44,94 mAh (liga moída mecanicamente) para 49,87 mAh (liga hidrogenada). Porém a capacidade de descarga da bateria fabricada co a liga hidrogenada a 0,9 Mpa não se estabiliza. Este fato, de alta capacidade de descarga inicial, pode estar 
relacionado ao tamanho das partículas, que facilita a absorção do hidrogênio no interior da liga durante os primeiros ciclos, mas, por outro lado, aumenta a decrepitação das partículas durante os ciclos de carga e descarga, diminuindo o tamanho de partículas e como consequência, ocorre uma queda drástica na capacidade de descarga.

Nas FIG. 74 e 75 estão apresentadas as distribuições de tamanho de partículas obtidas por CILAS das ligas $\mathrm{La}_{0,7} \mathrm{Mg}_{0,3} \mathrm{Al}_{0,3} \mathrm{Mn}_{0,4} \mathrm{Co}_{0,5} \mathrm{Ni}_{3,8}$ e $\mathrm{La}_{0,7} \mathrm{Mg}_{0,3} \mathrm{Al}_{0,3} \mathrm{Mn}_{0,4} \mathrm{Co}_{0,4} \mathrm{Nb}_{0,1} \mathrm{Ni}_{3,8}$ após hidrogenação a 0,9 Mpa.

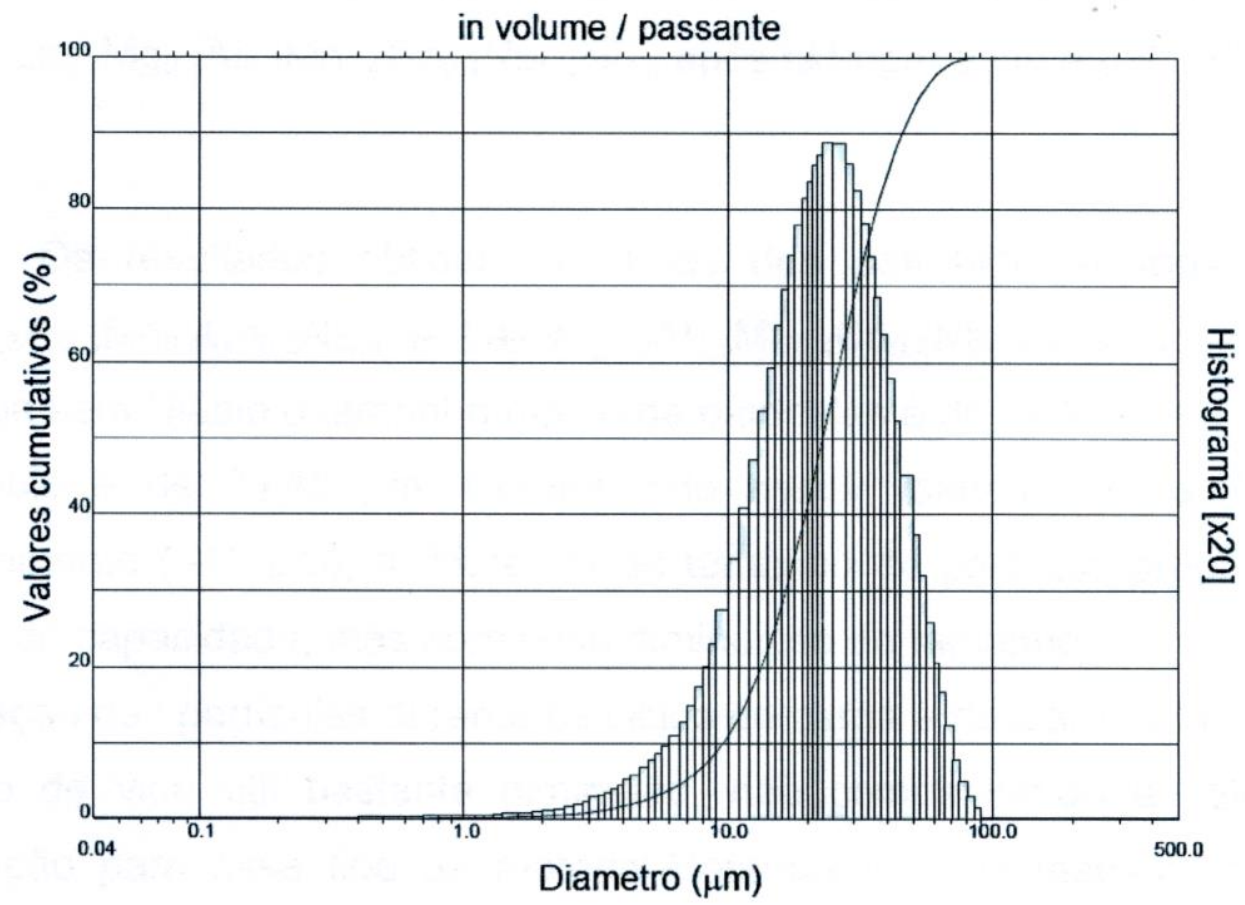

FIGURA 74 - Distribuição do tamanho de partícula obtida por CILAS para a liga $\mathrm{La}_{0,7} \mathrm{Mg}_{0,3} \mathrm{Al}_{0,3} \mathrm{Mn}_{0,4} \mathrm{Co}_{0,5} \mathrm{Ni}_{3,8}$ após hidrogenação a 0,9 Mpa. 


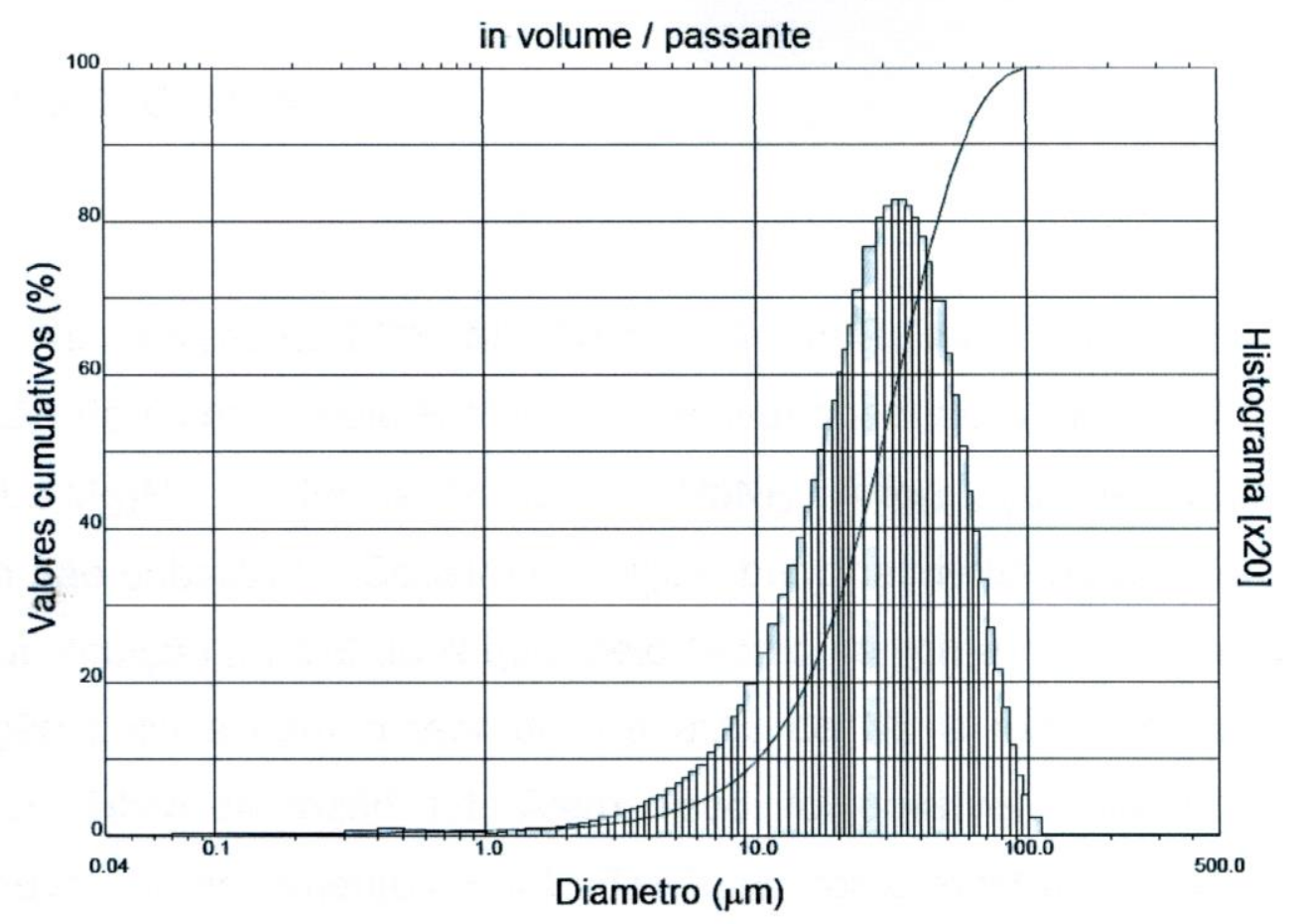

FIGURA 75 - Distribuição do tamanho de partícula obtida por CILAS para a liga $\mathrm{La}_{0,7} \mathrm{Mg}_{0,3} \mathrm{Al}_{0,3} \mathrm{Mn}_{0,4} \mathrm{Co}_{0,4} \mathrm{Nb}_{0,1} \mathrm{Ni}_{3,8}$ após hidrogenação a 0,9 Mpa.

Os resultados obtidos por Cilas dos pós hidrogenados das ligas $\mathrm{La}_{0,7} \mathrm{Mg}_{0,3} \mathrm{Al}_{0,3} \mathrm{Mn}_{0,4} \mathrm{Co}_{0,5} \mathrm{Ni}_{3,8}$ e $\mathrm{La}_{0,7} \mathrm{Mg}_{0,3} \mathrm{Al}_{0,3} \mathrm{Mn}_{0,4} \mathrm{Co}_{0,4} \mathrm{Nb}_{0,1} \mathrm{Ni}_{3,8}$ mostraram que para a liga sem nióbio o tamanho médio de partículas é de 29,23 $\mu \mathrm{m}$ e para a liga com nióbio é de 29,45 $\mu \mathrm{m}$. comparando esses valores com a liga moída mecanicamente $(\sim 45 \mu \mathrm{m})$, a diferença de tamanho de partícula proporciona um aumento de capacidade, mas com essa diminuição do tamanho ocorre uma maior decrepitação das partículas durante os ciclos de carga e descarga e a bateria tem seu ciclo de vida útil bastante diminuído, não compensando a utilização da pulverização para esse tipo de material. Materiais moídos mecanicamente tem um melhor desempenho de vida útil, mas dependendo do seu manuseio ao ar na montagem da bateria podem também ter uma perda significativa de tempo de vida. 


\section{CONCLUSÕES}

As analises de EDS, MEV e difração de Raios-X mostraram que com a substituição do Cobalto pelo Nióbio foi possível observar a diminuição das fases $\mathrm{LaNi}_{5}$ e (La,Mg)Ni $\mathrm{Ni}_{3}$ e a formação da fase $\mathrm{NbNi}_{3}$. A formação desta fase deve-se ao Nióbio não substituir o Cobalto nas ligas, principalmente na fase matriz $\mathrm{LaNi}_{5}$. Com a substituição parcial do Níquel pelo Nióbio na liga matriz muda para uma composição $\mathrm{NbNi}$ e razão 1:1. Além disso, foi possível observar que com o Nióbio houve um refinamento do grão das ligas, como mostram as FIG. 25 a 30.

Os resultados da pulverização por hidrogênio das ligas mostraram que a absorção de hidrogênio aumentou com a substituição parcial do Nióbio pelo Cobalto mais se manteve semelhante quando a substituição foi completa. A absorção de hidrogênio diminuiu com a substituição parcial do Nióbio pelo Níquel. Todas as ligas foram pulverizadas por completo somente na pressão de 0,9 Mpa.

Com a substituição do Cobalto pelo Nióbio a capacidade de descarga máxima das baterias seladas diminuiu com o aumento do teor de $\mathrm{Nb}$, passando de 45,36 mAh (sem Nb) para 30,94 mAh $\left(\mathrm{Nb}_{0,5}\right)$. Com a substituição parcial do Níquel pelo Nióbio a capacidade de descarga máxima das baterias seladas também diminuiu, passando de 30,94 $\mathrm{mAh}\left(\mathrm{Nb}_{0,5}\right)$ para 19,76 $\left(\mathrm{Nb}_{1,8}\right)$. A diminuição da capacidade de descarga, com o aumento do teor de $\mathrm{Nb}$ na liga pode ser atribuído ao aumento da concentração da fase $\mathrm{NbNi}_{3}$. Com o aumento do volume dessa fase, a fase $\mathrm{LaNi}_{5}$ conhecida por favorecer o armazenamento de hidrogênio tem sua concentração diminuída.

$\mathrm{O}$ melhor resultado encontrado para as baterias de $\mathrm{Ni}-\mathrm{HM}$ foi para a liga $\mathrm{La}_{0,7} \mathrm{Mg}_{0,3} \mathrm{Al}_{0,3} \mathrm{Mn}_{0,4} \mathrm{Co}_{0,4} \mathrm{Nb}_{0,1} \mathrm{Ni}_{3,8}$, obtendo uma capacidade de descarga máxima de 44.94 mAh $\left(321 \mathrm{mAhg}^{-1}\right.$ ) com 114 ciclos (perda de $10 \%$ da capacidade de descarga). Com o aumento do teor de $\mathrm{Nb}$ há uma perda do tempo de vida de ciclos da bateria e um aumento da resistência de polarização.

Os ensaios de corrosão apresentaram em linha gerais que a adição de Nióbio torna o material menos resistente a corrosão ( $E_{\text {corr }}$ é tanto mais negativo com o aumento no teor de Nióbio bem como o I corr é maior). 
O tratamento térmico influencia positivamente a capacidade elétrica do eletrodo. Dos testes realizados com a liga padrão $\mathrm{La}_{0,7} \mathrm{Mg}_{0,3} \mathrm{Al}_{0,3} \mathrm{Mn}_{0,4} \mathrm{Co}_{0,5} \mathrm{Ni}_{3,8}$ entre as temperaturas de $700^{\circ} \mathrm{C}$ a $1000^{\circ} \mathrm{C}$ o melhor resultado encontrado para as baterias de $\mathrm{Ni}-\mathrm{HM}$ foi para a liga tratada termicamente a $800^{\circ} \mathrm{C}$.

Utilizando os melhores resultados encontrados para a temperatura de tratamento térmico $\left(800^{\circ} \mathrm{C}\right)$ e pressão de pulverização $(0,9 \mathrm{MPa})$ na produção de eletrodos com a liga com melhor capacidade de descarga da série $\mathrm{Nb}$ $\left(\mathrm{La}_{0,7} \mathrm{Mg}_{0,3} \mathrm{Al}_{0,3} \mathrm{Mn}_{0,4} \mathrm{Co}_{0,4} \mathrm{Nb}_{0,1} \mathrm{Ni}_{3,8}\right)$ pode-se verificar que o tratamento térmico e a pulverização melhoram a capacidade máxima de descarga da liga. No entanto a bateria produzida com a liga pulverizada, quando comparada com a bateria produzida com a liga moída mecanicamente, tem a estabilidade de ciclos diminuída devido ao menor tamanho das partículas. 


\section{REFERÊNCIAS BIBLIOGRÁFICAS}

[1] SWARTZENDRUBERT, L.J.; BENNETTT, L.H.; WATSON, MOSSBAUER, R.E. studies of hydrided TiFe. Journal Phys. F: Metal Phys., v. 6, p. L331L334, 1976.

[2] SCHLAPBACH, L.; ZUTTEL, A. Hydrogen-storage materials for mobile applications. Nature., v. 414, p. 353-358, 2001.

[3] VUCHT, J.H.N.V.; KUJIPERS, F.A.; BRUNING, H.C.A.M. Philips Res. Repts., v. 25, p. 133, 1970.

[4] RUESTSCHI, P.; MELI, F.; DESILVESTRO, J. Nickel-metal hydride batteries-. The preferred batteries of the future?. Journal of Power Sources., v. 57, p. 85-91, 1995.

[5] DHAR, S.K.; OVSHINSKY, S.R.; GIFFORD, P.R.; CORRIGAN, D.A.; FETCENKO, M.A.; VENKATESAN, S. Nickel/metal hydride technology for consumer and electric vehicle batteries - a review and up-date. Journal of Power Sources., v. 65, p. 1-7, 1997.

[6] PUTOIS, F. Market for nickel-cadmium batteries. Journal of Power Sources., v. 57, p. 67-70, 1995.

[7] GENGA, M.; HAN, J.; FENG, .; NORTHWOOD, D.O. Electrochemical measurements of a metal hydride electrode for the $\mathrm{Ni} / \mathrm{MH}$ battery. International Journal of Hydrogen Energy., v. 25, p. 203-210, 2000.

[8] BUCHMANN, I. Batteries in a Portable World. Cadex Electronics Inc, 2001.cap. 2, Battery Chemistries. p. 2.

[9] NICHOLAS, D.M.; WILSON, E.A.; SHA, W. Microstructure and mechanical properties of high toughness. Microscopy and Analysis, p. 19-22, 05/2012.

[10] BARBOSA, L.P.; TAKIISHI, H.; FARIA, R.N. The effect of cobalt content on the microstructure of $\mathrm{Pr}-\mathrm{Fe}-\mathrm{Co}-\mathrm{B}-\mathrm{Nb}$ alloys and magnetic properties of HDDR. Journal of Magnetic Materials. v. 268, p. 132-139, 2004.

[11] BANCZEK, E.P.; Desenvolvimento e caracterização de camadas de fosfato de zinco/níquel e zinco/nióbio. Tese de doutorado, IPEN, São Paulo, 2008.

[12] LINDEN, D.; REDDY, T.B. Handbook of Batteries. 3o ed. 2001.

[13] FENG, F.; GENG, M.; NORTHWOOD, D.O. Electrochemical behaviour of intermetallic-based metal hydrides used in Ni-metal hydride $(\mathrm{MH})$ batteries: a review. International Journal of Hydrogen Energy., v. 26, p. 725-734, 2001. 
[14] SAKAI, T. Hydrogen Storage Alloys for Nickel-metal Hydride Battery. Zeitschift feur Physikalische Chemie., v. 183, p. 333-346, 1994.

[15] ZHANG, L.Y. Rare Earth-Based Metal Hydrides and NiMH Rechargeable Batteries. In: RARE EARTH: SCIENCE TECHONOLOGY AND APPLICATIONS 3rd SYMP. Feb, 1997, Orlando.

[16] KIM, D.M.; JEON, S.W.; LEE, J.Y. A study of the development of a high capacity and high performance $\mathrm{Zr}-\mathrm{Ti}-\mathrm{Mn}-\mathrm{V}-\mathrm{Ni}$ hydrogen storage alloy for $\mathrm{Ni}-\mathrm{MH}$ rechargeable batteries. Journal of Alloys and Compounds., v. 279, p. 209-214, 1998.

[17] PARK, HY.; CHANG, I.; CHO, W.I.; CHO, B.W.; JANG, H.; LEE, S.R.; YUN,K.S. Electrode characteristics of the $\mathrm{Cr}$ and La doped AB2-type hydrogen storage alloys. International Journal of Hydrogen Energy., v. 26, p. 949-955, 2001.

[18] KNOSP, B.; VALLET, L.; BLANCHARD, P. Performance of an AB2 alloy in sealed $\mathrm{Ni}-\mathrm{MH}$ batteries for electric vehicles: quantification of corrosion rate and consequences on the battery performance. Journal of Alloys and Compounds., v. 293-295, p. 770-774, 1999.

[19] GENG, M.; HAN, J.; FENG, F. Charging/discharging stability of a metal hydride battery electrode. Journal of the Electrochemical Society., v. 146(7), p. 2371-2375, 1999.

[20] SHUMIN, H.; ZHONG, Z. The effect of vacuum evaporation plating on phase structure and electrochemical properties of AB5-5 mass\% $\mathrm{LaMg}_{3}$ composite alloy. Electrochimica acta., v. 50, p. 5491-5495, 2005.

[21] SEO, C.Y.; CHOI, S.J.; CHOI, J.; PARK C.N.; LEE J.Y. Effect of vanadium content on electrochemical properties of la-based AB5-type metal hydride electrodes. International Journal of Hydrogen Energy., v. 28, p. 967-975, 2003.

[22] NAKAMURA, Y.; OGURO, K.; UEHARA, I.; AKIBA, E. X-ray diffraction peak broadening and degradation in LaNi5-based alloys. International Journal of Hydrogen Energy., v. 25, p. 531-537, 2000.

[23] Energizer Battery Manufacturing Inc. Nickel Metal Hydride (NiMH) Handbook and Application Manual. 2010.

[24] PAN, H.; MA, S.; SHEN, J.; TAN, J.; DENG, J.; GAO, M. Effect of the substitution of $\mathrm{Pr}$ for $\mathrm{La}$ on the microstructure and electrochemical properties of La0,7-xPrxMg0,3 $\mathrm{Ni}_{2,45} \mathrm{Co}_{0,75} \mathrm{Mnn}_{0,1} \mathrm{Al}_{0,2}(\mathrm{x}=0,0-0,3$ ) hydrogen storage electrode alloys. International Journal of Hydrogen Energy., $v$. 32, p. 2949-2956, 2007. 
[25] MA, S.; GAO, M.; LI, R.; PAN, H.; LEI, Y. A study on the structural and

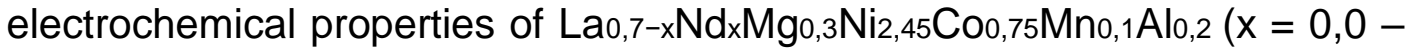
$3,0)$ hydrogen storage alloys. Journal of Alloys and Compounds., v. 457, p. 457-464, 2008.

[26] PAN, H.; JIN, Q.; GAO, M.; LIU, Y.; LI, R.; LEI, Y. Effect of the cerium content on the structural and electrochemical properties of the La0,7-xCexMgo,3Ni2,875Mn0,1 $\mathrm{Co}_{0,525}(\mathrm{x}=0$ - 0,5) hydrogen storage alloys. Journal of Alloys and Compounds., v. 373, p. 237-245, 2004.

[27] ZHANG, X.B.; SUN, D.Z.; YIN, W.Y.; CHAI, Y.J.; ZHAO, M.S. Effect of $\mathrm{La} / \mathrm{Ce}$ ratio on the structure and electrochemical characteristics of La0,7-xCexMg0,3Ni2,8Co0,5 $(x=0,1-0,5)$ hydrogen storage alloys. Electrochimica Acta., v. 50, p. 1957-1964, 2005.

[28] PAN, H.; YUE, Y.; GAO, M.; WU, X.; CHEN, N.; LEI, Y.; WANG, Q. The effect of substitution of $\mathrm{Zr}$ for $\mathrm{La}$ on the electrochemical properties of La0,7-xZrxMgo,3Ni2,45Mn0,1 $\mathrm{Co}_{0,75} \mathrm{Al}_{0,2}$ hydrogen storage electrode alloys. Journal of Alloys and Compounds., v. 397, p. 269-275, 2005.

[29] DONG, Z.; WU, Y.; MA, L.; SHEN, X.; WANG, L. Electrochemical Properties of (La1-x Tix)0,67Mg0,33Ni2,75Co0,25 ( $x=0-0,20$. at\%) hydrogen storage alloys. Materials Research Bulletin., v. 45, p. 256-261, 2010.

[30] LIU, Y.; PAN, H.; GAO, M.; ZHU, Y.; LEI, Y.; WANG, Q. The e\&ect of Mn substitution for $\mathrm{Ni}$ on the structural and electrochemical properties of La0,7Mg0,3 $\mathrm{Ni}_{2,55-x} \mathrm{Co}_{0,45} \mathrm{Mn}_{x}$ hydrogen storage electrode alloys. International Journal of Hydrogen Energy., v. 29, p. 297-305, 2004.

[31] LIU, Y.; PAN, H.; GAO, M.; ZHU, Y.; LEI, Y. Hydrogen storage and

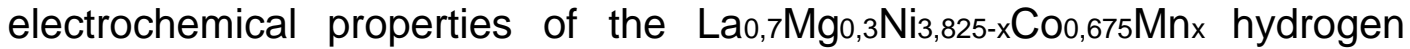
storage electrode alloys. Journal of Alloys and Compounds., v. 365, p. 246-252, 2004.

[32] LIU,Y.; PAN, H.; ZHU, Y.; LI, R.; LEI, Y. Influence of Mn content on the structural and electrochemical properties of the La0,7 $\mathrm{Mgg}_{0,3} \mathrm{Ni}_{4,25-\mathrm{x}} \mathrm{Co}_{0,75} \mathrm{Mn}_{\mathrm{x}}$ hydrogen storage alloys. Materials Science and Engineering., v. A372, p. 163-172, 2004.

[33] JIANG, L.; LI, G.; XU, L.; JIANG, W.; LAN, Z.; GUO, J. Effect of substituting $\mathrm{Mn}$ for $\mathrm{Ni}$ on the hydrogen storage and electrochemical properties of $\mathrm{ReNi}, 6-\mathrm{xMn} \times \mathrm{Co0,9}$ alloys. International Journal of Hydrogen Energy., v. 35, p. 204- 209, 2010.

[34] ZHANG, X.B.; SUN, D.Z.; YIN, W.Y.; CHAI, Y.J.; ZHAO, M.S. Effect of Mn content on the structure and electrochemical characteristics of La0,7Mg0,3Ni2,975-x Co0,525Mnx ( $\mathrm{x}=0$ - 0,4) hydrogen storage alloys. Electrochimica Acta., v. 50, p. 2911-2918, 2005. 
[35] LIU, Y.; PAN, H.; GAO, M.; LI, RUI.; LEI, Y. Effect of Co content on the structural and electrochemical properties of the $\mathrm{La}_{0,7} \mathrm{Mg}_{0,3} \mathrm{Ni}_{3,4-x \mathrm{Mn}_{0,1} \mathrm{Cox}}$ hydride alloys I. Electrochemical properties. Journal of Alloys and Compounds., v. 376, p. 296-303, 2004.

[36] LIAO, B.; LEI, Y.Q.; CHEN, L.X.; LU, G.L.; PAN, H.G.; WANG, Q.D. Effect of $\mathrm{Co}$ substitution for $\mathrm{Ni}$ on the structural and electrochemical properties of La2Mg(Ni1-xCox)9 $(x=0,1-0,5)$ hydrogen storage electrode alloys. Electrochimica Acta., v. 50, p. 1057-1063, 2004.

[37] LIU, Y.; PAN, H.; GAO, M.; LI, R.; LEI, Y. Effect of Co content on the

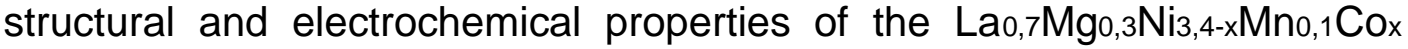
hydride alloys. Journal of Alloys and Compounds., v. 376, p. 304-313, 2004.

[38] LIAO, B.; LEI, Y.Q.; CHEN, L.X.; LU, G.L.; PAN, H.G.; WANG, Q.D. The effect of $\mathrm{Al}$ substitution for $\mathrm{Ni}$ on the structure and electrochemical properties of $\mathrm{AB}_{3}$-type $\mathrm{La} 2 \mathrm{Mg}\left(\mathrm{Ni}_{1-\mathrm{x}} \mathrm{Al}\right) \mathrm{I}_{9}(\mathrm{x}=0-0,05)$ alloys. Journal of Alloys and Compounds., v. 404-406, p. 665-668, 2005.

[39] PAN, H.; LIU, Y.; GAO, M.; LEI, WANG, Q. Electrochemical properties of the $\mathrm{La}_{0,7} \mathrm{Mg}_{0,3} \mathrm{Ni}_{2,65-x \mathrm{Mn} 0,1} \mathrm{Co0}_{, 75} \mathrm{Al} \times(\mathrm{x}=0-0,5)$ hydrogen storage alloy electrodes. Journal of Electrochemical Society., v. 152, p. A326-A332, 2005.

[40] LIU, Y.; PAN, H.; GAO, M.; MIAO H, LEI, Y.; WANG, Q. Function of AI on the cycling behavior of the La-Mg-Ni-Co-type alloy electrodes. International Journal of Hydrogen Energy., v. 33, p. 124-133, 2008.

[41] SAKINTUNA, B.; LAMARI-DARKRIM, F.; HISCHER, M. Metal hydride materials for solid hydrogen storage: A review. International Journal of Hydrogen Energy., v. 32, p. 1121-1140, 2007.

[42] GOO, N.; LEE, K. The electrochemical hydriding properties of $\mathrm{Mg}-\mathrm{Ni}-\mathrm{Zr}$ amorphous alloy. International Journal of Hydrogen Energy., v. 27, p. 433-438, 2002.

[43] NIU, H.; NOTHWOOD, D. Enhanced electrochemical properties of ballmilled $\mathrm{Mg}_{2} \mathrm{Ni}$ electrodes. International Journal of Hydrogen Energy., $\mathrm{v}$. 27, p. 69-77, 2002.

[44] SOUZA, E.C.; TICIANELLI, E.A. Structural and electrochemical properties of MgNi-based alloys with $\mathrm{Ti}, \mathrm{Pt}$ and Pd additives. International Journal of Hydrogen Energy., v. 32, p. 4917-4924, 2007.

[45] OESTERRICHER, H.; BITTNER, H. HYDRIDE FORMATION IN La1xMg ${ }_{x}$ Ni2.Journal of the Less-Common Metals., v. 13, p. 339-344, 1980. 
[46] KADIR, K.; SAKAI, T.; UEHARA, I. Structural investigation and hydrogen capacity of $\mathrm{YMg}_{2} \mathrm{Ni}$ and $\left(\mathrm{Y}_{0,5} \mathrm{Ca} 0,5\right)(\mathrm{MgCa}) \mathrm{Niq}$ : new phases in the $\mathrm{AB}_{2} \mathrm{C}_{9}$ system isostructural with $\mathrm{LaMg}_{2} \mathrm{Nig}$. Journal of Alloys and Compounds., v. 287, p. 264-270, 1999.

[47] KADIR, K.; SAKAI, T.; UEHARA, I. Structural investigation and hydrogen capacity of $\mathrm{YMg}_{2} \mathrm{Nig}$ and $\left(\mathrm{Y}_{0,5} \mathrm{Ca} 0,5\right)(\mathrm{MgCa}) \mathrm{Nig}$ : new phases in the $\mathrm{AB}_{2} \mathrm{C}_{9}$ system isostructural LaMg2Nig. Journal of Alloys and Compounds., v. 287, p. 264-270, 1999.

[48] KADIR, K.; SAKAI, T.; UEHARA, I. Structural investigation and hydrogen capacity of $\mathrm{LaMg}_{2} \mathrm{Nig}$ and $\left(\mathrm{La}_{0,65} \mathrm{Ca} 0,35\right)\left(\mathrm{Mg}_{1,32} \mathrm{Ca} 0,68\right) \mathrm{Nig}$ of the $\mathrm{AB}_{2} \mathrm{C}_{9}$ type structure. Journal of Alloys and Compounds., v. 302, p. 112-117, 2000.

[49] CHEN, J.; TAKESHITA, H.T.; TANAKA, H.; KURIYAMA, N.; SAKAI, T.; UEHARA, I.; HARUTA, M. Hydriding properties of $\mathrm{LaNi}_{3}$ and $\mathrm{CaNi} 3$ and their substitutes with PuNiz-type structure. Journal of Alloys and Compounds., v. 302, p. 304-313, 2000.

[50] PAN, H.; LIU, Y.; GAO, M.; ZHU, Y.; LEI, Y.; WANG, Q. A n investigation onthe structural and electrochemical properties of $\mathrm{La} 0,7 \mathrm{Mg} 0,3\left(\mathrm{Ni}_{0,85} \mathrm{Co}_{0,15}\right) \times(\mathrm{X}$ $=3,15-3,80$ ) hydrogen storage electrode alloys. Journal of Alloys and Compounds., v. 351, p. 228-234, 2003.

[51] LIU, Y.; PAN, H.; GAO, M.; ZHU, Y.; LEI, Y. Hydrogen storage and electrochemical properties of the $\mathrm{La0}, 7 \mathrm{Mg} 0,3 \mathrm{Ni}, 825-\times \mathrm{Co0}, 675 \mathrm{Mn} \times$ hydrogen storage electrode alloys. Journal of Alloys and Compounds., v. 365, p. 246-252, 2004.

[52] LIAO, B.; LEI, Y.Q.; LU, G.L.; CHEN, L.X.; PAN, H.G.; WANG, Q.D. The electrochemical properties of $\operatorname{LaxMg}_{3}-\mathrm{XNig}(\mathrm{X}=1,0-2,0)$ hydrogen storage alloys. Journal of Alloys and Compounds., v. 356-357, p. 746-749, 2003.

[53] LIAO, B.; LEI, Y.Q.; LU, G.L.; CHEN, L.X.; PAN, H.G.; WANG, Q.D. The electrochemical properties of $\mathrm{LaxMg}_{3}-\mathrm{XNig}(\mathrm{X}=1,0-2,0)$ hydrogen storage alloys. Journal of Power Sources., v. 129, p. 358-367, 2004.

[54] ZHANG, A.; HAN, S.; LI, Y.; JING, T. Electrochemical properties of

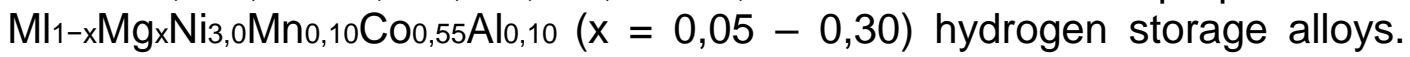
Journal of Power Sources., v. 431, p. 208-211, 2007.

[55] GOO, N.; LEE, K. The electrochemical hydriding properties of Mg-Ni-Zr amorphous alloy. International Journal of Hydrogen Energy., v. 27, p. 433-438, 2002.

[56] NIU, H.; NOTHWOOD, D. Enhanced electrochemical properties of ballmilled $\mathrm{Mg}_{2} \mathrm{Ni}$ electrodes. International Journal of Hydrogen Energy., $\mathrm{v}$. 27, p. 69-77, 2002. 
[57] HAN, S.; LEE, P.; LEE, J.; ZUTTEL, A.; SCLAPBACH, L. Effects of Ti on the cycle life of amorphous MgNi-based alloy prepared by ball milling. Journal of Alloys and Compounds., v. 306, p. 219-226, 2000.

[58] LIU, J.; YUAN, H.; CAO, J.; WANG, Y. Effect of Ti-Al substitution on the electrochemical properties of amorphous MgNi-based secondary hydride electrodes. Journal of Alloys and Compounds., v. 392, p. 300-305, 2005.

[59] ROUE, L.; RONGEAT, C. On the cycle life improvement of amorphous MgNibased alloy for $\mathrm{Ni}-\mathrm{MH}$ batteries. Journal of Alloys and Compounds., v. 404-406, p. 679-681, 2005.

[60] MA, T.; HATANO, Y.; ABE T.; WATANABE, K. Effects of Pd addition on electrochemical properties of MgNi. Journal of Alloys and Compounds., v. 372, p. 251-258, 2004.

[61] MA, T.; HATANO, Y.; ABE T.; WATANABE, K. Effects of bulk modification by $\mathrm{Pd}$ on electrochemical properties of MgNi. Journal of Alloys and Compounds., v. 391, p. 313-317, 2005.

[62] NAKAMURA, Y.; NAKAMURA, H.; FUJITANI, S.; YONEZU, I. Homogenizing behaviour in a hydrogen-absorbing LaNi4,55Alo,45 alloy through annealing and rapid quenching. Journal of Alloys and Compounds., v. 210, p. 299-303,1994.

[63] PAN, H.; CHEN, N.; GAO, M.; LI, R.; LEI, Y.; WANG, Q. Effects of annealing temperature on structure and the electrochemical properties of Lao, $7 \mathrm{Mgo}_{0,3} \mathrm{Ni}_{2,45} \mathrm{Co}_{0,75} \mathrm{Mno}_{0,1} \mathrm{Al}_{0,2}$ hydrogen storage alloy. Journal of Alloys and Compounds., v. 397, p. 306-312, 2005.

[64] YU, C, Z.; YAN, G, J.; LAI, W, H.; DONG, Q, H. A stydy of the main factors affecting Ni-MH battery activation. Journal of Alloys and Compounds., $v$. 293-295, p. 799-803, 1999.

[65] ZARPELON, L.M.C.; GALEGO, E.; TAKIISHI, H.; FARIA, R.N. Microstructure and composition of Rare Earth-transition Metal-AluminiumMagnesium alloys. Materials Research., v. 11, p. 17-21, 2008.

[66] CAI, Z.; LU, D.; LI, W.; LIANG, Y.; ZHOU, H. Study on anodic oxidation of magnesium in $6 \mathrm{M} \mathrm{KOH}$ solution by alternative current impedance. International Journal of Hydrogen Energy., v. 34, p. 467-472, 2009.

[67] LIU, Y.; PAN, H.; YUE, Y.; WU, X.; CHEN, W.; LEI, Y. Cycling durability and degradation behavior of $\mathrm{La}-\mathrm{Mg}-\mathrm{Ni}-\mathrm{Co}$-type metal hydride electrodes. Journal of Alloys and Compounds., v. 395, p. 291-299, 2005.

[68] CASINI, J.C.S.; ZARPELON, L.M.C.; FERREIRA, E.A.; TAKIISHI, H.; FARIA, R.N. Hydrogenation and Discharge Capacity of a La $0,7 \mathrm{Mg}_{0,3} \mathrm{Al}_{0,3} \mathrm{Mno}_{0,4} \mathrm{Co}_{0,5} \mathrm{Ni}_{3,8}$ Alloy for Nickel-Metal Hydride Batteries. Materials Science Forum., v. 660-661, p. 128-132, 2010. 
[69] ZHANG, Y, H.; WANG, G, Q.; DONG, X, P.; GUO, S, H.; WANG, X, L. Investigation on the microstructure and electrochemical performances of $\mathrm{La} 2 \mathrm{Mg}(\mathrm{Nio}, 85 \mathrm{Co0}, 15) 9 \mathrm{~B} \times(\mathrm{x}=0-0,2)$ hydrogen storage electrode alloys. Journal of Alloys and Compounds., v. 379, p. 298-304, 2004. 


\section{TRABALHOS PUBLICADOS}

- FERREIRA, E.A.; ZARPELON, L.M.C.; CASINI, J.C.S.; TAKIISHI, H.; FARIA, R.N. The effect of high charging rates activation on the specific discharge capacity and efficency of a negative electrode based on a LaMgAIMnCoNi alloy. Materials Science Forum., v. 660-661, p. 133138, 2010.

- FERREIRA, E.A.; SERRA, J.M.; CASINI, J.C.S.; TAKIISHI, H.; FARIA, R.N. Microstructure and eletrochemical properties of a LaMgAIMnCoNi based alloy for Ni/MH batteries. Materials Science Forum., 2012 (in press). 